\author{
UNIVERSIDADE DE BRASÍLIA \\ FACULDADE DE TECNOLOGIA \\ DEPARTAMENTO DE ENGENHARIA CIVIL E AMBIENTAL
}

\title{
ANÁLISE PROBABILÍSTICA DE COMPORTAMENTO DE TÚNEIS EM ROCHAS
}

LAOANA TUÍRA GONÇALVES MENDES

ORIENTADOR: PROF. ANDRÉ PACHECO DE ASSIS, PhD

DISSERTAÇÃO DE MESTRADO EM GEOTECNIA PUBLICAÇÃO: G.DM-282/17

BRASÍLIA/DF: MARÇO/2017 


\author{
UNIVERSIDADE DE BRASÍLIA \\ FACULDADE DE TECNOLOGIA \\ DEPARTAMENTO DE ENGENHARIA CIVIL E AMBIENTAL
}

\title{
ANÁLISE PROBABILÍSTICA DE COMPORTAMENTO DE TÚNEIS EM ROCHAS
}

\section{LAOANA TUÍRA GONÇALVES MENDES}

DISSERTAÇÃO SUBMETIDA AO DEPARTAMENTO DE ENGENHARIA CIVIL E AMBIENTAL DA FACULDADE DE TECNOLOGIA DA UNIVERSIDADE DE BRASÍLIA COMO PARTE DOS REQUISITOS NECESSÁRIOS PARA A OBTENÇÃO DO GRAU DE MESTRE EM GEOTECNIA.

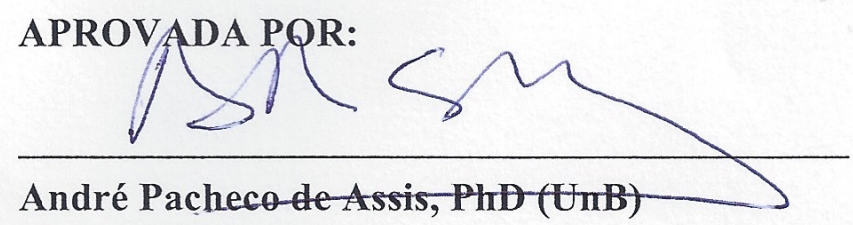

(ORIENTADOR)

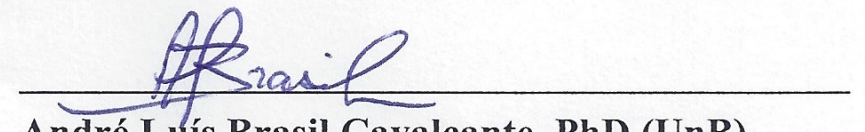

André Luís Brasil Cavalcante, $\mathrm{PhD}$ (UnB)

(EXAMINADOR INTERNO)

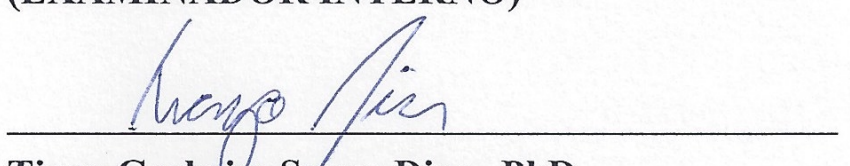

Tiago Gerhaim Souza Dias, PhD

(EXAMINADOR EXTERNO)

DATA: BRASÍLIA/DF, 24 DE MARÇO DE 2017 


\section{FICHA CATALOGRÁFICA}

\section{MENDES, LAOANA TUÍRA GONÇALVES}

Análise Probabilística de Comportamento de Túneis em Rochas [Distrito Federal] 2017 xxix, 149 p., 297mm (ENC/FT/UnB, Mestre, Geotecnia, 2017)

Dissertação de Mestrado - Universidade de Brasília. Faculdade de Tecnologia.

Departamento de Engenharia Civil e Ambiental
1. Obras Subterrâneas
2. Mecânica das Rochas
3. Análise Probabilística
4. Gestão de Riscos
I. ENC/FT/UnB
II. Título (série)

\section{REFERÊNCIA BIBLIOGRÁFICA}

MENDES, L.T.G. (2017). Análise Probabilística de Comportamento de Túneis em Rochas. Dissertação de Mestrado, Publicação, G.DM-282/17, Departamento de Engenharia Civil e Ambiental, Universidade de Brasília, Brasília, DF, 149 p.

\section{CESSÃO DE DIREITOS}

NOME DO AUTOR: Laoana Tuíra Gonçalves Mendes

TÍTULO DA DISSERTAÇÃO DE MESTRADO: Análise Probabilística de Comportamento de Túneis em Rochas.

GRAU / ANO: Mestre / 2017

É concedida à Universidade de Brasília a permissão para reproduzir cópias desta dissertação de mestrado e para emprestar ou vender tais cópias somente para propósitos acadêmicos e científicos. O autor reserva outros direitos de publicação e nenhuma parte desta dissertação de mestrado pode ser reproduzida sem a autorização por escrito do autor.

Laoana Túra Gonçalves Mendes

Rua Condessa Siciliano, 353, ap 8

02.044-050 - São Paulo/SP - Brasil 


\section{DEDICATÓRIA}

Dedico este trabalho especialmente ao meu esposo Leonardo e também à minha mãe Nídia e às minhas irmãs Laura e Júlia que sempre me incentivaram a seguir meus sonhos e concretizá-los. 


\section{AGRADECIMENTOS}

Ao professor André Assis pela orientação e confiança oferecidas desde o início deste trabalho. Pelos ensinamentos, disponibilidade e apoio constante. Muito obrigada de coração.

Ao meu esposo Leonardo por sempre me apoiar em todas as minhas decisões e por ter escutado as minhas ideias, exposto suas opiniões e ter até participado efetivamente no desenvolvimento desta dissertação. Muito obrigada, lindinho!

À minha família, colegas, amigos e todos que contribuíram de alguma forma para que este trabalho pudesse ser concluído com sucesso.

À CAPES pelo auxílio financeiro oferecido, sem o qual não seria possível a realização desta dissertação. 


\section{ANÁLISE PROBABILÍSTICA DE COMPORTAMENTO DE TÚNEIS EM ROCHAS}

\section{RESUMO}

O uso de obras subterrâneas vem crescendo significativamente nas últimas décadas, pois estas são cada vez mais a solução encontrada para questões de quando o uso das opções de superfície é insuficiente, seja pela crescente saturação do espaço urbano ou por motivos geológicos ou topográficos. Paralelo a este crescimento, depara-se também com o aumento do número de acidentes, o que pode causar um grave impacto sobre o processo de construção, levando a elevados prejuízos financeiros, atrasos no cronograma ou até mesmo levar à morte. A avaliação da segurança das obras subterrâneas, por muito tempo, foi feita através de abordagens determinísticas, em que os parâmetros e carregamentos são assumidos constantes e o resultado calculado é único. Contudo, lida-se com materiais geológicos que, por mais que se tenha uma investigação detalhada, podem apresentar características não previstas inicialmente e que só serão detectadas na construção. Devido a essa variabilidade natural dos solos e rochas, a abordagem probabilística é de importância crucial nesse meio. Neste sentido, o objetivo deste trabalho é, a partir do comportamento de túneis em rochas, definir indicadores de desempenho que possam ser utilizados para o cálculo da probabilidade de falha através de uma abordagem probabilística. A metodologia proposta engloba as seguintes etapas: definição dos dados de entrada; calibração do modelo comparando os resultados numéricos com as equações analíticas de Kirsch; execução dos cálculos determinísticos com 72 simulações para dois tipos de rochas, onde foi possível extrair dos dados de saída os indicadores de desempenho fator de segurança, área plástica e convergência e a partir deles elaboraram-se gráficos nos quais as mudanças de tendência foram tomadas como indicadores de falha; abordagem probabilística em que aplicou-se o método dos pontos de estimativas (Rosenblueth), considerando a variabilidade dos parâmetros coeficiente de empuxo no repouso $\left(\mathrm{k}_{\mathrm{o}}\right)$, coesão $(\mathrm{c})$ e ângulo de atrito $(\phi)$ para obter a probabilidade de falha para cada um dos indicadores. Os resultados mostraram que, em muitos casos, mesmo com a média acima ou abaixo do valor limite estipulado, a probabilidade de falha ainda é relevante. Desta forma, observou-se a aplicabilidade dos métodos probabilísticos frente aos tradicionais métodos determinísticos. 


\title{
PROBABILISTIC ANALYSIS OF THE BEHAVIOR OF ROCK TUNNELS
}

\begin{abstract}
The use of underground works has been increasingly growing in recent decades, once these are the solution found for the issues when the surface options are insuficient, either for the urban space saturation or geological or topographical reasons. Parallel to this growth, there is also an increase of the number of accidents, which can cause a serious impact on the construction process, leading to high financial losses, delays in the schedule or even lead to death. The safety evaluation of underground works, for a long time, was made through deterministic approaches, in which the parameters and loads are assumed constant and the calculated result is fixed. However, tunnels deal with geological materials that, even if they have detailed investigation, they can show characteristics not initially defined, which will be detected in the construction. Because of this natural variability of soils and rocks, a probabilistic approach is of crucial importance in this area. In this sense, the objective of this work is to define performance indicators from the behavior of rock tunnels and use them to calculate the probability of failure through a probabilistic approach. The proposed methodology includes the following steps: definition of the input data; model's calibration comparing the numerical results with Kirsch's analytical equations; 72 simulations of deterministic calculations for two types of rocks where it was possible to extract the performance indicators from the output data. These indicator are safety factor, plastic area and convergence and throught them was possible to elaborate graphics and obtain the failure indicators; probabilistic analysis aplying the Point Estimate Method (Rosenblueth), considering the variability of the parameters: at-rest earth pressure coeficiente $\left(\mathrm{k}_{\mathrm{o}}\right)$, cohesion (c) and friction angle $(\phi)$, and then, obtain a failure probability for each of the indicators. The results has shown that in many cases, even with an average above or below the stipulated threshold, a failure probability is still relevant. Thus, an applicability of probabilistic methods over the traditional deterministic methods is observed.
\end{abstract}




\section{SUMÁRIO}

ITEM

Página

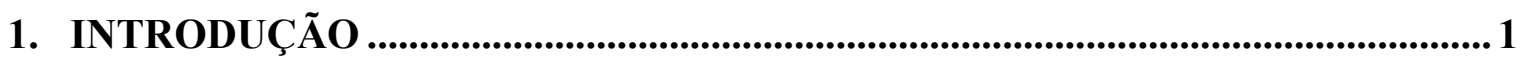

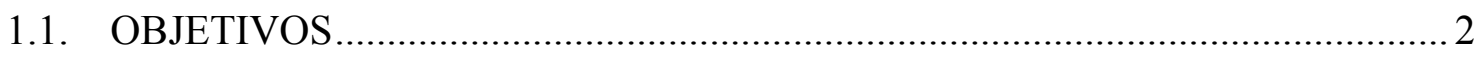

1.2. ORGANIZAÇÃO DA DISSERTAÇÃO .......................................................... 2

2. ABORDAGEM PROBABILÍSTICA E GESTÃo DE RISCOS EM GEOTECNIA 4

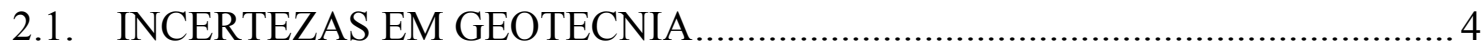

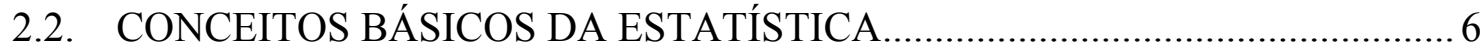

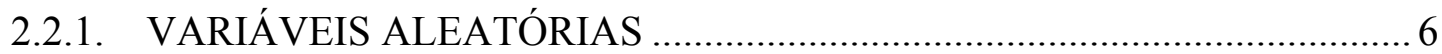

2.2.2. TENDÊNCIA CENTRAL, VARIABILIDADE E ASSOCIAÇÃO ............... 7

2.2.3. PRINCIPAIS DISTRIBUIÇÕES ESTATÍTICAS ....................................... 8

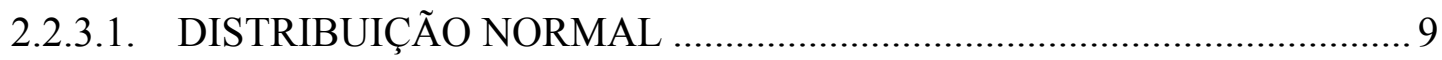

2.2.3.2. DISTRIBUIÇÃO LOG-NORMAL .......................................................... 10

2.2.3.3. DISTRIBUIÇÃO EXPONENCIAL ............................................................ 11

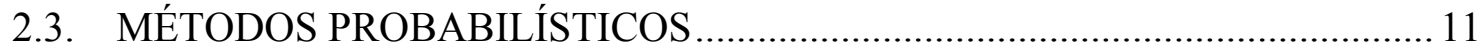

2.3.1. MÉTODO DE MONTE CARLO ................................................................. 12

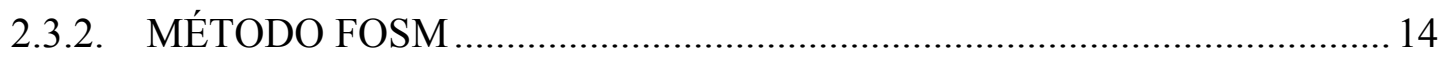

2.3.3. MÉTODO DOS PONTOS DE ESTIMATIVA........................................... 15

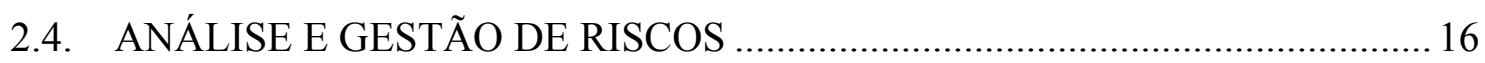

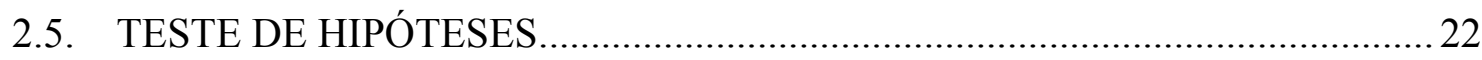

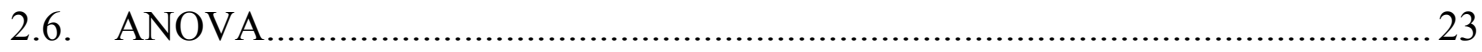

3. OBRAS SUBTERRÂNEAS EM MEIOS ROCHOSOS ........................................ 25

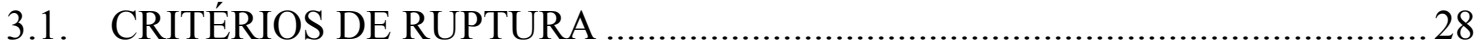

3.1.1. CRITÉRIO DE RUPTURA DE MOHR-COULOMB ................................ 29

3.1.2. CRITÉRIO DE RUPTURA DE HOEK \& BROWN .................................... 30

3.1.3. CONVERSÃO DO CRITÉRIO DE HOEK \& BROWN PARA MOHRCOULOMB

3.2. MODOS DE FALHA DE TÚNEIS EM ROCHAS E SEUS PRINCIPAIS

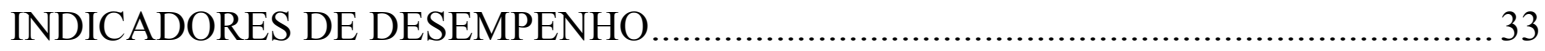

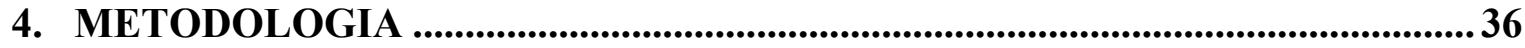




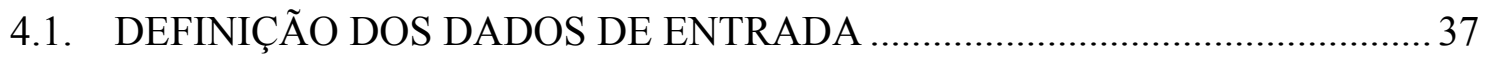

4.1.1. GEOLOGIA DO LOCAL E GEOMETRIA DA ESCAVAÇÃO .................. 37

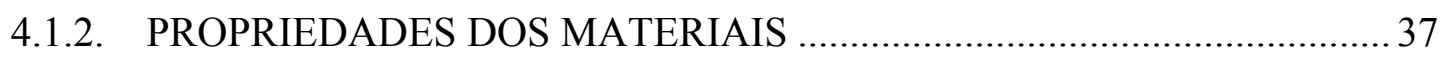

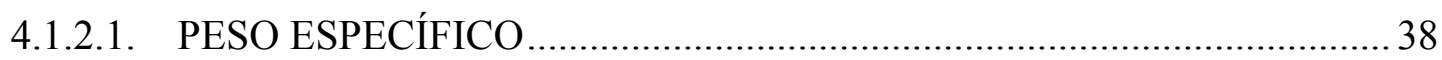

4.1.2.2. MÓDULO DE ELASTICIDADE E COEFICIENTE DE POISSON ......... 38

4.1.2.3. RESISTÊNCIA À COMPRESSÃO UNIAXIAL E PARÂMETRO DA

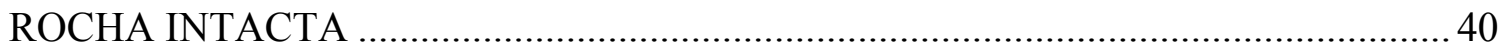

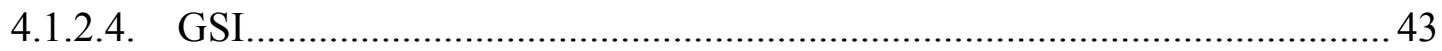

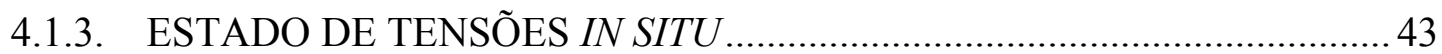

4.2. MODELAGEM NUMÉRICA E EXECUÇÃO DOS CÁLCULOS .................... 43

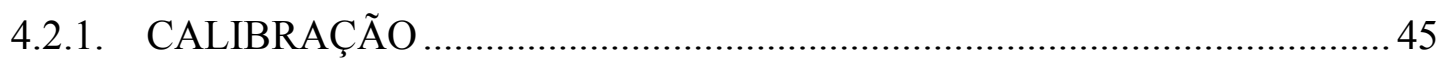

4.2.2. EXECUÇÃO DOS CÁLCULOS DETERMINÍSTICOS ............................ 46

4.2.3. ABORDAGEM PROBABILÍSTICA........................................................ 49

5. APRESENTAÇÃO E DISCUSSÃO DOS RESULTADOS ....................................50

5.1. RESULTADOS DO MODELO LINEAR-ELÁSTICO X KIRSCH ....................50

5.2. RESULTADOS DAS ANÁLISES DETERMINÍSTICAS _.................................. 53

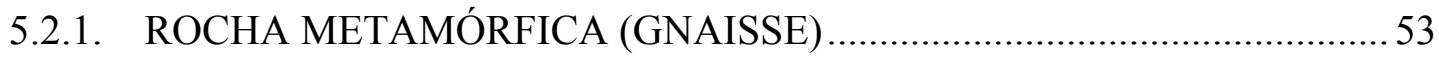

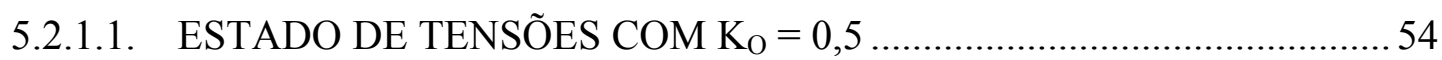

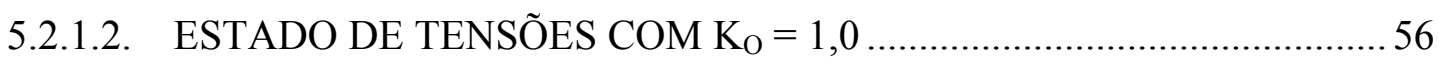

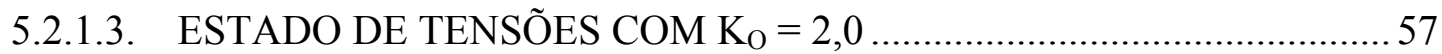

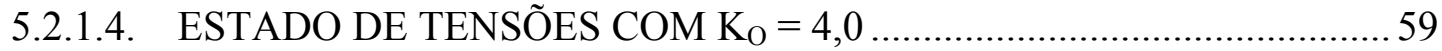

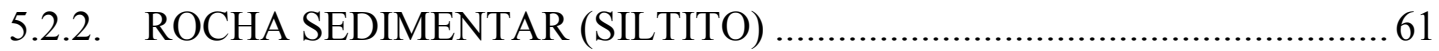

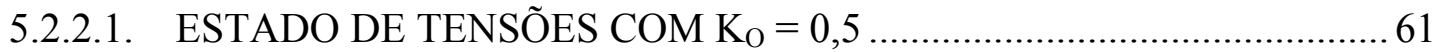

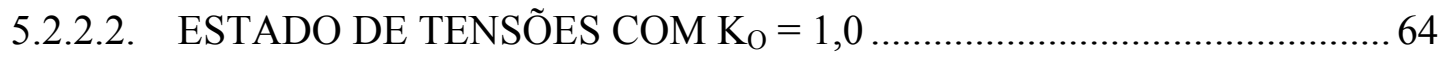

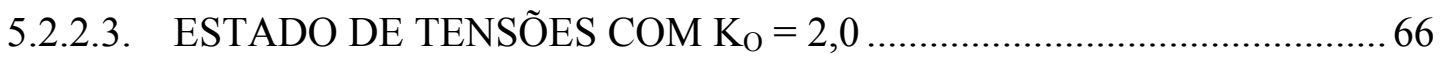

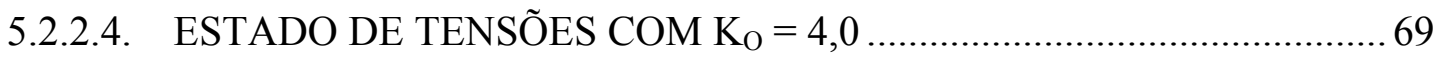

5.3. RESULTADOS DAS ANÁLISES PROBABILÍSTICAS .................................. 70

5.3.1. PROBABILIDADES DE FALHA PARA O CASO DE ROCHA

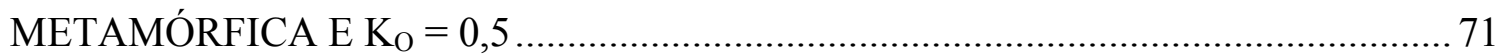

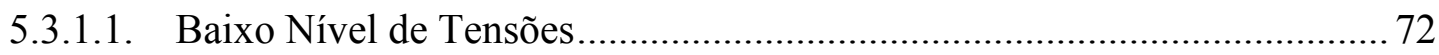

5.3.1.1.1. Maciço Rochoso Intensamente Fraturado ............................................. 72

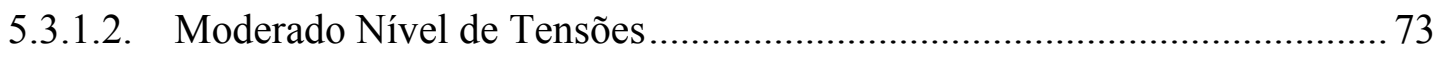

5.3.1.2.1. Maciço Rochoso Moderadamente Fraturado .......................................... 74 
5.3.1.2.2. Maciço Rochoso Intensamente Fraturado .............................................. 74

5.3.1.3. Elevado Nível de Tensões ........................................................................ 76

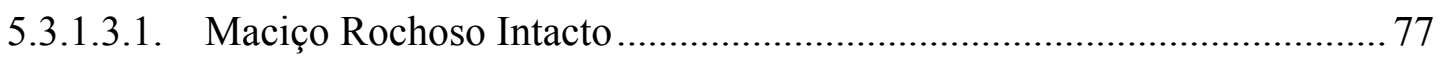

5.3.1.3.2. Maciço Rochoso Moderadamente Fraturado ......................................... 78

5.3.1.3.3. Maciço Rochoso Intensamente Fraturado .............................................. 79

5.3.2. COMPARAÇÃO ENTRE OS RESULTADOS COM Ko'S DIFERENTES 81

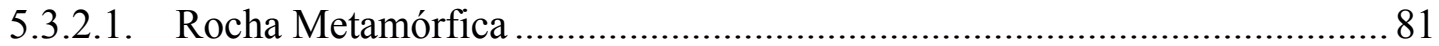

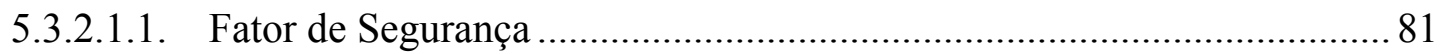

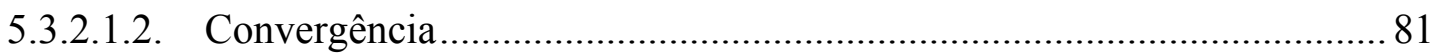

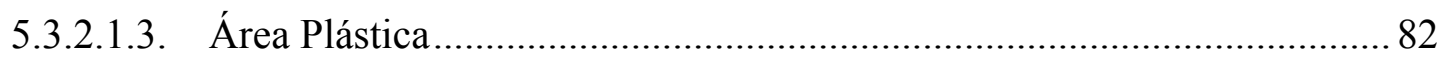

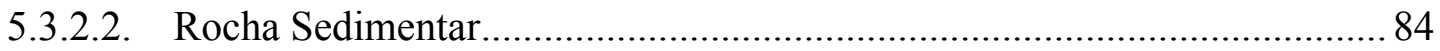

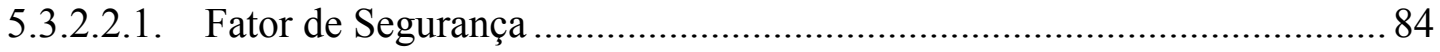

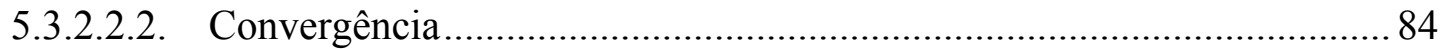

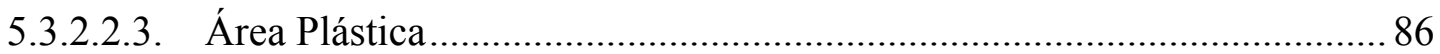

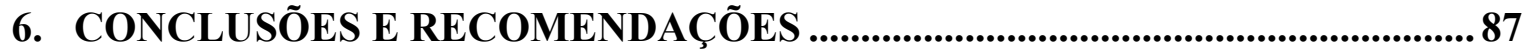

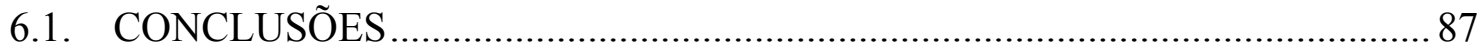

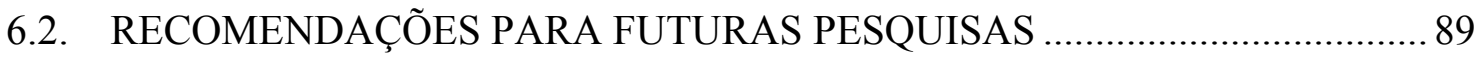

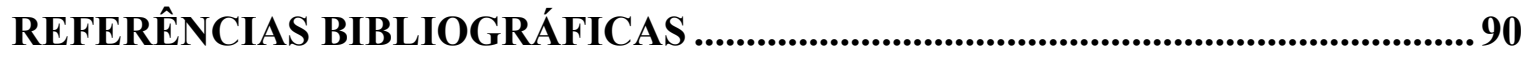

A. DADOS DE ENTRADA

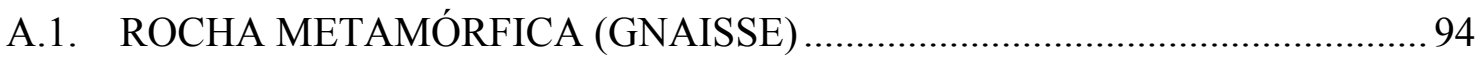

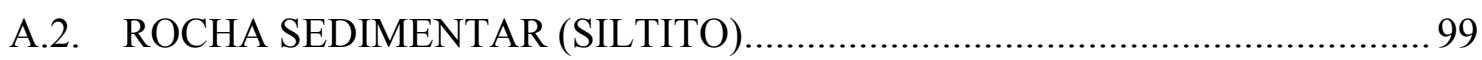

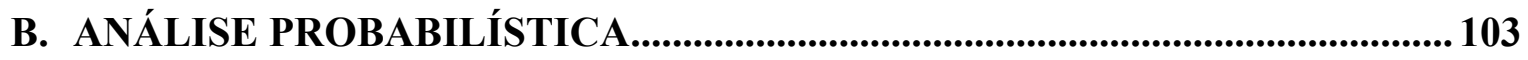

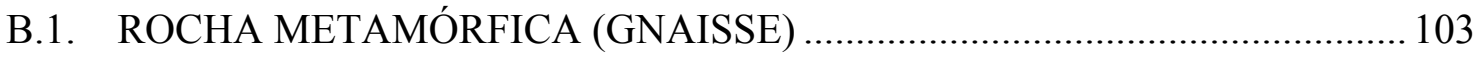

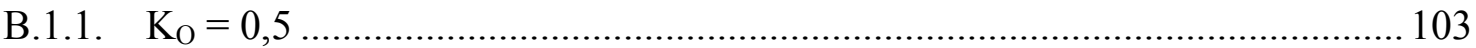

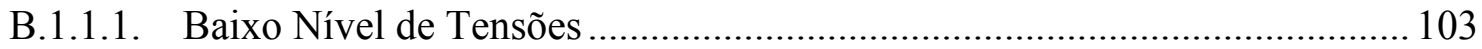

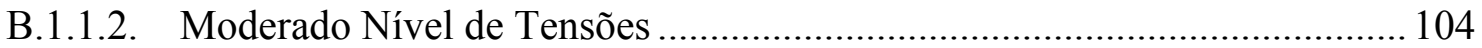

B.1.1.3. Elevado Nível de Tensões .......................................................................... 106

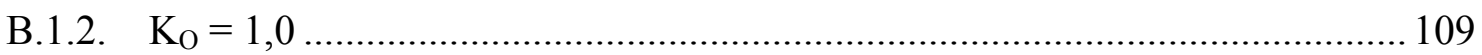

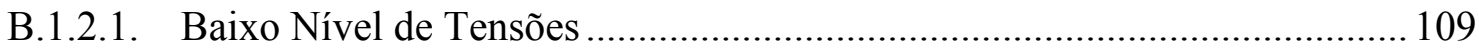

B.1.2.2. Moderado Nível de Tensões ...................................................................... 110

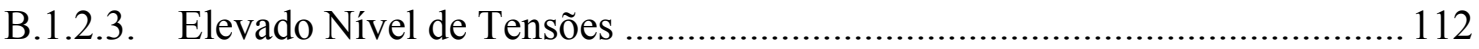

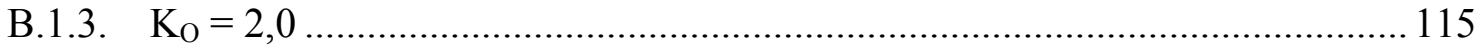




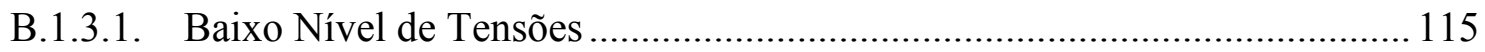

B.1.3.2. Moderado Nível de Tensões ...................................................................... 116

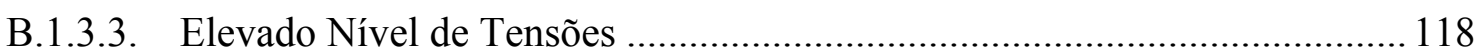

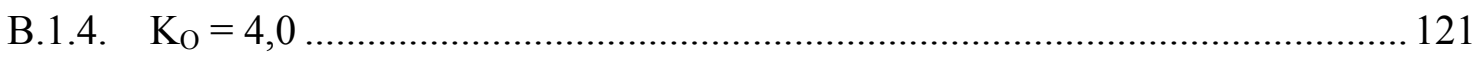

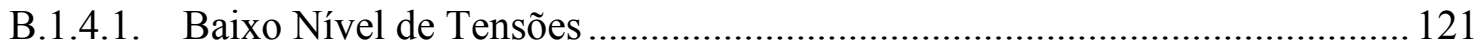

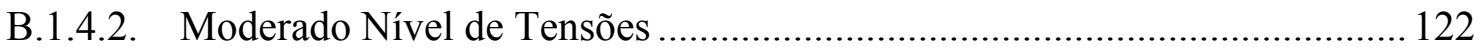

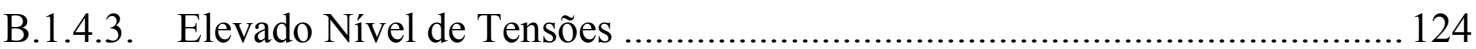

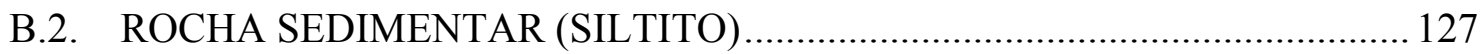

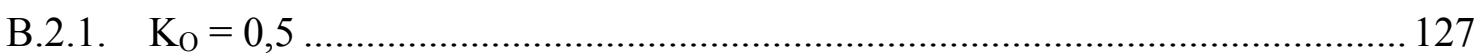

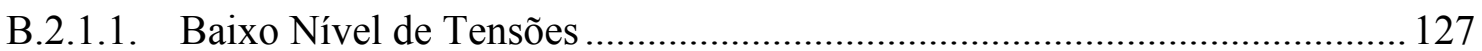

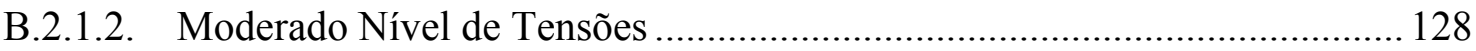

B.2.1.3. Elevado Nível de Tensões ..................................................................... 130

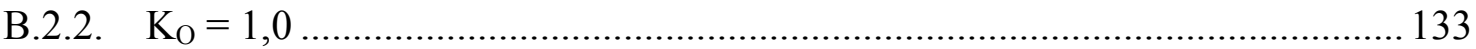

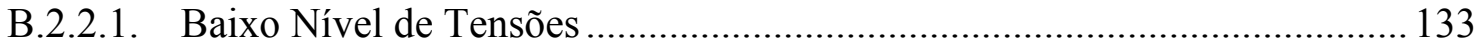

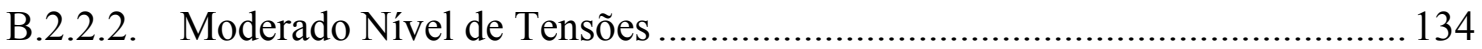

B.2.2.3. Elevado Nível de Tensões ...................................................................... 136

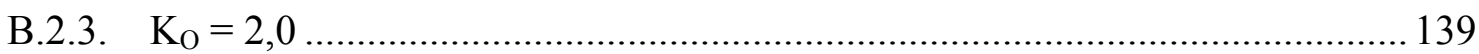

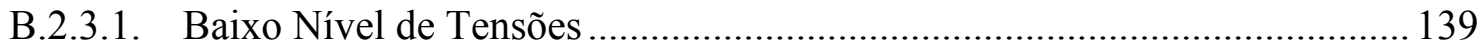

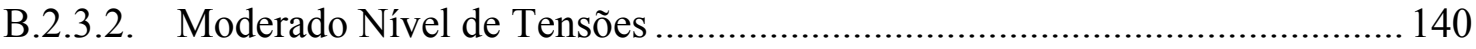

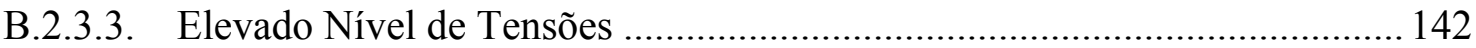

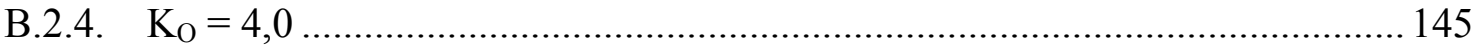

B.2.4.1. Baixo Nível de Tensões ............................................................................ 145

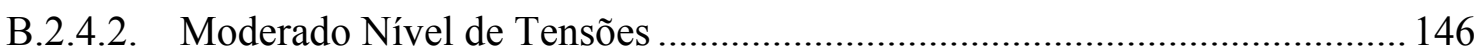

B.2.4.3. Elevado Nível de Tensões ........................................................................ 147 


\section{LISTA DE TABELAS}

Tabela 2.1 - Resumo das vantagens e desvantagens dos principais métodos probabilísticos (Assis et al., 2012).

Tabela 4.1 - Expressões para o cálculo do módulo de elasticidade em maciços rochosos (modificado de Miranda et al., 2006).

Tabela 4.2 - Resistência à compressão uniaxial da rocha intacta (modificado de Hoek, 2007).

Tabela 4.3 - Parâmetro da rocha intacta, $\mathrm{m}_{\mathrm{i}}$ (modificado de Hoek, 2007).

Tabela 4.4 - Valores adotados de GSI.

Tabela 4.5 - Valores estimados do coeficiente de variação (CV).

Tabela 5.1 - Valores dos indicadores de desempenho - Rocha metamórfica, $\mathrm{k}_{\mathrm{o}}=0,5 \ldots \ldots \ldots 55$

Tabela 5.2 - Valores dos indicadores de desempenho - Rocha metamórfica, $\mathrm{k}_{\mathrm{o}}=1,0 \ldots \ldots \ldots .58$

Tabela 5.3 - Valores dos indicadores de desempenho - Rocha metamórfica, $\mathrm{k}_{\mathrm{o}}=2,0 \ldots \ldots \ldots .60$

Tabela 5.4 - Valores dos indicadores de desempenho - Rocha metamórfica, $\mathrm{k}_{\mathrm{o}}=4,0 \ldots \ldots \ldots .62$

Tabela 5.5 - Valores dos indicadores de desempenho - Rocha sedimentar, $\mathrm{k}_{\mathrm{o}}=0,5 \ldots \ldots \ldots .64$

Tabela 5.6 - Valores dos indicadores de desempenho - Rocha sedimentar, $\mathrm{k}_{\mathrm{o}}=1,0 \ldots \ldots \ldots \ldots 6$

Tabela 5.7 - Valores dos indicadores de desempenho - Rocha sedimentar, $\mathrm{k}_{\mathrm{o}}=2,0 \ldots \ldots \ldots \ldots 6$

Tabela 5.8 - Valores dos indicadores de desempenho - Rocha sedimentar, $\mathrm{k}_{\mathrm{o}}=4,0 \ldots \ldots \ldots \ldots 71$

Tabela 5.9 - Resultados obtidos com o método dos pontos de estimativa (Rosenblueth) Rocha metamórfica, $\mathrm{k}_{\mathrm{o}}=0,5$, baixo nível de tensões, maciço rochoso intensamente fraturado. .73

Tabela 5.10 - Resultados obtidos com o método dos pontos de estimativa (Rosenblueth) Rocha metamórfica, $\mathrm{k}_{\mathrm{o}}=0,5$, moderado nível de tensões, maciço rochoso moderadamente fraturado.

Tabela 5.11 - Resultados obtidos com o método dos pontos de estimativa (Rosenblueth) Rocha metamórfica, $\mathrm{k}_{\mathrm{o}}=0,5$, moderado nível de tensões, maciço rochoso intensamente fraturado. 75

Tabela 5.12 - Resultados obtidos com o método dos pontos de estimativa (Rosenblueth) - 
Rocha metamórfica, $\mathrm{k}_{\mathrm{o}}=0,5$, elevado nível de tensões, maciço rochoso intacto.

Tabela 5.13 - Resultados obtidos com o método dos pontos de estimativa (Rosenblueth) Rocha metamórfica, $\mathrm{k}_{\mathrm{o}}=0,5$, elevado nível de tensões, maciço rochoso moderadamente fraturado.

Tabela 5.14 - Resultados obtidos com o método dos pontos de estimativa (Rosenblueth) Rocha metamórfica, $\mathrm{k}_{\mathrm{o}}=0,5$, elevado nível de tensões, maciço rochoso intensamente fraturado.

Tabela A.1 - Dados de entrada - Rocha metamórfica, $\mathrm{k}_{0}=0,5$. 95

Tabela A.2 - Dados de entrada - Rocha metamórfica, $\mathrm{k}_{0}=1,0$. 96

Tabela A.3 - Dados de entrada - Rocha metamórfica, $\mathrm{k}_{\mathrm{o}}=2,0$. 97

Tabela A.4 - Dados de entrada - Rocha metamórfica, $\mathrm{k}_{\mathrm{o}}=4,0$. 98

Tabela A.5 - Dados de entrada - Rocha sedimentar, $\mathrm{k}_{\mathrm{o}}=0,5$. 99

Tabela A.6 - Dados de entrada - Rocha sedimentar, $\mathrm{k}_{\mathrm{o}}=1,0$. 100

Tabela A.7 - Dados de entrada - Rocha sedimentar, $\mathrm{k}_{\mathrm{o}}=2,0$. 101

Tabela A.8 - Dados de entrada - Rocha sedimentar, $\mathrm{k}_{\mathrm{o}}=4,0$.

Tabela B.1 - Resultados obtidos com o método dos pontos de estimativa (Rosenblueth) Rocha metamórfica, $\mathrm{k}_{\mathrm{o}}=0,5$, baixo nível de tensões, maciço rochoso intensamente fraturado.

Tabela B.2 - Resultados obtidos com o método dos pontos de estimativa (Rosenblueth) Rocha metamórfica, $\mathrm{k}_{\mathrm{o}}=0,5$, moderado nível de tensões, maciço rochoso moderadamente fraturado. 104

Tabela B.3 - Resultados obtidos com o método dos pontos de estimativa (Rosenblueth) Rocha metamórfica, $\mathrm{k}_{\mathrm{o}}=0,5$, moderado nível de tensões, maciço rochoso intensamente fraturado.

Tabela B.4 - Resultados obtidos com o método dos pontos de estimativa (Rosenblueth) Rocha metamórfica, $\mathrm{k}_{\mathrm{o}}=0,5$, elevado nível de tensões, maciço rochoso intacto. 106

Tabela B.5 - Resultados obtidos com o método dos pontos de estimativa (Rosenblueth) Rocha metamórfica, $\mathrm{k}_{\mathrm{o}}=0,5$, elevado nível de tensões, maciço rochoso moderadamente fraturado. 
Tabela B.6 - Resultados obtidos com o método dos pontos de estimativa (Rosenblueth) Rocha metamórfica, $\mathrm{k}_{\mathrm{o}}=0,5$, elevado nível de tensões, maciço rochoso intensamente fraturado.

Tabela B.7 - Resultados obtidos com o método dos pontos de estimativa (Rosenblueth) Rocha metamórfica, $\mathrm{k}_{\mathrm{o}}=1,0$, baixo nível de tensões, maciço rochoso intensamente fraturado. 109

Tabela B.8 - Resultados obtidos com o método dos pontos de estimativa (Rosenblueth) Rocha metamórfica, $\mathrm{k}_{\mathrm{o}}=1,0$, moderado nível de tensões, maciço rochoso moderadamente fraturado.

Tabela B.9 - Resultados obtidos com o método dos pontos de estimativa (Rosenblueth) Rocha metamórfica, $\mathrm{k}_{\mathrm{o}}=1,0$, moderado nível de tensões, maciço rochoso intensamente fraturado.

Tabela B.10 - Resultados obtidos com o método dos pontos de estimativa (Rosenblueth) Rocha metamórfica, $\mathrm{k}_{\mathrm{o}}=1,0$, elevado nível de tensões, maciço rochoso intacto.

Tabela B.11 - Resultados obtidos com o método dos pontos de estimativa (Rosenblueth) Rocha metamórfica, $\mathrm{k}_{\mathrm{o}}=1,0$, elevado nível de tensões, maciço rochoso moderadamente fraturado.

Tabela B.12 - Resultados obtidos com o método dos pontos de estimativa (Rosenblueth) Rocha metamórfica, $\mathrm{k}_{\mathrm{o}}=1,0$, elevado nível de tensões, maciço rochoso intensamente fraturado.

Tabela B.13 - Resultados obtidos com o método dos pontos de estimativa (Rosenblueth) Rocha metamórfica, $\mathrm{k}_{\mathrm{o}}=2,0$, baixo nível de tensões, maciço rochoso intensamente fraturado.

Tabela B.14 - Resultados obtidos com o método dos pontos de estimativa (Rosenblueth) Rocha metamórfica, $\mathrm{k}_{\mathrm{o}}=2,0$, moderado nível de tensões, maciço rochoso moderadamente fraturado. 116

Tabela B.15 - Resultados obtidos com o método dos pontos de estimativa (Rosenblueth) Rocha metamórfica, $\mathrm{k}_{\mathrm{o}}=2,0$, moderado nível de tensões, maciço rochoso intensamente fraturado.

Tabela B.16 - Resultados obtidos com o método dos pontos de estimativa (Rosenblueth) Rocha metamórfica, $\mathrm{k}_{\mathrm{o}}=2,0$, elevado nível de tensões, maciço rochoso intacto. 
Tabela B.17 - Resultados obtidos com o método dos pontos de estimativa (Rosenblueth) Rocha metamórfica, $\mathrm{k}_{\mathrm{o}}=2,0$, elevado nível de tensões, maciço rochoso moderadamente fraturado.

Tabela B.18 - Resultados obtidos com o método dos pontos de estimativa (Rosenblueth) Rocha metamórfica, $\mathrm{k}_{\mathrm{o}}=2,0$, elevado nível de tensões, maciço rochoso intensamente fraturado. 120

Tabela B.19 - Resultados obtidos com o método dos pontos de estimativa (Rosenblueth) Rocha metamórfica, $\mathrm{k}_{\mathrm{o}}=4,0$, baixo nível de tensões, maciço rochoso intensamente fraturado.

Tabela B.20 - Resultados obtidos com o método dos pontos de estimativa (Rosenblueth) Rocha metamórfica, $\mathrm{k}_{\mathrm{o}}=4,0$, moderado nível de tensões, maciço rochoso moderadamente fraturado.

Tabela B.21 - Resultados obtidos com o método dos pontos de estimativa (Rosenblueth) Rocha metamórfica, $\mathrm{k}_{\mathrm{o}}=4,0$, moderado nível de tensões, maciço rochoso intensamente fraturado.

Tabela B.22 - Resultados obtidos com o método dos pontos de estimativa (Rosenblueth) Rocha metamórfica, $\mathrm{k}_{\mathrm{o}}=4,0$, elevado nível de tensões, maciço rochoso intacto.

Tabela B.23 - Resultados obtidos com o método dos pontos de estimativa (Rosenblueth) Rocha metamórfica, $\mathrm{k}_{\mathrm{o}}=4,0$, elevado nível de tensões, maciço rochoso moderadamente fraturado.

Tabela B.24 - Resultados obtidos com o método dos pontos de estimativa (Rosenblueth) Rocha metamórfica, $\mathrm{k}_{\mathrm{o}}=4,0$, elevado nível de tensões, maciço rochoso intensamente fraturado. 126

Tabela B.25 - Resultados obtidos com o método dos pontos de estimativa (Rosenblueth) Rocha sedimentar, $\mathrm{k}_{\mathrm{o}}=0,5$, baixo nível de tensões, maciço rochoso intensamente fraturado.

Tabela B.26 - Resultados obtidos com o método dos pontos de estimativa (Rosenblueth) Rocha sedimentar, $\mathrm{k}_{\mathrm{o}}=0,5$, moderado nível de tensões, maciço rochoso moderadamente fraturado.

Tabela B.27 - Resultados obtidos com o método dos pontos de estimativa (Rosenblueth) Rocha sedimentar, $\mathrm{k}_{\mathrm{o}}=0,5$, moderado nível de tensões, maciço rochoso intensamente 
fraturado.

Tabela B.28 - Resultados obtidos com o método dos pontos de estimativa (Rosenblueth) Rocha sedimentar, $\mathrm{k}_{\mathrm{o}}=0,5$, elevado nível de tensões, maciço rochoso intacto.

Tabela B.29 - Resultados obtidos com o método dos pontos de estimativa (Rosenblueth) Rocha sedimentar, $\mathrm{k}_{\mathrm{o}}=0,5$, elevado nível de tensões, maciço rochoso moderadamente fraturado.

Tabela B.30 - Resultados obtidos com o método dos pontos de estimativa (Rosenblueth) Rocha sedimentar, $\mathrm{k}_{\mathrm{o}}=0,5$, elevado nível de tensões, maciço rochoso intensamente fraturado.

Tabela B.31 - Resultados obtidos com o método dos pontos de estimativa (Rosenblueth) Rocha sedimentar, $\mathrm{k}_{\mathrm{o}}=1,0$, baixo nível de tensões, maciço rochoso intensamente fraturado.

Tabela B.32 - Resultados obtidos com o método dos pontos de estimativa (Rosenblueth) Rocha sedimentar, $\mathrm{k}_{\mathrm{o}}=1,0$, moderado nível de tensões, maciço rochoso moderadamente fraturado.

Tabela B.33 - Resultados obtidos com o método dos pontos de estimativa (Rosenblueth) Rocha sedimentar, $\mathrm{k}_{\mathrm{o}}=1,0$, moderado nível de tensões, maciço rochoso intensamente fraturado. 135

Tabela B.34 - Resultados obtidos com o método dos pontos de estimativa (Rosenblueth) Rocha sedimentar, $\mathrm{k}_{\mathrm{o}}=1,0$, elevado nível de tensões, maciço rochoso intacto. 136

Tabela B.35 - Resultados obtidos com o método dos pontos de estimativa (Rosenblueth) Rocha sedimentar, $\mathrm{k}_{\mathrm{o}}=1,0$, elevado nível de tensões, maciço rochoso moderadamente fraturado.

Tabela B.36 - Resultados obtidos com o método dos pontos de estimativa (Rosenblueth) Rocha sedimentar, $\mathrm{k}_{\mathrm{o}}=1,0$, elevado nível de tensões, maciço rochoso intensamente fraturado. 138

Tabela B.37 - Resultados obtidos com o método dos pontos de estimativa (Rosenblueth) Rocha sedimentar, $\mathrm{k}_{\mathrm{o}}=2,0$, baixo nível de tensões, maciço rochoso intensamente fraturado.

Tabela B.38 - Resultados obtidos com o método dos pontos de estimativa (Rosenblueth) - 
Rocha sedimentar, $\mathrm{k}_{\mathrm{o}}=2,0$, moderado nível de tensões, maciço rochoso moderadamente fraturado.

Tabela B.39 - Resultados obtidos com o método dos pontos de estimativa (Rosenblueth) Rocha sedimentar, $\mathrm{k}_{\mathrm{o}}=2,0$, moderado nível de tensões, maciço rochoso intensamente fraturado.

Tabela B.40 - Resultados obtidos com o método dos pontos de estimativa (Rosenblueth) Rocha sedimentar, $\mathrm{k}_{\mathrm{o}}=2,0$, elevado nível de tensões, maciço rochoso intacto.

Tabela B.41 - Resultados obtidos com o método dos pontos de estimativa (Rosenblueth) Rocha sedimentar, $\mathrm{k}_{\mathrm{o}}=2,0$, elevado nível de tensões, maciço rochoso moderadamente fraturado.

Tabela B.42 - Resultados obtidos com o método dos pontos de estimativa (Rosenblueth) Rocha sedimentar, $\mathrm{k}_{\mathrm{o}}=2,0$, elevado nível de tensões, maciço rochoso intensamente fraturado.

Tabela B.43 - Resultados obtidos com o método dos pontos de estimativa (Rosenblueth) Rocha sedimentar, $\mathrm{k}_{\mathrm{o}}=4,0$, baixo nível de tensões, maciço rochoso intensamente fraturado.

Tabela B.44 - Resultados obtidos com o método dos pontos de estimativa (Rosenblueth) Rocha sedimentar, $\mathrm{k}_{\mathrm{o}}=4,0$, moderado nível de tensões, maciço rochoso moderadamente fraturado.

Tabela B.45 - Resultados obtidos com o método dos pontos de estimativa (Rosenblueth) Rocha sedimentar, $\mathrm{k}_{\mathrm{o}}=4,0$, elevado nível de tensões, maciço rochoso intacto.

Tabela B.46 - Resultados obtidos com o método dos pontos de estimativa (Rosenblueth) Rocha sedimentar, $\mathrm{k}_{\mathrm{o}}=4,0$, elevado nível de tensões, maciço rochoso moderadamente fraturado. 148 


\section{LISTA DE FIGURAS}

Figura 2.1 - Categorias de incerteza na gestão de riscos (modificado de Baecher \& Christian, 2003)

Figura 2.2 - Curva típica de distribuição normal.................................................................. 9

Figura 2.3 - Curva típica de distribuição log-normal. 10

Figura 2.4 - Função de distribuição de probabilidade da variável dependente Y gerada a partir das funções das variáveis independentes $\mathrm{X}_{1}, \mathrm{X}_{2}, \ldots, \mathrm{X}_{\mathrm{n}}$.

Figura 2.5 - Procedimento para obtenção de números aleatórios através de uma distribuição.

Figura 2.6 - Combinação $2^{\mathrm{N}}$ dos pontos particulares $\mathrm{X}_{\mathrm{i}+}$ e $\mathrm{X}_{\mathrm{i}-}($ modificado de Harr, 1987).. 16

Figura 2.7 - Distribuição de desempenho típica com indicador de falha. 18

Figura 2.8 - Fluxograma para gestão de risco em engenharia (modificado de Fell et al., 2005) 20

Figura 3.1 - Ábaco do GSI em maciços rochosos homogeneamente fraturados (modificado de Marinos \& Hoek, 2000). 28

Figura 3.2 - Critério de Mohr-Coulomb representado no círculo de Mohr. 29

Figura 3.3 - Esquema do ajuste da envoltória de Mohr-Coulomb ao critério de ruptura de Hoek-Brown generalizado (modificado de Hoek et al., 2002). ....

Figura 3.4 - Modos de falha de acordo com as condições estruturais do maciço rochoso e do estados de tensões (modificado de Hoek et al., 1995).

Figura 3.5 - Fontes de incertezas nos dados de entrada e indicadores de desempenho para vários mecanismos de falha (modificado de Langford \& Diederichs, 2013).

Figura 4.1 - Fluxograma metodológico da dissertação........................................................ 36

Figura 4.2 - Valores típicos do coeficiente de Poisson (modificado de Gercek, 2007)........ 40

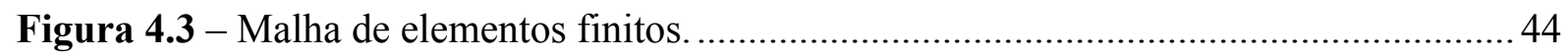

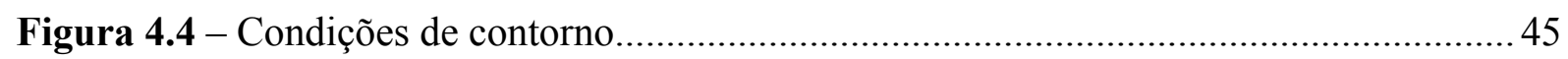

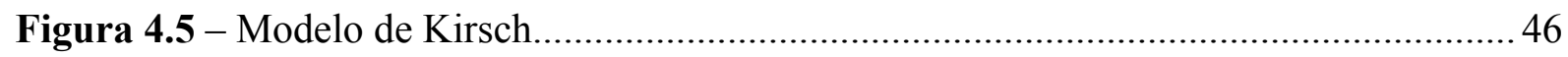

Figura 4.6 - Fluxograma das simulações numéricas iniciais (determinísticas). ..................... 47 
Figura 5.1 - Tensões induzidas após a escavação do túnel calculadas por Kirsch: a) Teto $(\theta=$ $\left.0^{\circ}\right)$; b) Lateral $\left(\theta=90^{\circ}\right)$..

Figura 5.2 - Tensões induzidas na direção x $\left(\sigma_{\mathrm{xx}}\right)$ após a escavação do túnel calculadas no PLAXIS

Figura 5.3 - Tensões induzidas na direção y $\left(\sigma_{\mathrm{yy}}\right)$ após a escavação do túnel calculadas no PLAXIS

Figura 5.4 - Deslocamentos após a escavação do túnel calculados por Kirsch 52

Figura 5.5 - Deslocamentos após a escavação do túnel calculados no PLAXIS. 53

Figura 5.6 - Resultados das zonas plásticas - Rocha metamórfica, $\mathrm{k}_{\mathrm{o}}=0,5$. 54

Figura 5.7 - Relação entre os indicadores de desempenho: a) FS x Ap (\%); b) FS x U (\%) Rocha metamórfica, $\mathrm{k}_{\mathrm{o}}=0,5$. 56

Figura 5.8 - Resultados das zonas plásticas - Rocha metamórfica, $\mathrm{k}_{\mathrm{o}}=1,0$. 57

Figura 5.9 - Relação entre os indicadores de desempenho: a) FS x Ap (\%); b) FS x U (\%) Rocha metamórfica, $\mathrm{k}_{\mathrm{o}}=1,0$. 58

Figura 5.10 - Resultados das zonas plásticas - Rocha metamórfica, $\mathrm{k}_{\mathrm{o}}=2,0$. 59

Figura 5.11 - Relação entre os indicadores de desempenho: a) FS x Ap (\%); b) FS x U (\%) Rocha metamórfica, $\mathrm{k}_{\mathrm{o}}=2,0$.

Figura 5.12 - Resultados das zonas plásticas - Rocha metamórfica, $\mathrm{k}_{\mathrm{o}}=4,0$. 61

Figura 5.13 - Relação entre os indicadores de desempenho: a) FS x Ap (\%); b) FS x U (\%) Rocha metamórfica, $\mathrm{k}_{\mathrm{o}}=4,0$.

Figura 5.14 - Resultados das zonas plásticas - Rocha sedimentar, $\mathrm{k}_{\mathrm{o}}=0,5$. 63

Figura 5.15 - Relação entre os indicadores de desempenho: a) FS x Ap (\%); b) FS x U (\%) Rocha sedimentar, $\mathrm{k}_{\mathrm{o}}=0,5$. 64

Figura 5.16 - Resultados das zonas plásticas - Rocha sedimentar, $\mathrm{k}_{\mathrm{o}}=1,0$. 65

Figura 5.17 - Relação entre os indicadores de desempenho: a) FS x Ap (\%); b) FS x U (\%) Rocha sedimentar, $\mathrm{k}_{\mathrm{o}}=1,0$. 66

Figura 5.18 - Resultados das zonas plásticas - Rocha sedimentar, $\mathrm{k}_{\mathrm{o}}=2,0$. 67

Figura 5.19 - Relação entre os indicadores de desempenho: a) FS x Ap (\%); b) FS x U (\%) - 
Rocha sedimentar, $\mathrm{k}_{\mathrm{o}}=2,0$.

Figura 5.20 - Resultados das zonas plásticas - Rocha sedimentar, $\mathrm{k}_{\mathrm{o}}=4,0$. 70

Figura 5.21 - Relação entre os indicadores de desempenho: a) FS x Ap (\%); b) FS x U (\%) Rocha sedimentar, $\mathrm{k}_{\mathrm{o}}=4,0$.

Figura 5.22 - Frequência de ocorrência e probabilidade de falha: a) Fator de Segurança (FS); b) Convergência (U); c) Área Plástica (Ap) - Rocha metamórfica, $\mathrm{k}_{\mathrm{o}}=0,5$, baixo nível de tensões, maciço rochoso intensamente fraturado. 73

Figura 5.23 - Frequência de ocorrência e probabilidade de falha: a) Fator de Segurança (FS); b) Convergência (U); c) Área Plástica (Ap) - Rocha metamórfica, $\mathrm{k}_{\mathrm{o}}=0,5$, moderado nível de tensões, maciço rochoso moderadamente fraturado. 75

Figura 5.24 - Frequência de ocorrência e probabilidade de falha: a) Fator de Segurança (FS); b) Convergência (U); c) Área Plástica (Ap) - Rocha metamórfica, $\mathrm{k}_{\mathrm{o}}=0,5$, moderado nível de tensões, maciço rochoso intensamente fraturado.

Figura 5.25 - Frequência de ocorrência e probabilidade de falha: a) Fator de Segurança (FS); b) Convergência (U); c) Área Plástica (Ap) - Rocha metamórfica, $\mathrm{k}_{\mathrm{o}}=0,5$, elevado nível de tensões, maciço rochoso intacto. 77

Figura 5.26 - Frequência de ocorrência e probabilidade de falha: a) Fator de Segurança (FS); b) Convergência (U); c) Área Plástica (Ap) - Rocha metamórfica, $\mathrm{k}_{\mathrm{o}}=0$,5, elevado nível de tensões, maciço rochoso moderadamente fraturado.

Figura 5.27 - Frequência de ocorrência e probabilidade de falha: a) Fator de Segurança (FS); b) Convergência (U); c) Área Plástica (Ap) - Rocha metamórfica, $\mathrm{k}_{\mathrm{o}}=0,5$, elevado nível de tensões, maciço rochoso intensamente fraturado.

Figura 5.28 - Frequência de ocorrência e probabilidade de falha do fator de segurança: a) $k_{o}$ $\left.=0,5 ; b) k_{0}=1,0 ; c\right) k_{0}=2,0 ;$ d) $k_{0}=4,0-$ Rocha Metamórfica.

Figura 5.29 - Frequência de ocorrência e probabilidade de falha da convergência: a) $k_{0}=0,5$; b) $\mathrm{k}_{\mathrm{o}}=1,0 ;$ c) $\mathrm{k}_{\mathrm{o}}=2,0 ;$ d) $\mathrm{k}_{\mathrm{o}}=4,0-$ Rocha Metamórfica. 83

Figura 5.30 - Frequência de ocorrência e probabilidade de falha da área plástica: a) $\mathrm{k}_{\mathrm{o}}=0,5$; b) $\mathrm{k}_{\mathrm{o}}=1,0 ;$ c) $\mathrm{k}_{\mathrm{o}}=2,0 ;$ d) $\mathrm{k}_{\mathrm{o}}=4,0$ - Rocha Metamórfica.

Figura 5.31 - Frequência de ocorrência e probabilidade de falha do fator de segurança: a) $k_{o}$ $=0,5 ; b) k_{o}=1,0$; $) k_{o}=2,0 ;$ d) $k_{0}=4,0-$ Rocha Sedimentar. 85 
Figura 5.32 - Frequência de ocorrência e probabilidade de falha da convergência: a) $k_{0}=0,5$; b) $\mathrm{k}_{\mathrm{o}}=1,0 ;$ c) $\mathrm{k}_{\mathrm{o}}=2,0$;) $\mathrm{k}_{\mathrm{o}}=4,0-$ Rocha Sedimentar. .85

Figura 5.33 - Frequência de ocorrência e probabilidade de falha da área plástica: a) $\mathrm{k}_{\mathrm{o}}=0,5$; b) $\mathrm{k}_{\mathrm{o}}=1,0 ;$ c) $\mathrm{k}_{\mathrm{o}}=2,0$; d) $\mathrm{k}_{\mathrm{o}}=4,0-$ Rocha Sedimentar. .86

Figura B.1- Frequência de ocorrência e probabilidade de falha: a) Fator de Segurança (FS); b) Convergência (U); c) Área Plástica (Ap) - Rocha metamórfica, $\mathrm{k}_{\mathrm{o}}=0,5$, baixo nível de tensões, maciço rochoso intensamente fraturado. 104

Figura B.2- Frequência de ocorrência e probabilidade de falha: a) Fator de Segurança (FS); b) Convergência (U); c) Área Plástica (Ap) - Rocha metamórfica, $\mathrm{k}_{\mathrm{o}}=0,5$, moderado nível de tensões, maciço rochoso moderadamente fraturado. 105

Figura B.3- Frequência de ocorrência e probabilidade de falha: a) Fator de Segurança (FS); b) Convergência (U); c) Área Plástica (Ap) - Rocha metamórfica, $\mathrm{k}_{\mathrm{o}}=0,5$, moderado nível de tensões, maciço rochoso intensamente fraturado. 106

Figura B.4- Frequência de ocorrência e probabilidade de falha: a) Fator de Segurança (FS); b) Convergência (U); c) Área Plástica (Ap) - Rocha metamórfica, $\mathrm{k}_{\mathrm{o}}=0,5$, elevado nível de tensões, maciço rochoso intacto. 107

Figura B.5- Frequência de ocorrência e probabilidade de falha: a) Fator de Segurança (FS); b) Convergência (U); c) Área Plástica (Ap) - Rocha metamórfica, $\mathrm{k}_{\mathrm{o}}=0$,5, elevado nível de tensões, maciço rochoso moderadamente fraturado. 108

Figura B.6- Frequência de ocorrência e probabilidade de falha: a) Fator de Segurança (FS); b) Convergência (U); c) Área Plástica (Ap) - Rocha metamórfica, $\mathrm{k}_{\mathrm{o}}=0,5$, elevado nível de tensões, maciço rochoso intensamente fraturado.

Figura B.7- Frequência de ocorrência e probabilidade de falha: a) Fator de Segurança (FS); b) Convergência (U); c) Área Plástica (Ap) - Rocha metamórfica, $\mathrm{k}_{\mathrm{o}}=1,0$, baixo nível de tensões, maciço rochoso intensamente fraturado. 110

Figura B.8- Frequência de ocorrência e probabilidade de falha: a) Fator de Segurança (FS); b) Convergência (U); c) Área Plástica (Ap) - Rocha metamórfica, $\mathrm{k}_{\mathrm{o}}=1,0$, moderado nível de tensões, maciço rochoso moderadamente fraturado.

Figura B.9- Frequência de ocorrência e probabilidade de falha: a) Fator de Segurança (FS); b) Convergência (U); c) Área Plástica (Ap) - Rocha metamórfica, $\mathrm{k}_{\mathrm{o}}=1,0$, moderado nível de tensões, maciço rochoso intensamente fraturado. 
Figura B.10 - Frequência de ocorrência e probabilidade de falha: a) Fator de Segurança (FS);

b) Convergência (U); c) Área Plástica (Ap) - Rocha metamórfica, $\mathrm{k}_{\mathrm{o}}=1,0$, elevado nível de tensões, maciço rochoso intacto.

Figura B.11- Frequência de ocorrência e probabilidade de falha: a) Fator de Segurança (FS); b) Convergência (U); c) Área Plástica (Ap) - Rocha metamórfica, $\mathrm{k}_{\mathrm{o}}=1,0$, elevado nível de tensões, maciço rochoso moderadamente fraturado.

Figura B.12- Frequência de ocorrência e probabilidade de falha: a) Fator de Segurança (FS); b) Convergência (U); c) Área Plástica (Ap) - Rocha metamórfica, $\mathrm{k}_{\mathrm{o}}=1,0$, elevado nível de tensões, maciço rochoso intensamente fraturado.

Figura B.13- Frequência de ocorrência e probabilidade de falha: a) Fator de Segurança (FS); b) Convergência (U); c) Área Plástica (Ap) - Rocha metamórfica, $\mathrm{k}_{\mathrm{o}}=2,0$, baixo nível de tensões, maciço rochoso intensamente fraturado.

Figura B.14- Frequência de ocorrência e probabilidade de falha: a) Fator de Segurança (FS); b) Convergência (U); c) Área Plástica (Ap) - Rocha metamórfica, $\mathrm{k}_{\mathrm{o}}=2,0$, moderado nível de tensões, maciço rochoso moderadamente fraturado.

Figura B.15- Frequência de ocorrência e probabilidade de falha: a) Fator de Segurança (FS); b) Convergência (U); c) Área Plástica (Ap) - Rocha metamórfica, $\mathrm{k}_{\mathrm{o}}=2,0$, moderado nível de tensões, maciço rochoso intensamente fraturado. 118

Figura B.16- Frequência de ocorrência e probabilidade de falha: a) Fator de Segurança (FS); b) Convergência (U); c) Área Plástica (Ap) - Rocha metamórfica, $\mathrm{k}_{\mathrm{o}}=2,0$, elevado nível de tensões, maciço rochoso intacto.

Figura B.17- Frequência de ocorrência e probabilidade de falha: a) Fator de Segurança (FS); b) Convergência (U); c) Área Plástica (Ap) - Rocha metamórfica, $\mathrm{k}_{\mathrm{o}}=2,0$, elevado nível de tensões, maciço rochoso moderadamente fraturado. 120

Figura B.18- Frequência de ocorrência e probabilidade de falha: a) Fator de Segurança (FS); b) Convergência (U); c) Área Plástica (Ap) - Rocha metamórfica, $\mathrm{k}_{\mathrm{o}}=2,0$, elevado nível de tensões, maciço rochoso intensamente fraturado.

Figura B.19- Frequência de ocorrência e probabilidade de falha: a) Fator de Segurança (FS); b) Convergência (U); c) Área Plástica (Ap) - Rocha metamórfica, $\mathrm{k}_{\mathrm{o}}=4,0$, baixo nível de tensões, maciço rochoso intensamente fraturado.

Figura B.20 - Frequência de ocorrência e probabilidade de falha: a) Fator de Segurança (FS); 
b) Convergência (U); c) Área Plástica (Ap) - Rocha metamórfica, $\mathrm{k}_{\mathrm{o}}=4,0$, moderado nível de tensões, maciço rochoso moderadamente fraturado.

Figura B.21- Frequência de ocorrência e probabilidade de falha: a) Fator de Segurança (FS); b) Convergência (U); c) Área Plástica (Ap) - Rocha metamórfica, $\mathrm{k}_{\mathrm{o}}=4,0$, moderado nível de tensões, maciço rochoso intensamente fraturado.

Figura B.22- Frequência de ocorrência e probabilidade de falha: a) Fator de Segurança (FS); b) Convergência (U); c) Área Plástica (Ap) - Rocha metamórfica, $\mathrm{k}_{\mathrm{o}}=4,0$, elevado nível de tensões, maciço rochoso intacto. 125

Figura B.23 - Frequência de ocorrência e probabilidade de falha: a) Fator de Segurança (FS); b) Convergência (U); c) Área Plástica (Ap) - Rocha metamórfica, $\mathrm{k}_{\mathrm{o}}=4,0$, elevado nível de tensões, maciço rochoso moderadamente fraturado. 126

Figura B.24- Frequência de ocorrência e probabilidade de falha: a) Fator de Segurança (FS); b) Convergência (U); c) Área Plástica (Ap) - Rocha metamórfica, $\mathrm{k}_{\mathrm{o}}=4,0$, elevado nível de tensões, maciço rochoso intensamente fraturado.

Figura B.25- Frequência de ocorrência e probabilidade de falha: a) Fator de Segurança (FS); b) Convergência (U); c) Área Plástica (Ap) - Rocha sedimentar, $\mathrm{k}_{\mathrm{o}}=0,5$, baixo nível de tensões, maciço rochoso intensamente fraturado. 128

Figura B.26- Frequência de ocorrência e probabilidade de falha: a) Fator de Segurança (FS); b) Convergência (U); c) Área Plástica (Ap) - Rocha sedimentar, $\mathrm{k}_{\mathrm{o}}=0,5$, moderado nível de tensões, maciço rochoso moderadamente.

Figura B.27- Frequência de ocorrência e probabilidade de falha: a) Fator de Segurança (FS); b) Convergência (U); c) Área Plástica (Ap) - Rocha sedimentar, $\mathrm{k}_{\mathrm{o}}=0,5$, moderado nível de tensões, maciço rochoso intensamente fraturado.

Figura B.28 - Frequência de ocorrência e probabilidade de falha: a) Fator de Segurança (FS); b) Convergência (U); c) Área Plástica (Ap) - Rocha sedimentar, $\mathrm{k}_{\mathrm{o}}=0,5$, elevado nível de tensões, maciço rochoso intacto.

Figura B.29- Frequência de ocorrência e probabilidade de falha: a) Fator de Segurança (FS); b) Convergência (U); c) Área Plástica (Ap) - Rocha sedimentar, $\mathrm{k}_{\mathrm{o}}=0,5$, elevado nível de tensões, maciço rochoso moderadamente fraturado.

Figura B.30 - Frequência de ocorrência e probabilidade de falha: a) Fator de Segurança (FS); b) Convergência (U); c) Área Plástica (Ap) - Rocha sedimentar, $\mathrm{k}_{\mathrm{o}}=0,5$, elevado nível 
de tensões, maciço rochoso intensamente fraturado.

Figura B.31- Frequência de ocorrência e probabilidade de falha: a) Fator de Segurança (FS); b) Convergência (U); c) Área Plástica (Ap) - Rocha sedimentar, $\mathrm{k}_{\mathrm{o}}=1,0$, baixo nível de tensões, maciço rochoso intensamente fraturado.

Figura B.32- Frequência de ocorrência e probabilidade de falha: a) Fator de Segurança (FS); b) Convergência (U); c) Área Plástica (Ap) - Rocha sedimentar, $\mathrm{k}_{\mathrm{o}}=1,0$, moderado nível de tensões, maciço rochoso moderadamente fraturado. 135

Figura B.33- Frequência de ocorrência e probabilidade de falha: a) Fator de Segurança (FS); b) Convergência (U); c) Área Plástica (Ap) - Rocha sedimentar, $\mathrm{k}_{\mathrm{o}}=1,0$, moderado nível de tensões, maciço rochoso intensamente fraturado. 136

Figura B.34- Frequência de ocorrência e probabilidade de falha: a) Fator de Segurança (FS); b) Convergência (U); c) Área Plástica (Ap) - Rocha sedimentar, $\mathrm{k}_{\mathrm{o}}=1,0$, elevado nível de tensões, maciço rochoso intacto.

Figura B.35- Frequência de ocorrência e probabilidade de falha: a) Fator de Segurança (FS); b) Convergência (U); c) Área Plástica (Ap) - Rocha sedimentar, $\mathrm{k}_{\mathrm{o}}=1,0$, elevado nível de tensões, maciço rochoso moderadamente fraturado. 138

Figura B.36- Frequência de ocorrência e probabilidade de falha: a) Fator de Segurança (FS); b) Convergência (U); c) Área Plástica (Ap) - Rocha sedimentar, $\mathrm{k}_{\mathrm{o}}=1,0$, elevado nível de tensões, maciço rochoso intensamente fraturado.

Figura B.37- Frequência de ocorrência e probabilidade de falha: a) Fator de Segurança (FS); b) Convergência (U); c) Área Plástica (Ap) - Rocha sedimentar, $\mathrm{k}_{\mathrm{o}}=2,0$, baixo nível de tensões, maciço rochoso intensamente fraturado.

Figura B.38- Frequência de ocorrência e probabilidade de falha: a) Fator de Segurança (FS); b) Convergência (U); c) Área Plástica (Ap) - Rocha sedimentar, $\mathrm{k}_{\mathrm{o}}=2,0$, moderado nível de tensões, maciço rochoso moderadamente fraturado.

Figura B.39- Frequência de ocorrência e probabilidade de falha: a) Fator de Segurança (FS); b) Convergência (U); c) Área Plástica (Ap) - Rocha sedimentar, $\mathrm{k}_{\mathrm{o}}=2,0$, moderado nível de tensões, maciço rochoso intensamente fraturado.

Figura B.40 - Frequência de ocorrência e probabilidade de falha: a) Fator de Segurança (FS); b) Convergência (U); c) Área Plástica (Ap) - Rocha sedimentar, $\mathrm{k}_{\mathrm{o}}=2,0$, elevado nível de tensões, maciço rochoso intacto. 
Figura B.41 - Frequência de ocorrência e probabilidade de falha: a) Fator de Segurança (FS);

b) Convergência $(\mathrm{U})$; c) Área Plástica (Ap) - Rocha sedimentar, $\mathrm{k}_{\mathrm{o}}=2,0$, elevado nível de tensões, maciço rochoso moderadamente fraturado.

Figura B.42- Frequência de ocorrência e probabilidade de falha: a) Fator de Segurança (FS);

b) Convergência (U); c) Área Plástica (Ap) - Rocha sedimentar, $\mathrm{k}_{\mathrm{o}}=2,0$, elevado nível de tensões, maciço rochoso intensamente fraturado.

Figura B.43 - Frequência de ocorrência e probabilidade de falha: a) Fator de Segurança (FS);

b) Convergência (U); c) Área Plástica (Ap) - Rocha sedimentar, $\mathrm{k}_{\mathrm{o}}=4,0$, baixo nível de tensões, maciço rochoso intensamente fraturado. 146

Figura B.44- Frequência de ocorrência e probabilidade de falha: a) Fator de Segurança (FS); b) Convergência (U); c) Área Plástica (Ap) - Rocha sedimentar, $\mathrm{k}_{\mathrm{o}}=4,0$, moderado nível de tensões, maciço rochoso moderadamente fraturado.

Figura B.45- Frequência de ocorrência e probabilidade de falha: a) Fator de Segurança (FS); b) Convergência (U); c) Área Plástica (Ap) - Rocha sedimentar, $\mathrm{k}_{\mathrm{o}}=4,0$, elevado nível de tensões, maciço rochoso intacto. 148

Figura B.46- Frequência de ocorrência e probabilidade de falha: a) Fator de Segurança (FS); b) Convergência (U); c) Área Plástica (Ap) - Rocha sedimentar, $\mathrm{k}_{\mathrm{o}}=4,0$, elevado nível de tensões, maciço rochoso moderadamente fraturado. 149 


\section{LISTA DE ABREVIAÇÕES, NOMENCLATURAS E SÍMBOLOS}

a

a

Ap

c

$\mathrm{C}(\mathrm{x})$

$\mathrm{c}_{\mathrm{i}}$

CRM - Curva de reação do maciço.

Cov - Covariância.

$\mathrm{CV}$

D

E (x) - Esperança matemática.

$\mathrm{E}_{\mathrm{m}}$

F

$\mathrm{f}(\mathrm{x}) \quad-$ Função de distribuição de probabilidade de $\mathrm{x}$.

FS

FOSM - First Order Second Moment (Primeira Ordem, Segundo Momento).

fdp - Função de densidade de probabilidade.

fmp - Função de massa de probabilidade.

G - Módulo de cisalhamento.

GSI - Geological Strength Index (Índice de Resistência Geológica).

$\mathrm{H}-$ - Profundidade do túnel desde a superfície até o centro, na aplicação em túneis. 
- Altura do talude, na aplicação em taludes.

$\mathrm{J}_{\mathrm{a}} \quad$ - Índice de influência da alteração das paredes das descontinuidades.

$\mathrm{J}_{\mathrm{n}} \quad-$ Índice de influência do número de famílias das descontinuidades.

$\mathrm{J}_{\mathrm{r}} \quad$ - Índice de influência da rugosidade das paredes das descontinuidades.

$\mathrm{J}_{\mathrm{w}} \quad$ - Índice de influência da ação da água subterrânea.

$\mathrm{K}_{\mathrm{o}} \quad-$ Coeficiente de empuxo no repouso.

$\mathrm{m}_{\mathrm{b}} \quad-$ Constante do maciço rochoso (Critério de ruptura de Hoek-Brown).

$\mathrm{m}_{\mathrm{i}} \quad-$ Constante da rocha intacta (Critério de ruptura de Hoek-Brown).

$\mathrm{N}-$ Número de valores para as variáveis aleatórias independentes (Monte Carlo).

$\mathrm{N}-$ Número de variáveis incertas (FOSM).

NATM - New Austrian Tunnelling Method (Método Austríaco de Escavação de Túneis).

$\mathrm{p}(\mathrm{x}) \quad-$ Probabilidade de ocorrência de $\mathrm{x}$.

PEM - Point Estimate Method (Método dos Pontos de Estimativa).

$\mathrm{p}_{\mathrm{f}} \quad-$ Probabilidade de falha.

$\mathrm{p}_{\mathrm{f} 1} \quad-$ Probabilidade de ocorrência do evento 1 (chuva)

$\mathrm{p}_{\mathrm{f} 2} \quad-$ Probabilidade de ocorrência do evento 2 (galgamento).

$\mathrm{p}_{\mathrm{fj}} \quad-$ Probabilidade de ocorrência do evento j.

$\mathrm{p}_{\mathrm{vi}} \quad-$ Probabilidade de ocorrência da consequência i devido à vulnerabilidade.

$\mathrm{p}_{\mathrm{x}} \quad-$ Carga horizontal (Kirsch).

$\mathrm{p}_{\mathrm{z}} \quad-$ Carga vertical (Kirsch).

Q - Tunnelling Quality Index (Índice de Qualidade de Barton).

r $\quad-$ Distância do ponto ao centro do túnel (Kirsch) 


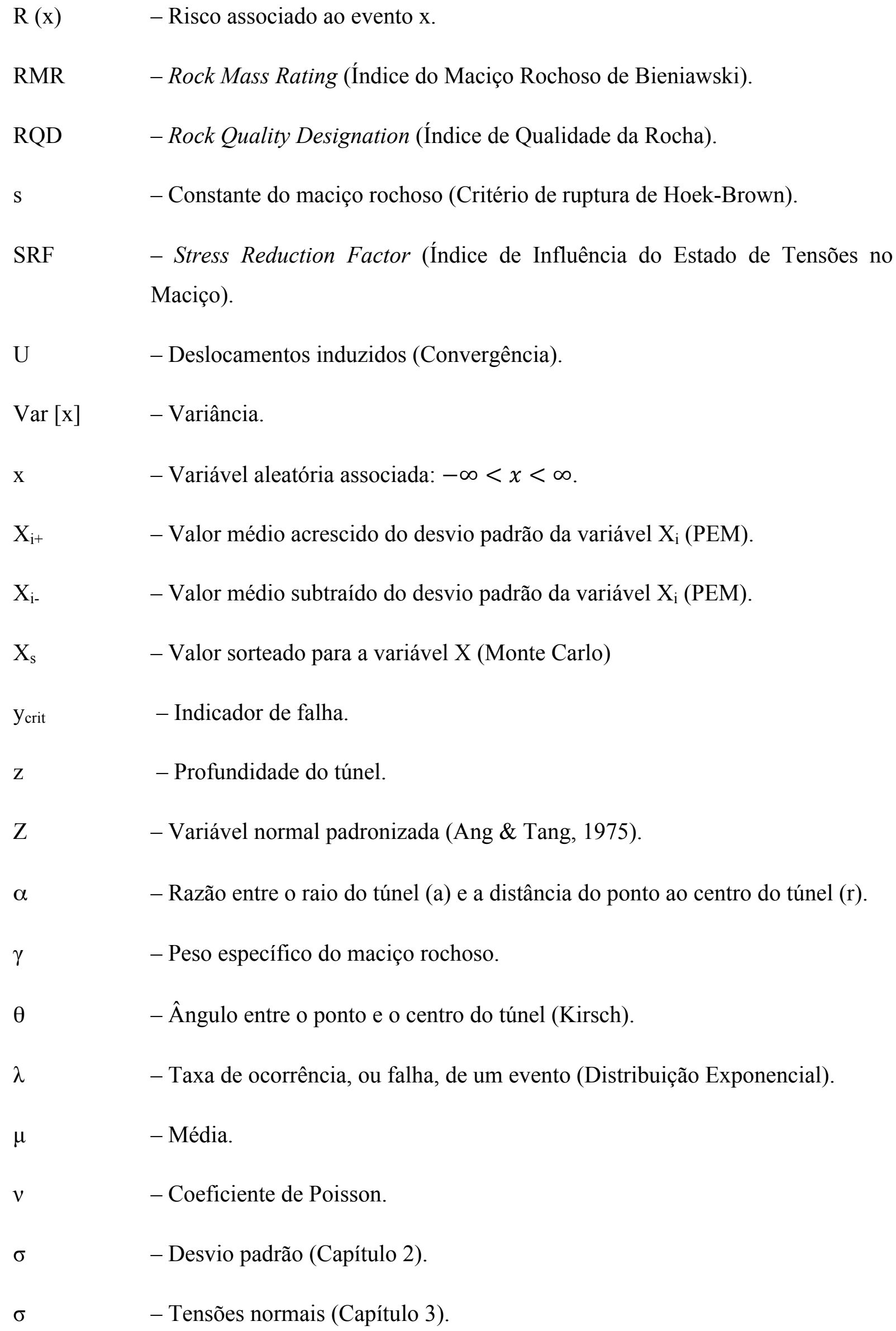


- Tensão principal maior.

$\sigma_{3}-$ Tensão principal menor.

$\sigma_{3}{ }_{3}-$ Tensão principal efetiva menor.

$\sigma_{3, \max }^{\prime} \quad-$ Limite superior da tensão de confinamento definido em função do tipo de obra.

$\sigma_{\mathrm{c}} \quad-$ Resistência à compressão uniaxial do maciço rochoso.

$\sigma_{\mathrm{ci}} \quad-$ Resistência à compressão uniaxial da rocha intacta.

$\sigma^{\prime}{ }_{\mathrm{cm}} \quad-$ Resistência global do maciço rochoso.

$\sigma_{\mathrm{h}} \quad-$ Tensão horizontal.

$\sigma_{\mathrm{r}} \quad-$ Tensão radial.

$\sigma_{\mathrm{t}} \quad-$ Resistência à tração do maciço.

$\sigma_{\mathrm{v}} \quad-$ Tensão vertical.

$\sigma_{\ominus} \quad-$ Tensão tangencial.

$\tau \quad-$ Tensão cisalhante.

$\phi \quad-$ Ângulo de atrito.

$\phi(\mathrm{z}) \quad$ - Função de densidade de probabilidade de uma variável normal padronizada. 


\section{INTRODUÇÃO}

A população mundial vem sofrendo, nas últimas décadas, um elevado crescimento demográfico e consequente inchamento das grandes cidades. Em decorrência disso, grande parte das cidades apresenta, atualmente, sérios problemas no trânsito, transporte e serviços de utilidade pública.

As obras subterrâneas são cada vez mais a solução encontrada para questões de quando o uso das opções de superfície é insuficiente, seja pela crescente saturação do espaço urbano ou por um motivo geológico ou topográfico.

Paralelo ao crescimento das construções subterrâneas, depara-se com o aumento do número de acidentes com estes tipos de obras. Falhas na construção de um túnel são eventos extraordinários, que têm grave impacto sobre o processo de construção, podendo causar elevados prejuízos financeiros, graves atrasos no cronograma ou até mesmo levar à morte.

Projetos de túneis estão entre as obras geotécnicas mais seguras, mas ainda assim já ocorreram alguns acidentes importantes ao redor do mundo, como: a construção do metrô de Porto, Portugal; o metrô de Barcelona, Espanha; o metrô de Munique, Alemanha; a estação Pinheiros da linha IV do metrô de São Paulo, Brasil; entre outros.

A engenharia geotécnica tradicional trata a maior parte de seus problemas de forma determinística, em que as propriedades, parâmetros e índices têm valores fixos, e se esquece que estes tipos de obra apresentam um elevado grau de incerteza. No caso de túneis, lida-se com materiais geológicos que, por mais que se tenha uma investigação detalhada, podem apresentar características não previstas inicialmente, e que só serão detectadas na construção. Portanto, uma obra subterrânea sempre apresenta risco geológico, fazendo com que a abordagem probabilística seja de importância crucial neste meio.

Nesse sentido, este trabalho pretende entender o comportamento de túneis profundos em rochas e analisar seus modos de falha. Para tanto, será feita uma análise probabilística das variáveis que afetam esse comportamento buscando indicadores de desempenho que possam ser utilizados como indicadores de falha. Então, será possível calcular a probabilidade de falha e comparar os resultados obtidos com os valores determinísticos encontrados. 


\subsection{OBJETIVOS}

O objetivo deste trabalho é, a partir do comportamento de túneis em rochas, definir indicadores de desempenho que possam ser utilizados para o cálculo da probabilidade de falha por meio de uma abordagem probabilística.

Como objetivos específicos têm-se:

- Analisar a importância de uma abordagem probabilística frente à abordagem determinística dentro da engenharia geotécnica.

- Comparar os resultados obtidos nas simulações numéricas com os modos de falha propostos na literatura;

- Analisar os dados de saída do programa e buscar possíveis indicadores de desempenho;

- Determinar, dentre os possíveis indicadores de desempenho, aqueles que podem ser transformados em indicadores de falha;

- A partir de um indicador de falha, calcular a probabilidade de falha;

\subsection{ORGANIZAÇÃO DA DISSERTAÇÃO}

O presente trabalho está estruturado em seis capítulos e dois apêndices, sucintamente descritos a seguir:

O Capítulo 1 expõe uma introdução sobre a importância e atualidade do tema. Além disso, apresentam-se os objetivos gerais e específicos propostos para esta dissertação.

O Capítulo 2 apresenta uma revisão da literatura em relação às incertezas geotécnicas, conceitos básicos da estatística, métodos probabilísticos e gestão de risco.

O Capítulo 3 apresenta revisão da literatura sobre obras subterrâneas e mecânica das rochas que unindo aos conhecimentos de probabilidade permitem estudos probabilísticos em meios rochosos.

O Capítulo 4 descreve a metodologia utilizada, que abrange a definição dos dados de entrada, modelagem numérica e aplicação da abordagem probabilística. 
O Capítulo 5 apresenta e discute os resultados obtidos na calibração, na abordagem determinística e, por fim, na análise probabilística.

O Capítulo 6 revela as conclusões e recomendações a partir dos resultados obtidos e propõe sugestões para o prosseguimento das pesquisas nessa área de interesse.

O Apêndice A reúne os dados de entrada necessários para o software PLAXIS (Versão 8.2), bem como a conversão dos parâmetros do critério de ruptura de Hoek \& Brown para o critério de ruptura de Mohr Coulomb.

O Apêndice B reúne os resultados obtidos na etapa de análise probabilística pelo método dos pontos de estimativa (Point Estimate Method) de Rosenblueth. 


\section{ABORDAGEM PROBABILÍSTICA E GESTÃO DE RISCOS EM GEOTECNIA}

Por muito tempo, predominou-se na engenharia tradicional um pré-conceito generalizado de exatidão. Esse conceito levou a um uso intenso de abordagens deterministas, em que os parâmetros e carregamentos são assumidos constantes e o resultado calculado é único.

Solos e rochas em seu estado natural estão entre os mais variáveis de todos os materiais de engenharia, e os engenheiros geotécnicos devem geralmente fazer uso de um material que está em um local específico. Para Fenton \& Griffiths (2008), em um mundo perfeito, sem restrições econômicas, seriam retiradas inúmeras amostras que seriam levadas ao laboratório para determinar as propriedades básicas do maciço, como permeabilidade, compressibilidade e resistência ao cisalhamento. Com todas essas informações, seria possível executar o projeto de um problema de fluxo, fundação ou estabilidade bem próximo das previsões. Contudo, a realidade é que os engenheiros geotécnicos lidam com dados de investigações limitados, e a maneira tradicional de lidar com essas incertezas geotécnicas é o uso de valores característicos para as propriedades do maciço acoplado a um alto fator de segurança.

Segundo Fenton \& Griffiths (2008), ao plotar todos os dados de uma investigação hipotética em um histograma para uma das propriedades do maciço, poder-se-ia visualizar uma ampla gama de valores em uma curva em forma de sino. Os valores mais prováveis dessa propriedade estariam no meio, mas um número significante de amostras indicariam valores maiores ou menores que esses. Essa variabilidade inerente aos solos e rochas sugere que os sistemas geotécnicos são altamente favoráveis para uma interpretação estatística. $\mathrm{Na}$ abordagem probabilística, as propriedades do maciço são caracterizadas em termos de médias e variâncias (primeiro e segundo momentos) levando a estimativas da probabilidade de falha ou confiabilidade do projeto. E quando essas probabilidades são acopladas às consequências da falha, tem-se, então, o risco associado a esse projeto.

\subsection{INCERTEZAS EM GEOTECNIA}

Para entender as implicações das incertezas na gestão de riscos, Baecher \& Christian (2003) classificaram as mesmas, na engenharia geotécnica, em duas categorias principais: variabilidade natural e incertezas no conhecimento (Figura 2.1). 


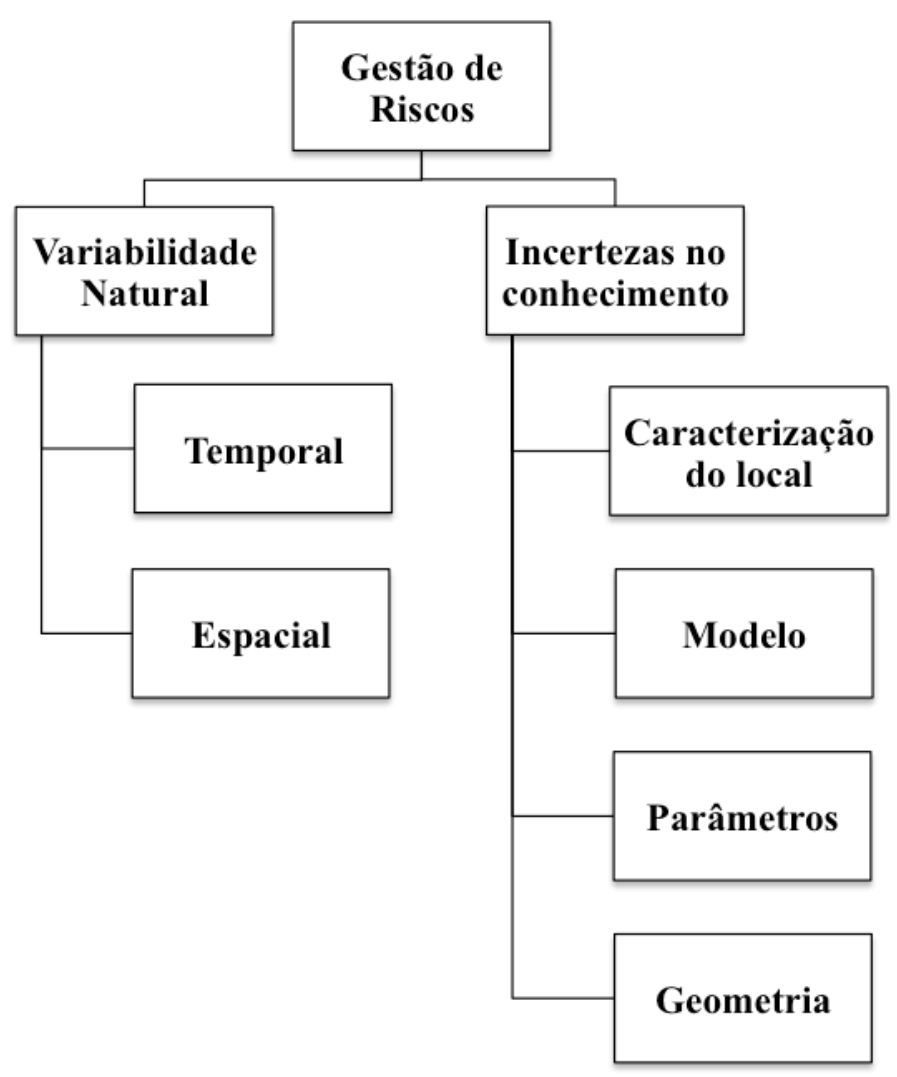

Figura 2.1 - Categorias de incerteza na gestão de riscos (modificado de Baecher \& Christian, 2003).

A variabilidade natural está associada à aleatoriedade inerente aos processos naturais, manifestando-se como variabilidade ao longo do tempo para fenômenos que ocorrem em um único local (variabilidade temporal), ou como variabilidade ao longo do espaço para fenômenos que acontecem em diferentes locais a um tempo único (variabilidade espacial), ou como variabilidade ao longo do tempo e do espaço. Para avaliar a variabilidade natural faz-se uso de simplificações matemáticas ou modelos, que podem ou não fornecer um bom ajuste para os fenômenos naturais, mas apenas propiciam uma aproximação desses fenômenos.

A incerteza no conhecimento deve-se à ausência de dados, de informações sobre eventos e processos ou de compreensão das leis da física que limitam a capacidade de modelar o mundo real. Incerteza no conhecimento é apenas uma descrição mais comum de incerteza epistêmica. Por vezes, esse tipo de incerteza tem sido chamada de incerteza subjetiva ou incerteza interna. A incerteza no conhecimento pode ser dividida em três grandes subcategorias para aplicações geotécnicas: incerteza na caracterização do local, incerteza no modelo, incerteza nos parâmetros e incerteza na geometria. 
A incerteza na caracterização do local tem a ver com a adequação das interpretações que se faz sobre a geologia subterrânea. É o resultado de incertezas nos dados e na exploração, incluindo (i) erros de medição, (ii) inconsistência ou heterogeneidade de dados, (iii) erros de manipulação e transcrição de dados, e (iv) representatividade inadequada de dados de amostras devido a limitações de tempo e espaço.

A incerteza no modelo depende do grau de acurácia que o modelo matemático escolhido representa a realidade. Essa incerteza reflete a incapacidade de um modelo de representar precisamente o verdadeiro comportamento físico do sistema, ou incapacidade do engenheiro de identificar o melhor modelo, ou a escolha de um modelo que pode mudar com o tempo de maneiras pouco conhecidas.

A incerteza nos parâmetros deve-se à precisão na estimativa dos parâmetros do modelo. Essa incerteza resulta da imprecisão na avaliação dos valores dos parâmetros a partir dos dados de ensaio ou calibração e é acentuada por um número limitado de observações, resultando em uma imprecisão estatística.

A incerteza na geometria de um túnel se dá pelo fato de que a geometria proposta em projeto nem sempre é obtida. Muitas vezes o formato definido anteriormente possui pequenas variações, ou seja incertezas, na obra.

\subsection{CONCEITOS BÁSICOS DA ESTATÍSTICA}

A seguir serão apresentados alguns conceitos básicos de probabilidade e estatística, ligados à análise probabilística de comportamento de túneis.

\subsubsection{VARIÁVEIS ALEATÓRIAS}

Variável aleatória pode ser definida como uma função que associa um número real a cada elemento do espaço amostral, ou seja, considerando um espaço amostral S que consiste de um conjunto de resultados $\left\{\mathrm{s}_{1}, \mathrm{~s}_{2}, \ldots\right\}$. Se $\mathrm{X}$ é a função que atribui um número real $\mathrm{X}$ (s) para resultado $\mathrm{s} \in \mathrm{S}$, então X é uma variável aleatória (Fenton \& Griffiths, 2008).

As variáveis aleatórias podem ser discretas, se os resultados possíveis são enumeráveis, ou contínuas, quando elas podem tomar valores numa escala contínua, ou seja, constituída de um intervalo ou conjunto de intervalos, que podem assumir um número infinito de resultados. 
Não se pode saber com certeza o valor de uma variável aleatória, e sim qual a probabilidade para cada um dos valores possíveis. O conjunto dessas probabilidades fornece uma distribuição de probabilidades, que no caso das variáveis discretas são as funções de massa de probabilidade (fmp); e para as variáveis contínuas são as funções de densidade de probabilidade (fdp)

\subsubsection{TENDÊNCIA CENTRAL, VARIABILIDADE E ASSOCIAÇÃO}

Um variável aleatória está completamente definida se sua distribuição de probabilidade é especificada. Contudo, não é possível saber a distribuição precisa de nenhum fenômeno natural, então faz-se uso de medidas mais facilmente estimadas, como a tendência central e a variabilidade (Fenton \& Griffiths, 2008).

A tendência central é medida pela média ou esperança matemática, que pode ser definida matematicamente :

$\mu_{x}= \begin{cases}E(x)=\sum_{i=1}^{\infty} x_{i} p\left(x_{i}\right) & , \text { para variáveis discretas } \\ E(x)=\int_{-\infty}^{\infty} x f(x) d x & , \text { para variáveis contínuas }\end{cases}$

em que,

$\mu_{x}:$ média ou esperança matemática;

$\mathrm{x}_{\mathrm{i}}$ : variável discreta;

$\mathrm{p}\left(\mathrm{x}_{\mathrm{i}}\right)$ : probabilidade de ocorrência de $\mathrm{x}_{\mathrm{i}}$;

x: variável contínua;

$\mathrm{f}(\mathrm{x})$ : função de distribuição de probabilidade de $\mathrm{x}$.

A variabilidade é obtida pela variância, que é a medida de dispersão dos valores em relação à média. A expressão matemática que define a variância é:

$\sigma_{x}^{2}=\operatorname{Var}[x]=E\left[\left(x-\mu_{x}\right)^{2}\right]= \begin{cases}\sum_{i=1}^{\infty}\left(x_{i}-\mu_{x}\right)^{2} p\left(x_{i}\right) & , \text { caso discreto } \\ \int_{-\infty}^{\infty}\left(x-\mu_{x}\right)^{2} f(x) d x & , \text { caso contínuo }\end{cases}$

Para se ter um indicador de dispersão na mesma unidade do valor esperado da variável, usase, comumente, o desvio padrão, que é a raiz quadrada da variância: 
$\sigma_{x}=\sqrt{\operatorname{Var}[x]}$

Em engenharia, usualmente, a variabilidade é expressa por um valor adimensional, o coeficiente de variação, que é a relação entre o desvio padrão e a média:

$C V=\sigma / \mu$

Para associar mais de uma variável no tempo faz-se uso da covariância, que é a medida do grau de interdependência entre duas variáveis aleatórias. Sejam duas variáveis aleatórias x e y, sua covariância é dada por:

$\operatorname{Cov}[x, y]=E\left[\left(x-\mu_{x}\right)\left(y-\mu_{y}\right)\right]= \begin{cases}\sum_{x} \sum_{y}\left(x-\mu_{x}\right)\left(y-\mu_{y}\right) p\left(x_{i}, y_{i}\right) & , \text { caso discreto } \\ \int_{-\infty}^{\infty} \int_{-\infty}^{\infty}\left(x-\mu_{x}\right)\left(y-\mu_{y}\right) f(x, y) d x d y & , \text { caso contínuo }\end{cases}$

Para medir o grau de linearidade na variação de uma variável aleatória x em relação a outra variável y, faz-se uso do coeficiente de correlação. Este coeficiente varia de -1 a 1, e quanto mais próximo desses limites, maior é linearidade entre as variáveis. O grau de linearidade é dado por:

$\rho=\operatorname{Cov}[x, y] / \sigma_{x} \sigma_{y}$

\subsubsection{PRINCIPAIS DISTRIBUIÇÕES ESTATÍTICAS}

Como mencionando anteriormente, uma variável aleatória só assume um valor numérico com uma probabilidade associada. O conjunto das probabilidades associadas a todos os valores de uma variável aleatória fornece a chamada distribuição de probabilidade.

De acordo com Fenton \& Griffiths (2008), existem inúmeras distribuições de probabilidade capazes de representar os fenômenos naturais aleatórios. No caso das variáveis discretas, as funções de massa de probabilidade mais comuns são Bernoulli, Binomial, Geométrica, Binomial Negativa, Poisson, Exponencial e Gama. Para as variáveis contínuas tem-se as funções de densidade de probabilidade, que podem ser, principalmente: Exponencial, Gama, Uniforme, Weibull, Rayleigh, Normal e Log-normal.

Contudo, a seguir serão apresentas apenas três distribuições estatísticas: a distribuição normal, log-normal e exponencial. 


\subsubsection{DISTRIBUIÇÃO NORMAL}

A distribuição normal é provavelmente a distribuição mais importante nos dias de hoje. Isso acontece porque grande parte das variáveis aleatórias tendem a uma distribuição normal, e isso foi provado pelo teorema do limite central.

Uma variável aleatória $\mathrm{X}$ segue uma distribuição normal (ou de Gauss) se a sua função de densidade de probabilidade possui a seguinte forma (Figura 2.2):

$f(x)=\frac{1}{\sigma \sqrt{2 \pi}} e^{\left[-\frac{1}{2}\left(\frac{x-\mu}{\sigma}\right)^{2}\right]}$

onde,

$\mathrm{x}$ : variável aleatória associada: $-\infty<x<\infty$;

$\mu$ : média;

$\sigma:$ desvio padrão.

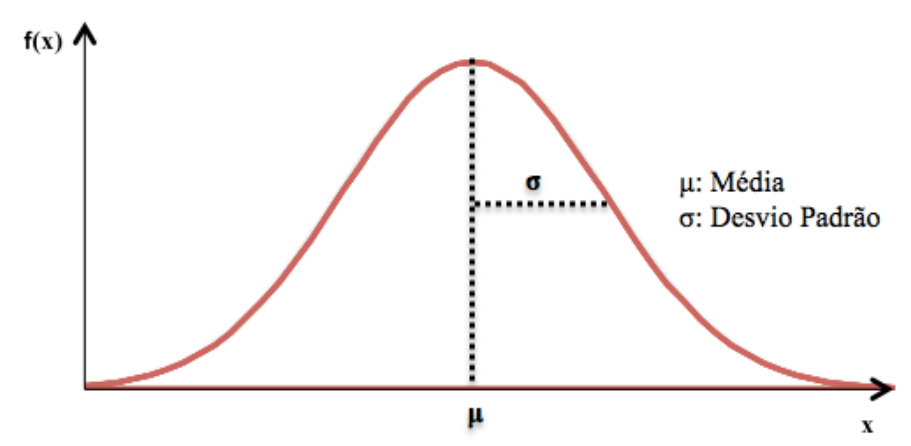

Figura 2.2 - Curva típica de distribuição normal.

Essa distribuição possui várias propriedades teóricas importantes:

1. A distribuição é simétrica em torno de um valor médio $(\mu)$ e possui o formato de um sino;

2. Suas medidas de tendência central (média, mediana, moda) são iguais;

3. Seu ponto de máximo, ou moda, ocorre no ponto de média $(\mu)$;

4. Os pontos de inflexão da função $\mathrm{f}(\mathrm{x})$ ocorrem para $x=\mu \pm \sigma$.

Infelizmente, não existe solução fechada para a integral da função normal de densidade de probabilidade. Assim, probabilidades associadas com a função normal devem ser obtidas por 
integração numérica. Tradicionalmente, isso significava que probabilidades normais deveriam ser obtidas por consultas a tabelas apresentadas em manuais e livros. Como nenhum livro é suficientemente grande para conter o conjunto de tabelas necessárias para todas os possíveis valores de $\mu$ e $\sigma$, surgiram algumas maneiras de padronizar essas tabelas.

Ang \& Tang (1975) apresentaram, então, a variável normal padronizada (Z), cuja média é $\mu=0$ e o desvio padrão $\sigma=1$ :

$z=\frac{x-\mu}{\sigma}$

Assim, a função de densidade de probabilidade de uma variável normal padronizada é agora expressa por:

$\phi(z)=\frac{1}{\sigma \sqrt{2 \pi}} e^{\left[-\frac{1}{2} z^{2}\right]}$

\subsubsection{DISTRIBUIÇÃO LOG-NORMAL}

Para os casos em que a distribuição normal não é aplicável, como assimetria e variáveis com valores negativos utiliza-se a distribuição log-normal.

A distribuição log-normal surge através de uma simples, embora não-linear, transformação da distribuição normal. Assim, a variável $x$ é log-normalmente distribuída se $\ln (\mathrm{x})$ é normalmente distribuída. Se isso é verdade, então, a função de densidade de probabilidade de x é (Figura 2.3):

$f(x)=\frac{1}{x \sigma \sqrt{2 \pi}} e^{\left[-\frac{1}{2}\left(\frac{\ln (x)-\mu}{\sigma}\right)^{2}\right]}$

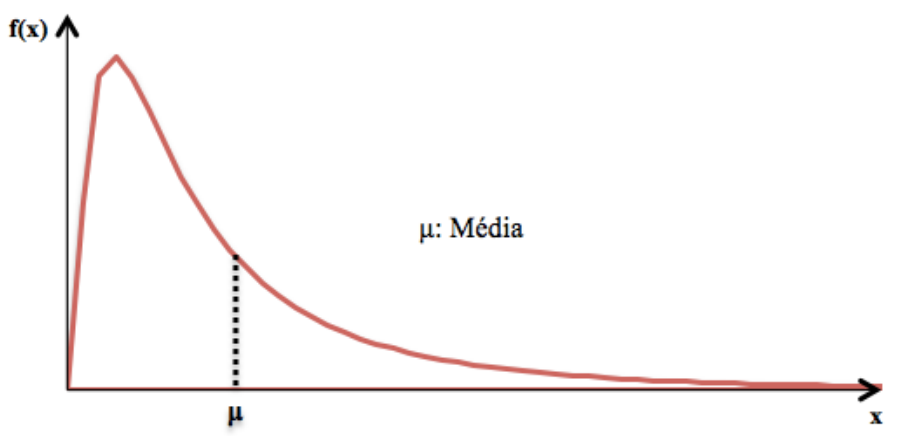

Figura 2.3 - Curva típica de distribuição log-normal. 


\subsubsection{DISTRIBUIÇÃO EXPONENCIAL}

A distribuição exponencial é uma das distribuições derivadas da família Bernoulli, que possui a ideia central de que cada instante no tempo constitui uma tentativa independente de Bernoulli. Uma tentativa de Bernoulli é um experimento no qual se tem apenas dois possíveis resultados, sucesso ou falha.

Essa distribuição é geralmente utilizada para descrever problemas de tempo até a falha, sendo que o tempo é regido pelo modelo de Poisson. Assim, se $\mathrm{T}_{1}$ é o tempo de ocorrência (ou falha) em questão e $T_{1}$ é distribuído exponencialmente, então, a função de densidade de probabilidade que o representa é:

$f_{T 1}(t)=\lambda e^{-\lambda t}, \quad t \geq 0$

em que $\lambda$ é a taxa de ocorrência (ou falha) de um evento. A função de distribuição cumulativa é:

$F_{T 1}(t)=P\left[T_{1} \leq t\right]=1-e^{-\lambda t}, \quad t \geq 0$

Nessa distribuição, a esperança matemática, E [ $\left.\mathrm{T}_{1}\right]$ e a variância, Var [ $\left.\mathrm{T}_{1}\right]$, são obtidas pelas seguintes equações:

$E\left[T_{1}\right]=\frac{1}{\lambda}$

$\operatorname{Var}\left[T_{1}\right]=\frac{1}{\lambda^{2}}$

Isto é, a média e o desvio padrão de uma distribuição exponencial de uma variável aleatória são iguais.

É importante lembrar que as formulações acima apresentadas são válidas tanto ao longo do tempo como ao longo do espaço.

\subsection{MÉTODOS PROBABILÍSTICOS}

Segundo Assis et al. (2012), métodos probabilísticos são aqueles que permitem avaliar a distribuição de probabilidades de uma variável dependente em função do conhecimento das distribuições estatísticas das variáveis independentes que a geram. 
Nos dias de hoje, os métodos mais utilizados na estatística aplicada são: método de Monte Carlo, método FOSM (índice de confiabilidade) e o método dos pontos de estimativa (Rosenblueth). Cada um destes métodos possui suas vantagens e desvantagens, e deve ser escolhido de acordo com o tipo de problema que está se tratando. A Tabela 2.1 apresenta um resumo das principais vantagens e desvantagens destes três métodos.

Tabela 2.1 - Resumo das vantagens e desvantagens dos principais métodos probabilísticos (Assis et al., 2012).

\begin{tabular}{|c|c|c|}
\hline Método & Vantagens & Desvantagens \\
\hline $\begin{array}{l}\text { Monte } \\
\text { Carlo }\end{array}$ & $\begin{array}{l}\text { - Solução pode ser exata } \\
\text { - Obtém a distribuição de } \\
\text { probabilidade }\end{array}$ & $\begin{array}{l}\text { - Requer distribuições } \\
\text { estatísticas dos dados } \\
\text { - Esforço computacional }\end{array}$ \\
\hline FOSM & $\begin{array}{l}\text { - Rápido } \\
\text { - Requer apenas a média e o } \\
\text { desvio padrão dos dados } \\
\text { - Obtém o peso de cada dado na } \\
\text { variância final }\end{array}$ & $\begin{array}{l}\text { - Obtém somente a média e } \\
\text { o desvio padrão } \\
\text { - Mecanismo fixo }\end{array}$ \\
\hline $\begin{array}{l}\text { Pontos de } \\
\text { Estimativa }\end{array}$ & $\begin{array}{l}\text { - Tempo adequado } \\
\text { - Requer apenas a média e o } \\
\text { desvio padrão dos dados }\end{array}$ & $\begin{array}{l}\text { - Assume uma distribuição } \\
\text { de probabilidade }\end{array}$ \\
\hline
\end{tabular}

\subsubsection{MÉTODO DE MONTE CARLO}

O método de Monte Carlo é um método que permite determinar a função de distribuição de probabilidade da variável dependente analisada mediante a geração de números aleatórios (sorteio) que representam as variáveis independentes. Este método considera que a variável dependente estudada apresenta uma função $\mathrm{Y}=\mathrm{f}\left(\mathrm{X}_{1}, \mathrm{X}_{2}, \ldots, \mathrm{X}_{\mathrm{n}}\right)$ e que são conhecidas as distribuições de probabilidade das variáveis $\mathrm{X}_{1}, \mathrm{X}_{2}, \ldots, \mathrm{X}_{\mathrm{n}}$ e a função $\mathrm{Y}$ é calculada para estes valores (Figura 2.4).

Convém ressaltar que a maioria das técnicas de geração de valores de distribuição fazem uso da distribuição acumulada. Por definição a distribuição acumulada para qualquer variável contínua é distribuída uniformemente no intervalo $[0,1]$ e, então, ao sortear um número neste intervalo de $[0,1]$, obtém-se um valor sorteado $\left(X_{s}\right)$ para a variável $X$, em que há mais probabilidade de se obter valores próximo à média. Este sorteio é feito de forma independente 
entre as variáveis $\mathrm{X}_{1}, \mathrm{X}_{2}, \ldots, \mathrm{X}_{\mathrm{n}}$. Na Figura 2.5 é apresentado o processo de conversão de um número aleatório em um valor da função por meio de uma distribuição de probabilidades.

O processo se repete de forma iterativa tantas vezes quanto for necessário para conseguir a convergência da distribuição de probabilidade, gerando um conjunto amostral de resultados. Quando o número de simulações $\mathrm{N}$ tende ao infinito $(\mathrm{N} \rightarrow \infty)$, o conjunto de resultados deixa de ser amostral e passa a ser populacional, então, o resultado é exato.

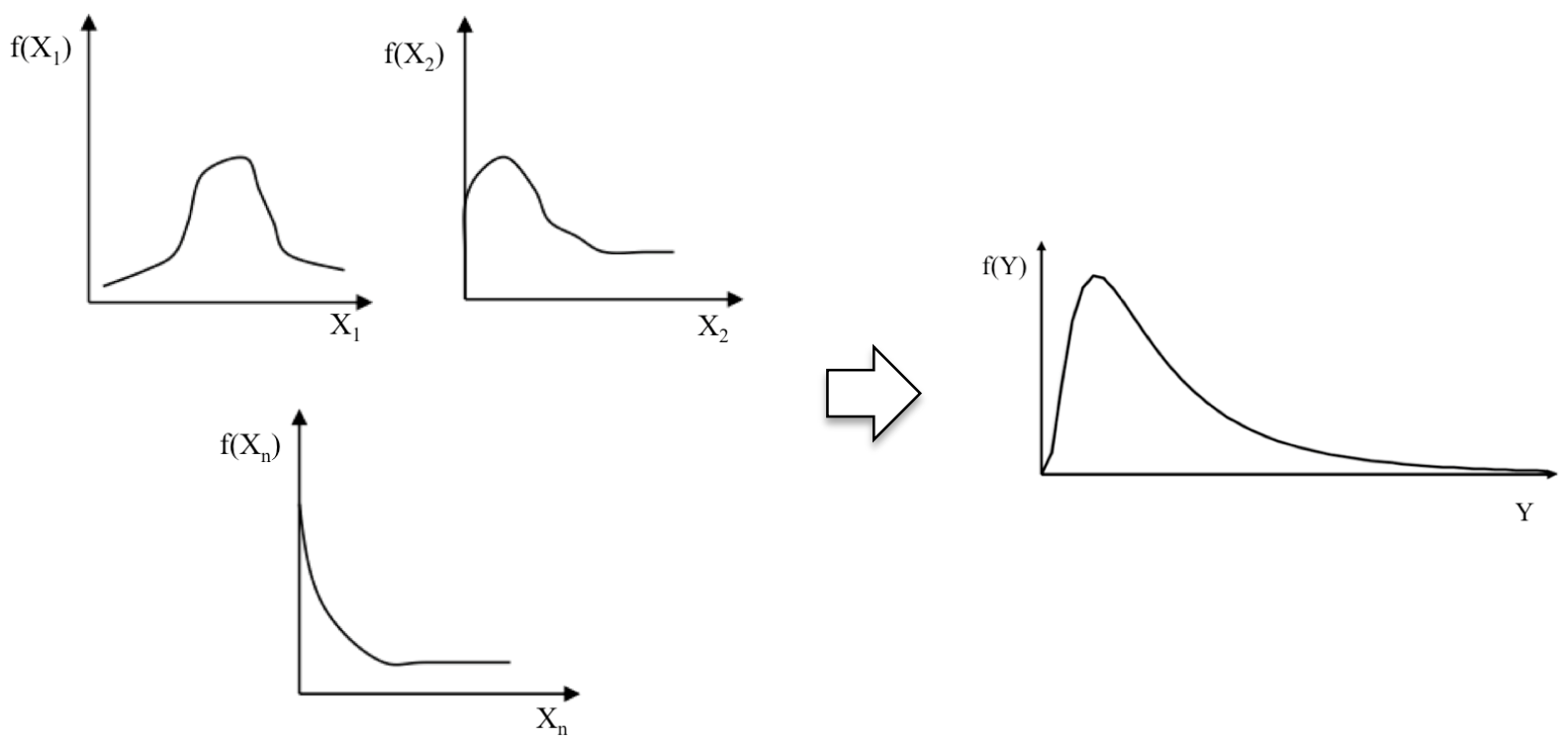

Figura 2.4 - Função de distribuição de probabilidade da variável dependente Y gerada a partir das funções das variáveis independentes $\mathrm{X}_{1}, \mathrm{X}_{2}, \ldots, \mathrm{X}_{\mathrm{n}}$.
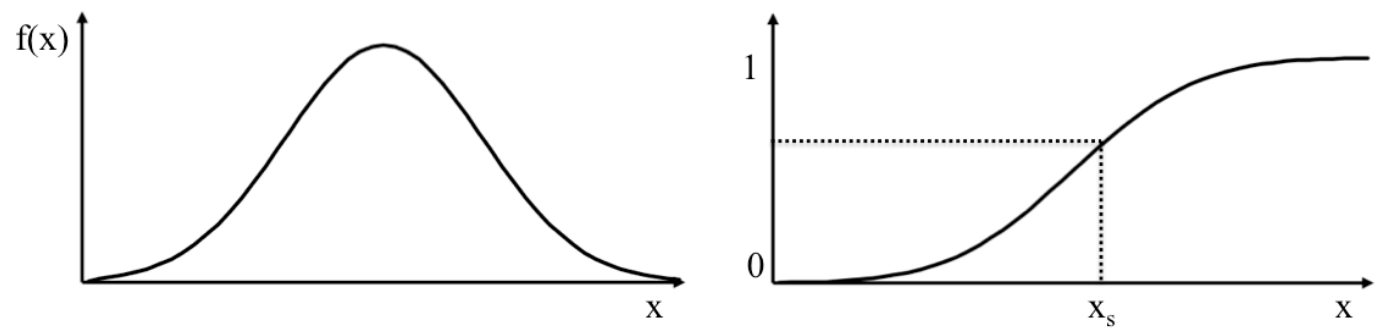

Figura 2.5 - Procedimento para obtenção de números aleatórios através de uma distribuição.

Cada tentativa é o resultado de um experimento onde têm-se os valores que indicam êxito ou falha $\mathrm{N}^{\mathrm{o}}\left(\mathrm{y}<\mathrm{ou}>\mathrm{y}_{\text {crit }}\right)$. Para se calcular a probabilidade de falha basta fazer a razão entre o número de valores de falha pelo número total de tentativas:

$p_{f}=\frac{N^{\mathrm{o}}\left(y>o u<y_{\text {crit }}\right)}{N}$ 
Para o caso da engenharia, a probabilidade de falha pode ser facilmente obtida a partir dos resultados da função de distribuição de probabilidade para todas as combinações de valores sorteados. Por exemplo, sendo F uma função que define o fator de segurança FS, basta analisar a porcentagem dos valores sorteados que geraram um $\mathrm{FS}<1$.

Após a geração de $\mathrm{N}$ resultados a partir da função $\mathrm{Y}=\mathrm{f}\left(\mathrm{X}_{1}, \mathrm{X}_{2}, \ldots, \mathrm{X}_{\mathrm{n}}\right)$, é possível calcular a média e o desvio padrão, obter um histograma e fazer o ajuste da distribuição estatística.

A principal desvantagem desse método é o elevado esforço computacional, pois a simulação do mesmo requer uma velocidade alta para os cálculos, para que se possa gerar uma ampla gama de números (Harr, 1987).

\subsubsection{MÉTODO FOSM}

O método FOSM (First-Order Second-Moment) utiliza os primeiros termos de uma expansão da série de Taylor da função de desempenho para estimar o valor esperado e variância da função de desempenho. Chama-se método do segundo momento pois a variância é uma forma do segundo momento e é o resultado de ordem estatístico mais elevado utilizado na análise. Se o número de variáveis incertas é $\mathrm{N}$, este método exige avaliar $\mathrm{N}$ derivadas parciais da função de desempenho ou executar uma aproximação numérica utilizando uma avaliação a $2 \mathrm{~N}+1$ pontos (Baecher \& Christian, 2003).

Para Harr (1987), as vantagens desta solução são cálculos matemáticos simples e o conhecimento apenas dos valores dos momentos das distribuições estatísticas das variáveis que formam a função. Por outro lado, têm-se como desvantagens o fato de que os requisitos matemáticos necessários às derivações, embora mais simples que de outros métodos exatos, geralmente não são elementares.

Para $\mathrm{N}$ variáveis aleatórias não correlacionadas, $\mathrm{f}\left(\mathrm{X}_{1}, \mathrm{X}_{2}, \ldots, \mathrm{X}_{\mathrm{n}}\right)$, conservando somente os termos lineares da série de Taylor, o valor esperado da função é dado por:

$E[f]=f\left(\bar{X}_{1}, \bar{X}_{2}, \ldots, \bar{X}_{n}\right)$

e a variância por:

$\operatorname{Var}[f]=\sum_{i=1}^{N}\left(\frac{\partial f}{\partial X_{i}}\right)^{2} V\left(X_{i}\right)$ 
onde,

$\bar{X}_{i}=E\left[\bar{X}_{i}\right]$

A função f é calculada para os pontos médios de todas as variáveis, assim como a variância de f. Nas expressões anteriores, a série de Taylor foi truncada a partir de seus termos de segunda ordem, eliminando, portanto, os efeitos dos terceiros e quartos momentos probabilísticos. Porém, esta aproximação é totalmente aceitável para fins práticos. Os valores das derivadas podem ser obtidos mediante cálculo analítico, contudo é mais usual e recomendável usar a aproximação numérica apresentada:

$\frac{\partial f}{\partial X_{i}}=\frac{f\left(X_{i}+\Delta X_{i}\right)-f\left(X_{i}\right)}{\Delta X_{i}}$

A análise probabilística pelo método FOSM segue as seguintes etapas:

i) Identificação das variáveis, seus valores médios e variâncias;

ii) Cálculo das derivadas parciais da função $\mathrm{f}\left(\mathrm{X}_{1}, \mathrm{X}_{2}, \ldots, \mathrm{X}_{\mathrm{n}}\right)$, em relação aos parâmetros;

iii) Cálculo do valor esperado da função, $E[f]$, e sua variância, $\operatorname{Var}[f]$;

iv) Assumir uma curva de distribuição de probabilidade para a função $\mathrm{F}$ e, então, associar indicadores de falha à probabilidade de falha. No caso do fator de segurança, a falha é caracterizada por um FS menor do que um.

O método FOSM tem aplicação limitada quando não há uma relação de linearidade entre a função analisada e as variáveis, pois, neste caso, as derivadas parciais não são constantes.

\subsubsection{MÉTODO DOS PONTOS DE ESTIMATIVA}

Rosenblueth (1975) propôs um método simples e elegante de obter os momentos da função de desempenho, avaliando a mesma num conjunto específico de pontos discretos. O método consiste em estimar os momentos (média, desvio padrão, coeficiente de assimetria etc.) da variável dependente em função das variáveis aleatórias independentes, para as quais se conheçam pelo menos dois momentos, média e desvio-padrão (ou pelo menos suas estimativas), sem a necessidade de conhecer as distribuições de probabilidade completas das variáveis independentes ou da dependente. 
De acordo com Rosenblueth (1975), a distribuição de uma variável aleatória $\mathrm{X}_{\mathrm{i}}$ é concentrada em dois pontos particulares localizados por:

$X_{i+}=\bar{X}_{i}+\sigma_{i}$

$X_{i-}=\bar{X}_{i}-\sigma_{i}$

onde $\bar{X}_{i}$ e $\sigma_{\mathrm{i}}$ são, respectivamente valor médio e o desvio padrão da distribuição da variável $\mathrm{X}_{\mathrm{i}}$.

As probabilidades associadas para estes pontos, $\mathrm{P}_{+}$e $\mathrm{P}_{-}$, são função da assimetria da distribuição. Esse método necessita, para o caso de $\mathrm{N}$ variáveis correlacionadas, de $2^{\mathrm{N}}$ valores estimados para cada combinação dos pontos particulares $X_{i+}$ e $X_{i-}$ (Figura 2.6).

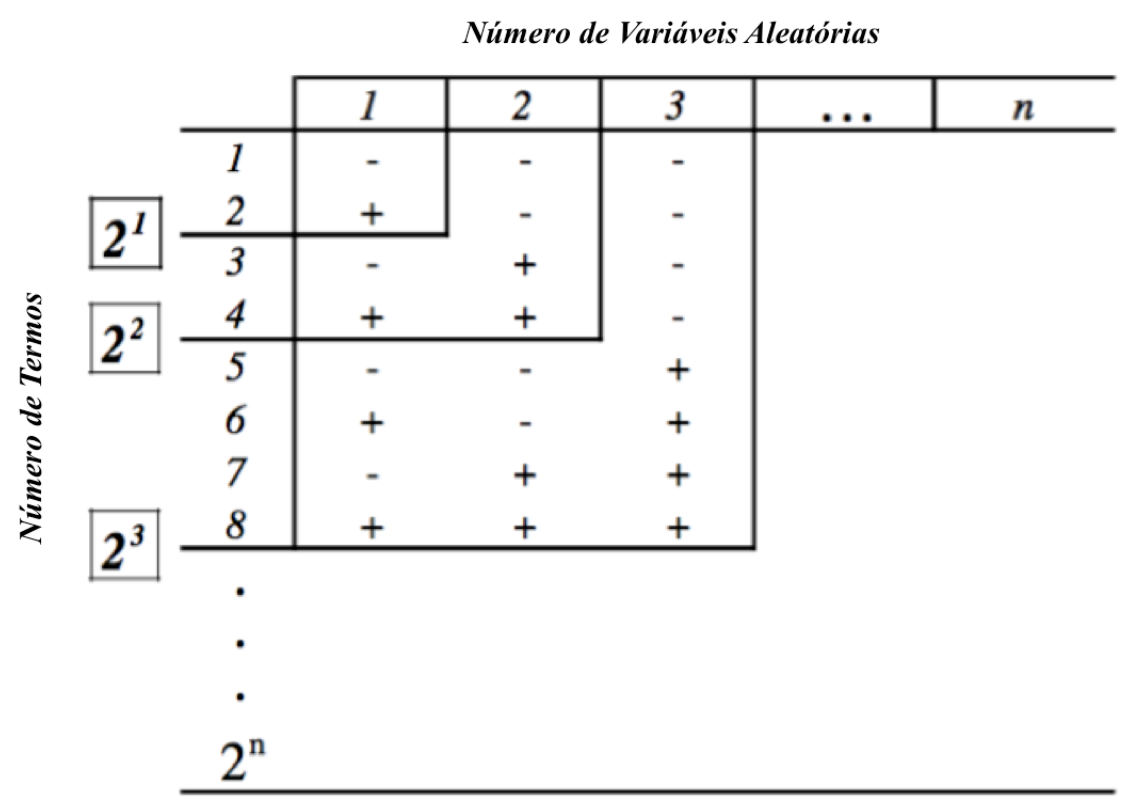

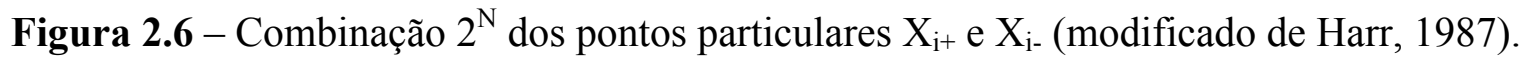
Após a combinação desses pontos particulares, o procedimento probabilístico é iniciado por meio de cálculos determinísticos, para este grupo de $2^{\mathrm{N}}$ valores. Desta forma, a cada nova etapa do processo probabilístico, alimenta-se os cálculos determinísticos por um grupo de novos dados de entrada a serem utilizados no próximo cálculo.

\subsection{ANÁLISE E GESTÃo DE RISCOS}

Assim como nas mais simples atividades do dia-a-dia, na engenharia lida-se com inúmeras situações que envolvem um evento que pode ocorrer, e se isso acontecesse, poderia trazer 
algum tipo de consequência adversa. É possível atribuir uma probabilidade de ocorrência para esse evento e quantificar a magnitude e custo da adversidade associada a essa ocorrência. Esta combinação de um evento incerto e sua consequência adversa é o que determina o risco:

$R(x)=p(x) \cdot C(x)$

onde,

p (x): probabilidade de ocorrência de um evento $\mathrm{x}$;

$\mathrm{C}(\mathrm{x})$ : consequência.

No uso comum, a palavra risco possui uma variedade de significados. Na engenharia, a definição é geralmente mais estreita. Kaplan \& Garrick (1981) escreveram que, para avaliar o risco, três coisas precisam ser definidas: um cenário, um conjunto de consequências e uma probabilidade dos eventos levarem às consequências. Neste sentido, Bier (1997) definiu que na análise de risco deve-se atentar para responder a três perguntas: $\mathrm{O}$ que pode acontecer? Qual a probabilidade de que isso aconteça? Tendo em conta que este evento ocorra, quais são as consequências?

Em engenharia civil, respondendo a essas três perguntas tem-se:

i) O que pode acontecer?

Falha: deficiência ou perda total do desempenho estrutural ou funcional da estrutura de engenharia. Para medi-la, define-se o limite de um indicador de desempenho ( $\mathrm{y}_{\text {crit }}$ ) que a partir do qual ocorre a falha (Figura 2.7):

$y>y_{\text {crit }}$ ou $y<y_{\text {crit }}$

ii) Qual a probabilidade de que isso aconteça?

Probabilidade de falha: abordagem probabilística aplicada ao parâmetro (y) escolhido como indicador de desempenho. A medição é feita a partir da geração da distribuição de probabilidade da variável $(\mathrm{y})$ :

$p_{f}=p\left(y>y_{\text {crit }}\right.$ ou $\left.y<y_{\text {crit }}\right)$

iii) Quais são as consequências? 
Custo associado às consequências decorrentes do evento de risco. A valoração das consequências permite a comparação entre riscos e sua utilização como elemento de tomada de decisão.

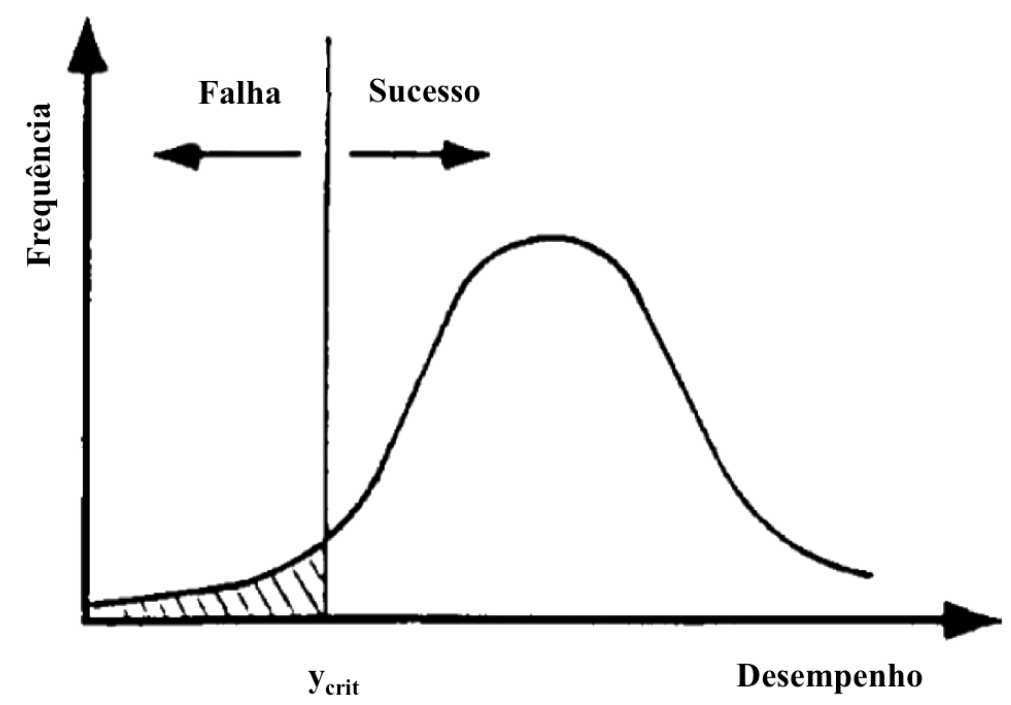

Figura 2.7 - Distribuição de desempenho típica com indicador de falha.

O cálculo do risco, hoje, na engenharia, é muito mais amplo do que apenas a multiplicação da probabilidade de falha pela consequência associada. Assim, é necessário expandir tanto o conceito de probabilidade de falha quando o de consequências.

Com relação à probabilidade de falha, podem ocorrer situações onde um evento de falha aconteça devido a outro evento deflagrador que também tem uma certa probabilidade de ocorrência. Por exemplo, a ocorrência de galgamento em uma barragem devido a ocorrência de uma chuva com um certo período de retorno. Neste caso, têm-se a probabilidade da ocorrência da chuva e, se esta ocorrer, a probabilidade da ocorrência do galgamento. $\mathrm{O}$ que gera uma relação de dependência entre as duas variáveis. Assim, o cálculo da probabilidade de falha é dado por:

$p_{f}=p_{f 1} \times p_{f 2}$

onde,

$\mathrm{p}_{\mathrm{fl}}$ : probabilidade de ocorrência do evento 1 (chuva);

$\mathrm{p}_{\mathrm{f} 2}$ : probabilidade de ocorrência do evento 2 (galgamento).

Generalizando: 
$p_{f}=\prod p_{f j}$

onde $\mathrm{p}_{\mathrm{fj}}$ é a probabilidade de ocorrência do evento $\mathrm{j}$.

As consequências também possuem uma certa probabilidade de ocorrência, já que o elemento que sofre a consequência pode ser mais ou menos vulnerável ou susceptível. Um exemplo claro seria na ocorrência de um terremoto, os idosos e crianças são mais vulneráveis que o jovens, os quais conseguem se locomover com maior facilidade. Outro exemplo, no caso de um escorregamento de encosta em um local onde passa um rodovia, há a probabilidade de atingir um carro passando no exato momento da ocorrência do escorregamento. Esta probabilidade pode ser alta ou baixa, dependendo da quantidade de carros que passam em um determinado período de tempo.

Assim, um determinado evento pode ter inúmeras consequências e cada uma destas possui uma certa probabilidade:

$C=\sum p_{v i} \cdot c_{i}$

onde,

$\mathrm{p}_{\mathrm{vi}}$ : probabilidade de ocorrência da consequência i devido à vulnerabilidade;

$\mathrm{c}_{\mathrm{i}}$ : consequência i da ocorrência de um evento.

Desta forma, o cálculo do risco, na sua forma mais ampla, é dado pela junção das equações 2.26 e 2.27 :

$R=\prod p_{f j} \cdot \sum p_{v i} \cdot c_{i}$

O que foi descrito acima, é apenas a estimação do risco. A gestão de riscos engloba outros inúmeros processos que vão desde a análise, avaliação até o processo mais completo que é a gestão de risco. Estes processos foram definidos por Fell et al. (2005) para o caso de estabilidade de taludes (Figura 2.8) e que foi aplicado aqui para o caso de túneis.

Contudo, não é objetivo do presente trabalho entrar no mérito de cada uma destas etapas. Esta dissertação limita-se apenas ao início do processo, que é a etapa de análise de falha, que é o processo de identificação e caracterização das potenciais falhas em conjunto com avaliação de sua probabilidade de ocorrência. 


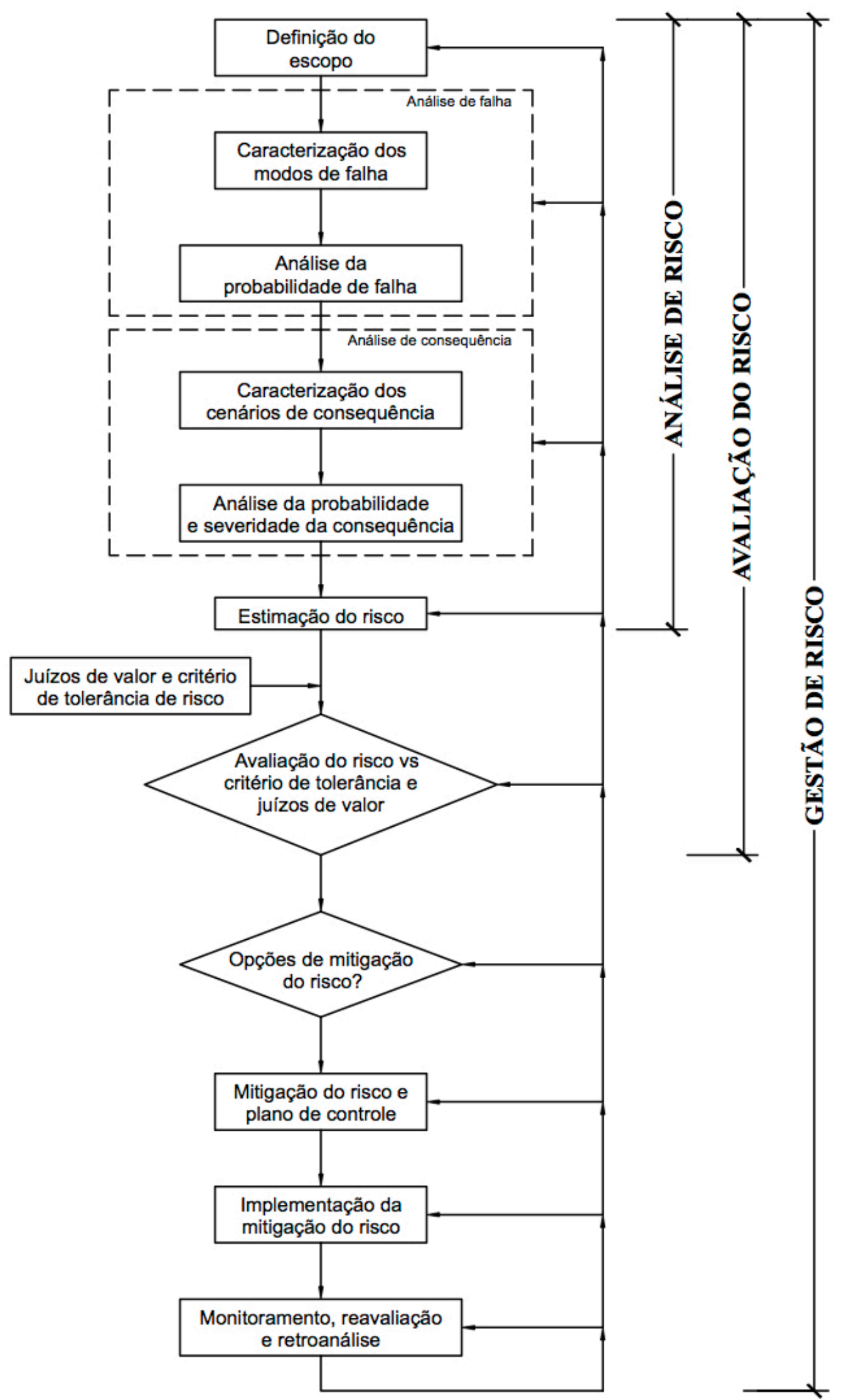

Figura 2.8 - Fluxograma para gestão de risco em engenharia (modificado de Fell et al., 2005). 
Portanto, a seguir, apresentam-se apenas as definições que se aplicam a esta dissertação: caracterização dos modos de falha e análise da probabilidade de falha.

Para Fell et al. (2005), a caracterização dos modos de falha requer a compreensão desses processos e a relação entre eles e a geomorfologia, geologia, hidrogeologia, mecanismos de ruptura, entre outros. A partir deste entendimento, será possível:

i) Classificar os tipos de potencial ruptura.

ii) Avaliar a extensão física de cada potencial evento, incluindo a localização, extensão da área afetada e do volume envolvido.

iii) Avaliar o evento deflagrador, as características físicas dos materiais envolvidos, tais como a resistência ao cisalhamento, poropressões e os mecanismos de ruptura.

iv) Identificar possíveis sinais de aviso de pré-falha que possam ser monitorados.

No caso da análise da probabilidade de falha, Fell et al. (2005) apresentaram algumas das várias formas de calcular:

i) Dados históricos dentro da área de estudo, ou áreas com características semelhantes, por exemplo, geologia, geomorfologia.

ii) Métodos empíricos baseado em correlações de acordo com os sistemas de classificação.

iii) Utilização de evidências geomorfológicas (juntamente com dados históricos), ou com base em pareceres de peritos.

iv) Relação com a frequência e intensidade do fato gerador, por exemplo, chuva, terremoto.

v) Avaliação direta com base em pareceres de peritos, que pode ser feita com referência a um modelo conceitual, por exemplo, utilização da metodologia de árvore de falhas.

vi) Modelagem da variável primária, por exemplo, pressão piezométrica versus evento gerador, juntamente com diferentes níveis de conhecimento da geometria e da resistência ao cisalhamento.

vii) Aplicação de métodos probabilísticos, tendo em conta as incertezas geotécnicas e geológicas. Esse método pode ser feito avaliando a confiabilidade ou levando em conta a 
frequência de falha.

viii) Combinações dos métodos acima.

$\mathrm{Na}$ prática, pode ser apropriado e aconselhável a utilização de mais de um método para a análise. Este trabalho, como já mostrado anteriormente, foca na aplicação do item vii) Aplicação de métodos probabilísticos.

\subsection{TESTE DE HIPÓTESES}

Os métodos probabilísticos podem ser tratados como uma "caixa preta" que toma amostras dos parâmetros incertos como entrada e retorna a função de distribuição ou probabilidade de falha como saída. Não são fornecidas informações sobre a propagação da incerteza através da análise, ou seja, não está claro como a incerteza se propaga a partir dos parâmetros de entrada, através dos modelos de análise determinística, para os resultados da análise de confiabilidade e como esses resultados (por exemplo, probabilidade de falha) são afetados. Para analisar os efeitos dos parâmetros incertos e testar o melhor ajuste das distribuições estatísticas dos dados de entra, a abordagem probabilística possui os testes de hipóteses.

Os efeitos dos vários parâmetros incertos $X=\left[X_{1}, X_{2}, \ldots, X_{n}\right]$ sobre a probabilidade de falha $\mathrm{p}_{\mathrm{f}}$ são priorizados comparando, estatisticamente, amostras de falha com suas respectivas amostras nominais (incondicionais). Quando a distribuição de amostras de falhas de um parâmetro de entrada se desvia significativamente da distribuição de amostras incondicionais, a incerteza do parâmetro de entrada tem um efeito significativo sobre $\mathrm{p}_{\mathrm{f}}$. $\mathrm{O}$ desvio entre a distribuição das amostras de falhas e das amostras incondicionais pode ser quantificado pela diferença entre a média $\mu_{\mathrm{f}}$ das amostras de falha do parâmetro e a média $\mu$ de suas amostras incondicionais. Quando $\mu_{\mathrm{f}}$ se desvia significativamente de $\mu$, a incerteza do parâmetro de entrada tem um efeito significativo sobre $\mathrm{p}_{\mathrm{f}}$. A diferença estatística entre $\mu_{\mathrm{f}}$ e $\mu$ é avaliada por testes de hipóteses. Uma hipótese nula $\mathrm{H}_{0}$ e hipótese alternativa $\mathrm{H}_{\mathrm{A}}$ são definidas como (Walpole et al., 1998):

$H_{0}: \mu=\mu_{f}$

$H_{A}: \mu \neq \mu_{f}$

Um teste de hipóteses estatístico do parâmetro é, então, formulado como: 
$Z_{H}=\frac{\mu-\mu_{f}}{\sigma / \sqrt{n_{f}}}$

onde $\sigma$ é o desvio padrão incondicional do parâmetro incerto em questão e $\mathrm{n}_{\mathrm{f}}$ é o número de amostras de falha. Com base no Teorema do Limite Central, $Z_{\mathrm{H}}$ segue a distribuição normal padrão quando $\mathrm{n}_{\mathrm{f}}$ é grande (por exemplo, $\mathrm{n}_{\mathrm{f}} \geq 30$ ) (Walpole et al., 1998). Quando a média da amostra de falha $\mu_{\mathrm{f}}$ se desvia estatisticamente da média incondicional $\mu$ do parâmetro, o valor absoluto de $Z_{\mathrm{H}}$ é relativamente grande. À medida que o valor absoluto de $Z_{\mathrm{H}}$ aumenta, a diferença estatística entre $\mu_{\mathrm{f}}$ e $\mu$ torna-se crescentemente significativa. $\mathrm{O}$ efeito do parâmetro incerto sobre a probabilidade de falha também se torna crescentemente significativo. $O$ valor absoluto de $\mathrm{Z}_{\mathrm{H}}$ pode, portanto, ser usado como um índice para medir os efeitos dos parâmetros incertos na probabilidade de falha e para priorizar seus efeitos relativos na probabilidade de falha. Ao comparar os valores absolutos de $\mathrm{Z}_{\mathrm{H}}$ para vários parâmetros incertos, aqueles parâmetros incertos que têm efeitos significativos sobre a probabilidade de falha são identificados.

\subsection{ANOVA}

No item anterior 2.5 foi apresentada a técnica de comparar as médias de duas populações por meio de testes de hipótese. Esta técnica está limitada a comparar populações duas a duas de cada vez e assim quando se tem um número maior de populações, o processo pode se tornar complicado ou tedioso. A técnica de comparar as médias de duas ou mais populações é conhecida como Análise de Variância (ANOVA). A análise de variância se aplica a comparação simultânea entre médias de diversas amostras ou para estimar a variabilidade associada a diferentes fontes de variação (Levine et al., 1998).

Essa análise se baseia no fato de que a variância de uma soma de variáveis aleatórias, não correlacionáveis entre si, é igual à soma das variâncias dessas mesmas variáveis. Em outras palavras, se duas ou mais variáveis, não correlacionáveis entre si, introduzem variabilidade em um conjunto de observações, essa variabilidade pode ser decomposta em partes e cada porção atribuída a cada uma das variáveis (Maia, 2007). Desse modo, a aplicação da análise de variância depende da identidade algébrica que estabelece:

Variância total = Variância dentro das amostras + Variância entre amostras

A variância total é a variação de todas as medidas em relação à média geral. A variância 
dentro das amostras é a variação média resultante da variação de cada amostra em relação à sua própria média e a variância entre amostras é a variação das médias de cada amostra em relação à média geral. Ambas as variâncias calculadas são estimativas independentes da variância populacional. O problema é saber se elas estimam o mesmo parâmetro, isto é, se essas duas variâncias amostrais provêm da mesma população ou não. Para tal teste, se utiliza a distribuição de Fisher (F), que verifica a razão entre a variância entre amostras e a variância dentro das amostras.

$\mathrm{F}=\frac{\text { Variância entre amostras }}{\text { Variância dentro das amostras }}$ 


\section{OBRAS SUBTERRÂNEAS EM MEIOS ROCHOSOS}

O uso de estruturas subterrâneas vem desde à pré-história, quando os humanos procuravam abrigo contra as chuvas e seus predadores, passando pela era mineral, era da navegação, era das ferrovias até os dias atuais, a era ambiental (Assis, 2002).

Os métodos de escavação de túneis se desenvolveram com o passar do tempo e com o acúmulo de experiência, principalmente no século XIX (Era das Ferrovias) com os chamados Métodos Clássicos para Abertura de Túneis. Mas, foi na década de 50 que surgiu o método denominado NATM - New Austrian Tunnelling Method (Novo Método Austríaco de Abertura de Túneis). Este método pode ser considerado como sendo uma filosofia de escavação pois, ao contrário dos métodos anteriores, não fixa qualquer sequência para a abertura da cavidade ou instalação de suporte. É aqui que surgem os princípios de comportamento de túneis.

Segundo a filosofia do NATM, o maciço não é mais visto apenas como elemento de carga, mas sim trabalha em conjunto com o sistema estrutural de suporte para a estabilização da cavidade. O NATM fundamenta-se em três princípios básicos:

- O maciço é visto como principal elemento estrutural;

- A complementação, quando necessária, da estrutura de sustentação deve ser executada através da instalação de um sistema de suporte otimizado;

- Deve-se promover a instrumentação do túnel.

Para Assis (2003), as principais dificuldades encontradas no projeto de estruturas localizadas em grandes profundidades em rocha são: a investigação do perfil geológico, a determinação das propriedades mecânicas das rochas, o estabelecimento do perfil detalhado das descontinuidades e suas propriedades, a determinação das tensões naturais e, finalmente, como a obra irá alterar estas tensões e como será a resposta do maciço frente a esta mudança.

Os matérias geotécnicos, a exemplo das rochas, se distinguem dos demais materiais de engenharia devido ao seu processo de formação, que ocorre através de processos naturais, não controlados pelo homem. Assim, projetar uma estrutura neste tipo de material é um processo, no mínimo, peculiar, já que suas características e parâmetros são altamente variáveis.

Primeiramente é necessário entender o que é um maciço rochoso. Que é um meio descontínuo 
formado pelas porções de rocha intacta e pelas descontinuidades que o atravessam. As propriedades e parâmetros que vão controlar o comportamento das obras executadas ou escavadas neste maciço rochoso vão depender da escala relativa entre o padrão de fraturamento do maciço rochoso e o tamanho da obra. Em alguns casos serão predominantes as propriedades da rocha intacta, em outros as propriedades das descontinuidades, e por fim, as do maciço rochoso como um todo.

Jaeger \& Cook (1979) definiram três etapas a serem seguidas em qualquer investigação prática em mecânica das rochas: primeiro deve-se fazer uma investigação geológica e geofísica detalhada para estabelecer a litologia e as fronteiras dos tipos de rocha envolvidos; em segundo lugar, realizar sondagens e escavações de exploração a fim de estabelecer um perfil detalhado do fraturamento e em determinar as propriedades mecânicas e petrológicas das rochas; e, por fim, a terceira etapa consiste na medição das tensões preexistentes na rocha não escavada (tensões in situ). De posse de todas essas informações, é possível prever o comportamento do maciço frente a escavação ou carregamento.

Seguir essas três etapas é praticamente inviável a medida que o tamanho e volume das amostras aumentam. Assim, faz-se necessário o uso de ferramentas teóricas que permitam analisar o comportamento deste tipo de material.

Neste sentido, as classificações geomecânicas surgiram como elemento fundamental no processo de melhor compreensão do comportamento do maciço rochoso. As classificações mais usadas são a de Bieniawski (1973, 1976 e 1989) com o índice RMR (Rock Mass Rating) e a de Barton et al. (1974) e Barton \& Grimstad (1994) com o índice de qualidade Q. E mais recentemente, Hoek (1994) propôs o sistema GSI (Geological Strength Index), que tenta fundir os dois sistemas anteriores para fins de obtenção de parâmetros de deformabilidade e resistência do maciço rochoso.

O sistema RMR, proposto por Bieniawski (1976), utiliza tabelas, onde são atribuídos pesos para seis parâmetros (resistência uniaxial da rocha intacta, índice RQD (Rock Quality Designation), espaçamento das descontinuidades, padrão das descontinuidades, ação da água subterrânea e orientação das descontinuidades. Estes pesos são somados para obter o valor de RMR (máximo de 100 pontos).

Para Hoek \& Brown (1980), a calibração do sistema RMR foi feita em túneis rasos com 
maciços de boa qualidade e não considerando o estado de tensões do meio rochoso. Assim, nos casos de maciços pouco resistentes e com comportamento mecânico dominado pelo estado de tensões sua aplicabilidade é limitada.

O outro sistema de classificação proposto foi o índice de Qualidade Q (Tunnelling Quality Index), proposto por Barton et al. (1974). O valor do índice Q varia numa faixa logarítmica de 0,001 até 1000 e é definido por:

$Q=\left(\frac{R Q D}{J_{n}}\right)\left(\frac{J_{r}}{J_{a}}\right)\left(\frac{J_{w}}{S R F}\right)$

onde,

RQD: Índice RQD;

$\mathrm{J}_{\mathrm{n}}$ : índice de influência do número de famílias das descontinuidades;

$\mathrm{J}_{\mathrm{r}}$ : índice de influência da rugosidade das paredes das descontinuidades;

$\mathrm{J}_{\mathrm{a}}$ : índice de influência da alteração das paredes das descontinuidades;

$\mathrm{J}_{\mathrm{w}}$ : índice de influência da ação da água subterrânea;

SRF: índice de influência do estado de tensões no maciço (Stress Reduction Factor).

Segundo Hoek \& Brown (1980), a limitação do sistema Q é que o mesmo não considera diretamente a influência da orientação das descontinuidades nem a resistência da rocha intacta, a qual é considerada indiretamente no RQD. Por outro lado, este considera as propriedades da família de descontinuidades mais desfavoráveis no índice de rugosidade e no índice de alteração das paredes das descontinuidades, que contribuem para a resistência ao cisalhamento do maciço rochoso.

Hoek (1994), percebendo que os sistemas de classificação existentes focavam em dar soluções de engenharia, definiu o índice de resistência geológica (GSI) que visa a obtenção de parâmetros geomecânicos. Este é, de certa forma, uma fusão dos sistemas RMR e Q, eliminando os parâmetros relacionados à obra em si.

O GSI sofreu várias evoluções e, no início, já fora calculado subtraindo uma porção do valor obtido no sistema RMR mas, atualmente, o valor do GSI é obtido por ábacos (Figura 3.1), 
sendo este valor determinado conforme as avaliações visuais das condições do maciço rochoso.

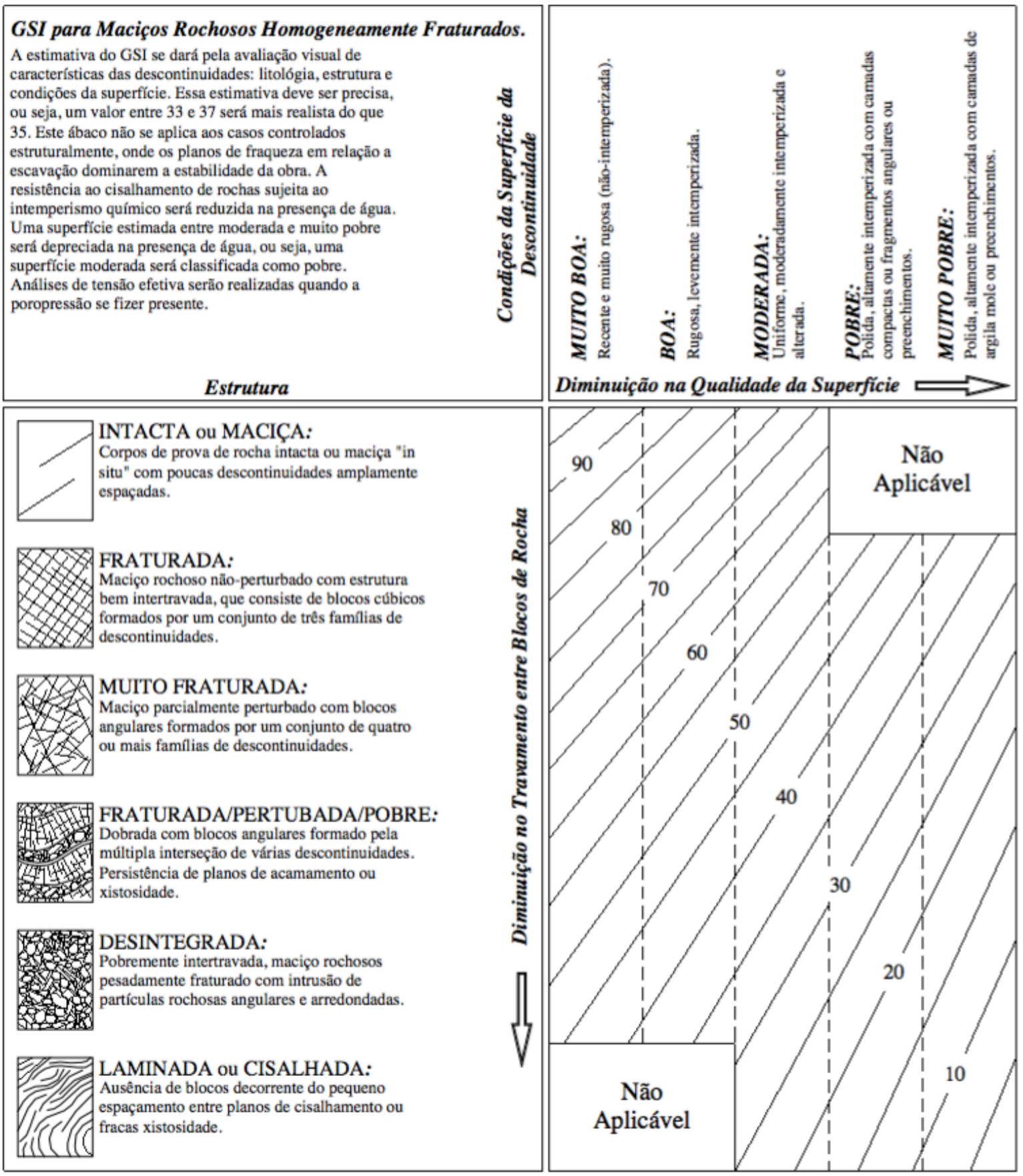

Figura 3.1 - Ábaco do GSI em maciços rochosos homogeneamente fraturados (modificado de Marinos \& Hoek, 2000).

\subsection{CRITÉRIOS DE RUPTURA}

Serão tratados a seguir o clássico critério de ruptura de Mohr-Coulomb e o critério de ruptura 
de Hoek \& Brown, proposto por Hoek et al. (2002).

\subsubsection{CRITÉRIO DE RUPTURA DE MOHR-COULOMB}

Para Assis (2001), o critério de Mohr-Coulomb é normalmente aplicado para solos, alguns tipos de rocha intacta e para descontinuidade planas e lisas, ou aquelas controladas por preenchimento.

Neste critério, o colapso ocorre quando a tensão cisalhante atuante no plano de resistência se iguala ao valor da tensão cisalhante de resistência do material. Comumente a envoltória é curva mas, muitas vezes é ajustada por uma reta no intervalo de tensões normais de interesse. A equação de reta que representa o critério de resistência proposta por Coulomb, em 1773, é:

$\tau=c+\sigma \tan \phi$

onde, $\sigma$ representa as tensões normais e $\tau$ as tensões cisalhantes atuando em um plano cujos parâmetros c representa a coesão e $\phi$ o ângulo de atrito.

A partir do conceito do círculo de Mohr (Figura 3.2) pode-se expressar a função de resistência em termos das tensões principais maior $\left(\sigma_{1}\right)$ e menor $\left(\sigma_{3}\right)$. Assim tem-se que:

$\frac{\sigma_{1}-\sigma_{3}}{2}=\frac{\sigma_{1}+\sigma_{3}}{2} \cdot \operatorname{sen} \phi+c \cdot \cos \phi$

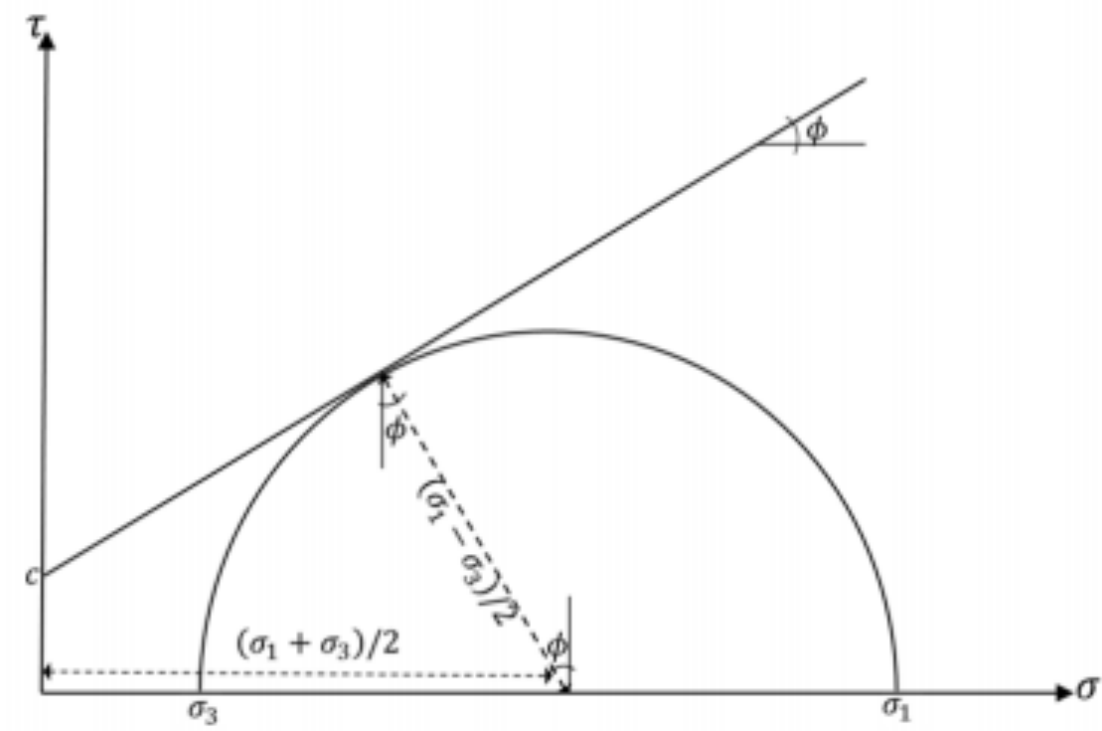

Figura 3.2 - Critério de Mohr-Coulomb representado no círculo de Mohr. 


\subsubsection{CRITÉRIO DE RUPTURA DE HOEK \& BROWN}

O comportamento das rochas difere do comportamento de solos no sentido de que são geralmente mais rígidas e mais fortes. A dependência da rigidez no nível de tensão é quase insignificante, de modo que a rigidez das rochas pode ser considerada constante. Por outro lado, a dependência da resistência (cisalhamento) é significativa. Neste sentido, um maciço rochoso fortemente fraturado ou intemperizado pode ser considerado um material com atrito. A primeira abordagem é modelar a resistência ao cisalhamento de rochas por meio do critério de ruptura de Mohr-Coulomb. No entanto, considerando a grande variedade de níveis de tensões onde a rocha pode ser submetida, um modelo linear, como o de Mohr-Coulomb, geralmente não é suficiente. Além disso, as rochas também podem apresentar uma resistência à tração significativa. Assim, o critério de Hoek-Brown é uma melhor aproximação não linear da resistência das rochas.

Este critério usa os resultados dos testes de laboratório em conjunto com o GSI para determinar um critério de falha para um dado maciço rochoso com base na sua resistência ao cisalhamento. O critério de falha para este método é definido pela seguinte equação:

$\sigma_{1}^{\prime}=\sigma_{3}^{\prime}+\sigma_{c i}^{\prime}\left(m_{b} \frac{\sigma_{3}^{\prime}}{\sigma_{c}^{\prime}}+s\right)^{a}$

onde,

$\sigma_{\mathrm{ci}}$ : resistência à compressão uniaxial da rocha intacta (MPa);

$\mathrm{m}_{\mathrm{b}}$, $\mathrm{s}$ e a: constantes referentes ao maciço rochoso;

$\sigma_{1}$ e $\sigma_{3}:$ tensões principais maior e menor, respectivamente (MPa).

As constantes $\mathrm{m}_{\mathrm{b}}$, $\mathrm{s}$ e a são calculadas utilizando o GSI do maciço rochoso, bem como o fator de perturbação - D (decorrente da técnica construtiva):

$$
\begin{aligned}
& m_{b}=m_{i} \exp \left(\frac{G S I-100}{28-14 D}\right) \\
& s=\exp \left(\frac{G S I-100}{9-3 D}\right) \\
& a=\frac{1}{2}+\frac{1}{6}\left(e^{\frac{-G S I}{15}}-e^{\frac{-20}{3}}\right)
\end{aligned}
$$


A partir do valor da resistência à compressão uniaxial do material da rocha intacta $\left(\sigma_{\mathrm{ci}}\right)$, podese obter a resistência à compressão uniaxial da rocha fraturada, $\sigma_{c}$ :

$\sigma_{c}=\sigma_{c i} \cdot s^{a}$

A resistência à tração da rocha fraturada, $\sigma_{\mathrm{t}}$, pode ser obtida por:

$\sigma_{t}=\frac{s \cdot \sigma_{c i}}{m_{b}}$

No âmbito da teoria da plasticidade, o critério de ruptura de Hoek-Brown é reformulado para a seguinte função de escoamento:

$F=\sigma_{1}^{\prime}-\sigma_{3}^{\prime}+\sigma_{c i}^{\prime}\left(m_{b} \frac{\sigma_{3}^{\prime}}{\sigma_{c}^{\prime}}+s\right)^{a}$

\subsubsection{CONVERSÃO DO CRITÉRIO DE HOEK \& BROWN PARA MOHR-COULOMB}

Como dito anteriormente, o critério de Hoek-Brown representa melhor o modo de ruptura das rochas. Contudo, vários programas geotécnicos ainda trabalham em termos do critério de ruptura de Mohr-Coulomb, onde se faz necessária a determinação do ângulo de atrito e da coesão do maciço rochoso a ser analisado.

A fim de comparar o critério de ruptura de Hoek-Brown com o critério de Mohr-Coulomb, um ajuste equilibrado pode ser feito para confinar tensões no intervalo (considerando a tensão positiva e compressão negativa), como mostrado na Figura 3.3:

$-\sigma_{\mathrm{t}}<\sigma_{3}^{\prime}<-\sigma_{3, \max }^{\prime}$

onde,

$\sigma_{\mathrm{t}}:$ resistência à tração do maciço $(\mathrm{MPa})$;

$\sigma_{3}$ : tensão principal efetiva menor $(\mathrm{MPa})$;

$\sigma_{3, \max }$ : tensão principal efetiva menor máxima definida em função do tipo de obra (MPa).

Isto dá as seguintes expressões para os parâmetros de resistência efetivos de Mohr-Coulomb $\phi^{\prime}$ e c' (Carranza-Torres, 2004): 


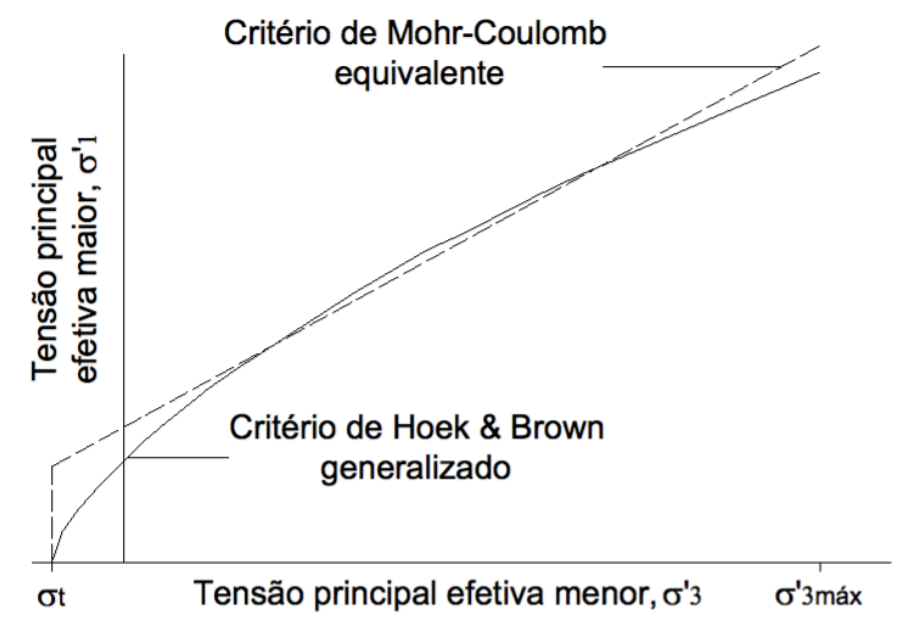

Figura 3.3 - Esquema do ajuste da envoltória de Mohr-Coulomb ao critério de ruptura de Hoek-Brown generalizado (modificado de Hoek et al., 2002).

$\operatorname{sen} \phi^{\prime}=\frac{6 a m_{b}\left(s+m_{b} \sigma_{3 n}^{\prime}\right)^{a-1}}{2(1+a)(2+a)+6 a m_{b}\left(s+m_{b} \sigma_{3 n}^{\prime}\right)^{a-1}}$

e

$c^{\prime}=\frac{\sigma_{c i}\left[(1+2 a) s+(1-a) m_{b} \sigma_{3 n}^{\prime}\right]\left(s+m_{b} \sigma_{3 n}^{\prime}\right)^{a-1}}{(1+a)(2+a) \sqrt{1+\frac{6 a m_{b}\left(s+m_{b} \sigma_{3 n}^{\prime}\right)^{a-1}}{(1+a)(2+a)}}}$

onde,

$\sigma_{3 \mathrm{n}}^{\prime}=-\sigma_{3 \max }^{\prime} / \sigma_{\mathrm{ci}}$

$\phi '$ : ângulo de atrito efetivo;

c': coesão efetiva (MPa);

$\sigma_{3, \max }^{\prime}$ : limite superior da tensão de confinamento ( $\left.\mathrm{MPa}\right)$, que deve ser selecionado segundo o tipo de aplicação;

$\mathrm{m}_{\mathrm{b}}$, s e a: parâmetros do critério de Hoek \& Brown (adimensionais);

$\sigma_{\mathrm{ci}}$ : resistência à compressão uniaxial da rocha intacta $(\mathrm{MPa})$.

Define-se ainda $\sigma^{\prime}{ }_{\mathrm{cm}}(\mathrm{MPa})$ como a resistência global do maciço rochoso para um intervalo de confinamento $\sigma_{\mathrm{t}}<\sigma_{3}^{\prime}<\frac{\sigma_{\mathrm{ci}}}{4}$. Seu cálculo se mostra a seguir:

$\sigma_{c m}^{\prime}=\sigma_{c i} \frac{\left[m_{b}+4 s-a\left(m_{b}-8 s\right)\right]\left(\frac{m_{b}}{4}+s\right)^{a-1}}{2(1+a)(2+a)}$ 
A partir disso, o valor de $\sigma_{3, \max }^{\prime}(\mathrm{MPa})$ pode ser definido para três situações diferentes:

- Aplicações gerais:

$\sigma_{3, \max }^{\prime}=\frac{\sigma_{c i}}{4}$

- Aplicação em túneis:

$\sigma_{3, \max }^{\prime}=0,47 \sigma_{c m}^{\prime}\left(\frac{\sigma_{c m}^{\prime}}{\gamma H}\right)^{-0,94}$

- Aplicação em taludes:

$\sigma_{3, \max }^{\prime}=0,72 \sigma_{c m}^{\prime}\left(\frac{\sigma_{c m}^{\prime}}{\gamma H}\right)^{-0,91}$

onde,

H: profundidade do túnel desde a superfície (m), na aplicação em túneis;

H: altura do talude (m), na aplicação em taludes;

$\gamma:$ peso específico do maciço rochoso $\left(\mathrm{MN} / \mathrm{m}^{3}\right)$.

\subsection{MODOS DE FALHA DE TÚNEIS EM ROCHAS E SEUS PRINCIPAIS INDICADORES DE DESEMPENHO}

Pode-se dizer que ocorre falha em uma obra subterrânea quando ocorre uma ruptura estrutural da mesma ou pela não concordância com as especificações de desempenhos impostas no projeto.

Engenheiros e pesquisadores vêm dedicando seus esforços para entender o comportamento de túneis escavados nas mais diversas condições. Em recompensa a esses esforços, alguns autores, como Hoek, Diederichs e outros, chegaram ao mesmo pensamento, no qual deve-se considerar dois modos de ruptura para obras subterrâneas. O primeiro devido aos processos de instabilidades estruturalmente controladas por descontinuidades. E o segundo originado do estado de tensões induzido pela escavação da estrutura subterrânea, cujas tensões poderão igualar a própria resistência do maciço rochoso.

Neste sentido, Hoek et al. (1995) resumiram os principais modos de falha de acordo com as condições estruturais do maciço rochoso e da magnitude das tensões in situ (Figura 3.4). 


\section{Maciço Rochoso \\ Intacto}

$(\mathrm{GSI}>70)$

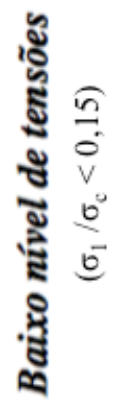

हัँ

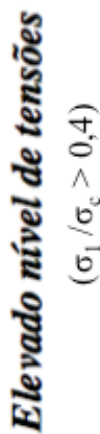

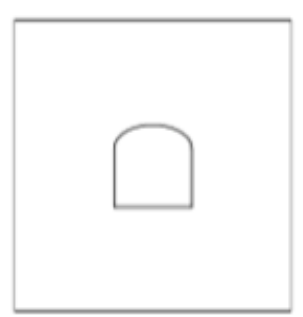

Estável.
Maciço Rochoso Moderadamente Fraturado

$(45<\mathrm{GSI}<70)$

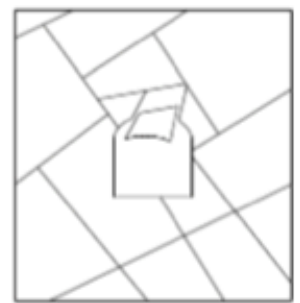

Queda de blocos e cunhas.

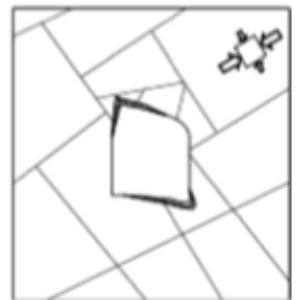

Ruptura localizada ao redor da escavação e movimento de blocos.

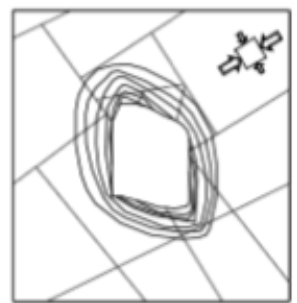

Ruptura generalizada ao redor da escavação.

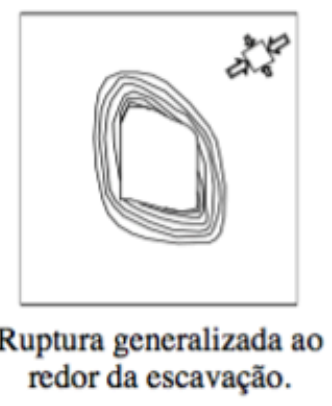

Maciço Rochoso Intensamente Fraturado

$(\mathrm{GSI}<45)$

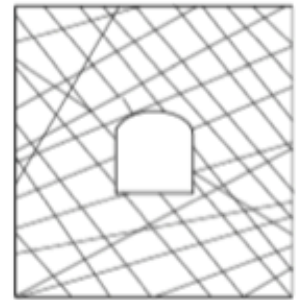

Desagregação da parede.

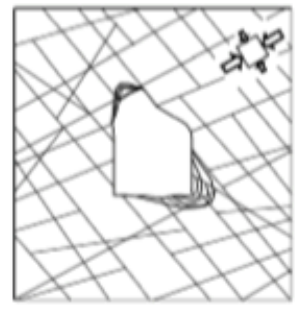

Ocorrência de ruptura localizada e desagregação da parede.

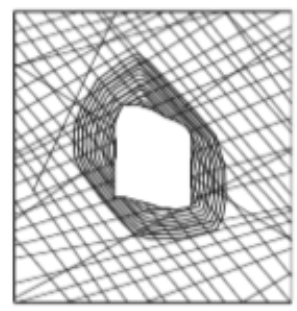

Desenvolvimento do processo de "squeezing".

Figura 3.4 - Modos de falha de acordo com as condições estruturais do maciço rochoso e do estados de tensões (modificado de Hoek et al., 1995).

A falha em túneis em rochas é uma função das magnitudes das tensões in situ e as características do maciço rochoso, isto é, resistência da rocha intacta e sua rede de descontinuidades. Em baixas magnitudes de tensões in situ, o processo falha é controlado pela continuidade e distribuição das descontinuidades naturais no maciço rochoso. No entanto, a medida que as tensões in situ aumentam, o processo de falha é dominado por fraturas induzidas pelo alto nível de tensões e essas fraturas crescem e se expandem ao redor de escavação. Este tipo de fraturamento é geralmente um processo frágil. Inicialmente, em 
profundidades intermediárias, estas regiões de falha são localizadas perto do perímetro do túnel, mas a grandes profundidades a região fraturada pode envolver toda a fronteira da escavação.

Uma vez que o modo de falha tenha sido identificado, é possível analisar quais os prováveis indicadores de desempenho e quais as possíveis incertezas nos dados de entrada. Langford \& Diederichs (2013) seguiram a linha de raciocínio de Hoek et al. (1995) e fizeram uma análise tanto dos indicadores quanto das incertezas para três dos principais mecanismos de falha (Figura 3.5).

\section{Modos de Falha}

\section{Squeezing \\ Estrutural \\ Ruptura Generalizada}
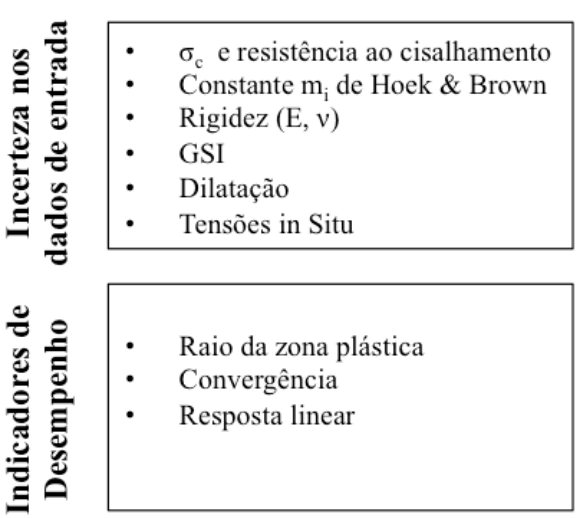

Orientação das juntas

Resistência das juntas

- Persistência / Comprimento

Fator deflagrador (água, sismos)

Presença de falha

- Tamanho e formato da cunha

- Estabilidade cinemática

- Bolt Loading $\sigma_{\mathrm{c}}$ e resistência ao cisalhamento

Início das fissuras

- Dilatação

- Tensões in Situ

Profundidade da falha

- Formato da falha

- Volume / Deslocamento

- Bolt Loading

Figura 3.5 - Fontes de incertezas nos dados de entrada e indicadores de desempenho para vários mecanismos de falha (modificado de Langford \& Diederichs, 2013). 


\section{METODOLOGIA}

Os materiais geotécnicos, em especial os materiais rochosos, possuem uma variabilidade natural de seus parâmetros, propriedades e índices, fazendo com que haja um aumento do uso de métodos probabilísticos nesta área da engenharia. Seguindo esta linha de raciocínio, esta pesquisa foi realizada a fim de obter indicadores de falha e elaborar um processo metodológico que possa ser utilizado no cálculo da probabilidade de falha de túneis em rocha.

Assim, neste capítulo são apresentadas as etapas da metodologia (Figura 4.1) proposta e que poderá ser utilizada como previsão durante as fases de projeto e executiva de obras subterrâneas em meios rochosos, bem como importantes considerações a respeito do processo de gestão de riscos neste tipo de obra.

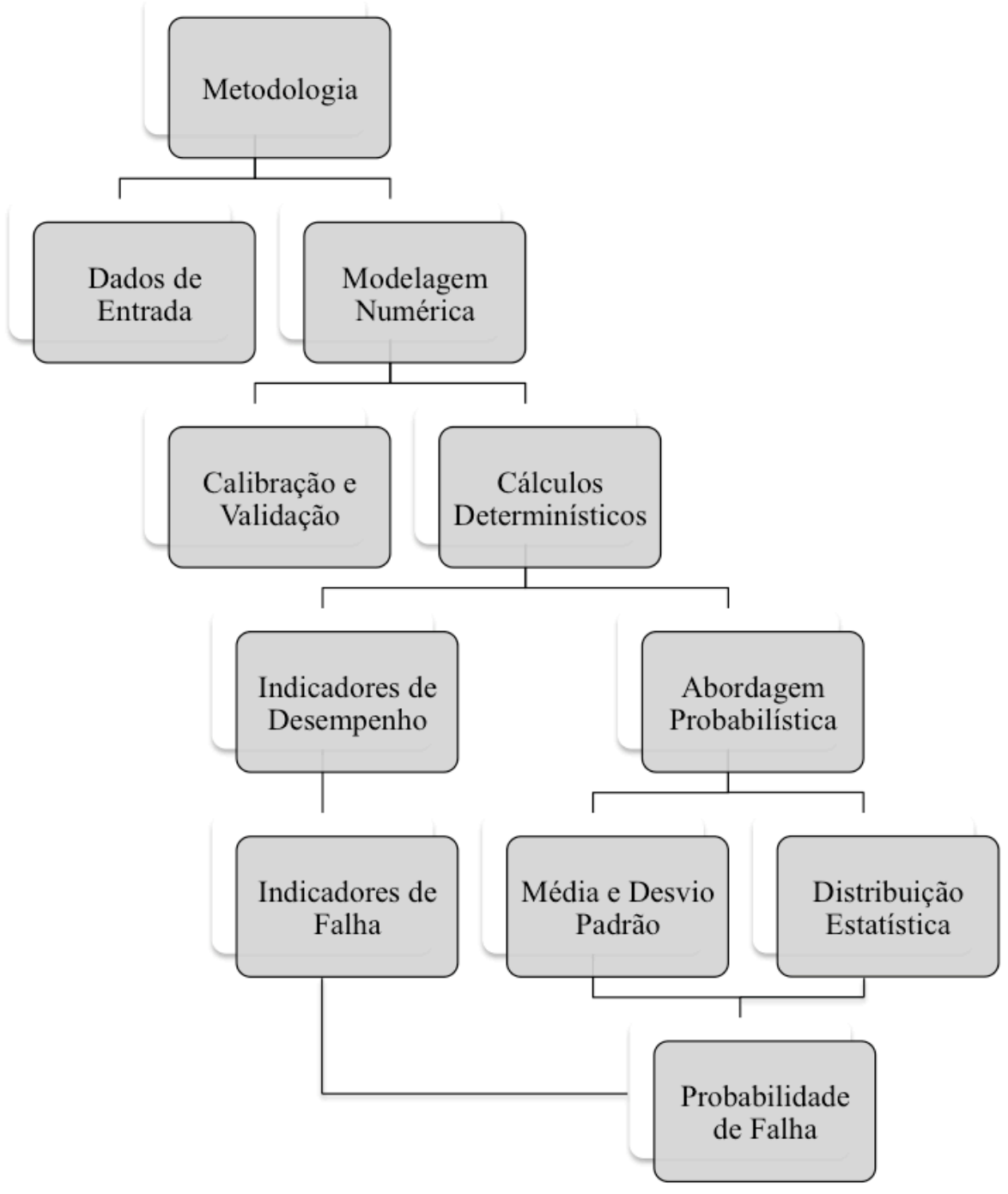

Figura 4.1 - Fluxograma metodológico da dissertação. 


\subsection{DEFINIÇÃO DOS DADOS DE ENTRADA}

O presente trabalho está sendo realizado com dados fictícios a fim de validar o processo em comparação com as bibliografias existentes. Assim, como sugestão, os dados de entrada básicos necessários à análise são:

- Geologia do local;

- Geometria da escavação;

- Propriedades dos materiais;

- Estado de tensões in situ.

\subsubsection{GEOLOGIA DO LOCAL E GEOMETRIA DA ESCAVAÇÃO}

Num projeto real, a geologia da região de interesse é definida a partir da construção de um modelo geológico. No caso de estudo deste trabalho, serão analisados dois casos, ambos com geologia simples de apenas um tipo de rocha: o primeiro caso é de uma rocha metamórfica, a exemplo do Gnaisse e o segundo caso será de uma rocha sedimentar, por exemplo o Siltito.

A geometria da escavação é definida em função do planejamento e diretrizes do projeto, ou seja, de acordo com a funcionalidade da obra. No presente trabalho será adotado um túnel circular com 10 m de diâmetro.

\subsubsection{PROPRIEDADES DOS MATERIAIS}

As propriedades são a base dos dados de entrada necessários a uma análise numérica. Essas propriedades são obtidas, em geral, através de ensaios de laboratórios e de campo.

Contudo, no caso de maciços rochosos, alguns ensaios de laboratórios e de campo se tornam de difícil execução ou com um custo muito elevado. Dessa maneira, os métodos e equações empíricas, como por exemplo a metodologia indireta do GSI apresentada no Capítulo 3, são amplamente utilizados na determinação de grande parte das propriedades.

Para aplicação do critério de ruptura de Hoek-Brown devem ser estimados os seguintes parâmetros:

- Peso específico $(\gamma)$;

- Módulo de elasticidade do maciço rochoso $\left(\mathrm{E}_{\mathrm{m}}\right)$; 
- Coeficiente de Poisson (v);

- Resistência à compressão uniaxial da rocha intacta $\left(\sigma_{c}\right)$;

- Parâmetro da rocha intacta $\left(\mathrm{m}_{\mathrm{i}}\right)$;

- GSI.

Lama \& Vutukuri (1978) apresentam uma base de dados de propriedades de rochas de diversos tipos e em diferentes lugares do mundo, possibilitando encontrar valores médios, desvios e até fazer a distribuição estatística desses dados.

\subsubsection{PESO ESPECÍFICO}

O peso específico foi adotado de acordo com os valores típicos médios apresentados por Lama \& Vutukuri (1978):

$$
\gamma_{\text {sat }} \approx \gamma_{\text {não-sat }} \approx 26 \mathrm{KN} / \mathrm{m}^{3}
$$

\subsubsection{MÓDULO DE ELASTICIDADE E COEFICIENTE DE POISSON}

Em princípio, o módulo de elasticidade de Young pode ser medido a partir de ensaios de compressão uniaxial ou ensaios de triaxiais em amostras de rocha. No entanto, este módulo é mais aplicável ao material de rocha intacta, e este valor deve ser reduzido para obter uma rigidez representativa do maciço rochoso.

Existem diversas correlações feitas de acordo com os vários sistemas de classificação de maciços existentes, que permitem calcular o módulo de elasticidade de um maciço rochoso. Contudo, deve-se ter uma atenção à aplicabilidade de cada uma dessas expressões, já que estas foram feitas para maciços com características específicas.

$\mathrm{Na}$ Tabela 4.1 apresentam-se algumas das expressões que permitem calcular o módulo de elasticidade em maciços rochosos, listadas por Miranda et al. (2006).

Nota-se que o módulo de elasticidade pode ser determinado de acordo com o sistema de classificação utilizado. Neste trabalho, o sistema empregado foi o GSI, portanto, deve-se escolher uma das correlações que usam este sistema.

Dentro deste sistema, as correlações mais utilizadas são as correlações de Hoek et al. (2002) que é uma adaptação da formulação de Serafim e Pereira (1983) e a correlação de Hoek e Diederichs (2006). Neste trabalho, fez-se uso da equação de Hoek e Diederichs (2006b). 
Tabela 4.1 - Expressões para o cálculo do módulo de elasticidade em maciços rochosos (modificado de Miranda et al., 2006).

\begin{tabular}{|c|c|c|c|}
\hline Sistema & Expressão & Limitações & Referência \\
\hline \multirow{7}{*}{ RMR } & $E_{M}(G P a)=10^{\frac{R M R-10}{40}}$ & $\mathrm{RMR} \leq 80$ & $\begin{array}{l}\text { Serafim e Pereira } \\
(1983)\end{array}$ \\
\hline & $E_{M}(G P a)=2 \cdot R M R-100$ & $\begin{array}{c}\mathrm{RMR}>50 \mathrm{e} \\
\sigma_{\mathrm{c}}>100 \mathrm{MPa}\end{array}$ & Bieniawski (1978) \\
\hline & $E_{M}(G P a)=\frac{\sqrt{\sigma_{c}}}{10} \cdot 10^{\frac{R M R-10}{40}}$ & $\sigma_{\mathrm{c}}>100 \mathrm{MPa}$ & $\begin{array}{l}\text { Hoek e Brown } \\
(1997) \\
\end{array}$ \\
\hline & $M R F=0,0028 \cdot R M R^{2}+0,9 \cdot e^{R M R / 22,28}$ & & $\begin{array}{c}\text { Nicholson e } \\
\text { Bieniawski (1990) }\end{array}$ \\
\hline & $M R F=0,5 \cdot[1-\cos (\pi \cdot R M R / 100)]$ & & Mitri et al. (1994) \\
\hline & $E_{M}(G P a)=0,3 \cdot H^{\alpha} \cdot 10^{\frac{R M R-20}{38}}$ & $\begin{array}{c}\sigma_{\mathrm{c}}<100 \mathrm{MPa} \\
\mathrm{e} \mathrm{H}>50 \mathrm{~m}\end{array}$ & Verman (1993) \\
\hline & $E_{M}(G P a)=0,1 \cdot(R M R / 10)^{3}$ & & $\begin{array}{l}\text { Read, Richards e } \\
\text { Perrin (1999) }\end{array}$ \\
\hline \multirow{5}{*}{$\mathbf{Q}$} & $E_{M}(G P a)=25 \cdot \log Q$ & $\mathrm{Q}>1$ & Barton et al. (1980) \\
\hline & $E_{M}(G P a)=10 \cdot Q_{c}^{1 / 3} ; Q_{c}=Q \cdot \sigma_{c i} / 100$ & $\mathrm{Q} \leq 1$ & $\begin{array}{l}\text { Barton e Quadros } \\
\quad(2002)\end{array}$ \\
\hline & $E_{M}(G P a)=H^{0,2} \cdot Q^{0,36}$ & $\mathrm{H}>50 \mathrm{~m}$ & Singh (1997) \\
\hline & $E_{M}(G P a)=1,5 \cdot Q^{0,6} \cdot E_{R}^{0,14}$ & $\begin{aligned} \mathrm{E}_{\mathrm{d}} & \leq \mathrm{E}_{\mathrm{R}} \mathrm{e} \\
\mathrm{Q} & \leq 500\end{aligned}$ & Singh (1997) \\
\hline & $E_{M}(G P a)=7( \pm 3) \sqrt{Q^{r}}$ & & $\begin{array}{c}\text { Diederichs e Kaiser } \\
(1999)\end{array}$ \\
\hline \multirow{6}{*}{ GSI } & $E_{M}(G P a)=\left(1-\frac{D}{2}\right) \cdot \sqrt{\frac{\sigma_{c}}{100}} \cdot 10^{(G S I-10) / 40}$ & $\sigma_{\mathrm{c}} \leq 100 \mathrm{MPa}$ & Hoek et al. (2002) \\
\hline & $E_{M}(G P a)=\left(1-\frac{D}{2}\right) \cdot 10^{(G S I-10) / 40}$ & $\sigma_{\mathrm{c}} \leq 100 \mathrm{MPa}$ & Hoek et al. (2002) \\
\hline & $E_{M}(G P a)=100000 \cdot\left(\frac{1-D / 2}{1+\exp \left(\frac{75+25 \cdot D-G S I}{11}\right)}\right)$ & & $\begin{array}{l}\text { Hoek e Diederichs } \\
\quad(2006 \mathrm{a})\end{array}$ \\
\hline & $E_{M}(G P a)=E_{i} \cdot\left(\frac{1-D / 2}{1+\exp \left(\frac{60+15 . D-G S I}{11}\right)}\right)$ & & $\begin{array}{l}\text { Hoek e Diederichs } \\
\quad(2006 b)\end{array}$ \\
\hline & $E_{M}(G P a)=E_{i} \cdot\left(s^{a}\right)^{0,4}$ & & $\begin{array}{c}\text { Sonmez, } \\
\text { Gokceoglu e } \\
\text { Ullusay (2004) }\end{array}$ \\
\hline & $E_{M}(G P a)=E_{i} \cdot s^{1 / 4}$ & & Carvalho (2004) \\
\hline
\end{tabular}

MRF - fator de redução do módulo de deformabilidade da rocha intacta $\left(E_{m} / E_{R}\right) ; \alpha-0,16$ a 0,30 (mais elevado para rochas mais fracas); $\mathrm{H}$ - profundidade da cavidade.

O coeficiente de Poisson, $v$, tem seus valores geralmente no intervalo $[0,1 ; 0,4]$. Os valores típicos para diferentes tipos de rocha foram listados por Gercek (2007) e são apresentados na Figura 4.2. 


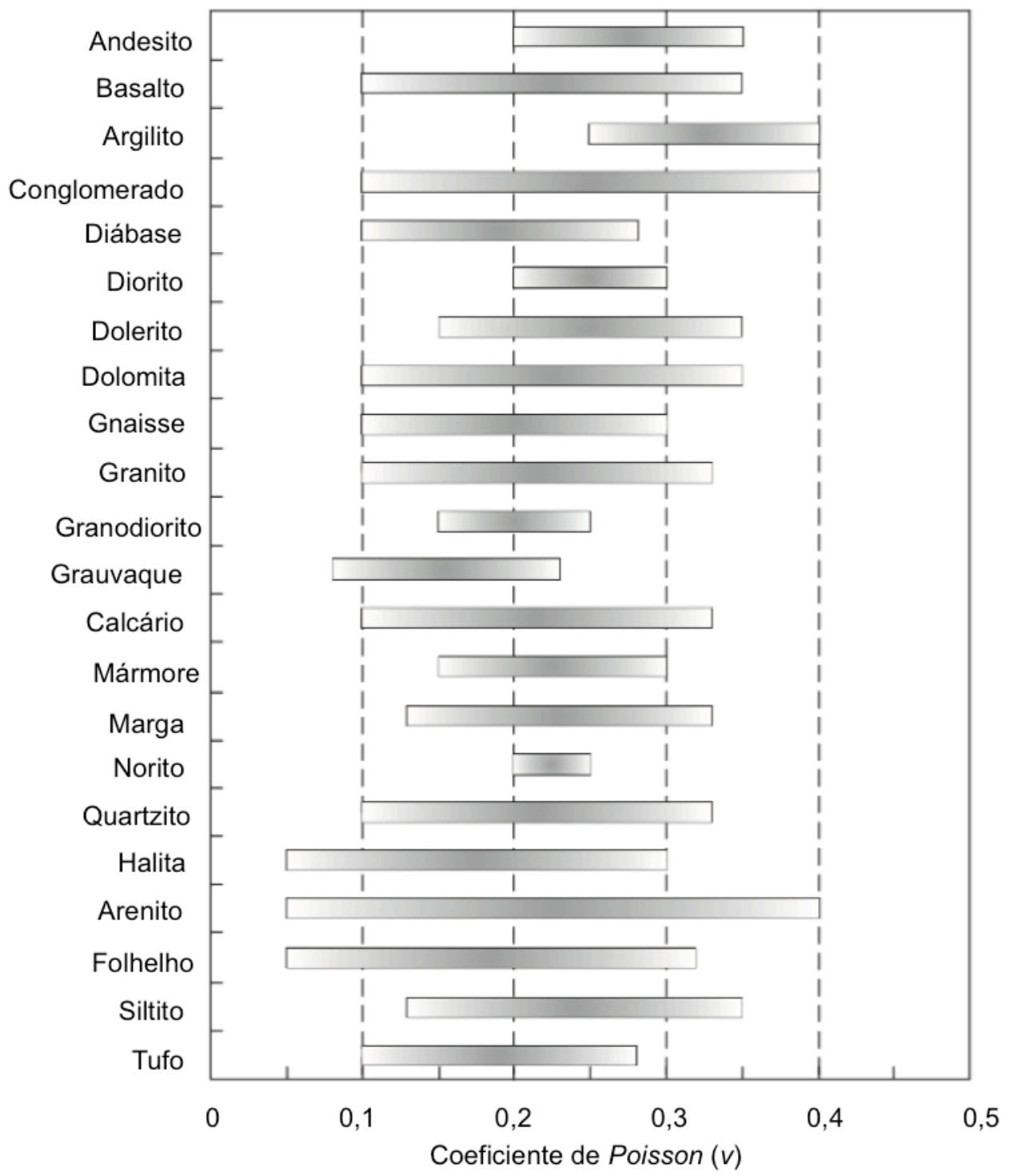

Figura 4.2 - Valores típicos do coeficiente de Poisson (modificado de Gercek, 2007).

De acordo com a Figura 4.2, para o caso das rochas metamórficas, como o Gnaisse, o valor aproximado do coeficiente de Poisson poderia ser 0,2 e para as rochas sedimentares, como o Siltito, esse valor é da ordem de 0,25.

\subsubsection{RESISTÊNCIA À COMPRESSÃO UNIAXIAL E PARÂMETRO DA ROCHA INTACTA}

A resistência uniaxial da rocha intacta, $\sigma_{\mathrm{ci}}$, pode ser determinada através de ensaios laboratoriais, por exemplo, o ensaio de compressão uniaxial. Este ensaio é, muitas vezes, realizado no material de rocha intacta (com GSI $=100$ e $\mathrm{D}=0$ ). Os valores típicos são apresentados na Tabela 4.2 elaborada por Hoek (2007). 
Tabela 4.2 - Resistência à compressão uniaxial da rocha intacta (modificado de Hoek, 2007).

\begin{tabular}{|c|c|c|c|c|}
\hline Classe & Termo & $\begin{array}{c}\text { Resistência à } \\
\text { Compressão } \\
\text { Uniaxial } \\
(\mathrm{MPa})\end{array}$ & $\begin{array}{c}\text { Estimação da } \\
\text { Resistência em Campo }\end{array}$ & Exemplos \\
\hline R6 & $\begin{array}{l}\text { Extremamente } \\
\text { Forte }\end{array}$ & $>250$ & $\begin{array}{l}\text { Amostra pode ser } \\
\text { lascada com um martelo } \\
\text { geológico }\end{array}$ & $\begin{array}{l}\text { Basalto fresco, sílex, } \\
\text { diábase, gnaisse, } \\
\text { granito, quartzito }\end{array}$ \\
\hline R5 & Muito Forte & $100-250$ & $\begin{array}{l}\text { Amostra requer muitos } \\
\text { golpes do martelo } \\
\text { geológico para fratura-la }\end{array}$ & $\begin{array}{l}\text { Anfibolito, arenito, } \\
\text { basalto, gabro, } \\
\text { gnaisse, granodiorito, } \\
\text { calcário, mármore, } \\
\text { riolito, tufo }\end{array}$ \\
\hline $\mathrm{R} 4$ & Forte & $50-100$ & $\begin{array}{l}\text { Amostra requer mais de } \\
\text { um golpe do martelo } \\
\text { geológico para fratura-la }\end{array}$ & $\begin{array}{l}\text { Calcário, mármore, } \\
\text { filito, arenito, xisto, } \\
\text { folhelho }\end{array}$ \\
\hline R3 & $\begin{array}{l}\text { Medianamente } \\
\text { Forte }\end{array}$ & $25-50$ & $\begin{array}{l}\text { Não pode ser raspada ou } \\
\text { descascada com uma } \\
\text { faca de bolso, amostra } \\
\text { requer um único golpe } \\
\text { do martelo geológico } \\
\text { para fratura-la }\end{array}$ & $\begin{array}{l}\text { Argilito, carvão, } \\
\text { concreto, xisto, } \\
\text { folhelho, siltito }\end{array}$ \\
\hline $\mathrm{R} 2$ & Fraca & $5-25$ & $\begin{array}{l}\text { Pode ser raspada com } \\
\text { uma faca de bolso, } \\
\text { endentação rasa feita por } \\
\text { golpe firme com ponto } \\
\text { do martelo geológico }\end{array}$ & Giz, halita, potassa \\
\hline $\mathrm{R} 2$ & Muito Fraca & $1-5$ & $\begin{array}{l}\text { Desmorona sob golpes } \\
\text { firmes com ponto do } \\
\text { martelo geológico, pode } \\
\text { ser raspada com uma } \\
\text { faca de bolso }\end{array}$ & $\begin{array}{l}\text { Rocha altamente } \\
\text { intemperizada e } \\
\text { alterada }\end{array}$ \\
\hline R0 & $\begin{array}{l}\text { Extremamente } \\
\text { Fraca }\end{array}$ & $0,25-1$ & $\begin{array}{l}\text { Endentada pelas unhas } \\
\text { do polegar }\end{array}$ & Falha rígida de goiva \\
\hline
\end{tabular}

Analisando a Tabela 4.2, infere-se que as rochas metamórficas, no caso do Gnaisse, estariam na classe R5 ou R6, então, um valor aproximado da resistência à compressão uniaxial poderia ser $200 \mathrm{MPa}$ e para as rochas sedimentares, como o Siltito, esse valor é de $75 \mathrm{MPa}$.

O parâmetro da rocha intacta, $\mathrm{m}_{\mathrm{i}}$, é um parâmetro empírico que depende do tipo de rocha. Os valores típicos são apresentados na Tabela 4.3 elaborada por Hoek (2007).

Por essa tabela é possível obter o valor aproximado do parâmetro da rocha intacta, $\mathrm{m}_{\mathrm{i}}$, para os dois tipos de rocha que serão analisadas neste trabalho. Para as rochas metamórficas, no caso 
do Gnaisse, o valor aproximado deste parâmetro poderia ser 30 e para as rochas sedimentares, como o Siltito, esse valor é de 10.

Tabela 4.3 - Parâmetro da rocha intacta, $m_{i}$ (modificado de Hoek, 2007).

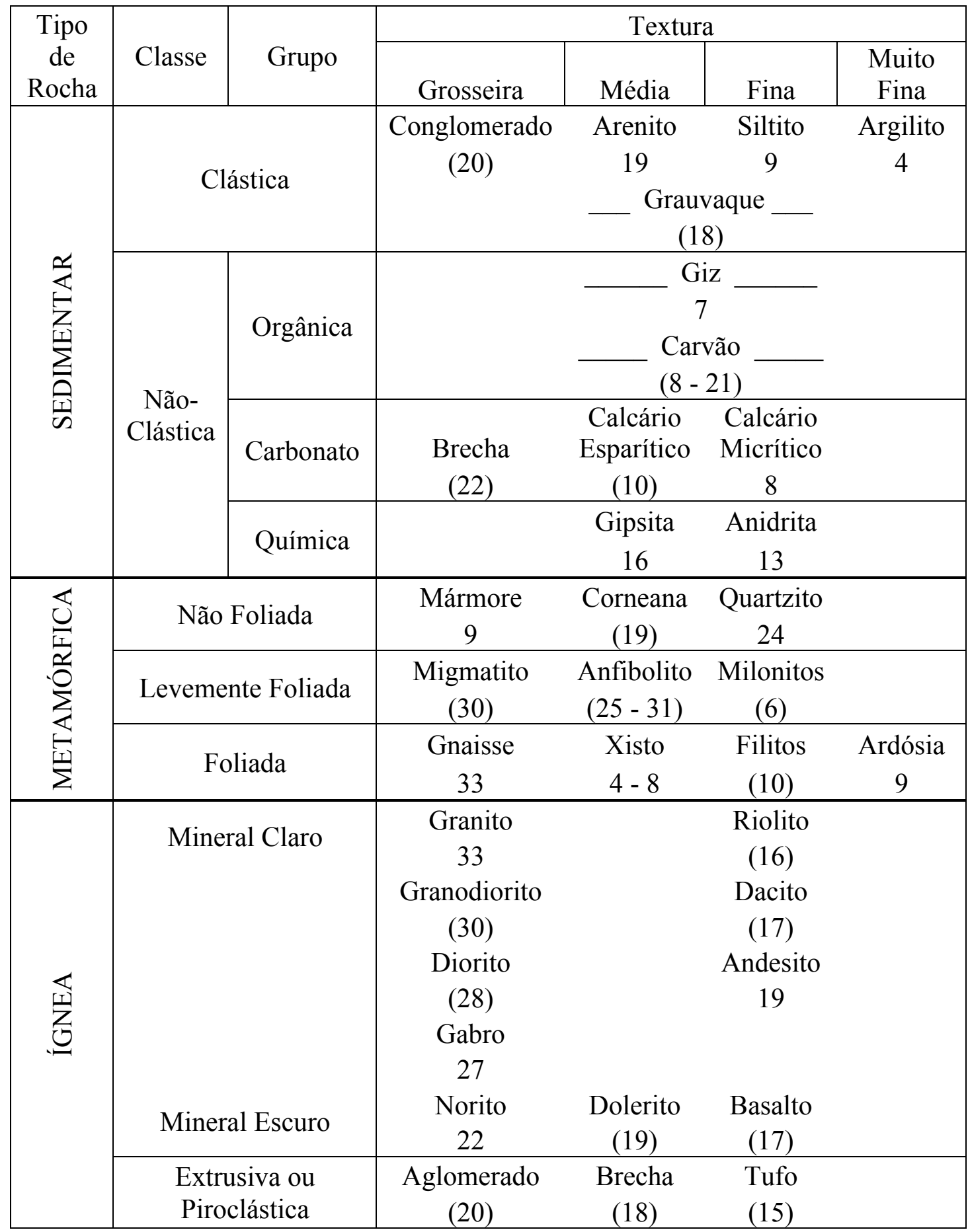




\subsubsection{GSI}

O parâmetro GSI pode ser selecionado com base nos ábacos apresentados nas Figuras 3.1 e 3.4 do Capítulo 3. Esta estimativa é dada por avaliação visual das características das descontinuidades e do grau de faturamento do maciço (intacto, moderadamente e intensamente fraturado). Para evitar que as análises ficassem muito onerosas, escolheu-se valores de GSI (Tabela 4.4) que representem bem as possíveis condições estruturais do maciço apresentadas por Hoek et al. (1995) mostradas na Figura 3.4.

Tabela 4.4 - Valores adotados de GSI.

\begin{tabular}{|c|c|c|}
\hline $\begin{array}{c}\text { Maciço } \\
\text { Rochoso } \\
\text { Intacto }\end{array}$ & $\begin{array}{c}\text { Maciço } \\
\text { Moderadamente } \\
\text { Fraturado }\end{array}$ & $\begin{array}{c}\text { Maciço } \\
\text { Intensamente } \\
\text { Fraturado }\end{array}$ \\
\hline GSI $>70$ & $45<$ GSI $<70$ & GSI $<45$ \\
GSI $\approx \mathbf{8 5}$ & GSI $\approx \mathbf{6 0}$ & GSI $\approx \mathbf{3 5}$ \\
\hline
\end{tabular}

\subsubsection{ESTADO DE TENSÕES IN SITU}

Antes de qualquer escavação, o maciço rochoso já se encontra sujeito a um estado de tensões, chamadas de tensões naturais ou tensões in situ, decorrentes de sua geologia e ações tectônicas. Durante a escavação, este estado de tensões modifica-se e gera um novo estado de tensões induzidas, que atua ao redor do túnel. Este novo estado de tensões depende basicamente da geometria e dimensões do túnel, do estado de tensões inicial e alguns outros fatores (Terzaghi \& Richart, 1952). Desta forma, é de suma importância que se conheça a magnitude e direção das tensões naturais.

O estado de tensões in situ assumido leva em consideração os estados de tensões apresentados na Figura 3.4. Para chegar nestes estados de tensões, variou-se a profundidade do túnel com $\mathrm{k}_{\mathrm{o}}=0,5, \mathrm{k}_{\mathrm{o}}=1, \mathrm{k}_{\mathrm{o}}=2 \mathrm{e}_{\mathrm{o}}=4$, com a orientação das tensões principais na horizontal e vertical, apenas.

\subsection{MODELAGEM NUMÉRICA E EXECUÇÃO DOS CÁLCULOS}

A modelagem numérica e execução dos cálculos resumem-se, fundamentalmente, na coleta dos dados de entrada e introdução dos mesmos em uma ferramenta numérica apropriada (Pariseau, 1993). A maioria dos programas computacionais utilizados como ferramentas numéricas baseiam-se nos elementos finitos. Estas ferramentas necessitam de validações 
através de comparações com soluções conhecidas e resultados obtidos de outros programas similares. Um dos principais programas de elementos finitos utilizados na engenharia geotécnica é o Plaxis 2D. Este programa é destinado a análises de duas dimensões de deformação e estabilidade.

Antes de iniciar os cálculos numéricos, além de definir os dados de entrada, também foi necessário definir a malha de elementos finitos e as condições de contorno.

A geração da malha de elementos finitos está condicionada à definição do contorno do túnel, onde a malha será mais refinada. Assim, a malha foi definida de acordo com o apresentado na Figura 4.3.

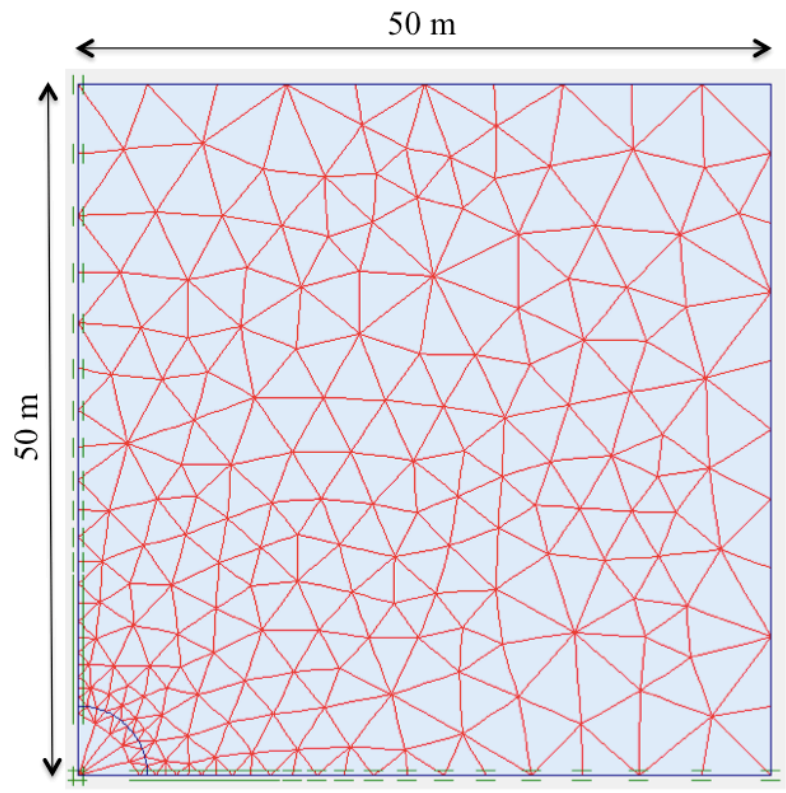

Figura 4.3 - Malha de elementos finitos.

As condições de contorno são divididas em condições essenciais (geométricas) e condições não essenciais (naturais ou mecânicas de contorno). As condições essenciais dizem respeito à prescrição das variáveis primárias. Já as condições não essenciais referem-se à prescrição das variáveis secundárias. A prescrição dos deslocamentos na superfície de apoios constitui-se em condições essenciais de contorno, e a especificação de forças de superfície constitui-se em condições não essenciais de contorno (Soriano, 2009).

Desta forma, as condições de contorno foram definidas para o caso de um quarto de túnel, já que há dupla simetria neste caso. Esta condições são apresentadas na Figura 4.4. 


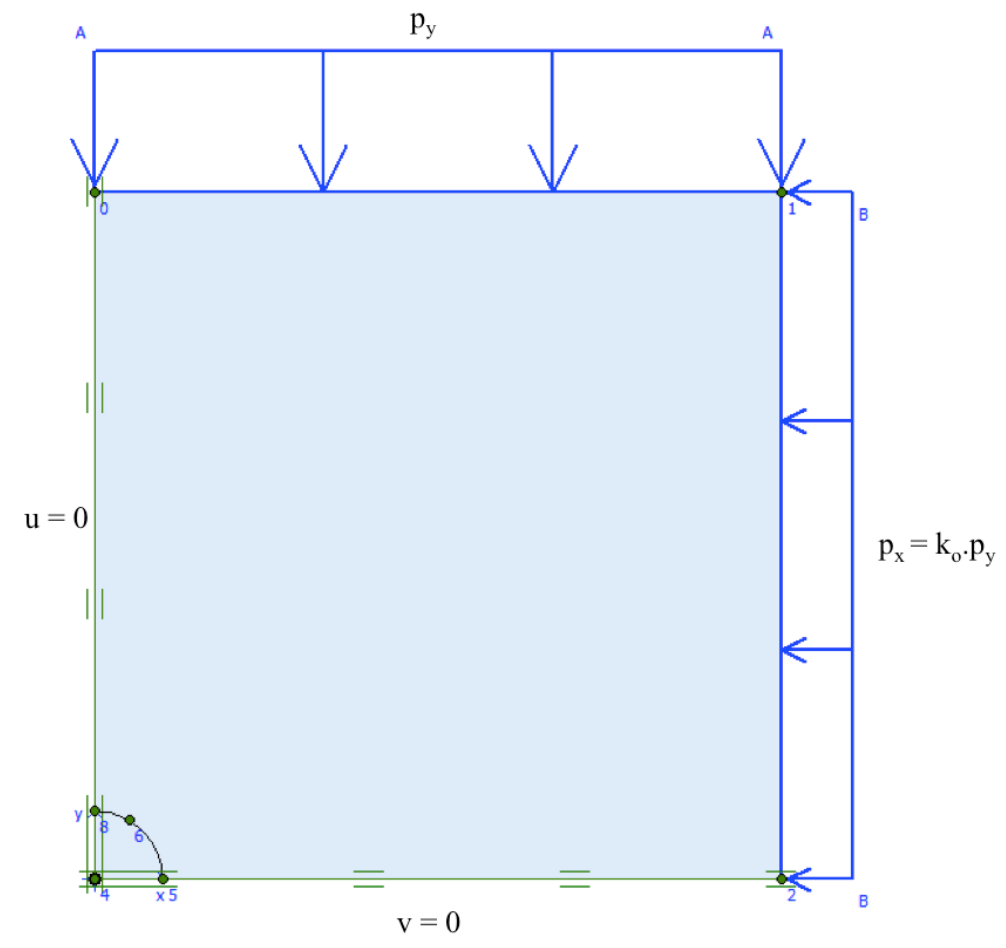

Figura 4.4 - Condições de contorno.

\subsubsection{CALIBRAÇÃO}

Para calibração uma modelagem numérica é necessário comparar os resultados numéricos com os resultados de equações analíticas. Assim, o procedimento de calibração irá mostrar se os resultados numéricos são suficientemente confiáveis. Finalmente, os objetivos da análise numérica, o seu grau de refinamento e as suas expectativas devem ser consistentes com as características do método de elementos finitos.

A expressão mais conhecida para determinação das tensões induzidas e dos deslocamentos provocados pela construção de um túnel é a Fórmula de Kirsch em 1898. Este modelo foi inicialmente concebido para a análise de chapas metálicas providas de orifícios circulares (estado plano de tensões), sendo posteriormente modificada para aberturas subterrâneas de geometria circular (estado plano de deformações). São admitidas as seguintes hipóteses:

- Maciço homogêneo e infinito;

- Túnel com seção transversal circular;

- Estado plano de deformações;

- Modelo linear-elástico; 
- Túnel profundo.

A formulação de Kirsch admite a nomenclatura indicada na Figura 4.5.

Variando-se " $r$ " e " $\theta$ ", pode-se calcular as tensões atuantes em qualquer ponto ao redor da abertura, que são dadas pelas seguintes expressões:

$\sigma_{r}=\frac{1}{2} \cdot p_{z} \cdot\left[\left(1+k_{o}\right) \cdot\left(1-\alpha^{2}\right)+\left(1-k_{o}\right) \cdot\left(1+3 \alpha^{4}-4 \alpha^{2}\right) \cdot \cos 2 \theta\right]$

$\sigma_{\theta}=\frac{1}{2} \cdot p_{z} \cdot\left[\left(1+k_{o}\right) \cdot\left(1+\alpha^{2}\right)-\left(1-k_{o}\right) \cdot\left(1+3 \alpha^{2}\right) \cdot \cos 2 \theta\right]$

$\tau_{\theta}=\frac{1}{2} \cdot p_{z} \cdot\left(1-k_{o}\right) \cdot\left(1-3 \alpha^{4}+2 \alpha^{2}\right) \cdot \operatorname{sen} 2 \theta$

onde $\alpha=\mathrm{a} / \mathrm{r}$.

Existindo um tensor de tensões induzidas causado pela abertura, haverá também por consequência deslocamentos induzidos, dados por:

$u=\frac{p_{z} \cdot r}{4 G} \cdot\left[\left(1+k_{o}\right) \cdot \alpha^{2}+\left(1-k_{o}\right) \cdot\left(-\alpha^{4}+4 \alpha^{2}-4 v \alpha^{2}\right) \cdot \cos 2 \theta\right]$

Restringindo a equação acima para $\alpha=1$ (parede da escavação), obtém-se a equação do deslocamento radial na parede da abertura, chamado de convergência:

$u=\frac{p_{z} \cdot a}{4 G} \cdot\left[\left(1+k_{o}\right)+\left(1-k_{o}\right) \cdot(3-4 v) \cdot \cos 2 \theta\right]$

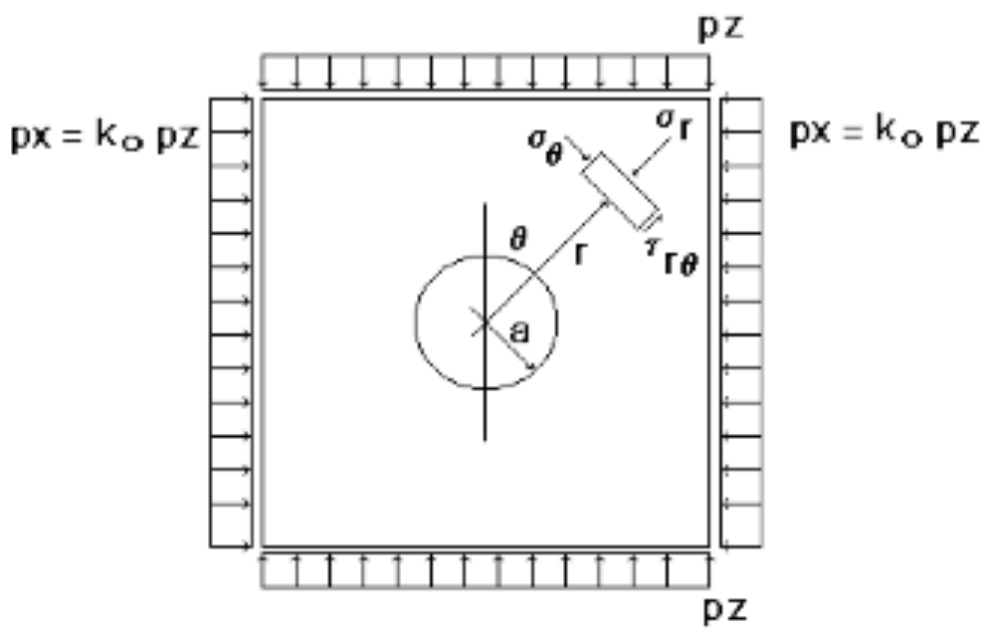

Figura 4.5 - Modelo de Kirsch.

\subsubsection{EXECUÇÃO DOS CÁLCULOS DETERMINÍSTICOS}

Após a calibração do modelo foram realizadas 72 simulações numéricas, sendo 36 para a 
rocha metamórfica e 36 para a rocha sedimentar. Essa quantidade de simulações engloba o estado de tensões (profundidade e $\mathrm{k}_{\mathrm{o}}$ ) e o grau de fraturamento do maciço (GSI), como apresentado na Figura 4.6.

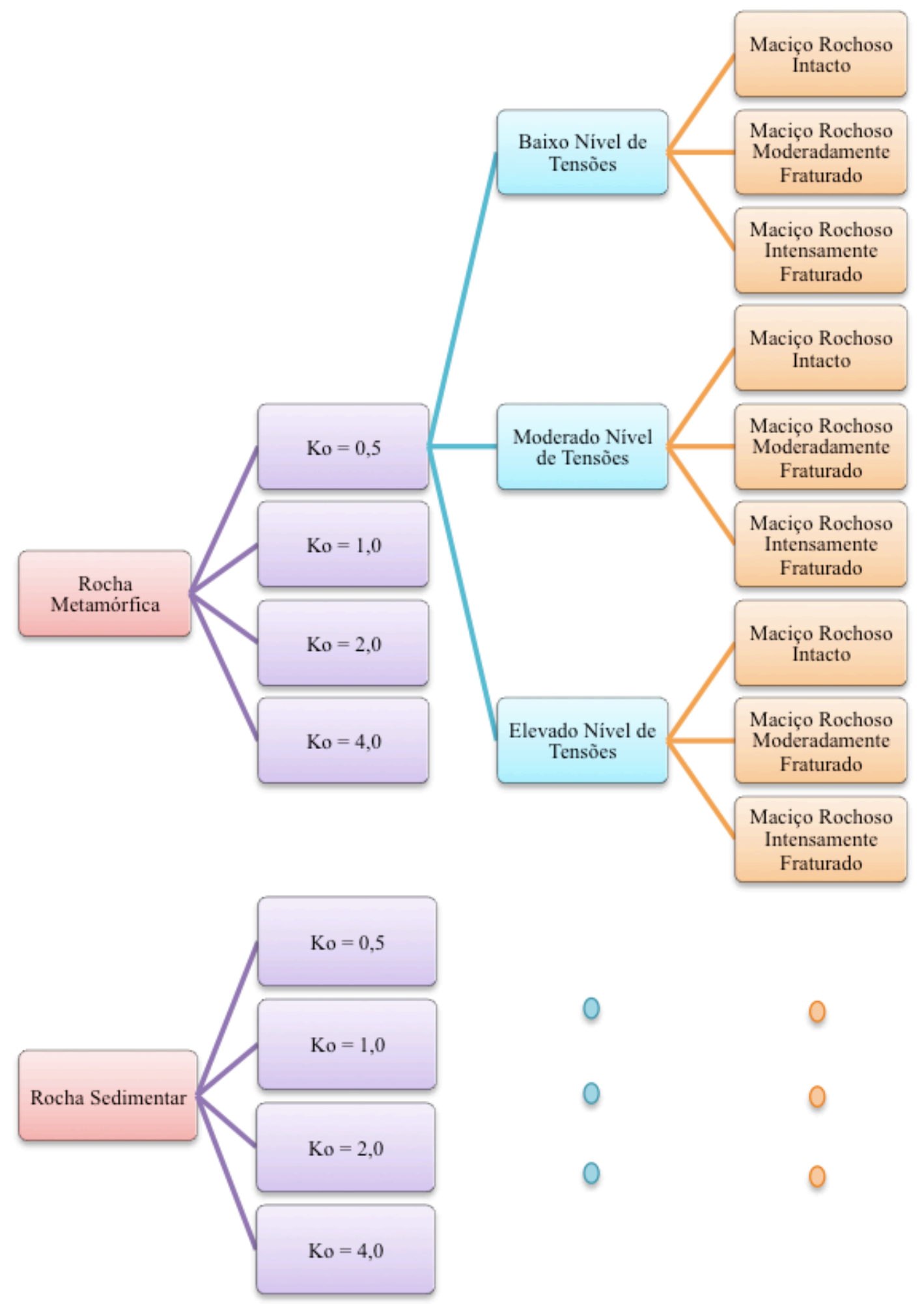

Figura 4.6 - Fluxograma das simulações numéricas iniciais (determinísticas). 
A partir dos resultados obtidos com as 72 simulações realizadas buscou-se indicadores de desempenho que poderiam ser utilizados como indicadores de falha. Para tanto, elaborou-se diversos gráficos com os principais indicadores (fator de segurança, área plástica, convergência) buscando correlações entre os mesmos e também mudanças de tendência que indicassem falha.

O valor encontrado nestes gráficos onde percebe-se uma mudança de tendência foi tomado como o indicador de falha que foi usado posteriormente na análise probabilística para o cálculo das probabilidades de falha.

Abaixo são apresentadas as formas de obtenção dos principais indicadores de desempenho:

Para a determinação do fator de segurança o PLAXIS v.8.2 utiliza a opção Phi-c reduction implementada no módulo plaxis calculations, que se baseia na resistência ao cisalhamento da rocha. Assim os parâmetros de resistência $\phi$ ' e c' são sucessivamente reduzidos até atingir a ruptura da estrutura. A resistência das interfaces, caso sejam utilizadas, são reduzidas da mesma maneira.. Para avaliar o fator de segurança de uma análise em um determinado estágio de carregamento ou escavação, o multiplicador total (total multiplier), $\Sigma$ Msf, é utilizado por meio da Equação 4.6:

$\sum M s f=\frac{\tan \phi_{\text {entrada }}}{\tan \phi_{\text {reduzido }}}=\frac{c_{\text {entrada }}}{c_{\text {reduzido }}}$

onde,

$\phi_{\text {entrada }}$ ângulo de atrito definido pelo usuário nas propriedades do material;

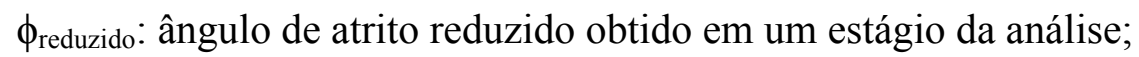

$\mathrm{c}_{\text {entrada }}$ : coesão do solo definida pelo usuário nas propriedades do material;

$\mathrm{c}_{\text {reduzido: }}$ coesão do solo reduzida obtida em um estágio da análise.

É importante comprovar se o processo de cálculo final resultou num mecanismo de ruptura completamente desenvolvido, caso contrário deve-se incrementar os processos de cálculo (entre 30 e 1000 processos disponíveis). Assim o fator de segurança está definido por:

$F S=\frac{\text { Resistência disponínel }}{\text { Resistência na ruptura }}=\sum M s f$ 
A área plástica foi obtida através de uma medição manual contornando os limites dos pontos plásticos fornecidos pelo programa.

Os valores do indicador convergência representam a convergência máxima, ou seja, o valor do maior deslocamento radial na parede do túnel, vezes ocorre no teto e outras na lateral.

\subsubsection{ABORDAGEM PROBABILÍSTICA}

A abordagem probabilística foi feita para alguns dos 72 casos anteriormente apresentados, selecionando principalmente aqueles com maiores níveis de tensões e maior grau de fraturamento do maciço.

Neste sentido, dentre os métodos probabilísticos apresentados no Capítulo 2, por questões de tempo e facilidade de aplicação, utilizou-se o método dos pontos de estimativas (Rosenblueth).

Assim, foram executadas novas simulações considerando a variabilidade dos parâmetros principais: coeficiente de empuxo no repouso $\left(\mathrm{k}_{\mathrm{o}}\right)$, coesão $(\mathrm{c})$ e ângulo de atrito $(\phi)$. Como média foi utilizado o valor determinístico encontrado nas simulações iniciais e para a obtenção do desvio padrão, fez-se uso do coeficiente de variação.

Baecher \& Christian (2003) apresentam valores de coeficientes de variação para areais e argilas, mas não para rochas. Assim, os coeficientes de variação para estes parâmetros foram estimados com valores próximos aos apresentados para areia e argila (Tabela 4.5).

Tabela 4.5 - Valores estimados do coeficiente de variação (CV).

\begin{tabular}{|c|c|}
\hline Parâmetro & $\mathbf{C V}$ \\
\hline $\mathrm{k}_{\mathrm{o}}$ & $25 \%$ \\
\hline $\mathrm{c}$ & $40 \%$ \\
\hline$\phi$ & $10 \%$ \\
\hline
\end{tabular}

Com a variação destes três parâmetros, têm-se $8\left(2^{\mathrm{N}}=2^{3}\right)$ simulações para cada caso inicial. A partir destas simulações extraiu-se os resultados apresentados para os indicadores de desempenho e calculou-se a média e o desvio padrão para cada um deles. Então, assumiu uma distribuição estatística que mais se aplicasse para cada caso e por fim foi possível obter a probabilidade de falha a partir do indicador de falha obtido na análise determinística. 


\section{APRESENTAÇÃO E DISCUSSÃO DOS RESULTADOS}

Serão apresentados neste capítulo os resultados obtidos com as simulações para três situações. Em primeiro lugar apresentam-se os resultados do modelo linear-elástico bem como sua comparação com os resultados analíticos de Kirsch, o que possibilita a calibração do modelo utilizado. Em sequência, apresentam-se os resultados das simulações dos 72 casos determinísticos e a obtenção dos indicadores de falha. Por fim, os resultados das simulações probabilísticas e a obtenção das probabilidades de falha.

\subsection{RESULTADOS DO MODELO LINEAR-ELÁSTICO X KIRSCH}

A calibração do modelo foi feita pela comparação dos resultados numéricos obtidos com os resultados das equações analíticas de Kirsch.

Os gráficos apresentados na Figura 5.1 fornecem o comportamento das tensões induzidas após a escavação do túnel no teto $\left(\theta=0^{\circ}\right)$ e na lateral do túnel $\left(\theta=90^{\circ}\right)$, respectivamente, para um caso com rocha metamórfica, $\mathrm{k}_{\mathrm{o}}=2,0$, elevado nível de tensões e maciço rochoso intensamente fraturado.

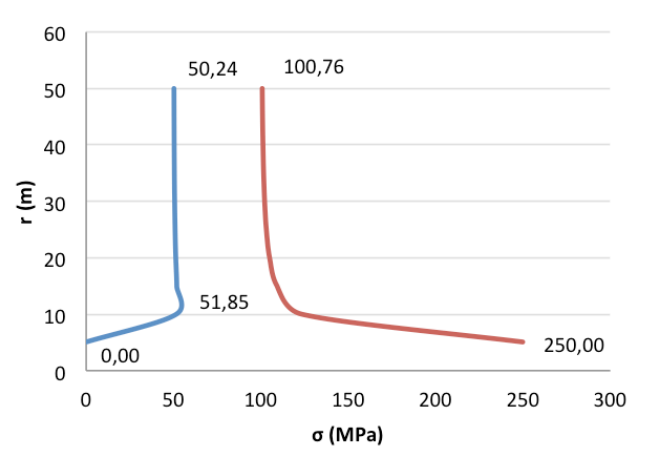

a)

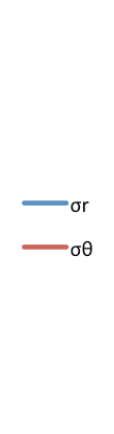

Figura 5.1- Tensões induzidas após a escavação do túnel calculadas por Kirsch: a) Teto $(\theta=$

$$
\left.0^{\circ}\right) \text {; b) Lateral }\left(\theta=90^{\circ}\right) \text {. }
$$

Para calibrar os valores das tensões, comparou-se os valores apresentados nesses gráficos com os valores das tensões apresentados nas Figuras 5.2 e 5.3. Por exemplo, analisando a Figura $5.1 \mathrm{~b})$, o valor da tensão radial $\left(\sigma_{\mathrm{r}}\right)$ ao longo da lateral do túnel começa em $\sigma_{\mathrm{r}}=0 \mathrm{MPa}$ na parede de escavação e chega a $\sigma_{\mathrm{r}}=98,26 \mathrm{MPa}$ afastado do túnel. Este mesmo comportamento é verificado na Figura 5.2, onde a tensão vertical $\left(\sigma_{\mathrm{xx}}\right)$ na lateral representa a tensão radial $\left(\sigma_{\mathrm{r}}\right)$. 
Nesta figura percebe-se que a tensão na parede de escavação começa com a cor azul que na escala representa $\sigma_{\mathrm{r}}=0 \mathrm{MPa}$ e termina em $\sigma_{\mathrm{r}}=100,01 \mathrm{MPa}$.

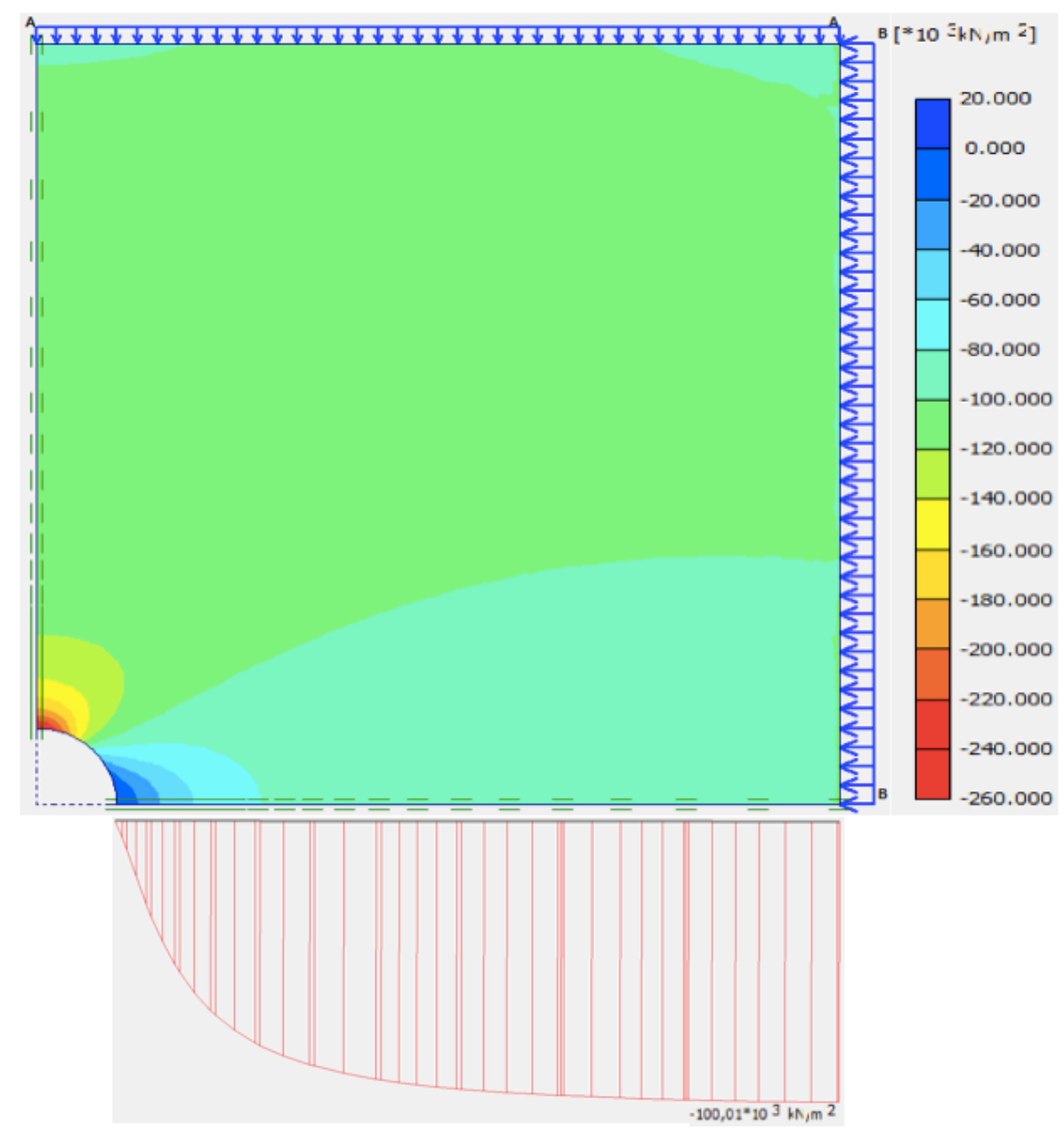

Figura 5.2 - Tensões induzidas na direção $\mathrm{x}\left(\sigma_{\mathrm{xx}}\right)$ após a escavação do túnel calculadas no PLAXIS

Agora analisando a Figura 5.1 a), o valor da tensão radial $\left(\sigma_{\mathrm{r}}\right)$ ao longo do teto do túnel começa em $\sigma_{\mathrm{r}}=0 \mathrm{MPa}$ na parede de escavação e chega a $\sigma_{\mathrm{r}}=50,24 \mathrm{MPa}$ afastado do túnel, tendo um máximo de 51,85 MPa. Este mesmo comportamento é verificado na Figura 5.3, onde a tensão vertical $\left(\sigma_{\mathrm{yy}}\right)$ no teto representa a tensão radial $\left(\sigma_{\mathrm{r}}\right)$.

Na Figura 5.3 percebe-se que a tensão na parede de escavação começa com a cor azul que na escala representa $\sigma_{\mathrm{r}}=0 \mathrm{MPa}$, passa por um valor máximo de $\sigma_{\mathrm{r}}=52,26 \mathrm{MPa}$ e termina com a escala de cor amarela $\left(\sigma_{\mathrm{r}}=50 \mathrm{MPa}\right)$. 


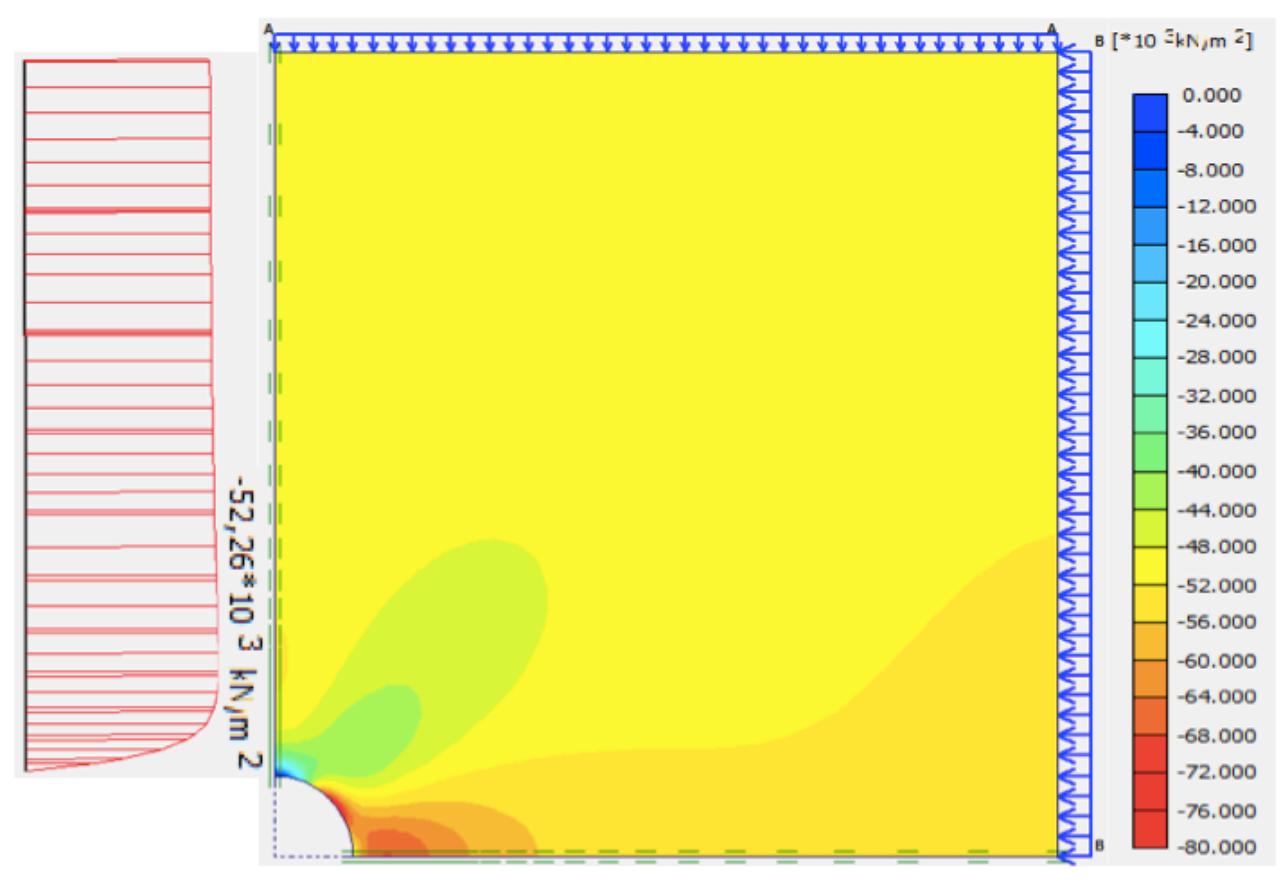

Figura 5.3 - Tensões induzidas na direção y $\left(\sigma_{y y}\right)$ após a escavação do túnel calculadas no PLAXIS

Fez-se essa mesma comparação para o caso dos deslocamentos induzidos na parede de escavação. Assim, é possível perceber que o deslocamento de $\mathrm{u}=17,65 \mathrm{~mm}$ no teto mostrado na Figura 5.4 está próximo ao deslocamento encontrado no PLAXIS $(\mathrm{u}=15,85 \mathrm{~mm})$.

Já o deslocamento na lateral do túnel foi de $\mathrm{u}=114,71 \mathrm{~mm}$ por Kirsch (Figura 5.4) e de $\mathrm{u}=$ $118,28 \mathrm{~mm}$ no PLAXIS (Figura 5.5).

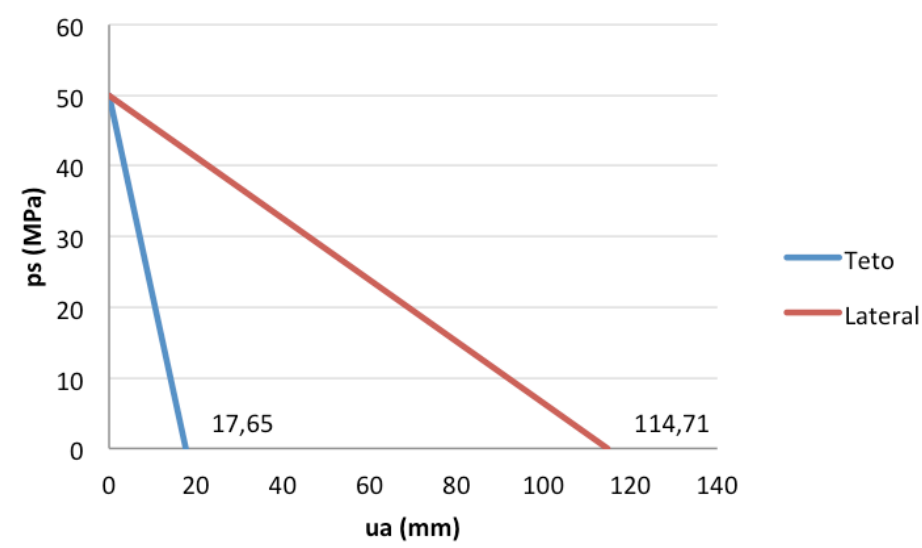

Figura 5.4 - Deslocamentos após a escavação do túnel calculados por Kirsch 


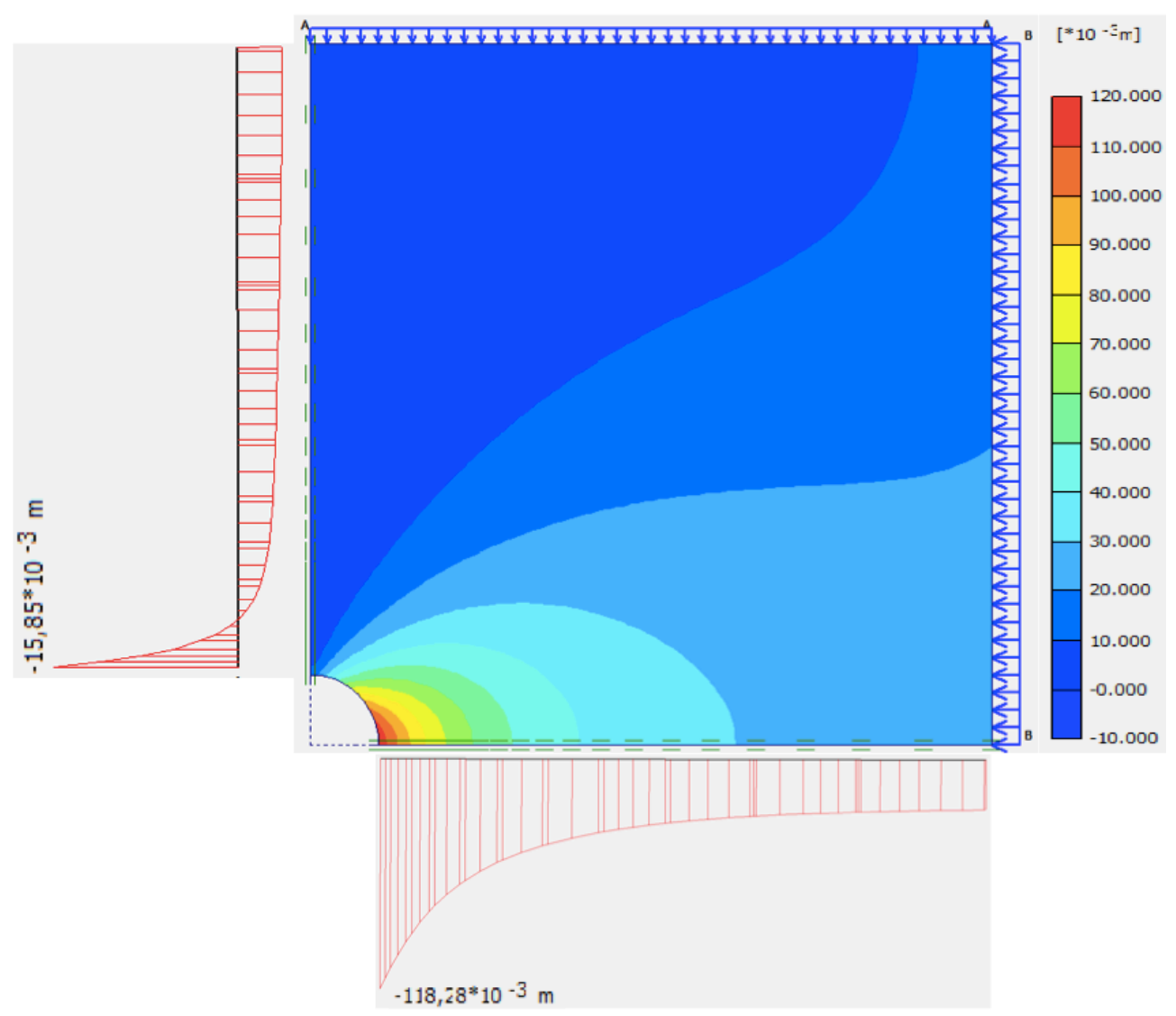

Figura 5.5 - Deslocamentos após a escavação do túnel calculados no PLAXIS

\subsection{RESULTADOS DAS ANÁLISES DETERMINÍSTICAS}

Nesta etapa foi possível comparar os resultados das áreas plásticas com os modos de falha propostos por Hoek et al. (1995), apresentados no Capítulo 3. A partir destes modos de falha, pôde-se analisar o comportamento dos dados de saída e escolheu-se os indicadores área plástica, fator de segurança e convergência por apresentarem um comportamento que permitisse determinar seu indicador de falha.

As análises determinísticas foram feitas para dois tipos de rocha: rocha metamórfica, como exemplo o Gnaisse e rocha sedimentar, sendo um exemplo o Siltito.

\subsubsection{ROCHA METAMÓRFICA (GNAISSE)}

Para cada tipo de rocha, variou-se o estado de tensões com $\mathrm{k}_{\mathrm{o}}=0,5, \mathrm{k}_{\mathrm{o}}=1, \mathrm{k}_{\mathrm{o}}=2$ e $\mathrm{k}_{\mathrm{o}}=4$, com a orientação das tensões principais na horizontal e vertical, apenas. Paralelo à variação do estado de tensões, as características de resistência do maciço rochoso foram alteradas por meio do GSI, de acordo com os modos de falha apresentados na Figura 3.4. 


\subsubsection{ESTADO DE TENSÕES COM $\mathrm{K}_{\mathrm{O}}=0,5$}

Na Figura 5.6 são apresentadas as zonas plásticas para o caso de rocha metamórfica e $\mathrm{k}_{\mathrm{o}}=$ 0,5. Percebe-se que para um baixo nível de tensões o programa PLAXIS não consegue prever quedas de blocos ou desagregação das paredes conforme o comportamento proposto por Hoek et al. (1995), apresentado no Capítulo 3. Isso se deve ao fato do programa tratar o material como um meio contínuo, ou seja, não considera as descontinuidades. Para tensões moderadas ocorre rupturas localizadas e para tensões elevadas a ruptura já ocorre de forma mais generalizada na lateral, seguindo bem o comportamento proposto por Hoek et al. (1995).

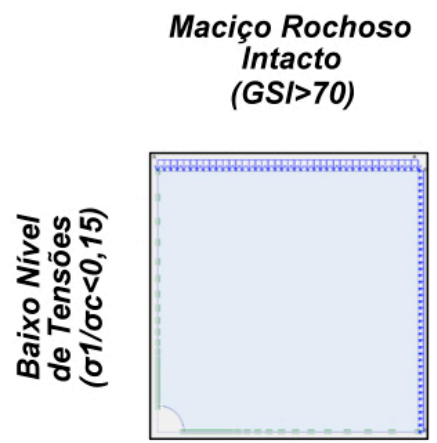

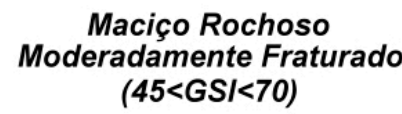
$(45<G S \mid<70)$
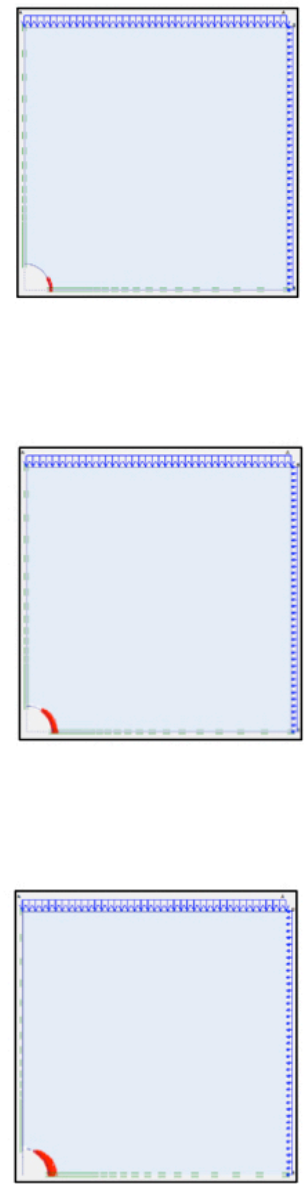
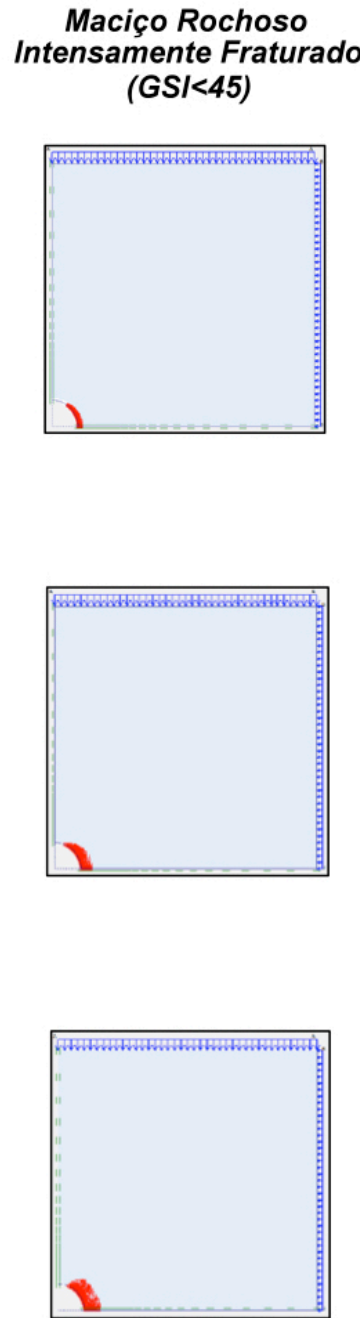

Figura 5.6 - Resultados das zonas plásticas - Rocha metamórfica, $\mathrm{k}_{\mathrm{o}}=0,5$.

A Tabela 5.1 apresenta os valores obtidos para os indicadores de desempenho escolhidos, onde $\mathrm{Ap}\left(\mathrm{m}^{2}\right)$ representa a área plástica $\mathrm{em} \mathrm{m}^{2}$, Ap (\%), a porcentagem de área plástica em relação à área do túnel, FS, o fator de segurança global, U (m), a convergência máxima do 
túnel em metros e U (\%) a porcentagem do deslocamento de convergência máxima em relação ao raio do túnel.

É possível perceber uma relação entre os indicadores área plástica e convergência com os parâmetros resistência do maciço $\left(\sigma_{\mathrm{c}}\right)$ e módulo de elasticidade do maciço $\left(\mathrm{E}_{\mathrm{m}}\right)$, respectivamente. Para maciços pouco fraturados, que possuem resistência e módulo mais elevados (Tabela A.1), obteve-se valores menores de área plástica e de convergência, enquanto que ao aumentar o grau de fraturamento, há uma queda dos parâmetros de resistência e do módulo e consequente aumento dos valores do indicadores área plástica e convergência.

Tabela 5.1 - Valores dos indicadores de desempenho - Rocha metamórfica, $\mathrm{k}_{\mathrm{o}}=0,5$.

\begin{tabular}{|c|c|c|c|c|}
\hline & & $\begin{array}{c}\text { Maciço } \\
\text { Rochoso } \\
\text { Intacto } \\
(\text { GSI }>70)\end{array}$ & $\begin{array}{c}\text { Maciço Rochoso } \\
\text { Moderadamente } \\
\text { Fraturado } \\
(45<\text { GSI }<70)\end{array}$ & $\begin{array}{c}\text { Maciço } \\
\text { Rochoso } \\
\text { Intensamente } \\
\text { Fraturado } \\
(\text { GSI }<45) \\
\end{array}$ \\
\hline \multirow{5}{*}{$\begin{array}{c}\text { Baixo Nível de } \\
\text { Tensões } \\
\left(\sigma_{1} / \sigma_{c}<0,15\right)\end{array}$} & $\operatorname{Ap}\left(m^{2}\right)$ & 0,0 & 1,2 & 9,8 \\
\hline & Ap $(\%)$ & $0 \%$ & $2 \%$ & $12 \%$ \\
\hline & FS & 5,2 & 3,5 & 2,6 \\
\hline & $\mathrm{U}(\mathrm{m})$ & 0,003 & 0,005 & 0,025 \\
\hline & U (\%) & $0,06 \%$ & $0,10 \%$ & $0,50 \%$ \\
\hline \multirow{5}{*}{$\begin{array}{c}\text { Moderado Nível } \\
\text { de Tensões } \\
\left(0,15<\sigma_{1} / \sigma_{c}<0,4\right)\end{array}$} & $\operatorname{Ap}\left(m^{2}\right)$ & 1,4 & 10,4 & 34,9 \\
\hline & Ap (\%) & $2 \%$ & $13 \%$ & $44 \%$ \\
\hline & FS & 3,5 & 2,6 & 1,9 \\
\hline & $\mathrm{U}(\mathrm{m})$ & 0,009 & 0,016 & 0,087 \\
\hline & $\mathrm{U}(\%)$ & $0,17 \%$ & $0,33 \%$ & $1,73 \%$ \\
\hline \multirow{5}{*}{$\begin{array}{c}\text { Elevado Nível de } \\
\text { Tensões } \\
\left(\sigma_{1} / \sigma_{c}>0,4\right)\end{array}$} & $\operatorname{Ap}\left(m^{2}\right)$ & 6,0 & 20,3 & 70,0 \\
\hline & Ap $(\%)$ & $8 \%$ & $26 \%$ & $89 \%$ \\
\hline & FS & 3,0 & 2,2 & 1,7 \\
\hline & $\mathrm{U}(\mathrm{m})$ & 0,015 & 0,029 & 0,165 \\
\hline & $\mathrm{U}(\%)$ & $0,30 \%$ & $0,58 \%$ & $3,29 \%$ \\
\hline
\end{tabular}

Os valores apresentados na Tabela 5.1 foram plotados em gráficos (Figura 5.7) a fim de encontrar uma relação entre os mesmos e até mesmo mudanças de tendências que indicassem o ponto de falha. A partir desses gráficos percebe-se uma mudança de tendência, ou seja, o fator de segurança sofre uma grande variação inicialmente para pouca variação da área plástica ou da convergência, enquanto que a partir dos pontos marcados $(\mathrm{Ap}=25 \% \mathrm{e} U=$ $0,6 \%$ ) percebe-se uma mudança brusca na inclinação da curva, o que indica que para uma 
pequena variação do fator de segurança houve um aumento significativo tanto na área plástica como na convergência.

Esses pontos de mudanças de comportamento foram tomados como indicadores de falha, ou seja, no caso de um túnel em rocha metamórfica, com $\mathrm{k}_{\mathrm{o}}=0,5$, uma porcentagem de área plástica acima de 25\% (Figura 5.7 a) ou uma porcentagem de convergência acima de $0,6 \%$ (Figura 5.7 b) indicam falha.

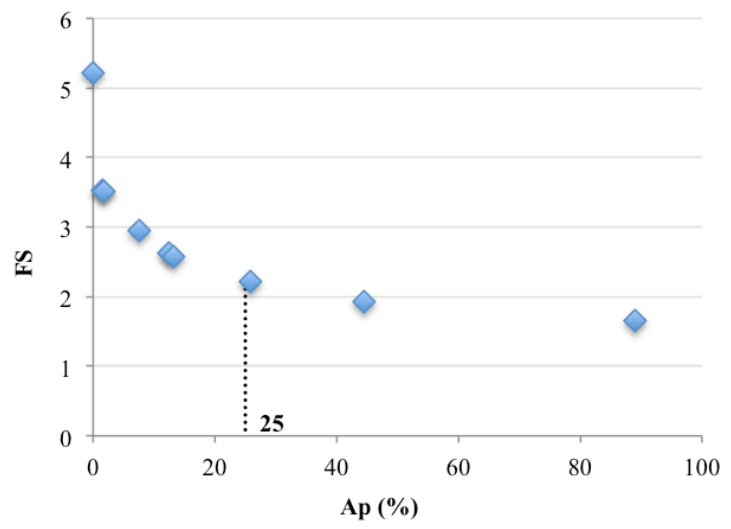

a)

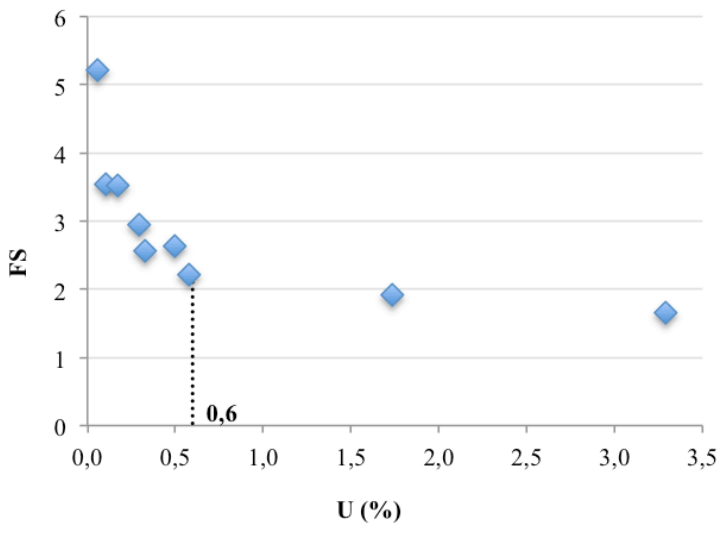

b)

Figura 5.7 - Relação entre os indicadores de desempenho: a) FS x Ap (\%); b) FS x U (\%) Rocha metamórfica, $\mathrm{k}_{\mathrm{o}}=0,5$.

\subsubsection{ESTADO DE TENSÕES COM $K_{0}=1,0$}

A Figura 5.8, mostra as zonas plásticas, para o caso de rocha metamórfica e $\mathrm{k}_{\mathrm{o}}=1,0 . \mathrm{O}$ comportamento segue o proposto por Hoek et al. (1995), em que para um moderado nível de tensões ocorrem rupturas localizadas enquanto que para um elevado nível de tensões a ruptura já ocorre de forma mais generalizada ao redor de todo o túnel.

Com os valores dos indicadores para um túnel em rocha metamórfica, com $\mathrm{k}_{\mathrm{o}}=1,0$, apresentados na Tabela 5.2, plotou-se os gráficos da Figura 5.7. A partir destes gráficos obtêm-se os indicadores de falha de 45\% (Figura 5.9 a) para a área plástica e de 0,5\% (Figura 5.9 b) para a convergência.

Novamente percebe-se, na Tabela 5.2, o aumento dos valores indicadores área plástica e convergência com a diminuição dos parâmetros resistência do maciço, $\sigma_{c}$, e módulo de elasticidade do maciço, $\mathrm{E}_{\mathrm{m}}$, devido ao grau de fraturamento do maciço. 

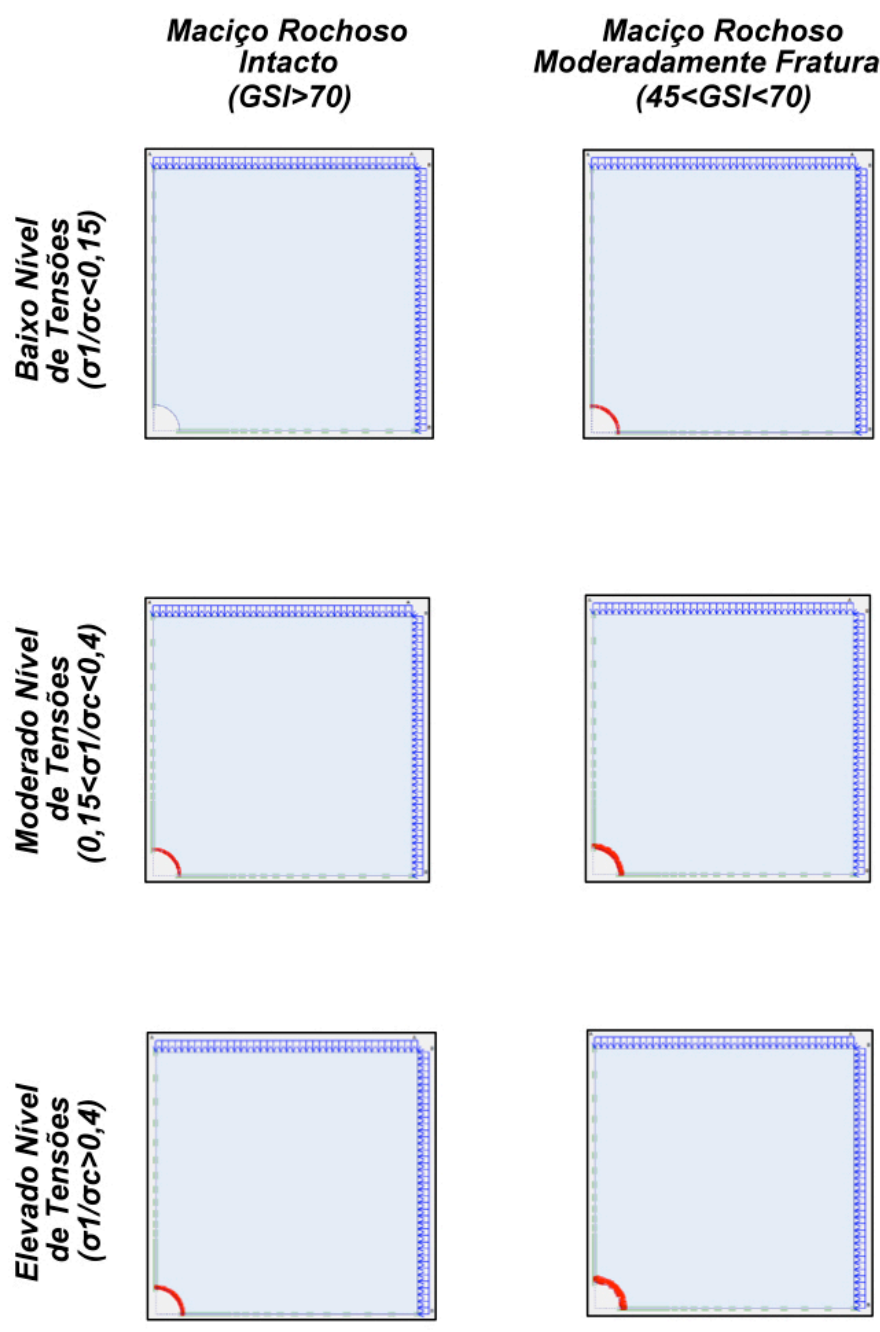
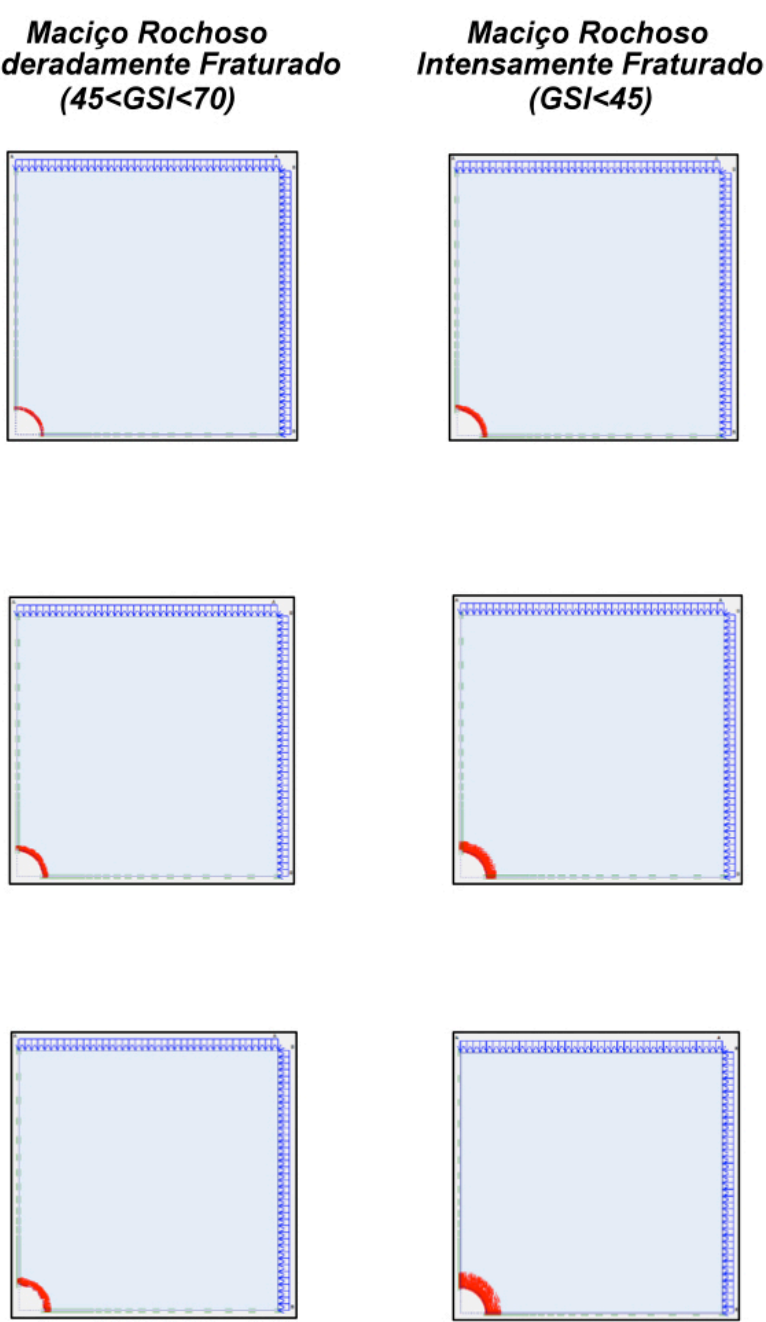

Figura 5.8 - Resultados das zonas plásticas - Rocha metamórfica, $\mathrm{k}_{\mathrm{o}}=1,0$.

\subsubsection{ESTADO DE TENSÕES COM $K_{0}=2,0$}

A Figura 5.10, mostra as zonas plásticas, para o caso de rocha metamórfica e $\mathrm{k}_{\mathrm{o}}=2,0$. $\mathrm{O}$ comportamento novamente segue o proposto por Hoek et al. (1995) e é bem semelhante ao comportamento apresentado no caso de $\mathrm{k}_{\mathrm{o}}=0,5$, com a diferença que agora as zonas plásticas se concentram no teto.

Os valores dos indicadores de falha para um túnel em rocha metamórfica, com $\mathrm{k}_{\mathrm{o}}=2,0$, foram determinados a partir dos valores dos indicadores de desempenho apresentados na Tabela 5.3 e dos gráficos da Figura 5.11. Assim, obteve-se os indicadores de falha de 30\% (Figura 5.11 a) para a área plástica e de $0,6 \%$ (Figura 5.11 b) para a convergência.

Percebe-se que esses indicadores foram bem próximos aos encontrados para o caso de $\mathrm{k}_{\mathrm{o}}=$ 
0,5, já que o comportamento apresentado na Figura 5.10 foi bem similar, diferenciando apenas que para $\mathrm{k}_{\mathrm{o}}=2,0$ a ruptura ocorre no teto, enquanto que para $\mathrm{k}_{\mathrm{o}}=0,5$, ocorre na lateral.

Pela Tabela 5.3, nota-se um aumento dos valores indicadores área plástica e convergência a medida que os parâmetros resistência do maciço, $\sigma_{c}$, e módulo de elasticidade do maciço, $\mathrm{E}_{\mathrm{m}}$, diminuem devido ao grau de fraturamento do maciço.

Tabela 5.2 - Valores dos indicadores de desempenho - Rocha metamórfica, $\mathrm{k}_{\mathrm{o}}=1,0$.

\begin{tabular}{|c|c|c|c|c|}
\hline & & $\begin{array}{c}\text { Maciço } \\
\text { Rochoso } \\
\text { Intacto } \\
(\text { GSI }>70)\end{array}$ & $\begin{array}{c}\text { Maciço Rochoso } \\
\text { Moderadamente } \\
\text { Fraturado } \\
(45<\text { GSI }<70)\end{array}$ & $\begin{array}{c}\text { Maciço } \\
\text { Rochoso } \\
\text { Intensamente } \\
\text { Fraturado } \\
(\mathbf{G S I}<\mathbf{4 5}) \\
\end{array}$ \\
\hline \multirow{5}{*}{$\begin{array}{c}\text { Baixo Nível de } \\
\text { Tensões } \\
\left(\sigma_{1} / \sigma_{c}<0,15\right)\end{array}$} & $\operatorname{Ap}\left(m^{2}\right)$ & 0,0 & 3,6 & 18,4 \\
\hline & $\mathrm{Ap}(\%)$ & $0 \%$ & $5 \%$ & $23 \%$ \\
\hline & FS & 7,2 & 4,8 & 3,5 \\
\hline & $\mathrm{U}(\mathrm{m})$ & 0,002 & 0,004 & 0,020 \\
\hline & $\mathrm{U}(\%)$ & $0,04 \%$ & $0,08 \%$ & $0,39 \%$ \\
\hline \multirow{5}{*}{$\begin{array}{c}\text { Moderado Nível } \\
\text { de Tensões } \\
\left(0,15<\sigma_{1} / \sigma_{\mathrm{c}}<0,4\right)\end{array}$} & $\operatorname{Ap}\left(m^{2}\right)$ & 3,6 & 21,5 & 57,1 \\
\hline & Ap $(\%)$ & $5 \%$ & $27 \%$ & $73 \%$ \\
\hline & FS & 4,8 & 3,5 & 2,6 \\
\hline & $\mathrm{U}(\mathrm{m})$ & 0,007 & 0,013 & 0,080 \\
\hline & $U(\%)$ & $0,13 \%$ & $0,26 \%$ & $1,60 \%$ \\
\hline \multirow{5}{*}{$\begin{array}{c}\text { Elevado Nível de } \\
\text { Tensões } \\
\left(\sigma_{1} / \sigma_{c}>0,4\right)\end{array}$} & $\operatorname{Ap}\left(m^{2}\right)$ & 10,1 & 35,5 & 102,2 \\
\hline & Ap $(\%)$ & $13 \%$ & $45 \%$ & $130 \%$ \\
\hline & FS & 4,0 & 3,0 & 2,2 \\
\hline & $\mathrm{U}(\mathrm{m})$ & 0,011 & 0,025 & 0,169 \\
\hline & $\mathrm{U}(\%)$ & $0,23 \%$ & $0,49 \%$ & $3,37 \%$ \\
\hline
\end{tabular}

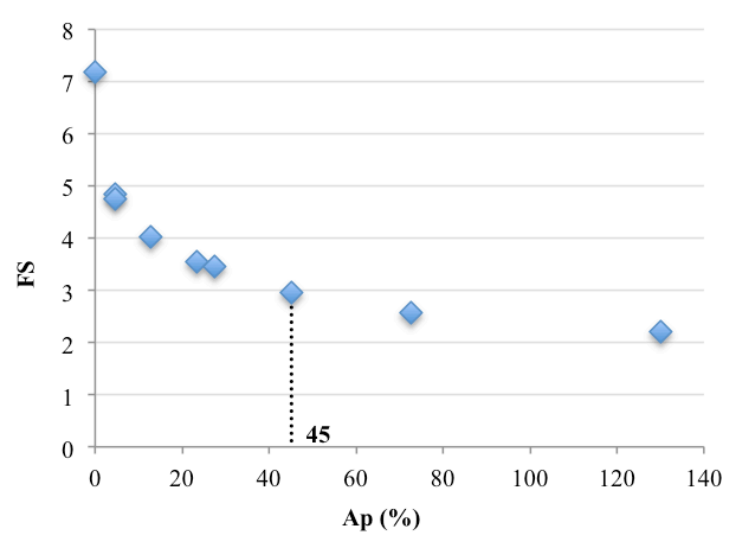

a)

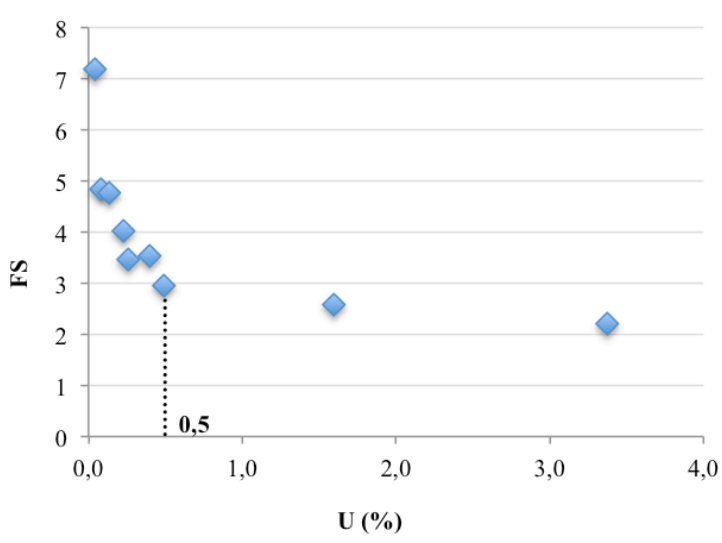

b)

Figura 5.9 - Relação entre os indicadores de desempenho: a) FS x Ap (\%); b) FS x U (\%) Rocha metamórfica, $\mathrm{k}_{\mathrm{o}}=1,0$. 

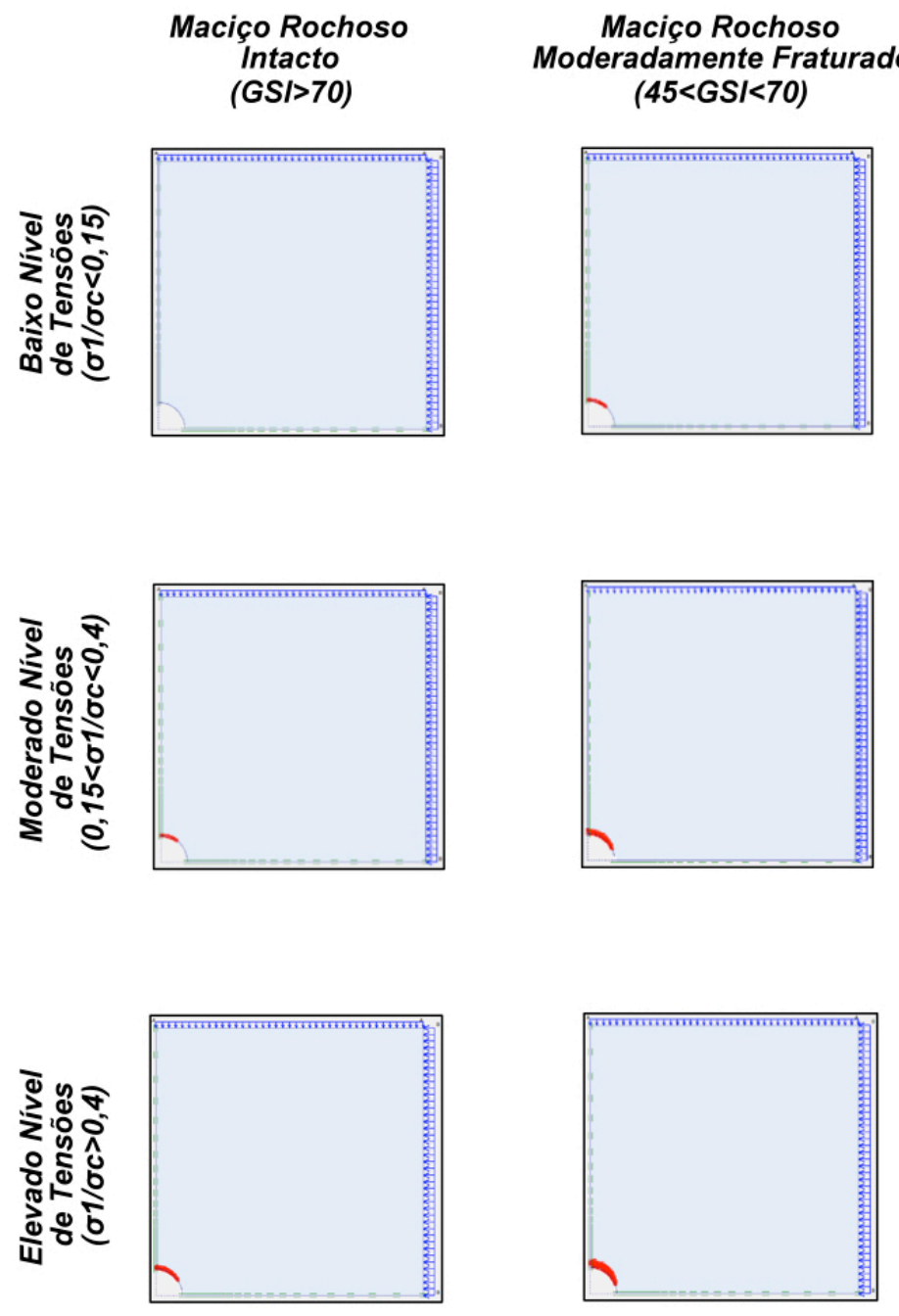
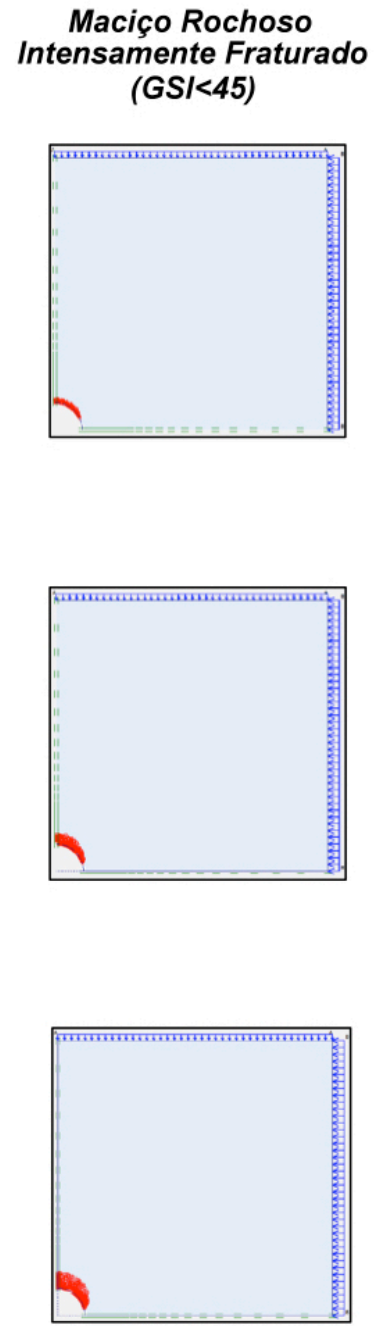

Figura 5.10 - Resultados das zonas plásticas - Rocha metamórfica, $\mathrm{k}_{\mathrm{o}}=2,0$.

\subsubsection{ESTADO DE TENSÕES COM $K_{0}=4,0$}

Já no caso de rocha metamórfica e $\mathrm{k}_{\mathrm{o}}=4,0$ (Figura 5.12), o comportamento das zonas plásticas tem características um pouco diferentes do comportamento apresentado no Capítulo 3. Neste caso, essas regiões plásticas começam a se afastar da parede do túnel de forma irregular e adquirem proporções mais elevadas.

Mesmo que este comportamento não siga exatamente o proposto por Hoek et al. (1995), ainda é possível perceber que a área plástica aumenta a medida que se aumenta o nível de tensões e que se aumenta o grau de fraturamento da rocha.

A partir dos valores dos indicadores de desempenho apresentados na Tabela 5.4 e dos gráficos da Figura 5.13, foi possível obter os indicadores de falha de $70 \%$ para a área plástica (Figura 
5.13 a) e de $0,8 \%$ para a convergência (Figura 5.13 b). Percebe-se que, para o caso de rocha metamórfica e $\mathrm{k}_{\mathrm{o}}=4,0$, é necessário que a área plastificada e a convergência sejam maiores que os casos anteriores para que se possa dizer que ocorreu a falha.

Tabela 5.3 - Valores dos indicadores de desempenho - Rocha metamórfica, $\mathrm{k}_{\mathrm{o}}=2,0$.

\begin{tabular}{|c|c|c|c|c|}
\hline & & $\begin{array}{c}\text { Maciço } \\
\text { Rochoso } \\
\text { Intacto } \\
\text { (GSI }>70)\end{array}$ & $\begin{array}{c}\text { Maciço Rochoso } \\
\text { Moderadamente } \\
\text { Fraturado } \\
(45<\text { GSI }<70)\end{array}$ & $\begin{array}{c}\text { Maciço } \\
\text { Rochoso } \\
\text { Intensamente } \\
\text { Fraturado } \\
(\mathbf{G S I}<\mathbf{4 5}) \\
\end{array}$ \\
\hline \multirow{5}{*}{$\begin{array}{c}\text { Baixo Nível de } \\
\text { Tensões } \\
\left(\sigma_{1} / \sigma_{c}<0,15\right)\end{array}$} & $\operatorname{Ap}\left(m^{2}\right)$ & 0,0 & 1,9 & 12,3 \\
\hline & Ap (\%) & $0 \%$ & $2 \%$ & $16 \%$ \\
\hline & FS & 5,3 & 3,6 & 2,6 \\
\hline & $\mathrm{U}(\mathrm{m})$ & 0,003 & 0,005 & 0,025 \\
\hline & $\mathrm{U}(\%)$ & $0,06 \%$ & $0,10 \%$ & $0,51 \%$ \\
\hline \multirow{5}{*}{$\begin{array}{c}\text { Moderado Nível } \\
\text { de Tensões } \\
\left(0,15<\sigma_{1} / \sigma_{c}<0,4\right)\end{array}$} & $\operatorname{Ap}\left(m^{2}\right)$ & 1,8 & 12,7 & 38,3 \\
\hline & Ap (\%) & $2 \%$ & $16 \%$ & $49 \%$ \\
\hline & $\mathrm{FS}$ & 3,6 & 2,6 & 2,0 \\
\hline & $\mathrm{U}(\mathrm{m})$ & 0,009 & 0,017 & 0,089 \\
\hline & $\mathrm{U}(\%)$ & $0,17 \%$ & $0,33 \%$ & $1,78 \%$ \\
\hline \multirow{5}{*}{$\begin{array}{c}\text { Elevado Nível de } \\
\text { Tensões } \\
\left(\sigma_{1} / \sigma_{c}>0,4\right)\end{array}$} & $\operatorname{Ap}\left(m^{2}\right)$ & 7,0 & 23,1 & 66,1 \\
\hline & Ap $(\%)$ & $9 \%$ & $29 \%$ & $84 \%$ \\
\hline & FS & 3,0 & 2,2 & 1,7 \\
\hline & $\mathrm{U}(\mathrm{m})$ & 0,015 & 0,030 & 0,169 \\
\hline & $\mathrm{U}(\%)$ & $0,30 \%$ & $0,59 \%$ & $3,38 \%$ \\
\hline
\end{tabular}

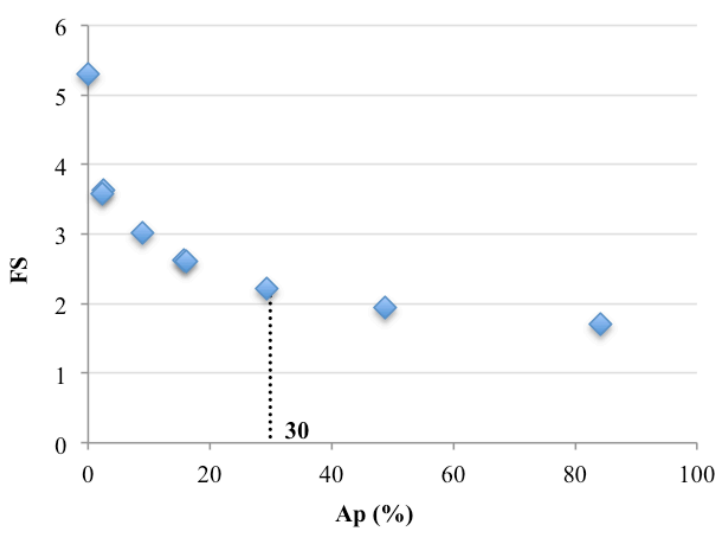

a)

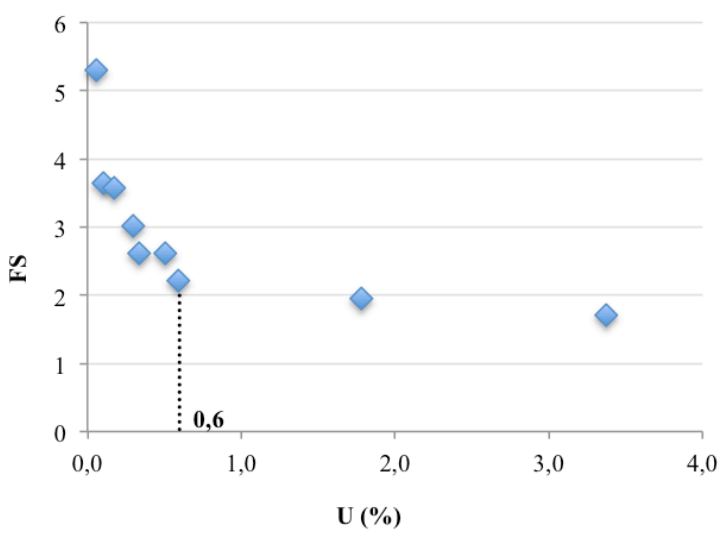

b)

Figura 5.11 - Relação entre os indicadores de desempenho: a) FS x Ap (\%); b) FS x U (\%) Rocha metamórfica, $\mathrm{k}_{\mathrm{o}}=2,0$. 

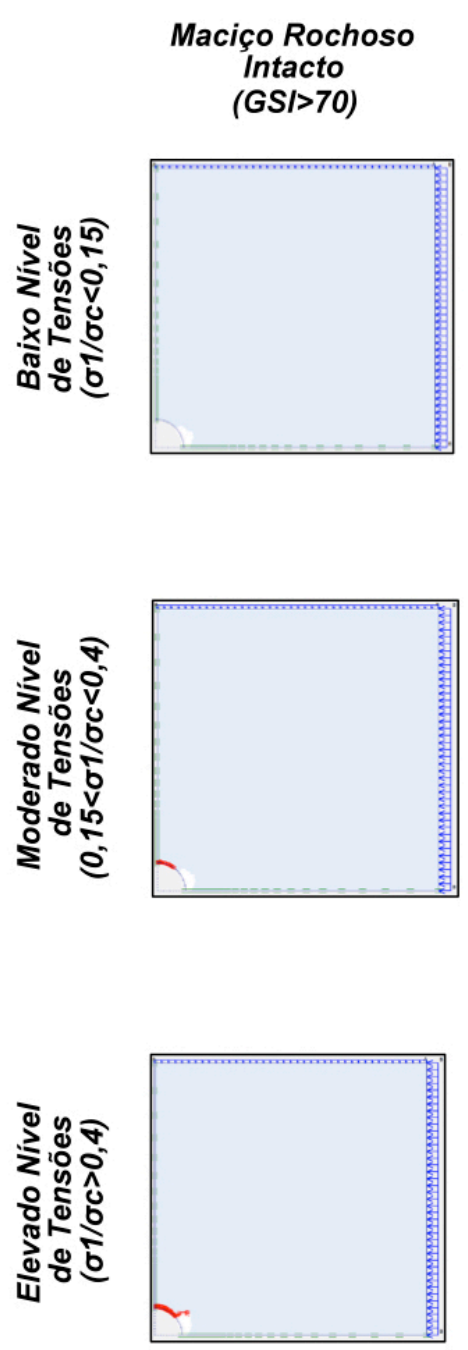
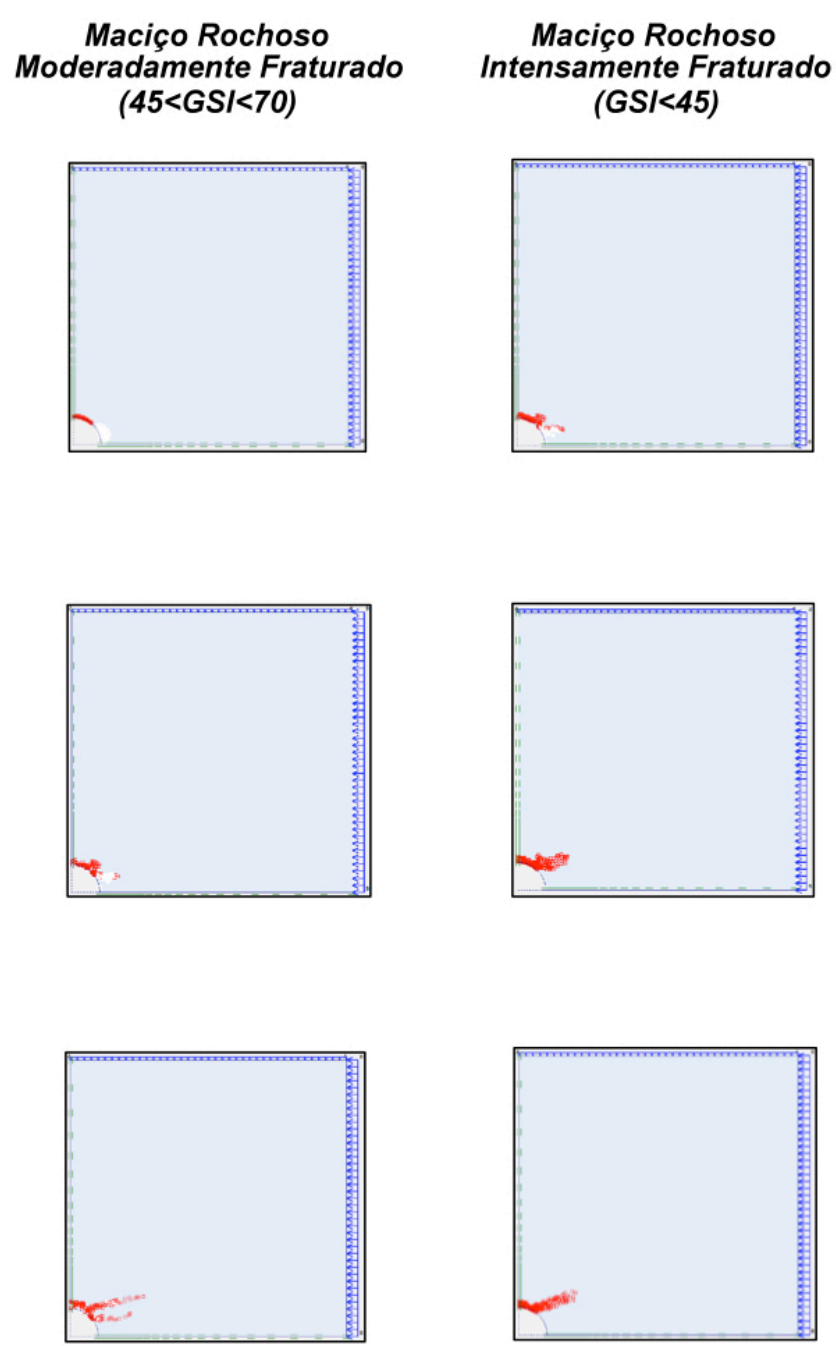

Figura 5.12 - Resultados das zonas plásticas - Rocha metamórfica, $\mathrm{k}_{\mathrm{o}}=4,0$.

$\mathrm{Na}$ Tabela 5.4, observa-se que os valores dos indicadores área plástica e convergência aumentam a medida que os parâmetros resistência do maciço, $\sigma_{\mathrm{c}}$, e módulo de elasticidade do maciço, $\mathrm{E}_{\mathrm{m}}$, decrescem devido ao grau de fraturamento do maciço.

\subsubsection{ROCHA SEDIMENTAR (SILTITO)}

Assim como para a rocha metamórfica, fez simulações com o caso de rocha sedimentar variando o estado de tensões com $\mathrm{k}_{\mathrm{o}}=0,5, \mathrm{k}_{\mathrm{o}}=1, \mathrm{k}_{\mathrm{o}}=2$ e $\mathrm{k}_{\mathrm{o}}=4$, com a orientação das tensões principais na horizontal e vertical, apenas. Abaixo, são apresentados as análises dos resultados dessas simulações.

\subsubsection{ESTADO DE TENSÕES COM $K_{0}=0,5$}

No caso de rocha sedimentar e $\mathrm{k}_{\mathrm{o}}=0,5$ (Figura 5.14), já se começa a ter um 
comportamento de plastificação intensa que se alastra por uma grande área afastada na parede do túnel. Mas, ainda assim é possível perceber que o comportamento das zonas plásticas seguem, até certo ponto, o proposto por Hoek et al. (1995), onde para um moderado nível de tensões ocorrem rupturas localizadas enquanto que para um elevado nível de tensões a ruptura já ocorre de forma mais generalizada na lateral do túnel. Especificamente no caso de um maciço intensamente fraturado, essa ruptura generalizada ocorre ao redor de todo o túnel.

Os indicadores de falha para o caso de rocha sedimentar adquirem valores mais elevados que os apresentados para o caso de rocha metamórfica. Neste caso, para $\mathrm{k}_{\mathrm{o}}=0,5$, a partir dos valores dos indicadores de desempenho apresentados na Tabela 5.5 e dos gráficos da Figura 5.15, os indicadores de falha obtidos foram de 105\% para a área plástica (Figura 5.15 a) e de 1,7\% para a convergência (Figura 5.15 b).

Nota-se também uma relação entre os indicadores área plástica e convergência com os parâmetros resistência do maciço $\left(\sigma_{\mathrm{c}}\right)$ e módulo de elasticidade do maciço $\left(\mathrm{E}_{\mathrm{m}}\right)$, respectivamente (Tabela 5.5), pois esses parâmetros dependem do grau de fraturamento.

Tabela 5.4 - Valores dos indicadores de desempenho - Rocha metamórfica, $\mathrm{k}_{\mathrm{o}}=4,0$.

\begin{tabular}{|c|c|c|c|c|}
\hline & & $\begin{array}{c}\text { Maciço } \\
\text { Rochoso } \\
\text { Intacto } \\
(\text { GSI }>70)\end{array}$ & $\begin{array}{c}\text { Maciço Rochoso } \\
\text { Moderadamente } \\
\text { Fraturado } \\
(45<\text { GSI }<70)\end{array}$ & $\begin{array}{c}\text { Maciço } \\
\text { Rochoso } \\
\text { Intensamente } \\
\text { Fraturado } \\
(\text { GSI }<45)\end{array}$ \\
\hline \multirow{5}{*}{$\begin{array}{c}\text { Baixo Nível de } \\
\text { Tensões } \\
\left(\sigma_{1} / \sigma_{c}<0,15\right)\end{array}$} & $\operatorname{Ap}\left(m^{2}\right)$ & 0,0 & 3,3 & 20,2 \\
\hline & $\operatorname{Ap}(\%)$ & $0 \%$ & $4 \%$ & $26 \%$ \\
\hline & FS & 3,3 & 2,0 & 1,5 \\
\hline & $\mathrm{U}(\mathrm{m})$ & 0,003 & 0,006 & 0,031 \\
\hline & $\mathrm{U}(\%)$ & $0,07 \%$ & $0,12 \%$ & $0,61 \%$ \\
\hline \multirow{5}{*}{$\begin{array}{c}\text { Moderado Nível } \\
\text { de Tensões } \\
\left(0,15<\sigma_{1} / \sigma_{c}<0,4\right)\end{array}$} & $\operatorname{Ap}\left(m^{2}\right)$ & 1,8 & 22,8 & 231,1 \\
\hline & Ap $(\%)$ & $2 \%$ & $29 \%$ & $294 \%$ \\
\hline & FS & 1,9 & 1,4 & 1,0 \\
\hline & $\mathrm{U}(\mathrm{m})$ & 0,010 & 0,020 & 0,095 \\
\hline & $\mathrm{U}(\%)$ & $0,20 \%$ & $0,40 \%$ & $1,90 \%$ \\
\hline \multirow{5}{*}{$\begin{array}{c}\text { Elevado Nível de } \\
\text { Tensões } \\
\left(\sigma_{1} / \sigma_{\mathrm{c}}>\mathbf{0}, 4\right)\end{array}$} & $\operatorname{Ap}\left(m^{2}\right)$ & 10,1 & 52,8 & 378,6 \\
\hline & Ap $(\%)$ & $13 \%$ & $67 \%$ & $482 \%$ \\
\hline & FS & 1,7 & 1,2 & 0,9 \\
\hline & $\mathrm{U}(\mathrm{m})$ & 0,017 & 0,041 & 0,160 \\
\hline & $\mathrm{U}(\%)$ & $0,34 \%$ & $0,82 \%$ & $3,21 \%$ \\
\hline
\end{tabular}




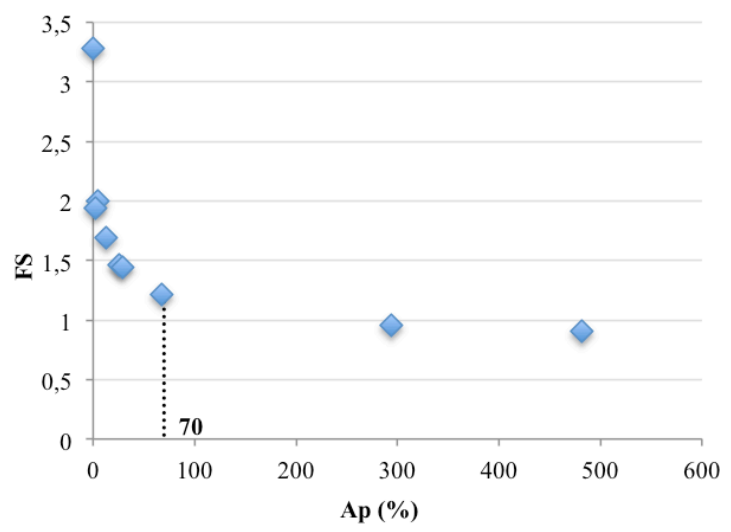

a)

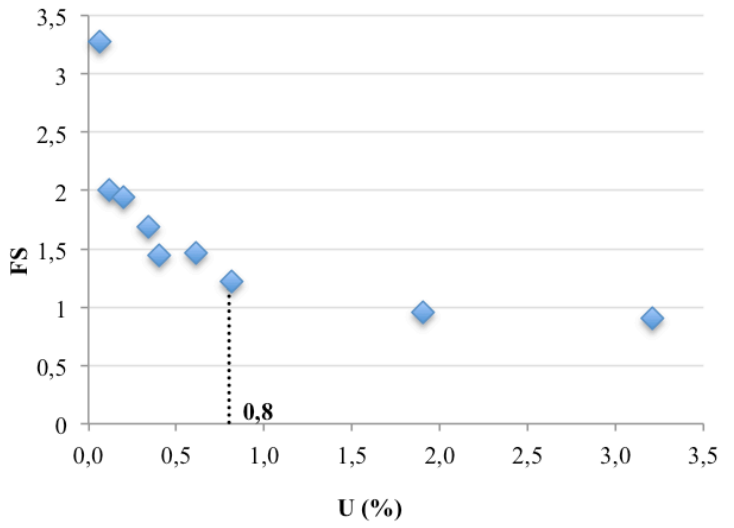

b)

Figura 5.13 - Relação entre os indicadores de desempenho: a) FS x Ap (\%); b) FS x U (\%) Rocha metamórfica, $\mathrm{k}_{\mathrm{o}}=4,0$.

\section{Maciço Rochoso}

Intacto

$(G S />70)$
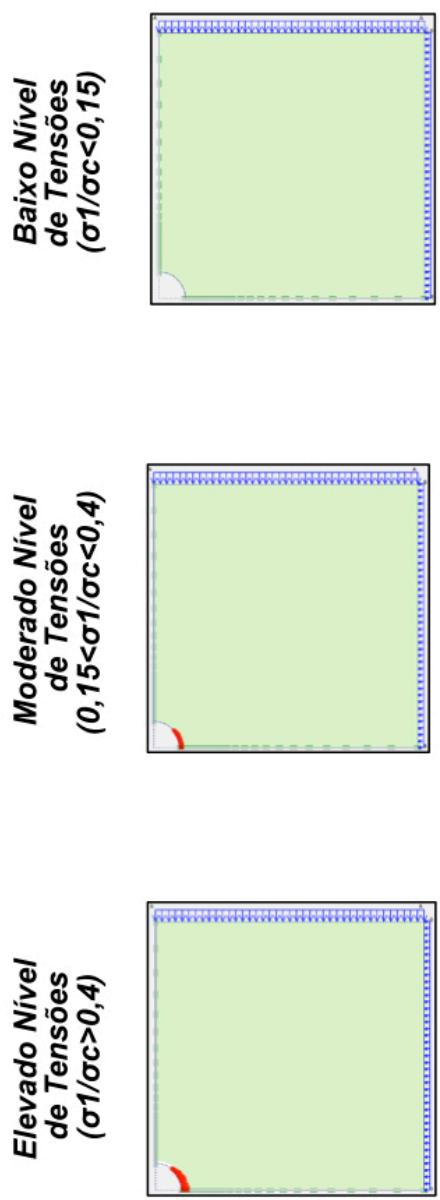

Maciço Rochoso Moderadamente Fraturado $(45<G S /<70)$
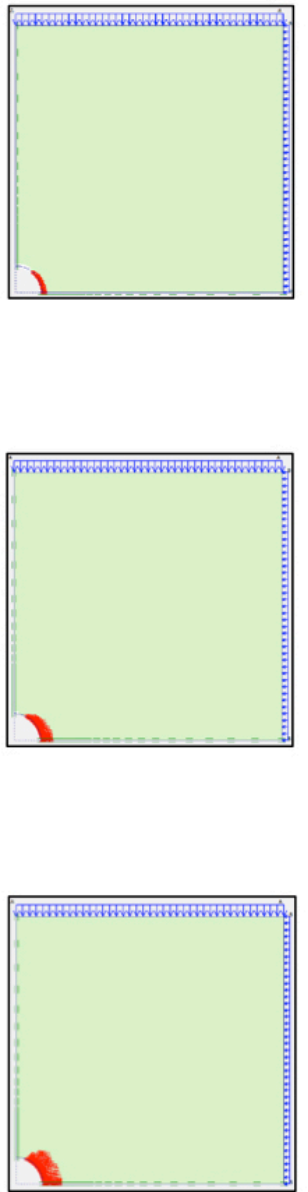

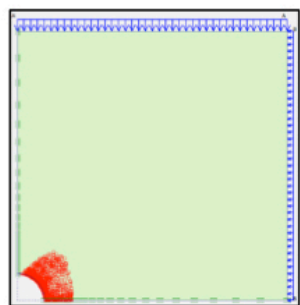

Maciço Rochoso Intensamente Fraturado $(G S \mid<45)$
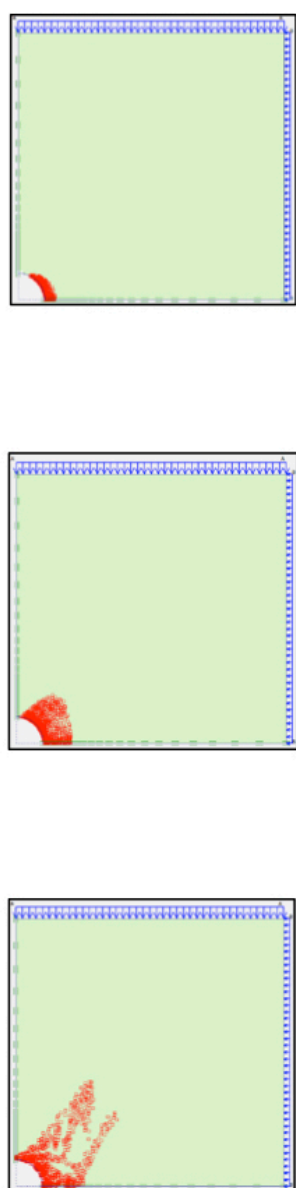

Figura 5.14 - Resultados das zonas plásticas - Rocha sedimentar, $\mathrm{k}_{\mathrm{o}}=0,5$. 
Tabela 5.5 - Valores dos indicadores de desempenho - Rocha sedimentar, $\mathrm{k}_{\mathrm{o}}=0,5$.

\begin{tabular}{|c|c|c|c|c|}
\hline & & \\
\hline & & $\begin{array}{c}\text { Maciço } \\
\text { Rochoso } \\
\text { Intacto } \\
\text { (GSI }>70)\end{array}$ & $\begin{array}{c}\text { Maciço Rochoso } \\
\text { Moderadamente } \\
\text { Fraturado } \\
(45<\text { GSI }<70)\end{array}$ & $\begin{array}{c}\text { Maciço } \\
\text { Rochoso } \\
\text { Intensamente } \\
\text { Fraturado } \\
(\text { GSI }<45) \\
\end{array}$ \\
\hline \multirow{5}{*}{$\begin{array}{c}\text { Baixo Nível de } \\
\text { Tensões } \\
\left(\sigma_{1} / \sigma_{\mathrm{c}}<0,15\right)\end{array}$} & $\operatorname{Ap}\left(m^{2}\right)$ & 0,0 & 5,8 & 31,9 \\
\hline & $\operatorname{Ap}(\%)$ & $0 \%$ & $7 \%$ & $41 \%$ \\
\hline & FS & 4,8 & 2,8 & 1,9 \\
\hline & $\mathrm{U}(\mathrm{m})$ & 0,007 & 0,012 & 0,065 \\
\hline & $\mathrm{U}(\%)$ & $0,13 \%$ & $0,24 \%$ & $1,30 \%$ \\
\hline \multirow{5}{*}{$\begin{array}{c}\text { Moderado Nível } \\
\text { de Tensões } \\
\left(0,15<\sigma_{1} / \sigma_{\mathbf{c}}<0,4\right)\end{array}$} & $\operatorname{Ap}\left(m^{2}\right)$ & 4,9 & 33,3 & 201,2 \\
\hline & Ap $(\%)$ & $6 \%$ & $42 \%$ & $256 \%$ \\
\hline & FS & 2,8 & 1,9 & 1,4 \\
\hline & $\mathrm{U}(\mathrm{m})$ & 0,020 & 0,042 & 0,282 \\
\hline & $\mathrm{U}(\%)$ & $0,40 \%$ & $0,85 \%$ & $5,63 \%$ \\
\hline \multirow{5}{*}{$\begin{array}{c}\text { Elevado Nível de } \\
\text { Tensões } \\
\left(\sigma_{1} / \sigma_{c}>0,4\right)\end{array}$} & $\operatorname{Ap}\left(m^{2}\right)$ & 13,9 & 80,9 & 525,3 \\
\hline & Ap $(\%)$ & $18 \%$ & $103 \%$ & $669 \%$ \\
\hline & FS & 2,3 & 1,6 & 1,2 \\
\hline & $\mathrm{U}(\mathrm{m})$ & 0,035 & 0,082 & 0,981 \\
\hline & $\mathrm{U}(\%)$ & $0,71 \%$ & $1,65 \%$ & $19,63 \%$ \\
\hline
\end{tabular}

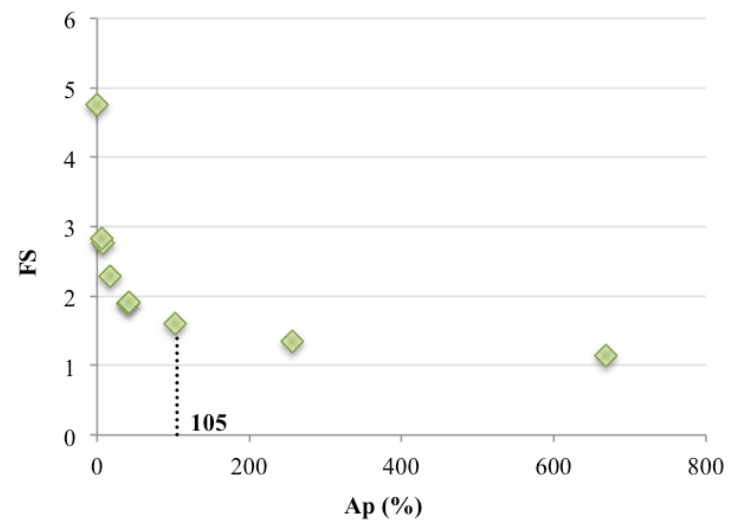

a)

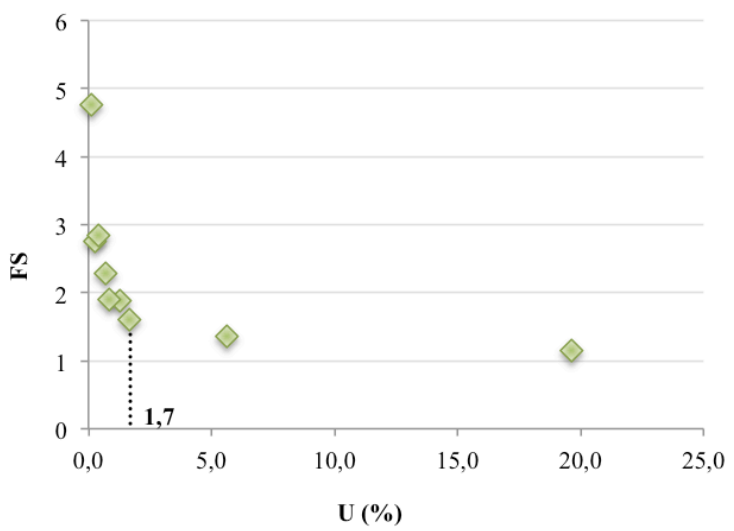

b)

Figura 5.15 - Relação entre os indicadores de desempenho: a) FS x Ap (\%); b) FS x U (\%) Rocha sedimentar, $\mathrm{k}_{\mathrm{o}}=0,5$.

\subsubsection{ESTADO DE TENSÕES COM $K_{0}=1,0$}

A Figura 5.16, mostra as zonas plásticas, para o caso de rocha sedimentar e $\mathrm{k}_{\mathrm{o}}=1,0$. Notase que o comportamento segue o proposto por Hoek et al. (1995), em que para um moderado 
nível de tensões ocorrem rupturas pontuais enquanto que para um elevado nível de tensões a ruptura já ocorre de forma mais generalizada ao redor de todo o túnel. Comparando-se com o caso da rocha metamórfica e $\mathrm{k}_{\mathrm{o}}=1,0$, percebe-se que o comportamento é similar, mas com uma magnitude de área plastificada maior.

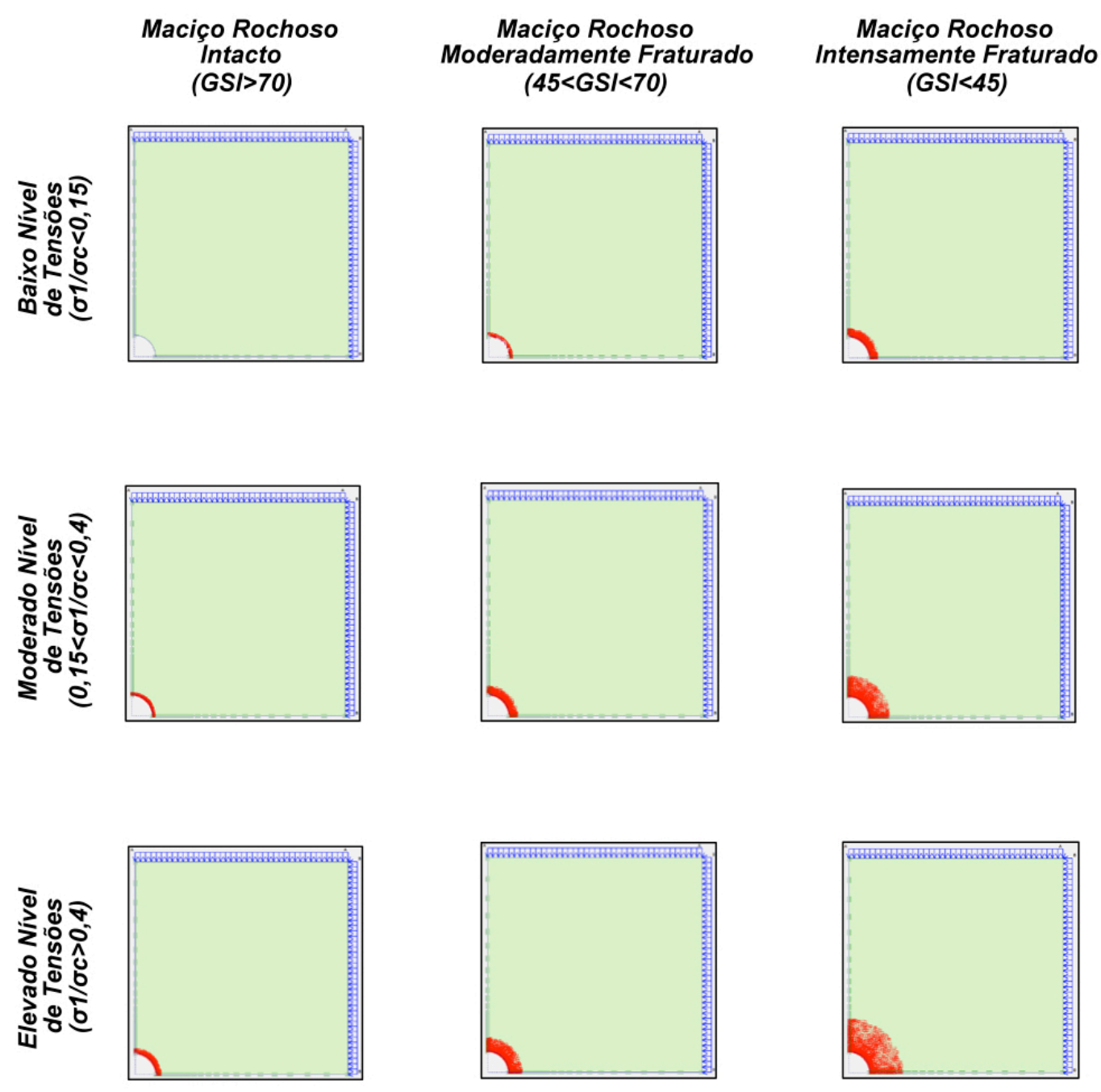

Figura 5.16 - Resultados das zonas plásticas - Rocha sedimentar, $\mathrm{k}_{\mathrm{o}}=1,0$.

Com os valores dos indicadores de desempenho para um túnel em rocha sedimentar, $\operatorname{com} \mathrm{k}_{\mathrm{o}}=$ 1,0, apresentados na Tabela 5.6, plotou-se os gráficos da Figura 5.17. A partir destes gráficos obteve-se os indicadores de falha de 140\% para a área plástica (Figura 5.17 a) e de 1,8\% para a convergência (Figura 5.17 b).

$\mathrm{Na}$ Tabela 5.6, é possível notar que os valores dos indicadores área plástica e convergência tem valores mais elevados quando os parâmetros resistência do maciço, $\sigma_{c}$, e módulo de elasticidade do maciço, $\mathrm{E}_{\mathrm{m}}$, possuem valores mais baixos devido ao grau de fraturamento do 
maciço.

Tabela 5.6 - Valores dos indicadores de desempenho - Rocha sedimentar, $\mathrm{k}_{\mathrm{o}}=1,0$.

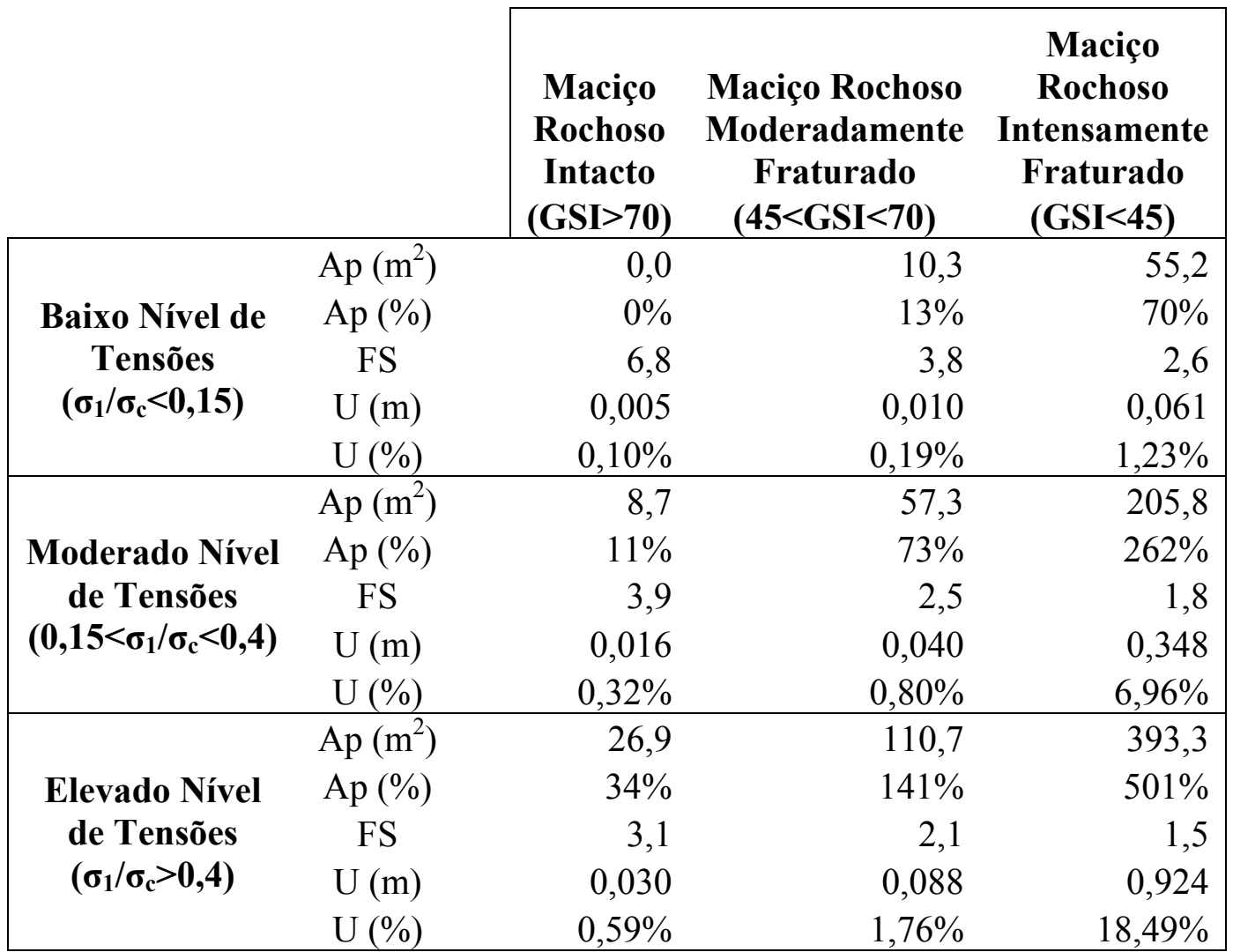

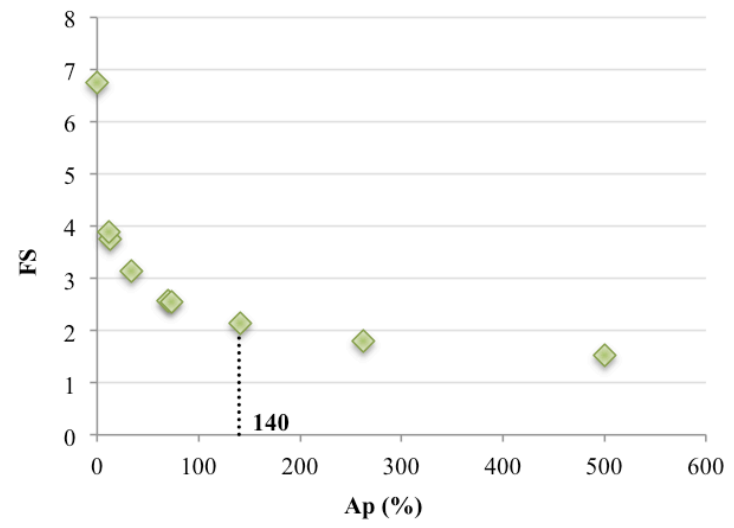

a)

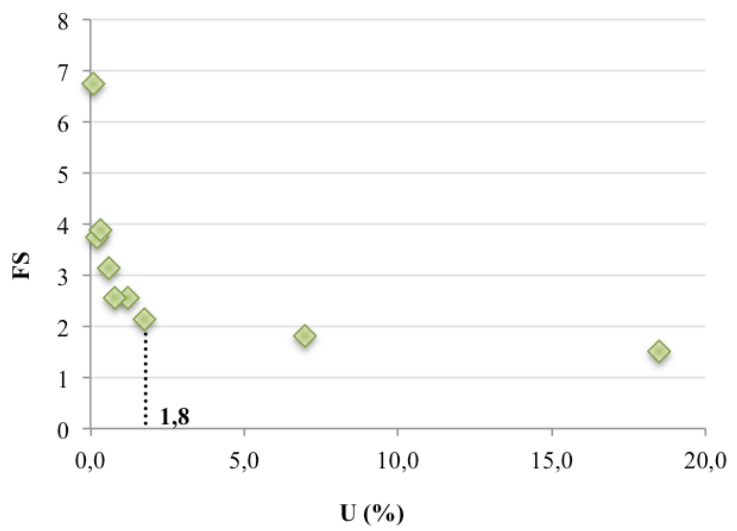

b)

Figura 5.17 - Relação entre os indicadores de desempenho: a) FS x Ap (\%); b) FS x U (\%) Rocha sedimentar, $\mathrm{k}_{\mathrm{o}}=1,0$.

\subsubsection{ESTADO DE TENSÕES COM $\mathrm{K}_{0}=2,0$}

A Figura 5.18, mostra as zonas plásticas, para o caso de rocha sedimentar e $\mathrm{k}_{\mathrm{o}}=2,0$. $\mathrm{O}$ 
comportamento novamente segue o proposto por Hoek et al. (1995) e assemelha-se ao comportamento apresentado no caso de $\mathrm{k}_{\mathrm{o}}=0,5$, com a diferença que agora as zonas plásticas se concentram no teto e no caso de um maciço intensamente fraturado, o comportamento deste último se deu de forma mais próxima ao proposto por Hoek.
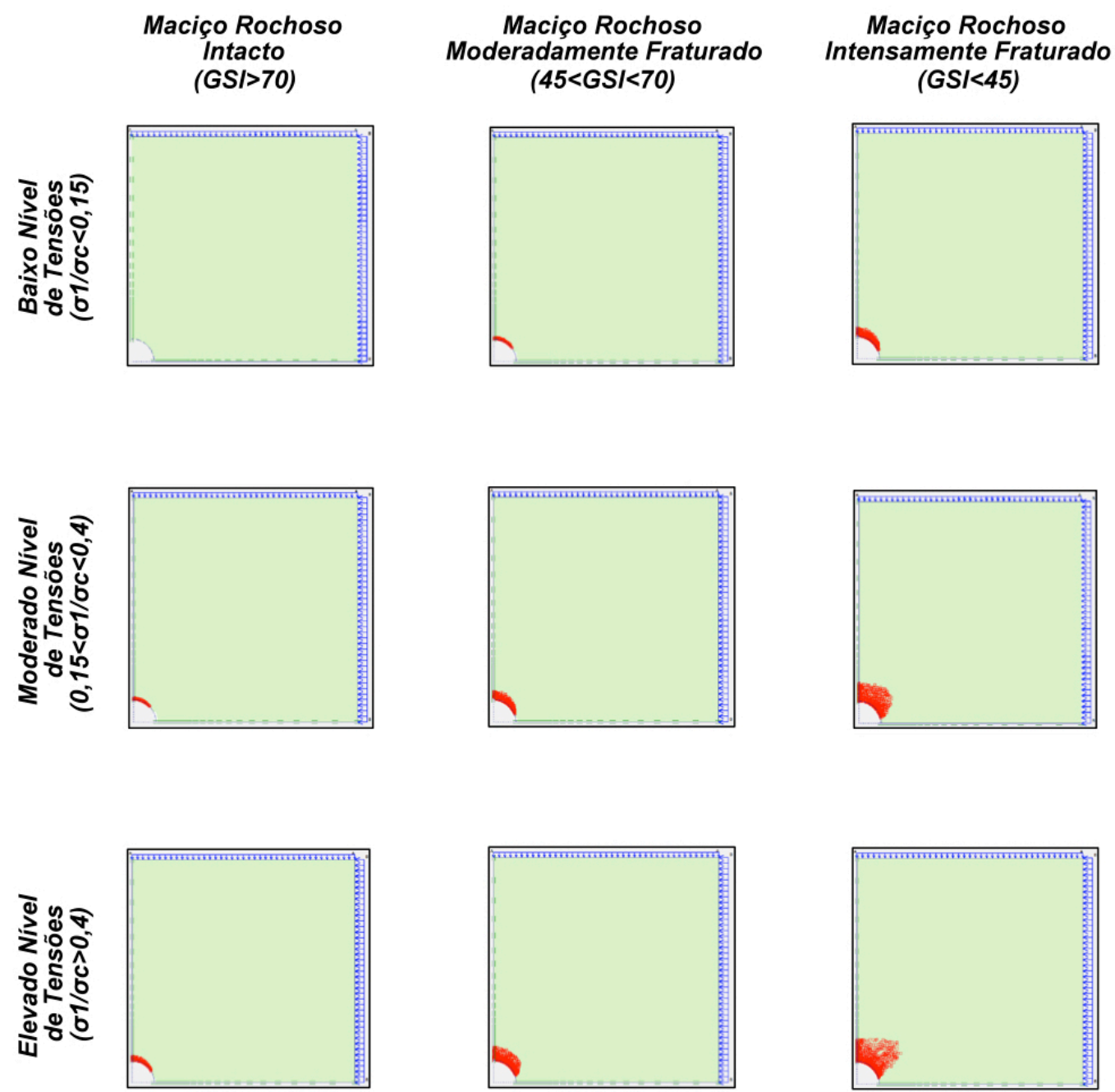

Figura 5.18 - Resultados das zonas plásticas - Rocha sedimentar, $\mathrm{k}_{\mathrm{o}}=2,0$.

A Tabela 5.7 apresenta os valores obtidos dos indicadores de desempenho para o caso de rocha sedimentar e $\mathrm{k}_{\mathrm{o}}=2,0$. Esses valores foram plotados em gráficos (Figura 5.19) onde é possível buscar os pontos em que se percebe uma mudança de tendência, ou seja, pontos onde ocorre uma mudança brusca na inclinação da curva, o que indica que para uma pequena variação do fator de segurança houve um aumento significativo tanto na área plástica como na convergência.

Neste caso, os valores desses pontos de mudanças de comportamento, os chamados 
indicadores de falha, foram de 95\% para a área plástica (Figura 5.19 a) e de 1,7\% para a convergência (Figura 5.19 b).

Os valores desses indicadores foram bem próximos aos encontrados para o caso de $\mathrm{k}_{\mathrm{o}}=0,5$, já que o comportamento apresentado na Figura 5.18 foi bem similar, diferenciando apenas que para $\mathrm{k}_{\mathrm{o}}=2,0$ a ruptura ocorre no teto, enquanto que para $\mathrm{k}_{\mathrm{o}}=0,5$, ocorre na lateral.

Outro ponto importante a se notar, na Tabela 5.7, é a relação entre os indicadores área plástica e convergência com os parâmetros resistência do maciço $\left(\sigma_{c}\right)$ e módulo de elasticidade do maciço $\left(E_{m}\right)$, respectivamente. Para maciços pouco fraturados, que possuem resistência e módulo mais elevados (Tabela A.7), obteve-se valores menores de área plástica e de convergência, enquanto que ao aumentar o grau de fraturamento, há uma queda dos parâmetros de resistência e do módulo e consequente aumento dos valores do indicadores área plástica e convergência.

Tabela 5.7 - Valores dos indicadores de desempenho - Rocha sedimentar, $\mathrm{k}_{\mathrm{o}}=2,0$.

\begin{tabular}{|c|c|c|c|c|}
\hline & & \\
\hline & & $\begin{array}{c}\text { Maciço } \\
\text { Rochoso } \\
\text { Intacto } \\
(\text { GSI }>70)\end{array}$ & $\begin{array}{c}\text { Maciço Rochoso } \\
\text { Moderadamente } \\
\text { Fraturado } \\
(45<\text { GSI }<70)\end{array}$ & $\begin{array}{c}\text { Maciço } \\
\text { Rochoso } \\
\text { Intensamente } \\
\text { Fraturado } \\
(\text { GSI }<45)\end{array}$ \\
\hline \multirow{5}{*}{$\begin{array}{c}\text { Baixo Nível de } \\
\text { Tensões } \\
\left(\sigma_{1 / \sigma_{c}}<0,15\right)\end{array}$} & $\operatorname{Ap}\left(m^{2}\right)$ & 0,0 & 6,5 & 33,5 \\
\hline & Ap (\%) & $0 \%$ & $8 \%$ & $43 \%$ \\
\hline & FS & 4,9 & 2,9 & 1,9 \\
\hline & $\mathrm{U}(\mathrm{m})$ & 0,007 & 0,012 & 0,066 \\
\hline & U (\%) & $0,13 \%$ & $0,24 \%$ & $1,33 \%$ \\
\hline \multirow{5}{*}{$\begin{array}{c}\text { Moderado Nível } \\
\text { de Tensões } \\
\left(0,15<\sigma_{1} / \sigma_{\mathrm{c}}<0,4\right)\end{array}$} & $\operatorname{Ap}\left(m^{2}\right)$ & 5,0 & 33,2 & 146,8 \\
\hline & Ap $(\%)$ & $6 \%$ & $42 \%$ & $187 \%$ \\
\hline & FS & 2,9 & 2,0 & 1,4 \\
\hline & $\mathrm{U}(\mathrm{m})$ & 0,020 & 0,043 & 0,270 \\
\hline & U (\%) & $0,40 \%$ & $0,86 \%$ & $5,40 \%$ \\
\hline \multirow{5}{*}{$\begin{array}{c}\text { Elevado Nível de } \\
\text { Tensões } \\
\left(\sigma_{1} / \sigma_{c}>0,4\right)\end{array}$} & $\operatorname{Ap}\left(m^{2}\right)$ & 12,4 & 72,9 & 347,7 \\
\hline & Ap $(\%)$ & $16 \%$ & $93 \%$ & $443 \%$ \\
\hline & FS & 2,4 & 1,7 & 1,2 \\
\hline & $\mathrm{U}(\mathrm{m})$ & 0,035 & 0,083 & 0,494 \\
\hline & $\mathrm{U}(\%)$ & $0,70 \%$ & $1,66 \%$ & $9,88 \%$ \\
\hline
\end{tabular}




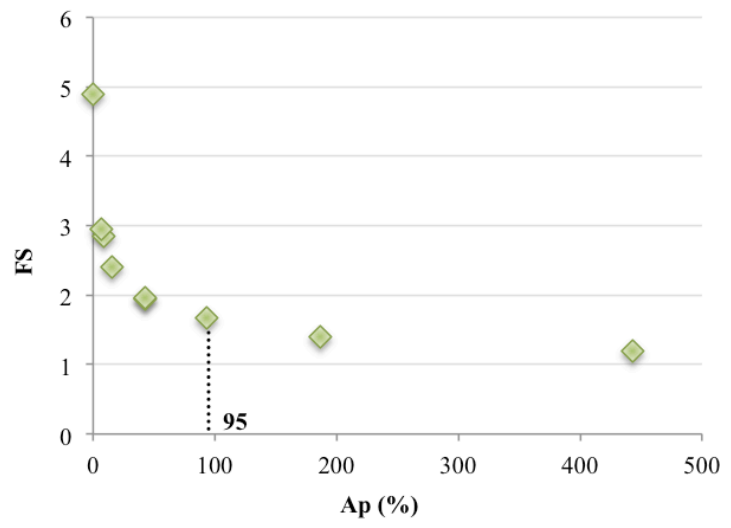

a)

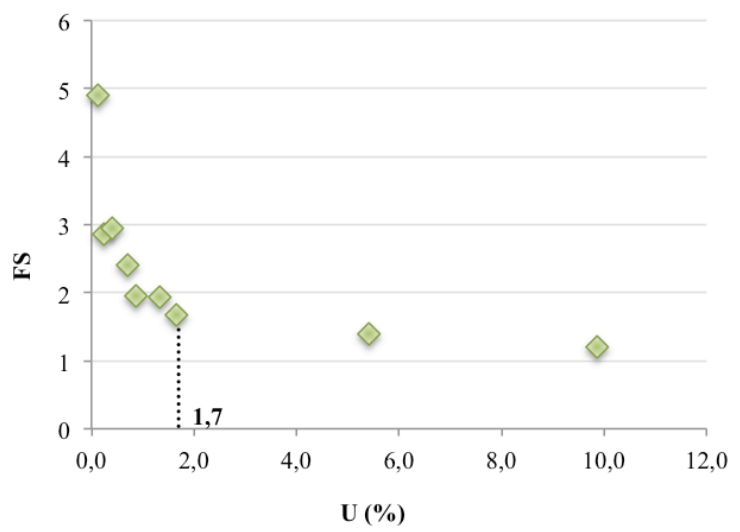

b)

Figura 5.19 - Relação entre os indicadores de desempenho: a) FS x Ap (\%); b) FS x U (\%) Rocha sedimentar, $\mathrm{k}_{\mathrm{o}}=2,0$.

\subsubsection{ESTADO DE TENSÕES COM $K_{0}=4,0$}

Assim como no caso de rocha metamórfica e $\mathrm{k}_{\mathrm{o}}=4,0$ (Figura 5.12), o comportamento das zonas plásticas no caso de rocha sedimentar e $\mathrm{k}_{\mathrm{o}}=4,0$ (Figura 5.20) tem características que possuem uma certa discrepância do comportamento proposto por Hoek et al. (1995) apresentado no Capítulo 3. Nestes casos, as regiões plásticas adquirem um formato irregular e tendem a se afastar da parede do túnel adquirindo valores elevadíssimos.

Com os valores dos indicadores de desempenho para um túnel em rocha sedimentar, $\operatorname{com} \mathrm{k}_{\mathrm{o}}=$ 4,0, apresentados na Tabela 5.8 e os gráficos da Figura 5.21, foi possível obter os indicadores de falha de $415 \%$ para a área plástica (Figura 5.21 a) e de 1,6\% para a convergência (Figura $5.21 \mathrm{~b})$.

Percebe-se que o indicador de falha para a porcentagem de zona plástica é altíssimo, ou seja, para que se possa dizer que ocorreu falha neste túnel devido à quantidade de área plástica, é preciso que ocorra plastificação numa área que equivalha a $415 \%$ da área do túnel.

Pela Tabela 5.8 é possível notar também que os valores dos indicadores área plástica e convergência tem valores mais altos quando os parâmetros resistência do maciço, $\sigma_{\mathrm{c}}$, e módulo de elasticidade do maciço, $\mathrm{E}_{\mathrm{m}}$, são mais baixos devido ao grau de fraturamento do maciço. 

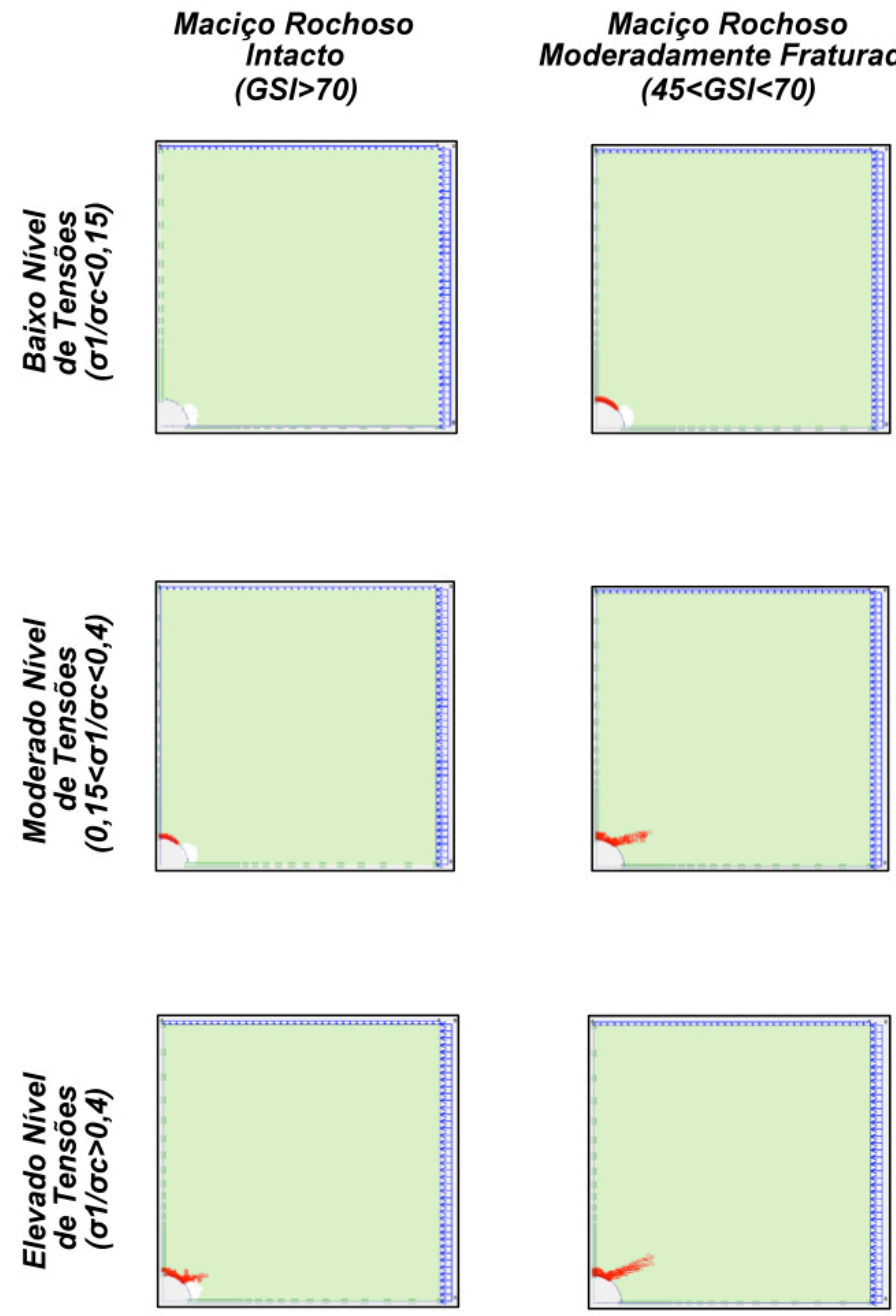
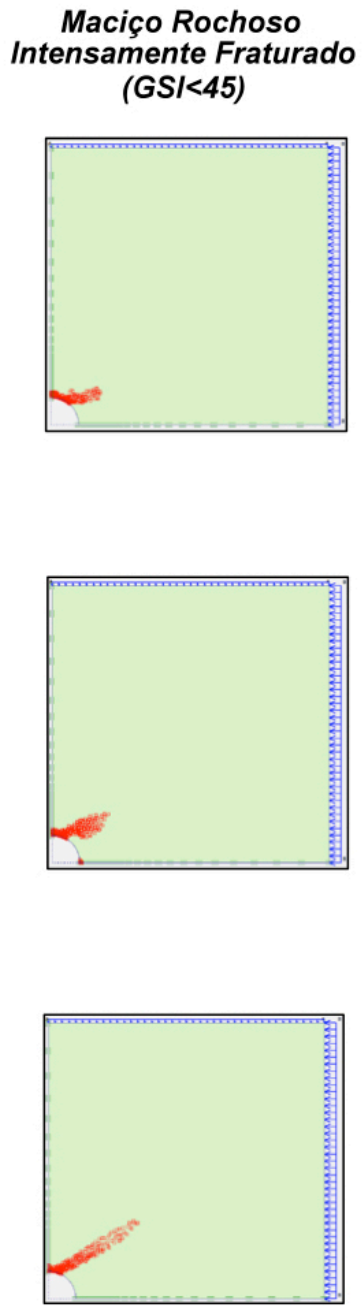

Figura 5.20 - Resultados das zonas plásticas - Rocha sedimentar, $\mathrm{k}_{\mathrm{o}}=4,0$.

\subsection{RESULTADOS DAS ANÁLISES PROBABILÍSTICAS}

A etapa da análise probabilística foi feita pelo método de Rosenblueth (Point Estimate Method), com a variação dos parâmetros $\mathrm{k}_{\mathrm{o}}$, c' e $\phi^{\prime}$, onde o caso + representa o parâmetro adicionado do desvio padrão e -, o parâmetro subtraído do desvio padrão.

O dados de saída utilizados foram o fator de segurança (FS), área plástica (Ap) e convergência (U). A partir da média e desvio destes indicadores e aplicando uma distribuição estatística aos mesmos foi possível obter a probabilidade de falha.

Foi feita uma análise mais completa e detalhada do caso de rocha metamórfica e $\mathrm{k}_{\mathrm{o}}=0,5 \mathrm{e}$, para que não ficasse repetitivo, apenas comparou-se o caso de elevado nível de tensões e maciço rochoso moderadamente fraturado dos demais $k_{\mathrm{o}}$ 's. 
Tabela 5.8 - Valores dos indicadores de desempenho - Rocha sedimentar, $\mathrm{k}_{\mathrm{o}}=4,0$.

\begin{tabular}{|c|c|c|c|c|}
\hline & & $\begin{array}{c}\text { Maciço } \\
\text { Rochoso } \\
\text { Intacto } \\
(\text { GSI }>70) \\
\end{array}$ & $\begin{array}{c}\text { Maciço Rochoso } \\
\text { Moderadamente } \\
\text { Fraturado } \\
(45<\text { GSI }<70) \\
\end{array}$ & $\begin{array}{c}\text { Maciço } \\
\text { Rochoso } \\
\text { Intensamente } \\
\text { Fraturado } \\
(\mathbf{G S I}<\mathbf{4 5}) \\
\end{array}$ \\
\hline \multirow{5}{*}{$\begin{array}{c}\text { Baixo Nível de } \\
\text { Tensões } \\
\left(\sigma_{1} / \sigma_{\mathrm{c}}<\mathbf{0 , 1 5}\right)\end{array}$} & $\operatorname{Ap}\left(m^{2}\right)$ & 0,0 & 5,7 & 239,9 \\
\hline & Ap $(\%)$ & $0 \%$ & $7 \%$ & $305 \%$ \\
\hline & FS & 3,3 & 1,7 & 1,1 \\
\hline & $\mathrm{U}(\mathrm{m})$ & 0,007 & 0,014 & 0,071 \\
\hline & $\mathrm{U}(\%)$ & $0,15 \%$ & $0,27 \%$ & $1,42 \%$ \\
\hline \multirow{5}{*}{$\begin{array}{c}\text { Moderado Nível } \\
\text { de Tensões } \\
\left(0,15<\sigma_{1} / \sigma_{c}<0,4\right)\end{array}$} & $\operatorname{Ap}\left(m^{2}\right)$ & 3,9 & 175,1 & 888,0 \\
\hline & Ap $(\%)$ & $5 \%$ & $223 \%$ & $1131 \%$ \\
\hline & $\mathrm{FS}$ & 1,8 & 1,2 & 0,7 \\
\hline & $\mathrm{U}(\mathrm{m})$ & 0,023 & 0,048 & 0,220 \\
\hline & U (\%) & $0,45 \%$ & $0,95 \%$ & $4,40 \%$ \\
\hline \multirow{5}{*}{$\begin{array}{c}\text { Elevado Nível de } \\
\text { Tensões } \\
\left(\sigma_{1} / \sigma_{c}>0,4\right)\end{array}$} & $\operatorname{Ap}\left(m^{2}\right)$ & 21,9 & 326,1 & 1298,0 \\
\hline & $\operatorname{Ap}(\%)$ & $28 \%$ & $415 \%$ & $1653 \%$ \\
\hline & $\mathrm{FS}$ & 1,5 & 1,0 & 0,6 \\
\hline & $\mathrm{U}(\mathrm{m})$ & 0,040 & 0,081 & 0,445 \\
\hline & U (\%) & $0,79 \%$ & $1,62 \%$ & $8,89 \%$ \\
\hline
\end{tabular}

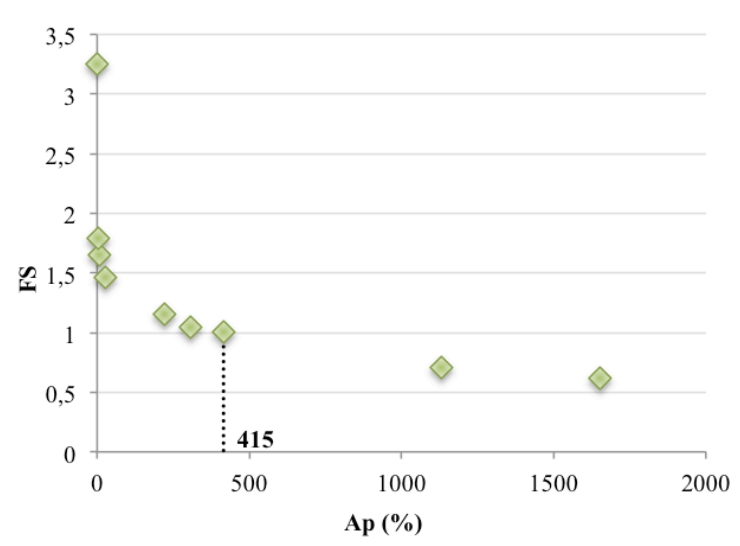

a)

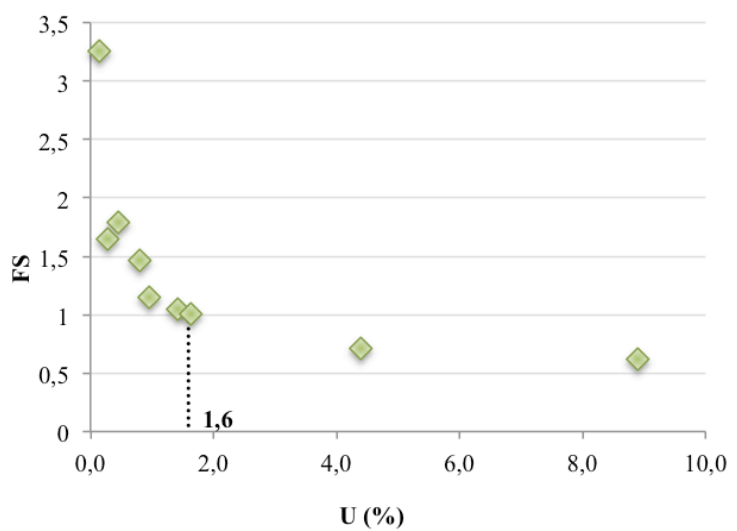

b)

Figura 5.21 - Relação entre os indicadores de desempenho: a) FS x Ap (\%); b) FS x U (\%) Rocha sedimentar, $\mathrm{k}_{\mathrm{o}}=4,0$.

\subsubsection{PROBABILIDADES DE FALHA PARA O CASO DE ROCHA METAMÓRFICA E $\mathrm{K}_{\mathrm{O}}=\mathbf{0 , 5}$}

A seguir são apresentados os resultados para o caso de rocha metamórfica e $\mathrm{k}_{\mathrm{o}}=0,5$, os demais resultados, para a rocha metamórfica e rocha sedimentar, estão apresentados no 
Apêndice B desta dissertação.

As probabilidade foram calculadas para três níveis de tensões (baixo, moderado e elevado) de acordo com a relação entre a tensão principal maior $\left(\sigma_{1}\right)$ e a resistência à compressão uniaxial do maciço rochoso $\left(\sigma_{\mathrm{c}}\right)$, apresentados na Figura 3.4 do Capítulo 3.

Para cada nível de tensões, modificou-se as características de resistência do maciço rochoso por meio do GSI, também de acordo com os modos de falha propostos da Figura 3.4.

\subsubsection{Baixo Nível de Tensões}

Para o caso de baixo nível de tensões, são apresentados apenas os resultados para o caso de um maciço rochoso intensamente fraturado.

\subsection{Maciço Rochoso Intensamente Fraturado}

Com os dados de saída para cada um dos oito casos apresentados na Tabela 5.9, foi possível plotar as curvas de distribuição estatística para o fator de segurança, área plástica e convergência (Figura 5.22).

A partir destas distribuições nota-se que mesmo com uma média dentro dos limites aceitáveis, ainda é possível ter uma alta probabilidade de falha. No caso do fator de segurança, a média é de FS $=2,6$, que é considerada alta mas, quando se analisa a probabilidade do fator de segurança ser menor que 1, depara-se com uma probabilidade de 0,9\%, ou seja, aproximadamente 1 em cada 100 tem a chance de ter FS $\leq 1$ (Figura 5.22 a).

A média da convergência do túnel foi de $0,51 \%$ do raio, um valor abaixo do indicador de falha, que foi de $0,6 \%$. Contudo, a probabilidade de $U \geq 0,6 \%$ é de 3,5\% (Figura 5.22 b).

Outro indicador de desempenho analisado foi a porcentagem de área plástica em relação à área do túnel (Figura 5.22 c). Este indicador teve uma média de 21,41\%, ou seja, deterministicamente falando, 21,41\% do túnel plastifica. Mas, ao considerar a variabilidade dos parâmetros existe uma probabilidade de $27 \%$ de que a porcentagem de área plástica seja superior a $25 \%$ (valor limite encontrado).

Ao se comparar os resultado das probabilidades de falha para os três indicadores percebe-se, no caso de baixo nível de tensões e maciço rochoso intensamente fraturado (Figura 5.22), que a probabilidade de falha do indicador de desempenho área plástica (Ap) tem uma certa discrepância com as probabilidades dos demais indicadores. Mostrando que o programa 
PLAXIS não simulou bem o comportamento para baixo nível de tensões.

Tabela 5.9 - Resultados obtidos com o método dos pontos de estimativa (Rosenblueth) Rocha metamórfica, $\mathrm{k}_{\mathrm{o}}=0,5$, baixo nível de tensões, maciço rochoso intensamente fraturado.

\begin{tabular}{|c|c|c|c|c|c|c|c|c|c|}
\hline \multirow{2}{*}{$\begin{array}{l}\text { PEM } \\
\text { Caso }\end{array}$} & \multicolumn{3}{|c|}{ Dados de Entrada } & & \multicolumn{5}{|c|}{ Dados de Saída } \\
\hline & $\mathbf{k}_{\mathbf{0}}$ & $\mathrm{c}^{\prime}(\mathrm{MPa})$ & $\phi^{\prime}$ & & FS & $\operatorname{Ap}\left(m^{2}\right)$ & Ap (\%) & $\mathrm{U}(\mathrm{m})$ & U (\%) \\
\hline$+\quad+\quad+$ & 0,625 & 5,03 & 53,7 & & 3,8 & 2,17 & $2,76 \%$ & 0,0224 & $0,45 \%$ \\
\hline$+\quad+\quad-$ & 0,625 & 5,03 & 43,9 & & 3,1 & 9,80 & $12,48 \%$ & 0,0231 & $0,46 \%$ \\
\hline$+\quad-\quad+$ & 0,625 & 2,15 & 53,7 & & 3,0 & 14,84 & $18,89 \%$ & 0,0242 & $0,48 \%$ \\
\hline$+\quad-\quad-$ & 0,625 & 2,15 & 43,9 & & 2,3 & 35,05 & $44,62 \%$ & 0,0271 & $0,54 \%$ \\
\hline$-\quad+\quad+$ & 0,375 & 5,03 & 53,7 & & 2,7 & 2,84 & $3,62 \%$ & 0,0253 & $0,51 \%$ \\
\hline$-\quad+\quad-$ & 0,375 & 5,03 & 43,9 & & 2,1 & 8,03 & $10,23 \%$ & 0,0262 & $0,52 \%$ \\
\hline$-\quad-\quad+$ & 0,375 & 2,15 & 53,7 & & 2,0 & 11,56 & $14,72 \%$ & 0,0271 & $0,54 \%$ \\
\hline$-\quad-\quad-$ & 0,375 & 2,15 & 43,9 & & 1,6 & 50,25 & $63,98 \%$ & 0,0302 & $0,60 \%$ \\
\hline & & & & $\sigma$ & $\begin{array}{l}2,6 \\
0,7\end{array}$ & & $\begin{array}{l}21,41 \% \\
20,22 \%\end{array}$ & & $\begin{array}{l}0,51 \% \\
0,05 \%\end{array}$ \\
\hline
\end{tabular}

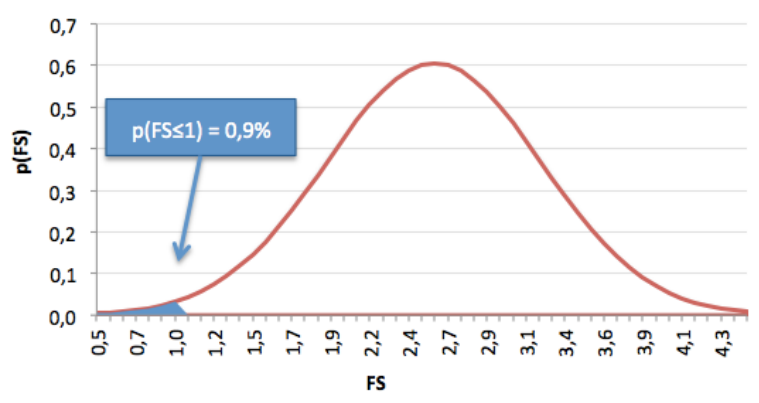

a)

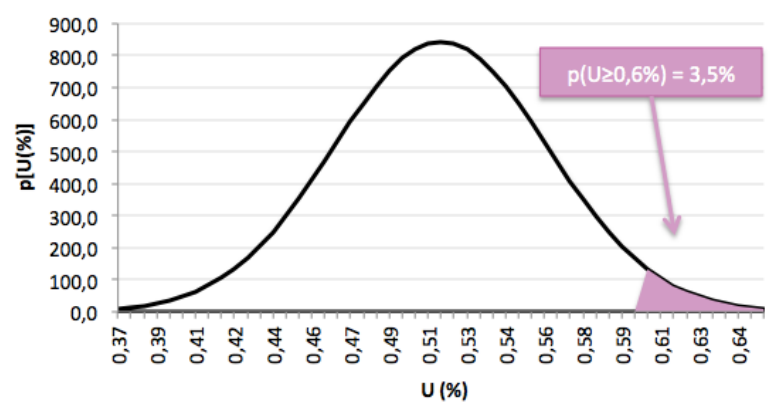

b)

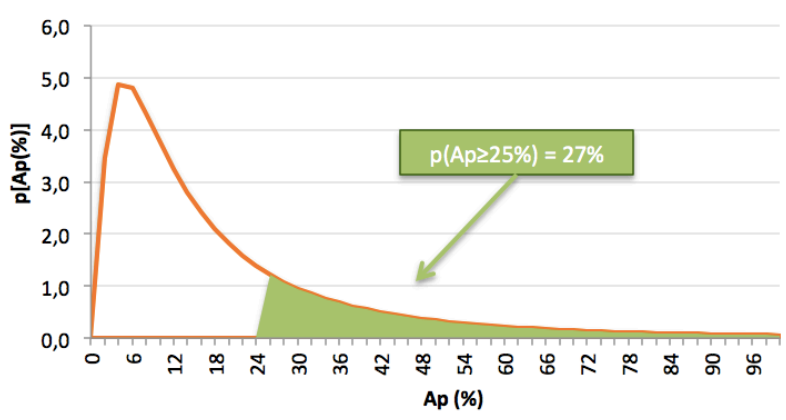

c)

Figura 5.22 - Frequência de ocorrência e probabilidade de falha: a) Fator de Segurança (FS);

b) Convergência (U); c) Área Plástica (Ap) - Rocha metamórfica, $\mathrm{k}_{\mathrm{o}}=0,5$, baixo nível de tensões, maciço rochoso intensamente fraturado.

\subsubsection{Moderado Nível de Tensões}

Para o caso de moderado nível de tensões, analisou-se os resultados para os casos de maciços 
rochosos moderadamente e intensamente fraturado.

\subsection{Maciço Rochoso Moderadamente Fraturado}

Para o caso de rocha metamórfica, $\mathrm{k}_{\mathrm{o}}=0,5$, tensões moderadas e maciço moderadamente fraturado (Figura 5.23), a probabilidade do fator de segurança ser menor que 1 é de 0,8\% (Figura 5.23 a), da convergência ser maior que $0,6 \%$ é de $0 \%$ (Figura 5.23 b) e da área plástica ser acima de $25 \%$ é de $30 \%$ (Figura 5.23 c). Mostrando novamente que a média (Tabela 5.10) não diz tudo sobre o comportamento, fazendo-se necessária uma análise probabilística do problema.

Assim como no caso de baixo nível de tensões, para moderado nível de tensões e maciço rochoso moderadamente fraturado (Figura 5.23), a probabilidade de falha para o indicador área plástica foi bem acima das probabilidades de falha dos indicadores fator de segurança e convergência.

Tabela 5.10 - Resultados obtidos com o método dos pontos de estimativa (Rosenblueth) -

Rocha metamórfica, $\mathrm{k}_{\mathrm{o}}=0,5$, moderado nível de tensões, maciço rochoso moderadamente fraturado.

\begin{tabular}{|c|c|c|c|c|c|c|c|c|c|}
\hline \multirow{2}{*}{$\begin{array}{l}\text { PEM } \\
\text { Caso }\end{array}$} & \multicolumn{3}{|c|}{ Dados de Entrada } & & \multicolumn{5}{|c|}{ Dados de Saída } \\
\hline & $\mathbf{k}_{\mathbf{0}}$ & $\mathrm{c}^{\prime}$ (MPa) & $\phi^{\prime}$ & & FS & $\operatorname{Ap}\left(\mathrm{m}^{2}\right)$ & Ap (\%) & $\mathbf{U}(\mathrm{m})$ & $\mathrm{U}(\%)$ \\
\hline$+\quad+\quad+$ & 0,625 & 15,10 & 52,4 & & 3,7 & 2,44 & $3,10 \%$ & 0,0147 & $0,29 \%$ \\
\hline$+\quad+\quad-$ & 0,625 & 15,10 & 42,9 & & 3,0 & 10,09 & $12,85 \%$ & 0,0152 & $0,30 \%$ \\
\hline$+\quad-\quad+$ & 0,625 & 6,47 & 52,4 & & 2,9 & 16,99 & $21,63 \%$ & 0,0159 & $0,32 \%$ \\
\hline$+\quad-\quad-$ & 0,625 & 6,47 & 42,9 & & 2,3 & 39,61 & $50,43 \%$ & 0,0180 & $0,36 \%$ \\
\hline$-\quad+\quad+$ & 0,375 & 15,10 & 52,4 & & 2,6 & 3,14 & $4,00 \%$ & 0,0166 & $0,33 \%$ \\
\hline$-\quad+\quad-$ & 0,375 & 15,10 & 42,9 & & 2,1 & 8,85 & $11,27 \%$ & 0,0172 & $0,34 \%$ \\
\hline$-\quad-\quad+$ & 0,375 & 6,47 & 52,4 & & 2,0 & 13,24 & $16,86 \%$ & 0,0179 & $0,36 \%$ \\
\hline$-\quad-$ & 0,375 & 6,47 & 42,9 & & 1,6 & 55,72 & $70,94 \%$ & 0,0201 & $0,40 \%$ \\
\hline & & & & $\begin{array}{l}\boldsymbol{\mu} \\
\boldsymbol{\sigma}\end{array}$ & $\begin{array}{l}2,5 \\
0,6\end{array}$ & & $\begin{array}{l}23,89 \% \\
22,59 \%\end{array}$ & & $\begin{array}{l}0,34 \% \\
0,03 \%\end{array}$ \\
\hline
\end{tabular}

\subsection{Maciço Rochoso Intensamente Fraturado}

Neste caso com maciço rochoso intensamente fraturado, as probabilidades de falha já aumentam (Figura 5.24): a probabilidade do fator de segurança ser menor que 1 é de 2,7\% (Figura 5.24 a), enquanto que da convergência ser maior que 0,6\% é de 99,96\% (Figura 5.24 b). A média da convergência já era acima do limite (Tabela 5.11), portanto na análise 
determinística já se indicaria falha, mas, ainda assim percebe-se a importância de uma abordagem probabilística, pois é quase $100 \%$ de chance de ocorrer.

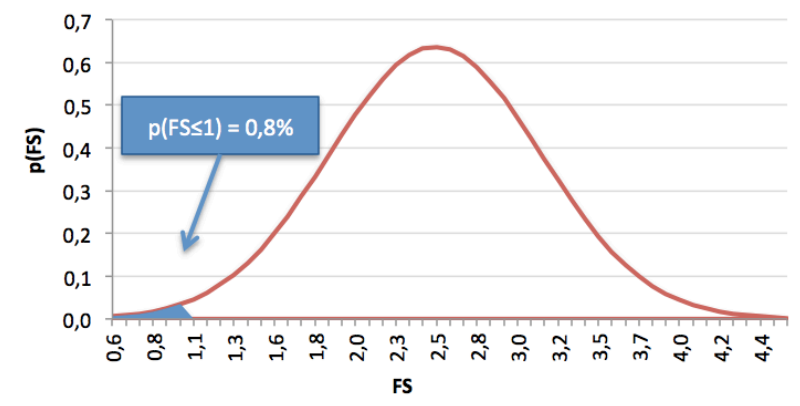

a)

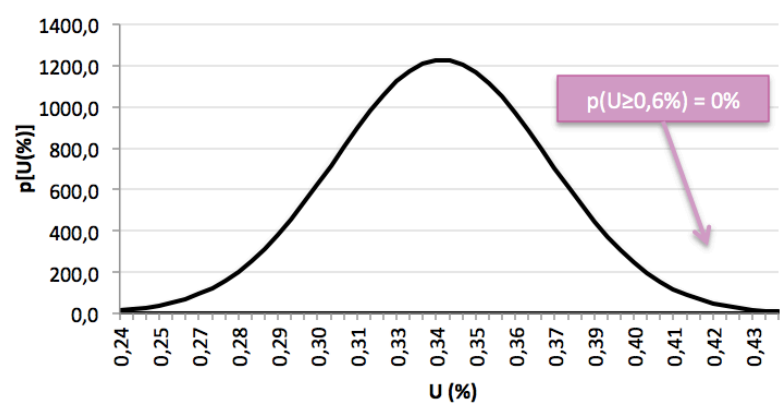

b)

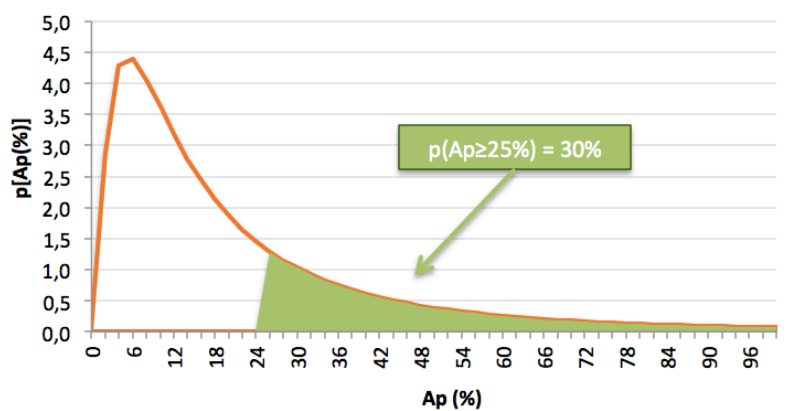

c)

Figura 5.23 - Frequência de ocorrência e probabilidade de falha: a) Fator de Segurança (FS);

b) Convergência (U); c) Área Plástica (Ap) - Rocha metamórfica, $\mathrm{k}_{\mathrm{o}}=0,5$, moderado nível de tensões, maciço rochoso moderadamente fraturado.

Tabela 5.11 - Resultados obtidos com o método dos pontos de estimativa (Rosenblueth) -

Rocha metamórfica, $\mathrm{k}_{\mathrm{o}}=0,5$, moderado nível de tensões, maciço rochoso intensamente fraturado.

\begin{tabular}{|c|c|c|c|c|c|c|c|c|c|}
\hline \multirow{2}{*}{$\begin{array}{l}\text { PEM } \\
\text { Caso }\end{array}$} & \multicolumn{3}{|c|}{ Dados de Entrada } & & \multicolumn{5}{|c|}{ Dados de Saída } \\
\hline & $\mathbf{k}_{\mathbf{0}}$ & $\mathbf{c}^{\prime}$ (MPa) & $\phi^{\prime}$ & & FS & $\operatorname{Ap}\left(m^{2}\right)$ & Ap (\%) & $\mathrm{U}(\mathrm{m})$ & $\mathrm{U}(\%)$ \\
\hline$+\quad+\quad+$ & 0,625 & 10,39 & 44,5 & & 2,7 & 16,71 & $21,28 \%$ & 0,0725 & $1,45 \%$ \\
\hline$+\quad+\quad-$ & 0,625 & 10,39 & 36,4 & & 2,3 & 34,02 & $43,32 \%$ & 0,0795 & $1,59 \%$ \\
\hline$+\quad-\quad+$ & 0,625 & 4,45 & 44,5 & & 2,1 & 51,26 & $65,27 \%$ & 0,0892 & $1,78 \%$ \\
\hline$+\quad-\quad-$ & 0,625 & 4,45 & 36,4 & & 1,7 & 103,51 & $131,79 \%$ & 0,1082 & $2,16 \%$ \\
\hline$-\quad+\quad+$ & 0,375 & 10,39 & 44,5 & & 1,9 & 14,28 & $18,19 \%$ & 0,0818 & $1,64 \%$ \\
\hline$-\quad+\quad-$ & 0,375 & 10,39 & 36,4 & & 1,6 & 45,74 & $58,24 \%$ & 0,0891 & $1,78 \%$ \\
\hline$-\quad-\quad+$ & 0,375 & 4,45 & 44,5 & & 1,4 & 50,91 & $64,82 \%$ & 0,1028 & $2,06 \%$ \\
\hline$-\quad-\quad-$ & 0,375 & 4,45 & 36,4 & & 1,2 & 144,30 & $183,73 \%$ & 0,1378 & $2,76 \%$ \\
\hline & & & & $\begin{array}{l}\boldsymbol{\mu} \\
\boldsymbol{\sigma}\end{array}$ & $\begin{array}{l}1,9 \\
0,5\end{array}$ & & $\begin{array}{l}73,33 \% \\
53,18 \%\end{array}$ & & $\begin{array}{l}1,90 \% \\
0,39 \%\end{array}$ \\
\hline
\end{tabular}


Esta mesma situação ocorre para a área plástica, em que a probabilidade de ser acima de $25 \%$ é de $86 \%$ (Figura 5.24 c).

Ao aumentar o grau de fraturamento, ou seja, moderado nível de tensões e maciço rochoso intensamente fraturado (Figura 5.24), já é possível notar que, embora o valor seja conservador, as probabilidades de falha dos indicadores convergência e área plástica deram resultados da mesma ordem de grandeza. Isso mostra que estes são bons indicadores, falta apenas calibrar o valor limite.

Percebe-se, porém, que o indicador fator de segurança obteve um valor de probabilidade de falha bem abaixo dos demais. Uma possível explicação para esse fato é que o indicador área plástica está relacionado à ruptura, enquanto os demais indicadores dizem respeito ao comportamento do túnel.

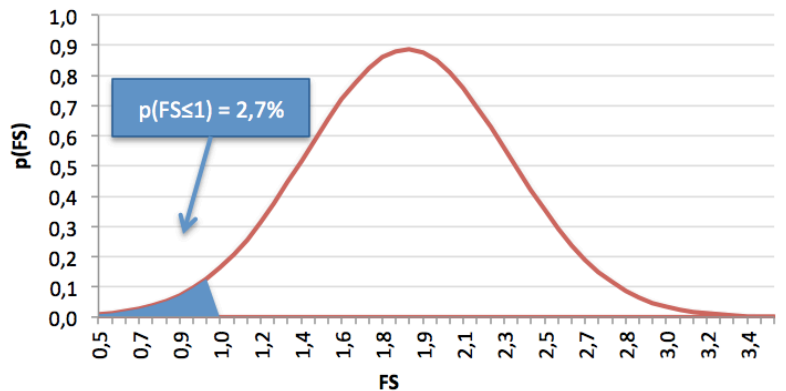

a)

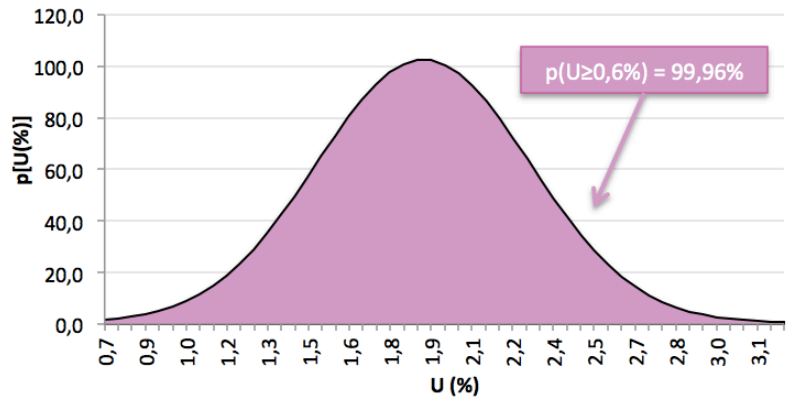

b)

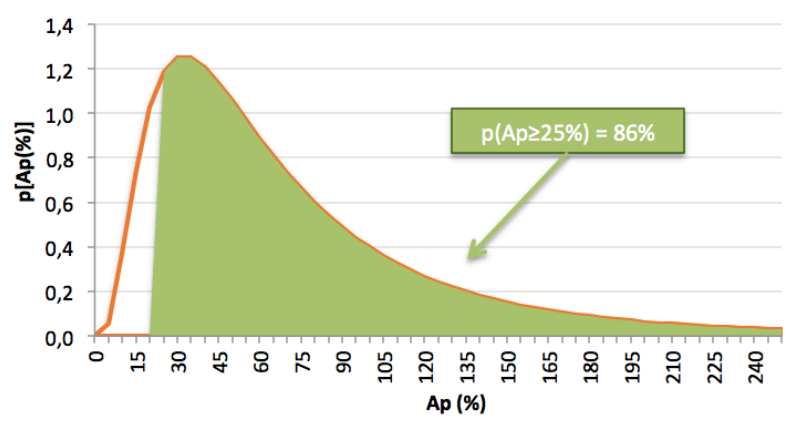

c)

Figura 5.24 - Frequência de ocorrência e probabilidade de falha: a) Fator de Segurança (FS);

b) Convergência $(\mathrm{U})$; c) Área Plástica (Ap) - Rocha metamórfica, $\mathrm{k}_{\mathrm{o}}=0,5$, moderado nível de tensões, maciço rochoso intensamente fraturado.

\subsubsection{Elevado Nível de Tensões}

Já no caso de elevado nível de tensões, foi possível analisar os três graus de faturamento (maciço rochoso intacto, moderadamente fraturado e intensamente fraturado). 


\subsection{Maciço Rochoso Intacto}

Com os dados de saída para cada um dos oito casos apresentados na Tabela 5.12, foi possível plotar as curvas de distribuição estatística para o fator de segurança, área plástica e convergência (Figura 5.25).

Tabela 5.12 - Resultados obtidos com o método dos pontos de estimativa (Rosenblueth) -

Rocha metamórfica, $\mathrm{k}_{\mathrm{o}}=0,5$, elevado nível de tensões, maciço rochoso intacto.

\begin{tabular}{|c|c|c|c|c|c|c|c|c|c|}
\hline \multirow{2}{*}{$\begin{array}{l}\text { PEM } \\
\text { Caso }\end{array}$} & \multicolumn{3}{|c|}{ Dados de Entrada } & & \multicolumn{5}{|c|}{ Dados de Saída } \\
\hline & $\mathbf{k}_{\mathbf{0}}$ & $\mathrm{c}^{\prime}$ (MPa) & $\phi^{\prime}$ & & FS & $\operatorname{Ap}\left(m^{2}\right)$ & Ap (\%) & $\mathbf{U}(\mathbf{m})$ & $\mathrm{U}(\%)$ \\
\hline$+\quad+\quad+$ & 0,625 & 31,74 & 55,5 & & 4,3 & 0,20 & $0,26 \%$ & 0,0136 & $0,27 \%$ \\
\hline$+\quad+\quad-$ & 0,625 & 31,74 & 45,4 & & 3,5 & 3,89 & $4,95 \%$ & 0,0137 & $0,27 \%$ \\
\hline$+\quad-\quad+$ & 0,625 & 13,60 & 55,5 & & 3,4 & 8,62 & $10,98 \%$ & 0,0141 & $0,28 \%$ \\
\hline$+\quad-\quad-$ & 0,625 & 13,60 & 45,4 & & 2,6 & 23,51 & $29,93 \%$ & 0,0154 & $0,31 \%$ \\
\hline$-\quad+\quad+$ & 0,375 & 31,74 & 55,5 & & 3,0 & 0,86 & $1,10 \%$ & 0,0154 & $0,31 \%$ \\
\hline$-\quad+\quad-$ & 0,375 & 31,74 & 45,4 & & 2,4 & 4,08 & $5,20 \%$ & 0,0156 & $0,31 \%$ \\
\hline$-\quad-\quad+$ & 0,375 & 13,60 & 55,5 & & 2,3 & 7,85 & $10,00 \%$ & 0,0160 & $0,32 \%$ \\
\hline$-\quad-\quad-$ & 0,375 & 13,60 & 45,4 & & 1,8 & 18,87 & $24,02 \%$ & 0,0172 & $0,34 \%$ \\
\hline & & & & $\begin{array}{l}\mu \\
\sigma\end{array}$ & $\begin{array}{l}2,9 \\
0,7\end{array}$ & & $\begin{array}{l}10,80 \% \\
10,08 \%\end{array}$ & & $\begin{array}{l}0,30 \% \\
0,02 \%\end{array}$ \\
\hline
\end{tabular}

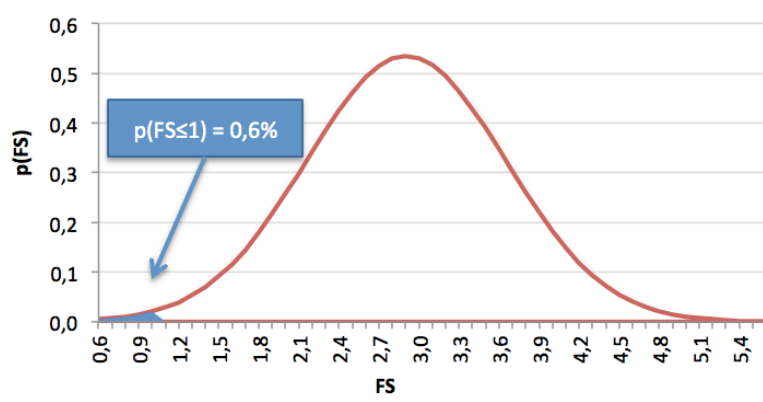

a)

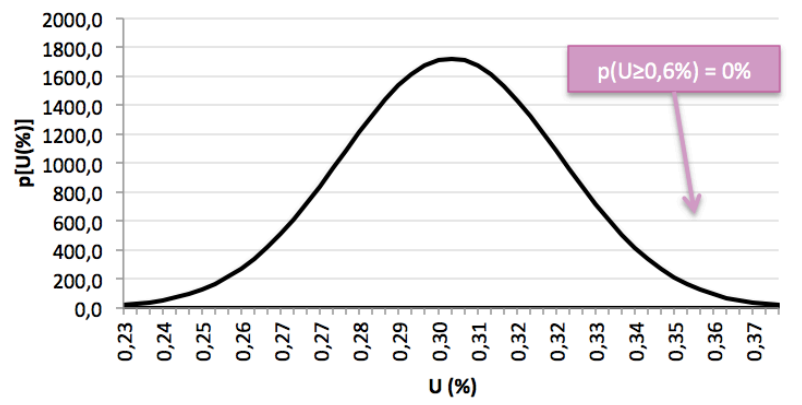

b)

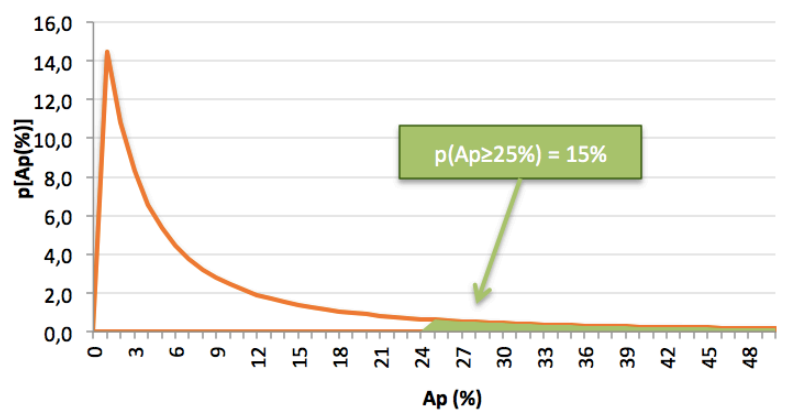

c)

Figura 5.25 - Frequência de ocorrência e probabilidade de falha: a) Fator de Segurança (FS); b) Convergência (U); c) Área Plástica (Ap) - Rocha metamórfica, $\mathrm{k}_{\mathrm{o}}=0$,5, elevado nível de tensões, maciço rochoso intacto. 
Para o caso de rocha metamórfica, $\mathrm{k}_{\mathrm{o}}=0,5$, elevado nível de tensões e maciço intacto, $\mathrm{a}$ probabilidade do fator de segurança ser menor que 1 é de $0,6 \%$ (Figura 5.25 a), da convergência ser maior que $0,6 \%$ é de $0 \%$ (Figura 5.25 b) e da área plástica ser acima de $25 \%$ é de $15 \%$ (Figura 5.25 c). Nota-se que para o caso de maciço intacto, as probabilidades de falha são menores.

Ao comparar os três indicadores, para elevado nível de tensões e maciço rochoso intacto (Figura 5.25), a probabilidade de falha para o indicador área plástica não está na mesma ordem de grandeza das probabilidades de falha dos demais indicadores.

Nota-se, então, que para maciços pouco fraturados, mesmo com elevado nível de tensões, o indicador área plástica não fornece bons resultados.

\subsection{Maciço Rochoso Moderadamente Fraturado}

Com os dados da Tabela 5.13, plotou-se as curvas de distribuição estatística na Figura 5.26. E foi possível perceber que quando se aumenta o grau de fraturamento, ou seja, um maciço moderadamente fraturado, as probabilidades de falha sofrem um aumento significativo. Neste caso, a probabilidade do fator de segurança ser menor que 1 é de 1,7\% (Figura 5.26 a), da convergência ser maior que $0,6 \%$ é de $55 \%$ (Figura 5.26 b) e da área plástica ser acima de $25 \%$ é de $61 \%$ (Figura 5.26 c).

Tabela 5.13 - Resultados obtidos com o método dos pontos de estimativa (Rosenblueth) -

Rocha metamórfica, $\mathrm{k}_{\mathrm{o}}=0,5$, elevado nível de tensões, maciço rochoso moderadamente fraturado.

\begin{tabular}{|c|c|c|c|c|c|c|c|c|c|}
\hline \multirow{2}{*}{$\begin{array}{l}\text { PEM } \\
\text { Caso }\end{array}$} & \multicolumn{3}{|c|}{ Dados de Entrada } & & \multicolumn{5}{|c|}{ Dados de Saída } \\
\hline & $\mathbf{k}_{\mathbf{0}}$ & $\mathrm{c}^{\prime}(\mathrm{MPa})$ & $\phi^{\prime}$ & & FS & $\operatorname{Ap}\left(m^{2}\right)$ & Ap (\%) & $\mathbf{U}(\mathbf{m})$ & $\mathbf{U}(\%)$ \\
\hline$+\quad+\quad+$ & 0,625 & 20,91 & 48,1 & & 3,1 & 8,42 & $10,72 \%$ & 0,0251 & $0,50 \%$ \\
\hline$+\quad+\quad-$ & 0,625 & 20,91 & 39,3 & & 2,6 & 20,03 & $25,51 \%$ & 0,0267 & $0,53 \%$ \\
\hline$+\quad-\quad+$ & 0,625 & 8,96 & 48,1 & & 2,5 & 30,41 & $38,72 \%$ & 0,0290 & $0,58 \%$ \\
\hline$+\quad-\quad-$ & 0,625 & 8,96 & 39,3 & & 2,0 & 62,34 & $79,37 \%$ & 0,0340 & $0,68 \%$ \\
\hline$-\quad+\quad+$ & 0,375 & 20,91 & 48,1 & & 2,2 & 7,85 & $10,00 \%$ & 0,0285 & $0,57 \%$ \\
\hline$-\quad+\quad-$ & 0,375 & 20,91 & 39,3 & & 1,8 & 16,25 & $20,68 \%$ & 0,0301 & $0,60 \%$ \\
\hline$-\quad-\quad+$ & 0,375 & 8,96 & 48,1 & & 1,7 & 38,15 & $48,57 \%$ & 0,0321 & $0,64 \%$ \\
\hline$-\quad-\quad-$ & 0,375 & 8,96 & 39,3 & & 1,3 & 91,81 & $116,89 \%$ & 0,0387 & $0,77 \%$ \\
\hline & & & & $\begin{array}{l}\boldsymbol{\mu} \\
\sigma\end{array}$ & $\begin{array}{l}2,2 \\
0,5\end{array}$ & & $\begin{array}{l}43,81 \% \\
34,93 \%\end{array}$ & & $\begin{array}{l}0,61 \% \\
0,08 \%\end{array}$ \\
\hline
\end{tabular}

Para um maior grau de fraturamento, ou seja, elevado nível de tensões e maciço rochoso 
moderadamente fraturado (Figura 5.26), obteve também resultados da mesma ordem de grandeza para as probabilidades de falha dos indicadores convergência e área plástica e um valor abaixo para o indicador fator de segurança.

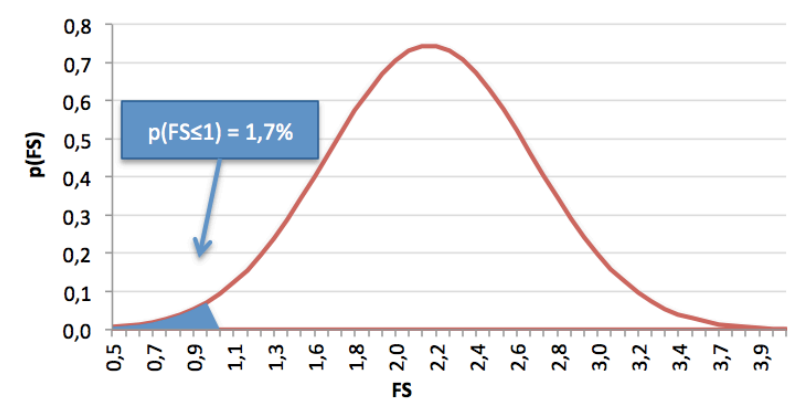

a)

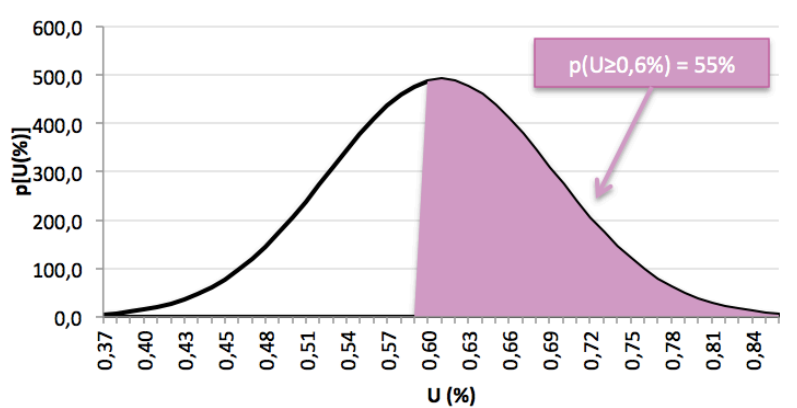

b)

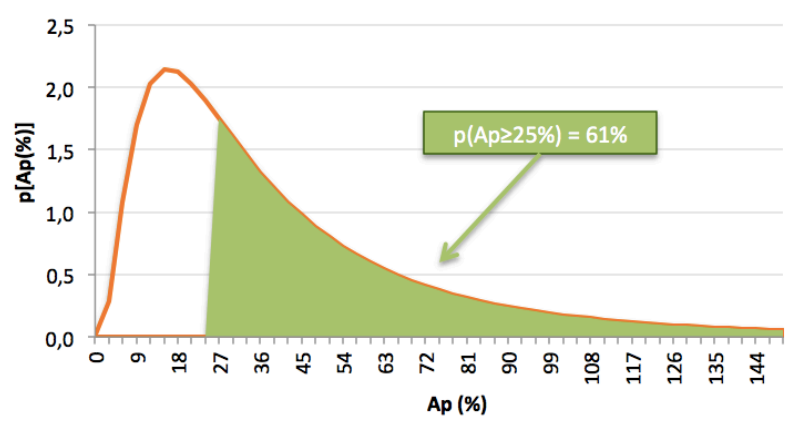

c)

Figura 5.26 - Frequência de ocorrência e probabilidade de falha: a) Fator de Segurança (FS); b) Convergência (U); c) Área Plástica (Ap) - Rocha metamórfica, $\mathrm{k}_{\mathrm{o}}=0$,5, elevado nível de tensões, maciço rochoso moderadamente fraturado.

\subsection{Maciço Rochoso Intensamente Fraturado}

Com as curvas de distribuição estatística Figura 5.27 plotadas a partir dos dados da Tabela 5.14, percebe-se que aumentando-se ainda mais o grau de faturamento para um maciço intensamente fraturado, as probabilidades de falha se elevam consideravelmente. Assim, a probabilidade do fator de segurança ser menor que 1 chega a 5,9\% (Figura 5.27 a), da convergência ser maior que $0,6 \%$ a 99,93\% (Figura 5.27 b) e da área plástica ser acima de $25 \%$ a $97 \%$ (Figura 5.27 c).

Aumentando ainda mais grau de fraturamento, ou seja, elevado nível de tensões e maciço rochoso intensamente fraturado (Figura 5.27), obteve-se também resultados da mesma ordem de grandeza para as probabilidades de falha dos indicadores convergência e área plástica.

O valor de probabilidade de falha obtido para o indicador fator de segurança é bem abaixo 
dos demais, mas é considerado um valor alto para ruptura. Então, ao analisar os valores, os valores elevados obtidos para os indicadores de comportamento podem ser plausíveis já que com antes de ocorrer a ruptura ocorrem os sinais de comportamento inadequado.

Tabela 5.14 - Resultados obtidos com o método dos pontos de estimativa (Rosenblueth) -

Rocha metamórfica, $\mathrm{k}_{\mathrm{o}}=0,5$, elevado nível de tensões, maciço rochoso intensamente fraturado.

\begin{tabular}{|c|c|c|c|c|c|c|c|c|c|}
\hline \multirow{2}{*}{$\begin{array}{l}\text { PEM } \\
\text { Caso }\end{array}$} & \multicolumn{3}{|c|}{ Dados de Entrada } & & \multicolumn{5}{|c|}{ Dados de Saída } \\
\hline & $\mathbf{k}_{\mathbf{0}}$ & $\mathbf{c}^{\prime}(\mathrm{MPa})$ & $\phi^{\prime}$ & & FS & $\operatorname{Ap}\left(m^{2}\right)$ & Ap (\%) & $\mathbf{U}(\mathbf{m})$ & U (\%) \\
\hline$+\quad+\quad+$ & 0,625 & 14,52 & 40,1 & & 2,3 & 30,86 & $39,29 \%$ & 0,1325 & $2,65 \%$ \\
\hline$+\quad+\quad-$ & 0,625 & 14,52 & 32,8 & & 1,9 & 53,49 & $68,11 \%$ & 0,1494 & $2,99 \%$ \\
\hline$+\quad-\quad+$ & 0,625 & 6,22 & 40,1 & & 1,8 & 88,98 & $113,30 \%$ & 0,1737 & $3,47 \%$ \\
\hline$+\quad-\quad-$ & 0,625 & 6,22 & 32,8 & & 1,5 & 164,41 & $209,33 \%$ & 0,2659 & $5,32 \%$ \\
\hline$-\quad+\quad+$ & 0,375 & 14,52 & 40,1 & & 1,6 & 40,28 & $51,29 \%$ & 0,1481 & $2,96 \%$ \\
\hline$-\quad+\quad-$ & 0,375 & 14,52 & 32,8 & & 1,4 & 109,89 & $139,92 \%$ & 0,1708 & $3,42 \%$ \\
\hline$-\quad-\quad+$ & 0,375 & 6,22 & 40,1 & & 1,2 & 118,14 & $150,42 \%$ & 0,2087 & $4,17 \%$ \\
\hline$-\quad-\quad-$ & 0,375 & 6,22 & 32,8 & & 1,1 & 503,81 & $641,47 \%$ & 0,2730 & $5,46 \%$ \\
\hline & & & & $\begin{array}{l}\mu \\
\boldsymbol{\sigma}\end{array}$ & $\begin{array}{l}1,6 \\
0,4\end{array}$ & & $\begin{array}{l}176,64 \% \\
183,56 \%\end{array}$ & & $\begin{array}{l}3,81 \% \\
1,01 \%\end{array}$ \\
\hline
\end{tabular}

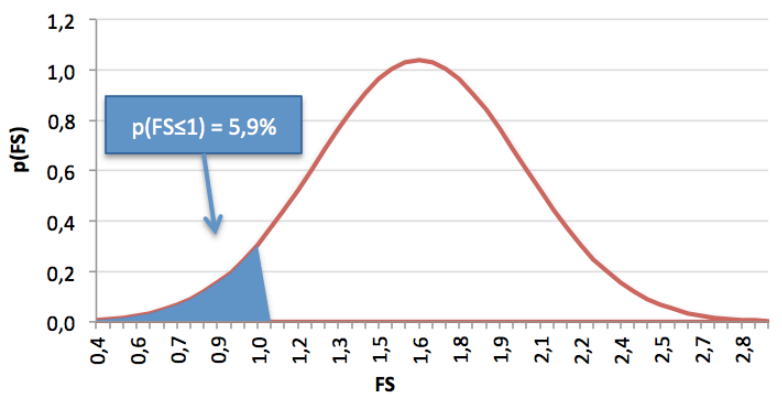

a)

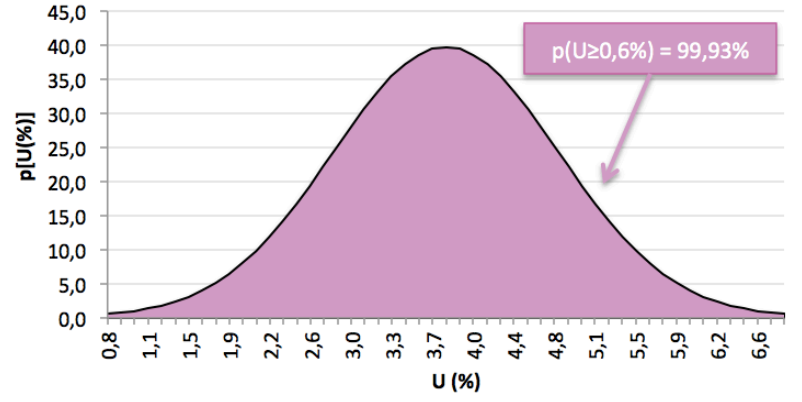

b)

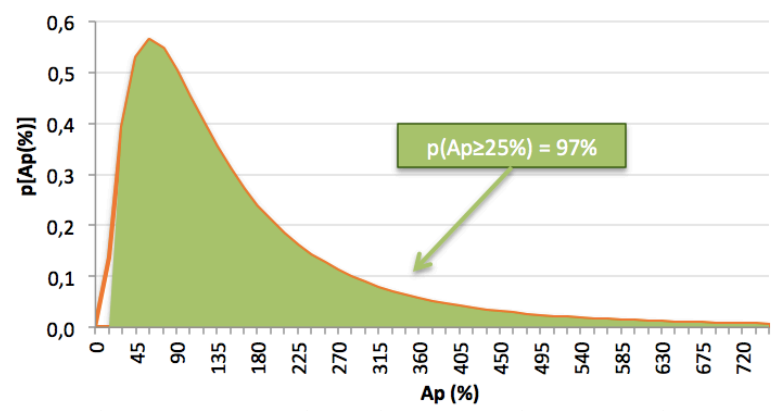

c)

Figura 5.27 - Frequência de ocorrência e probabilidade de falha: a) Fator de Segurança (FS); b) Convergência (U); c) Área Plástica (Ap) - Rocha metamórfica, $\mathrm{k}_{\mathrm{o}}=0$,5, elevado nível de tensões, maciço rochoso intensamente fraturado. 


\subsubsection{COMPARAÇÃO ENTRE OS RESULTADOS COM K Ko'S DIFERENTES}

Comparando-se o caso de elevado nível de tensões e maciço rochoso moderadamente fraturado dos diferentes $\mathrm{k}_{\mathrm{o}}$ 's $\left(\mathrm{k}_{\mathrm{o}}=0,5, \mathrm{k}_{\mathrm{o}}=1,0, \mathrm{k}_{\mathrm{o}}=2,0\right.$ e $\left.\mathrm{k}_{\mathrm{o}}=4,0\right)$ foi possível analisar $\mathrm{o}$ comportamento das probabilidades de falha para os três indicadores de desempenho: fator de segurança, convergência e área plástica.

É importante lembrar que para cada $\mathrm{k}_{\mathrm{o}}$ há um indicador de falha diferente para os indicadores de convergência e área plástica, determinados no item 5.2 deste capítulo. Portanto, a análise aqui foca na probabilidade de ocorrência e não no valor do indicador de falha.

\subsubsection{Rocha Metamórfica}

Abaixo são apresentados os resultados para o caso de rocha metamórfica, onde são analisados os três indicadores de desempenho: fator de segurança, convergência e área plástica.

\subsection{Fator de Segurança}

No caso de um túnel em rocha metamórfica, quando se analisa o indicador fator de segurança (Figura 5.28), percebe-se que a probabilidade de falha é menor para $\mathrm{k}_{\mathrm{o}}=1,0$ (Figura $5.28 \mathrm{~b}$ ), pois há mesma magnitude de tensões nas duas direções, o que não gera tensões cisalhantes iniciais.

À medida que a discrepância entre a tensão horizontal e vertical aumenta e aumenta também a cisalhante, a probabilidade de falha também aumenta. No caso de uma ser o dobro da outra $\left(\mathrm{k}_{\mathrm{o}}=0,5\right.$ ou $\mathrm{k}_{\mathrm{o}}=2$ ), essa probabilidade é em torno de $2 \%$ (Figura 5.28 a e c). Já no caso da tensão horizontal ser quatro vezes maior que a tensão vertical $\left(\mathrm{k}_{\mathrm{o}}=4\right)$, a probabilidade de falha aumenta significativamente para 24\% (Figura $5.28 \mathrm{~d}$ ).

As probabilidades de falha do fator de segurança sofrem uma variação de $0,01 \%$ a $24 \%$, indicando que a presença e magnitude da tensão cisalhante (variação do $k_{0}$ ), tem influência neste indicador.

\subsection{Convergência}

Com a convergência (Figura 5.29) acontece o oposto do fator de segurança. Para $\mathrm{k}_{\mathrm{o}}=1$, temse a maior probabilidade de ocorrência, $85 \%$ (Figura 5.29 b). E ao se afastar do $k_{0}=1$, essa 
probabilidade tende a diminuir, sendo $55 \%$ para $\mathrm{k}_{\mathrm{o}}=0,5$ (Figura 5.29 a) e $56 \%$ para $\mathrm{k}_{\mathrm{o}}=2$ (Figura 5.29 c) e chegando a $24 \%$ para $\mathrm{k}_{\mathrm{o}}=4$ (Figura $5.29 \mathrm{~d}$ ).

Então, à medida que a discrepância entre a tensão horizontal e vertical aumenta, a probabilidade de falha com relação à convergência diminui.

Percebe-se uma variação muito grande da probabilidade de falha para a convergência, indo de $24 \%$ até $85 \%$. Isso mostra que a convergência do túnel sofre grande influência do parâmetro $\mathrm{k}_{\mathrm{o}}$.

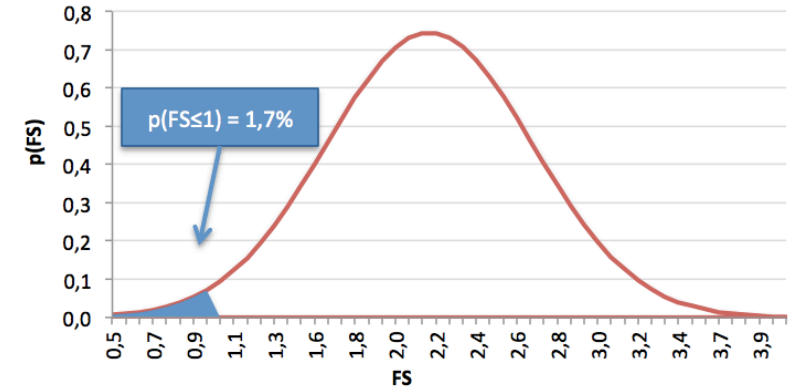

a)

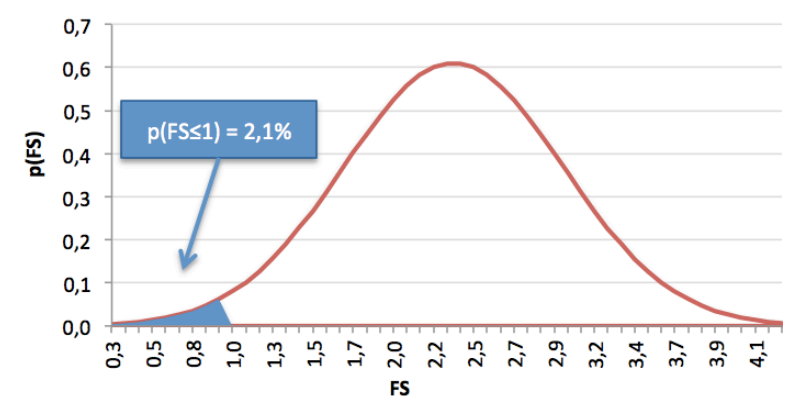

c)

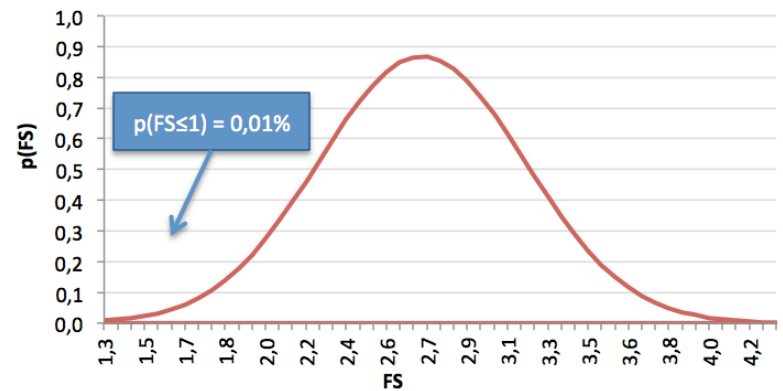

b)

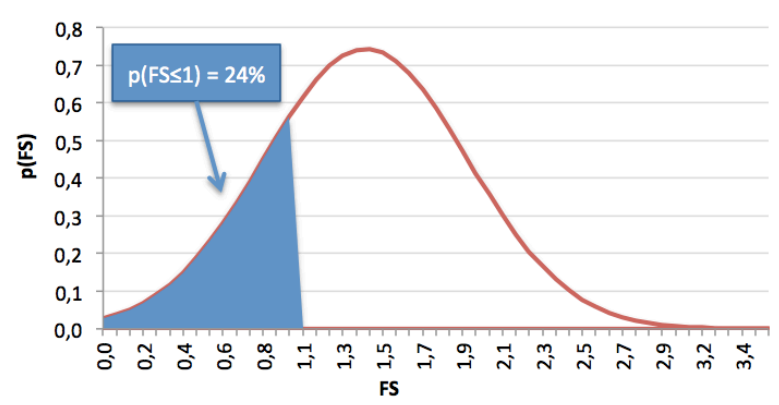

d)

Figura 5.28 - Frequência de ocorrência e probabilidade de falha do fator de segurança: a) $k_{o}$ $=0,5 ; b) \mathrm{k}_{\mathrm{o}}=1,0 ;$ c) $\mathrm{k}_{\mathrm{o}}=2,0 ;$ d) $\mathrm{k}_{\mathrm{o}}=4,0-$ Rocha Metamórfica.

\subsubsection{3. Área Plástica}

O comportamento do indicador área plástica é semelhante do comportamento do fator de segurança, em que a probabilidade de falha aumenta com o aumento da discrepância entre a tensão horizontal e vertical (Figura 5.30).

Para $\mathrm{k}_{\mathrm{o}}=1$, tem-se a menor probabilidade de ocorrência, 47\% (Figura $5.30 \mathrm{~b}$ ). E ao se afastar do $\mathrm{k}_{\mathrm{o}}=1$, essa probabilidade tende a aumentar, sendo $61 \%$ para $\mathrm{k}_{\mathrm{o}}=0,5$ (Figura $5.30 \mathrm{a}$ ) e $50 \%$ para $\mathrm{k}_{\mathrm{o}}=2$ (Figura $5.30 \mathrm{c}$ ) e chegando a $58 \%$ para o caso de $\mathrm{k}_{\mathrm{o}}=4$ (Figura $5.30 \mathrm{~d}$ ). 


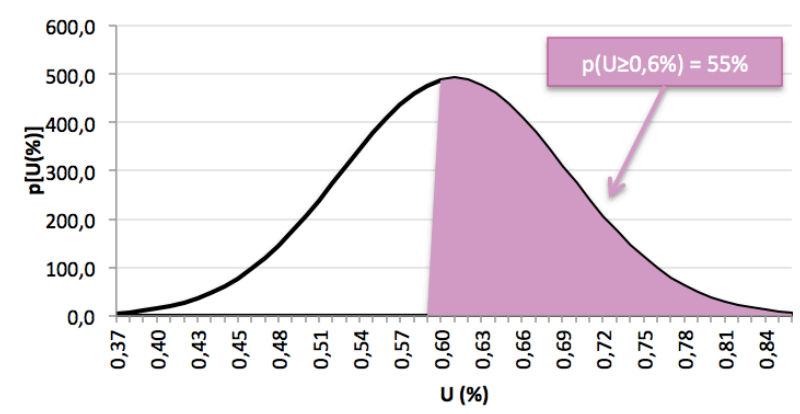

a)

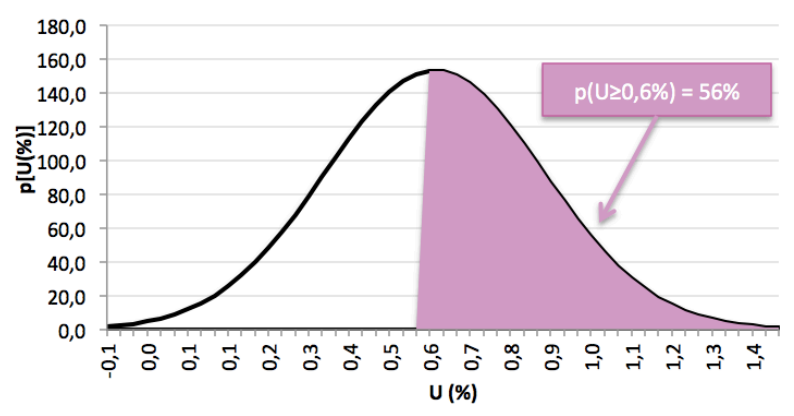

c)

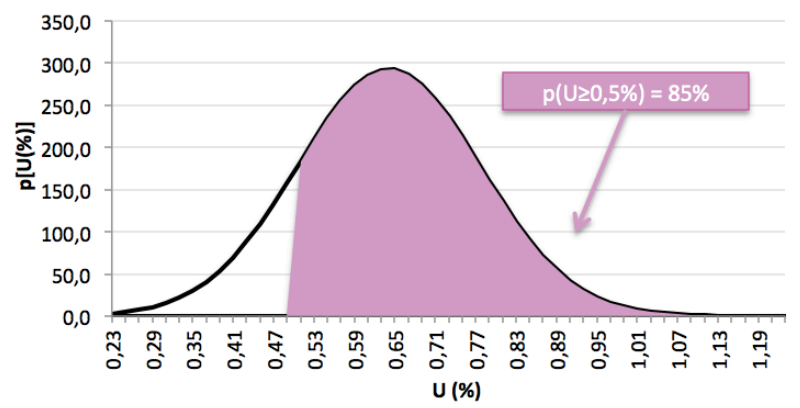

b)

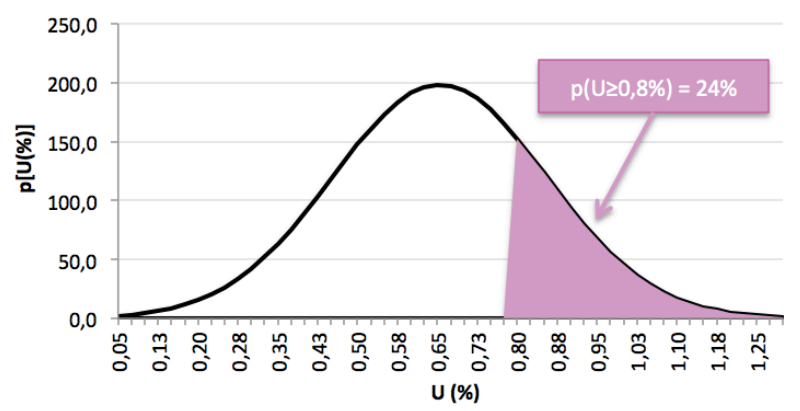

d)

Figura 5.29 - Frequência de ocorrência e probabilidade de falha da convergência: a) $k_{o}=$ 0,$5 ;$ b) $\mathrm{k}_{\mathrm{o}}=1,0 ;$ c) $\mathrm{k}_{\mathrm{o}}=2,0 ;$ d) $\mathrm{k}_{\mathrm{o}}=4,0-$ Rocha Metamórfica.

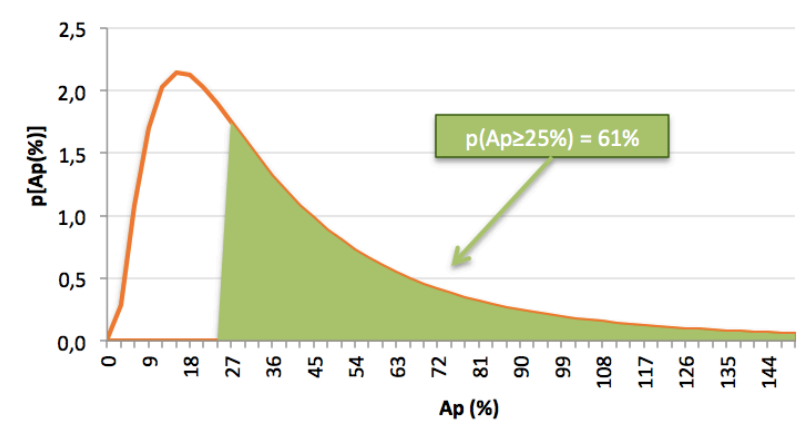

a)

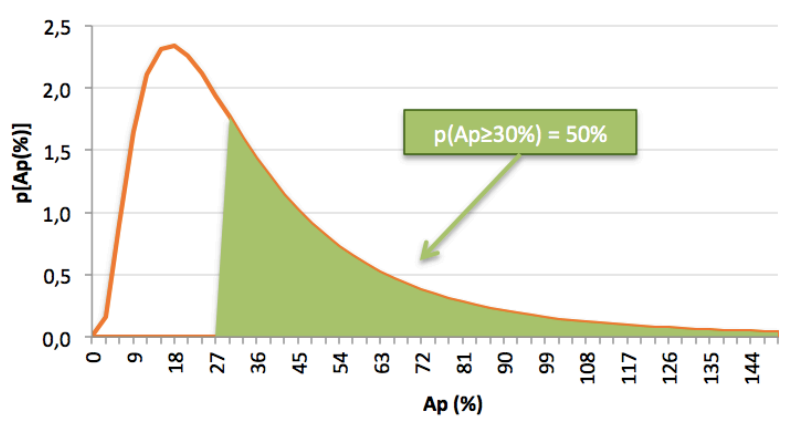

c)

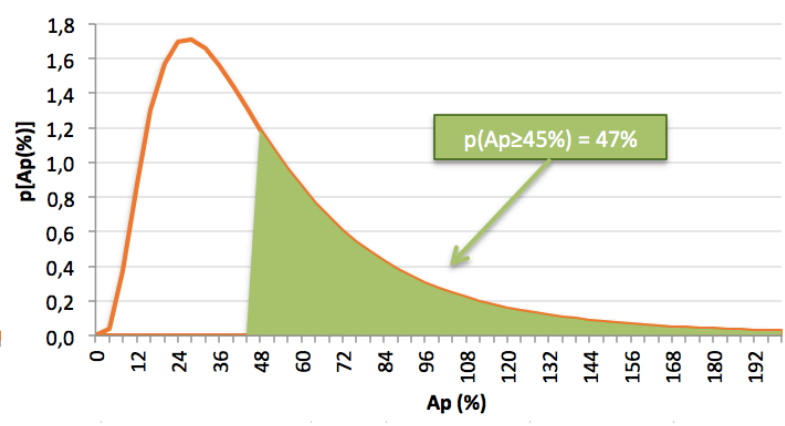

b)

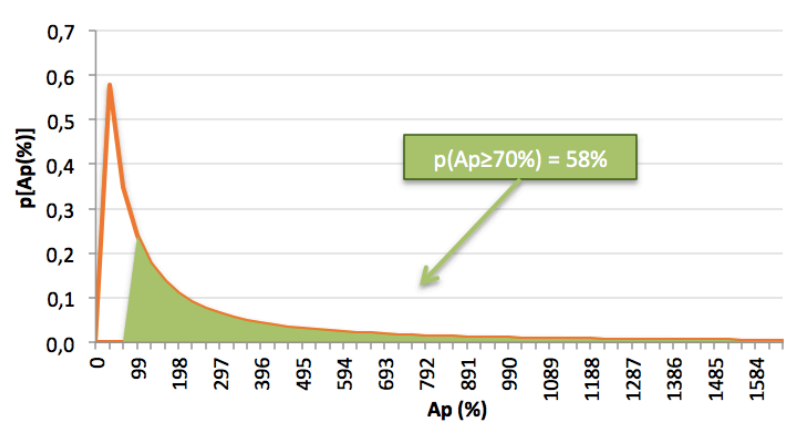

d)

Figura 5.30 - Frequência de ocorrência e probabilidade de falha da área plástica: a) $\mathrm{k}_{\mathrm{o}}=0,5$; b) $\mathrm{k}_{\mathrm{o}}=1,0 ;$ c) $\mathrm{k}_{\mathrm{o}}=2,0 ;$ d) $\mathrm{k}_{\mathrm{o}}=4,0-$ Rocha Metamórfica. 
Nota-se que as probabilidades de falha para este indicador não sofrem grandes variações, mesmo com a variação do $\mathrm{k}_{0}$, ficando sempre entre $45 \%$ e $60 \%$.

\subsubsection{Rocha Sedimentar}

O caso de rocha sedimentar foi analisado da mesma forma como a rocha metamórfica, assim, são apresentados, a seguir, os resultados para os três indicadores de desempenho.

\subsection{Fator de Segurança}

No caso de um túnel em rocha sedimentar, percebe-se que a probabilidade de falha em relação ao fator de segurança (Figura 5.31) tem um comportamento semelhante ao de rocha metamórfica, mas, com uma magnitude maior.

A probabilidade de falha, $\mathrm{p}(\mathrm{FS}<1)=0,1 \%$, é menor para $\mathrm{k}_{\mathrm{o}}=1,0$ (Figura $5.31 \mathrm{~b}$ ), onde as tensões de mesma magnitude nas duas direções não geram cisalhante. À medida que a discrepância entre a tensão horizontal e vertical aumenta, o que provoca o aumento das tensões cisalhantes, a probabilidade de falha também aumenta.

Ao se afastar do $\mathrm{k}_{\mathrm{o}}=1$, essa probabilidade tende a aumentar, sendo 7,2\% para $\mathrm{k}_{0}=0,5$ (Figura 5.31 a) e $6,8 \%$ para $\mathrm{k}_{\mathrm{o}}=2$ (Figura $5.31 \mathrm{c}$ ) e chegando a $48 \%$ para o caso de $\mathrm{k}_{\mathrm{o}}=4$ (Figura $5.31 \mathrm{~d}$ ).

\subsection{Convergência}

O comportamento das probabilidades de falha para o indicador convergência (Figura 5.32), no caso de rocha sedimentar, não foi exatamente o esperado, como ocorreu para o caso de rocha metamórfica.

Para $\mathrm{k}_{\mathrm{o}}=1$, tem-se a maior probabilidade de ocorrência, 70\% (Figura $5.32 \mathrm{~b}$ ). E ao se afastar do $\mathrm{k}_{\mathrm{o}}=1$, essa probabilidade tende a diminuir, sendo $65 \%$ para $\mathrm{k}_{\mathrm{o}}=0,5$ (Figura 5.32 a) e $59 \%$ para $\mathrm{k}_{\mathrm{o}}=2$ (Figura $5.32 \mathrm{c}$ ), mas, sofreu um pequeno aumento para $\mathrm{k}_{\mathrm{o}}=4$, chegando a $68 \%$ (Figura $5.32 \mathrm{~d}$ ).

Nota-se, então, que as probabilidades de falha, neste caso, não sofrem grandes variações, mesmo com a variação do $\mathrm{k}_{0}$, ficando sempre entre $59 \%$ e $70 \%$. 


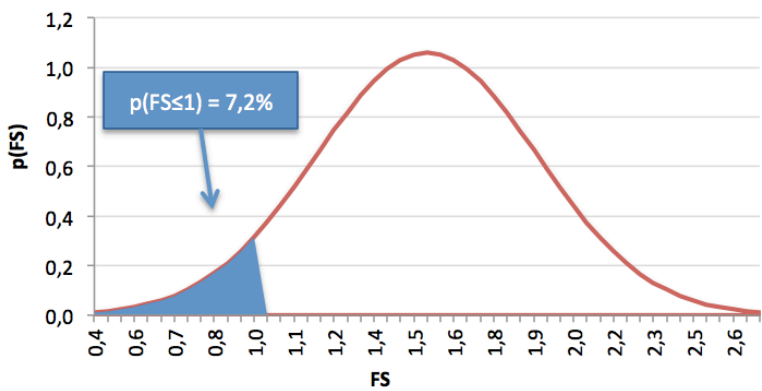

a)

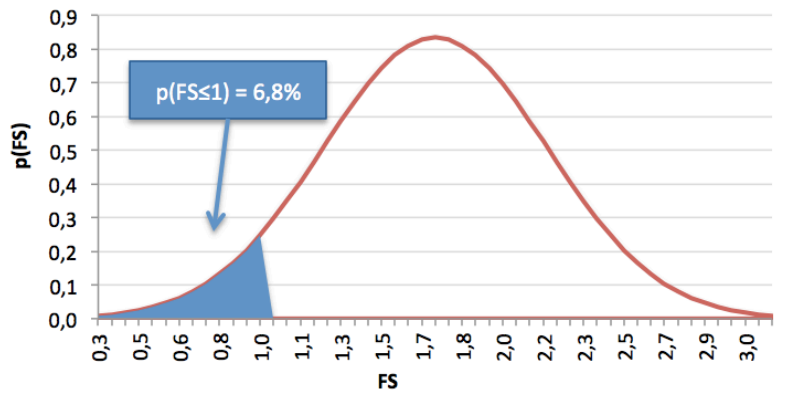

c)

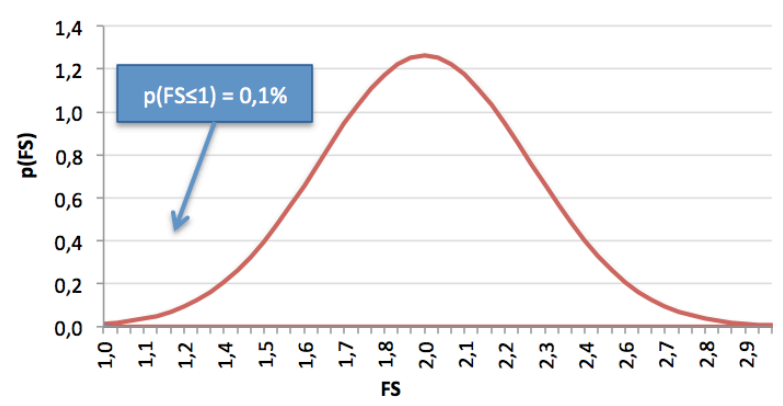

b)

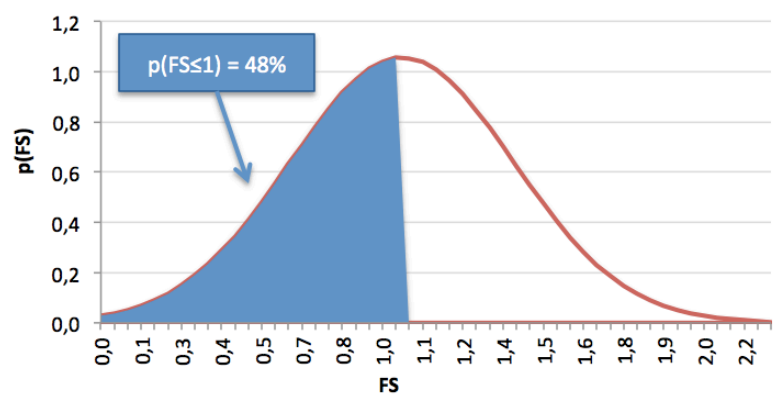

d)

Figura 5.31 - Frequência de ocorrência e probabilidade de falha do fator de segurança: a) $k_{o}$ $\left.=0,5 ; \mathrm{b}) \mathrm{k}_{\mathrm{o}}=1,0 ; \mathrm{c}\right) \mathrm{k}_{\mathrm{o}}=2,0 ;$ d) $\mathrm{k}_{\mathrm{o}}=4,0-$ Rocha Sedimentar.

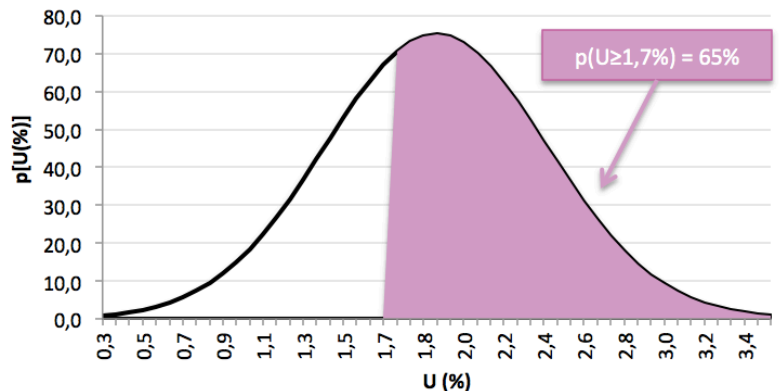

a)

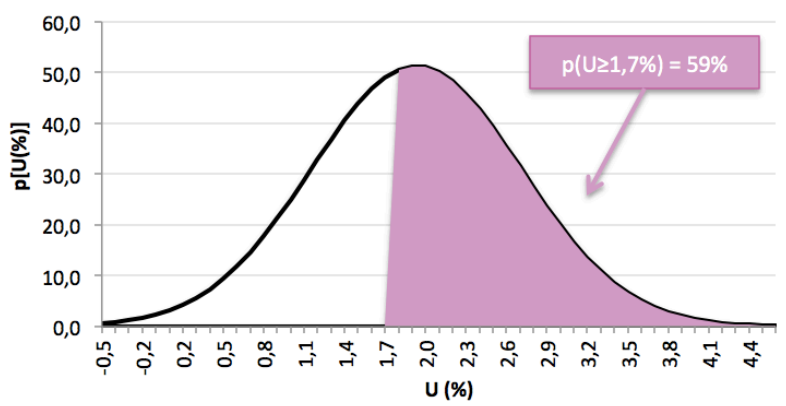

c)

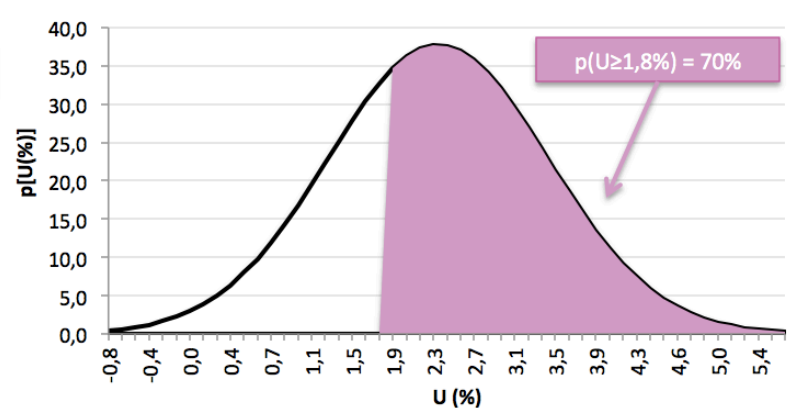

b)

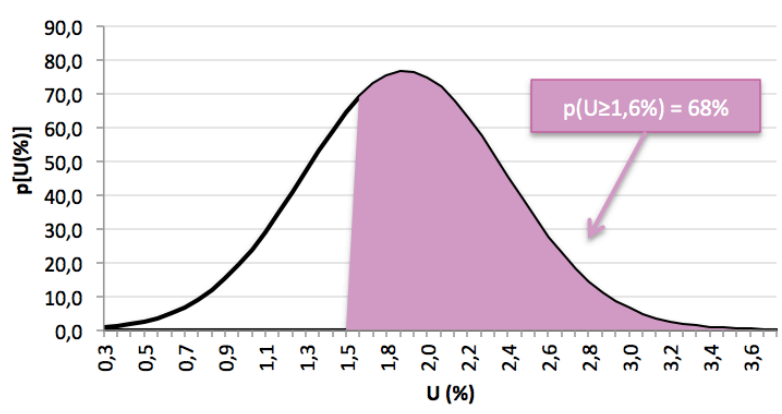

d)

Figura 5.32 - Frequência de ocorrência e probabilidade de falha da convergência: a) $k_{0}=0,5$;

b) $\mathrm{k}_{\mathrm{o}}=1,0 ;$ c) $\mathrm{k}_{\mathrm{o}}=2,0$;) $\mathrm{k}_{\mathrm{o}}=4,0-$ Rocha Sedimentar. 


\subsubsection{3. Área Plástica}

O comportamento das probabilidades de falha para o indicador área plástica (Figura 5.33), no caso de rocha sedimentar, também não foi exatamente o esperado, como ocorreu para o caso de rocha metamórfica.

Para $\mathrm{k}_{\mathrm{o}}=1$, tem-se a menor probabilidade de ocorrência, 53\% (Figura $5.33 \mathrm{~b}$ ). E ao se afastar do $\mathrm{k}_{\mathrm{o}}=1$, essa probabilidade tende a aumentar, sendo $66 \%$ para $\mathrm{k}_{\mathrm{o}}=0,5$ (Figura 5.33 a) e $71 \%$ para $\mathrm{k}_{\mathrm{o}}=2$ (Figura $5.33 \mathrm{c}$ ), mas, sofreu uma pequena queda para $\mathrm{k}_{\mathrm{o}}=4$, chegando a $53 \%$ (Figura $5.33 \mathrm{~d}$ ).

Uma possível explicação para essa diferença é que para o caso de $\mathrm{k}_{\mathrm{o}}=4$, o comportamento das zonas plásticas apresentado na Figura 5.20 tem características que possuem uma certa discrepância do comportamento proposto por Hoek et al. (1995). As regiões plásticas para o caso de $\mathrm{k}_{\mathrm{o}}=4$ adquirem um formato irregular e tendem a se afastar da parede do túnel adquirindo valores elevadíssimos.

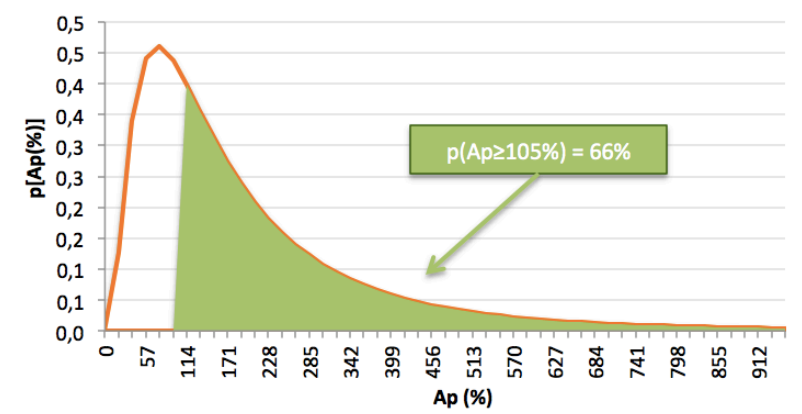

a)

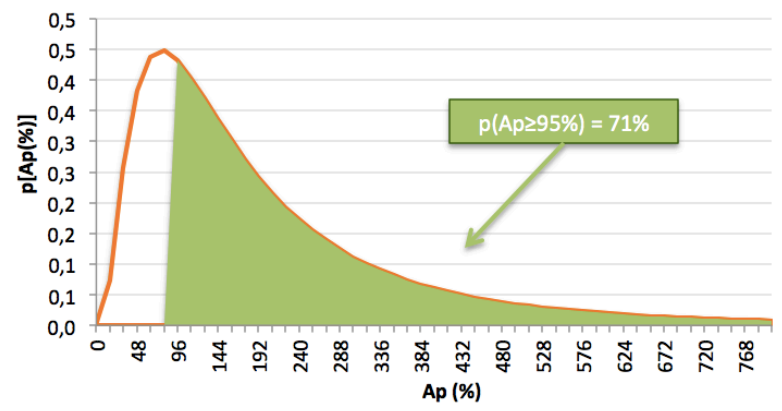

c)

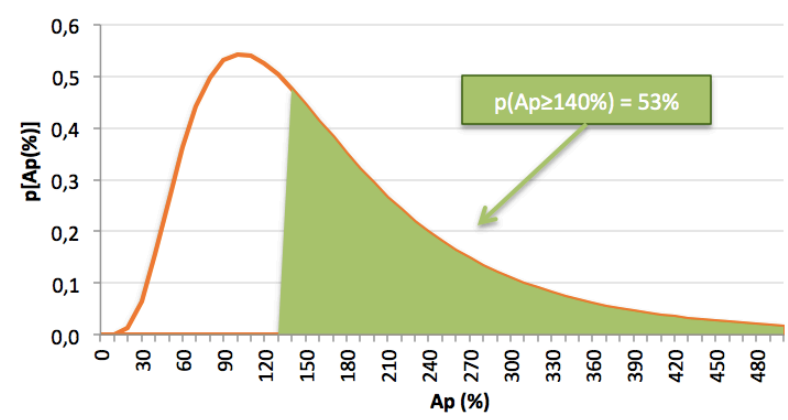

b)

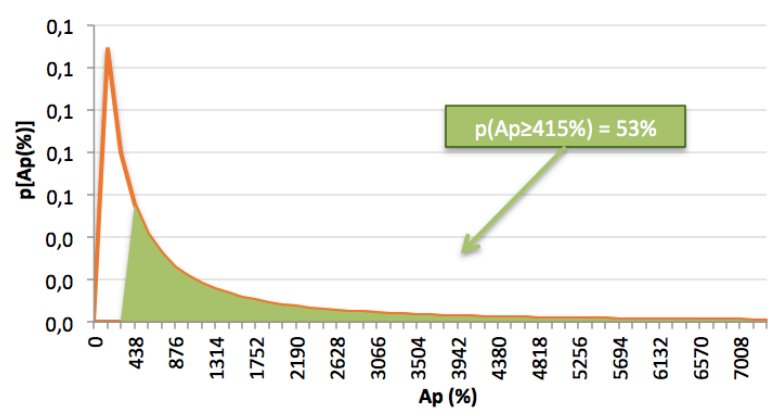

d)

Figura 5.33 - Frequência de ocorrência e probabilidade de falha da área plástica: a) $\mathrm{k}_{\mathrm{o}}=0,5$;

b) $\mathrm{k}_{\mathrm{o}}=1,0 ;$ c) $\mathrm{k}_{\mathrm{o}}=2,0 ;$ d) $\mathrm{k}_{\mathrm{o}}=4,0-$ Rocha Sedimentar. 


\section{CONCLUSÕES E RECOMENDAÇÕES}

As conclusões apresentadas abrangem considerações sobre os modos de ruptura de túneis em rochas, as limitações do programa PLAXIS, a aplicabilidade dos métodos probabilísticos frente aos tradicionais métodos determinísticos, além de observações sobre a metodologia proposta. Somam-se às conclusões, as recomendações para futuras pesquisas.

\subsection{CONCLUSÕES}

A avaliação da segurança das obras subterrâneas e outras obras geotécnicas não deve se restringir ao cálculo determinístico de seus indicadores de desempenho. A falha de uma estrutura geotécnica é condicionada pela variabilidade das propriedades dos maciços rochosos. Os diversos tipos de incertezas devem ser avaliados e aplicados numa abordagem probabilística que possibilite a elaboração de um processo de gestão de riscos.

Uma das primeiras etapas do processo de gestão de riscos é a caracterização dos modos de falha, a partir dos quais é possível determinar os prováveis indicadores de desempenho e suas principais fontes de incertezas. No caso de túneis, foi possível comparar os resultados obtidos com os modos de falha determinados por Hoek et al. (1995), mostrando que, para os casos de moderado a alto nível de tensões, o programa PLAXIS simulou de maneira satisfatória esses mecanismos de falha.

O PLAXIS, assim como outros programas que utilizam o método dos elementos finitos, possui algumas limitações devido às aproximações realizadas. Neste caso, como o meio é contínuo, o software não consegue descrever os modos de falha para baixo nível de tensões, pois estes sofrem grande dependência das descontinuidades.

A caracterização dos modos de falha permite identificar indicadores de desempenho e, então, determinar seus indicadores de falha, ou seja, valores limites a partir dos quais ocorre a falha. O processo de determinação desses indicadores de falha, com exceção do fator de segurança $(\mathrm{FS}=1)$, ainda não é um tema abordado nas diversas bibliografias.

Procurou-se relacionar os demais indicadores de desempenho (convergência e área plástica) com o fator de segurança, que é um indicador mais conhecido e mais estudado. Os gráficos obtidos possibilitaram avaliar visualmente os pontos onde ocorreram mudanças de tendência, que foram tomados como indicadores de falha. 
Os valores de probabilidades de falha para o indicador área plástica não foram satisfatórios para os casos de baixo nível de tensões, moderado nível de tensões e maciço rochoso moderadamente fraturado e também para o caso de maciço rochoso intacto.

Mas quando se aumenta o nível de tensões ou o grau de fraturamento destes casos obtêm-se valores da mesma ordem de grandeza do indicador convergência, mostrando que, mesmo que o valor limite seja conservador, estes são bons indicadores, falta apenas calibrar o valor limite.

É recomendável uma análise matemática da equação da curva de tendência desses gráficos, onde seria possível obter, a partir das derivadas, o ponto de maior mudança na inclinação da curva. Este processo matemático é mais preciso e confiável que a análise puramente visual.

Os valores obtidos para os indicadores de falha possibilitaram o cálculo das probabilidades de falha para os três indicadores de desempenho avaliados por meio do método dos pontos de estimativas. Nesta etapa, encontrou-se, por exemplo, valores de probabilidades de falha da ordem de $6 \%$, quando a média do fator de segurança era de 1,6 , mostrando, claramente, que a probabilidade de ocorrência do evento de falha é alta.

Contudo, é necessário determinar valores de referência para a probabilidade de falha aceitável, assim, as análises de probabilísticas poderiam conduzir a conclusões definitivas no que diz respeito ao comportamento dos túneis em rochas.

Outro ponto relevante, é a importância de determinar faixas de variação dos parâmetros geotécnicos com melhor aproximação (coeficiente de variação), já que a probabilidade de falha é bastante sensível a esta variável. Valores altos do desvio padrão de parâmetros, como a coesão, levam a importantes diferenças entre os valores médios, probabilísticos, e o valor determinístico do indicador.

A gestão de riscos é um processo complexo, onde o cálculo das probabilidades de falha é apenas uma de suas etapas. Então, os resultados obtidos na análise probabilística não são, sozinhos, conclusivos e não garantem que as estruturas, assim projetadas, serão imunes a possíveis falhas. Porém avaliar os diferentes cenários do projeto pode criar melhores ferramentas para tomada de decisões.

Por fim, este trabalho contribui com um referencial teórico sobre variabilidade, abordagem probabilística, modos de falha em túneis e seus indicadores de desempenho e uma metodologia probabilística que poderá ser utilizada como previsão durante as fases de projeto e executiva de obras subterrâneas em meios rochosos, bem como importantes considerações a 
respeito do processo de gestão de riscos neste tipo de obra.

\subsection{RECOMENDAÇÕES PARA FUTURAS PESQUISAS}

A seguir serão apresentadas algumas sugestões para futuras pesquisas, a fim de dar prosseguimento ao tema abordado no presente trabalho:

- Nesta dissertação comparou-se os resultados fixando o $\mathrm{k}_{0}$, sugere-se fazer comparações fixando o nível de tensões ou o grau de faturamento.

- Análise probabilística a partir do método FOSM, pois este permite determinar quais variáveis apresentam maior ou menor influência na variação das variáveis dependentes.

- Comparação com as probabilidades de falha obtidas com a aplicação dos outros métodos probabilísticos: Monte Carlo e FOSM.

- Combinar as probabilidades de falha dos diversos indicadores de desempenho, buscando um valor de probabilidade de falha para a obra como um todo.

- Complementar o estudo com as demais etapas do processo de gestão de riscos: avaliação das consequências, cálculo do risco, critérios de tolerância e medidas mitigadoras.

- Realizar simulações numéricas 3-D e utilizando outras variáveis independentes.

- Aplicação da análise probabilística em um caso real, já que, com o objetivo de estender este trabalho tornando-o uma ferramenta de apoio à decisão, foram admitidos valores para os parâmetros conforme os casos apresentados por Hoek et al. (1995) e valores típicos apresentados nas bibliografias.

- Aplicação da análise probabilística em outras áreas da geotecnia, como, por exemplo, no cálculo da probabilidade de falha de fundações, barragens, minas, etc.

- Utilizar programas de elementos distintos para captar os modos de falhas a baixas tensões. 


\section{REFERÊNCIAS BIBLIOGRÁFICAS}

Ang, A.H.S. \& Tang, W. (1975). Probability Concepts in Engineering Planning and Design: Basic Principles. John Wiley \& Sons, New York, USA, vol. 1, 422 p.

Assis, A.P. (2001). Geotecnia Aplicada à Mineração. Publicação G.AP-001/2001, Departamento de Engenharia Civil e Ambiental, Universidade de Brasília, Brasília, DF, $112 \mathrm{p}$.

Assis, A.P. (2002). Mecânica das Rochas: Obras Subterrâneas. Publicação G.APAA004/2002, Mestrado Profissional em Geotécnica de Barragens, Universidade Federal de Ouro Preto, Belo Horizonte, MG, 82 p.

Assis, A.P. (2003). Mecânica das Rochas. Publicação G.AP-001/03, Departamento de Engenharia Civil e Ambiental, Universidade de Brasília, Brasília, DF 100 p.

Assis, A.P., Espósito, T.J., Gardoni, M.G., Silva, P.D.E.A. \& Maia, J.A. (2012). Métodos Estatísticos e Probabilísticos em Geotecnia. Publicação G.AP-002/2012, Departamento de Engenharia Civil e Ambiental, Universidade de Brasília, Brasília, DF, 278 p.

Baecher G.B. \& Christian J.T. (2003). Reliability and Statistics in Geotechnical Engineering. 203. Wiley, London, UK, 605 p.

Barton, N.R., Lien, R. and Lunde, J. (1974). Engineering Classification of Rock Masses for the Design of Tunnel Support. Rock Mech. 6(4): 189-239.

Bieniawski, Z.T. (1973). Engineering Classification of Jointed Rock Masses. Trans S. Afr. Inst. Civ. Engrs 15: 335-344.

Bieniawski, Z.T. (1976). Rock Mass Classification in Rock Engineering. In Exploration for rock engineering, proc. of the symp. Balkema, Cape Town, South Africa. 1: 97-106.

Bieniawski, Z.T. (1989). Engineering Rock Mass Classifications. Wiley, New York, USA.

Bier, V.M. (1997). An Overview of Probabilistic Risk Analysis for Complex Engineered Systems. Fundamentals of Risk Analysis and Risk Management. V ed., Molak, Boca Raton, Lewis Publishers, USA.

Carranza-Torres, C. (2004). Elastoplastic Solution of Tunnel Problems Using the Generalized 
Form of the Hoek-Brown Failure Criterion. Int.J. of Rock Mechanics and Mining Sci., 41(3): 480-481.

Fell R., Ho K.K.S., Lacasse S., Leroi E. (2005). A Framework for Landslide Risk Assessment and Management. Proceedings International Conference on Landslide Risk Management, Taylor \& Francis, London, UK, 3-25.

Fenton, G.A. \& Griffiths, D. V. (2008). Risk Assessment in Geotechnical Engineering. Wiley, USA. 480 p.

Gercek, H. (2007). Typical Poisson's Ratio Values. Int. J. Rock Mech. Min. Sci., 44: 1-13.

Barton, N. \& Grimstad, E. 1994. The Q-system following twenty years of application in NMT support selection. 43rd Geomechanic Colloquy, Salzburg. Felsbau, Austria, 6/94: 428-436.

Harr, M.E. (1987). Reliability - Based Design in Civil Engineering. McGraw-Hill, New York, USA, $291 \mathrm{p}$.

Hoek, E. (1994). Strength of Rock and Rock Masses, ISRM News Journal, 2(2): 4-16.

Hoek E. \& Brown E.T. (1980). Underground Excavations in Rock. Institution of Mining and Metallurgy, London, UK, 527 p.

Hoek, E., Kaiser, P.K., Bawden, W.F. (1995). Support of Underground Excavations in Hard Rock. A.A. Balkema, Rotterdam, Netherlands, 215 p.

Hoek E., Carranza-Torres C. T., Corkum B. (2002). Hoek-Brown Failure Criterion - 2002 edition. In: Hammah R, Bawden W, Curran J, Telesnicki M (eds) Proceedings of the Fifth North American Rock Mechanics Symposium (NARMS-TAC), University of Toronto Press, Toronto, Canada, 267-273.

Hoek, E. \& Diederichs, M.S. (2006). Empirical Estimation of Rock Mass Modulus. International Journal of Rock Mechanics and Mining Sciences, 43(2): 203-215.

Hoek, E. (2007). Practical Rock Engineering. North Vancouver, Canada. Disponível em www.rocscience.com. Acesso em: 29 de agosto de 2016. Notas de Aula.

Jaeger, J.C. \& Cook, N.G.W. (1979). Fundamentals of Rock Mechanics. 3rd ed. Chapman and Hall, London, UK, 593 p. 
Kaplan, S. \& Garrick, B.J. (1981). On the Quantitative Definition of Risk. Risk Analysis. 1(1): 11-27.

Langford, J.C. \& Diederichs, M.S. (2013). Evaluating Uncertainty in Intact and Rockmass Parameters for the Purposes of Reliability Assessment. American Rock Mechanics Association. San Francisco, CA, USA.

Lama, R.D.; Vutukuri, V.S. (1978). Handbook on Mechanical Properties of Rocks - Testing Techniques and Results. Trans Tech Publications, Bay Village, Ohio, USA, 318-453.

Levine, D.M., Berenson, M.L. \& Stephan, D. (1998). Estatística: Teoria e Aplicações. Livros Técnicos e Científicos Editora S.A., Rio de Janeiro, RJ, 811 p.

Maia, J.A.C. (2007). Modelagem Probabilística da Zona Plástica de Obras Subterrâneas em Meios Rochosos. Tese de Doutorado, Publicação G.TD-040/07, Departamento de Engenharia Civil e Ambiental, Universidade de Brasília, Brasília, DF, 161 p.

Marinos, P \& Hoek, E. (2000). GSI - A Geologically Friendly Tool for Rock Mass Strength Estimation. Proc. GeoEng2000 Conference, Melbourne, Australia, 1422-1442.

Miranda, T., Correia, A. G., Ribeiro e Sousa, L. (2006). Determinação de Parâmetros Geomecânicos em Formações Rochosas e Maciços Heterogéneos. Universidade do Minho, Guimarães, Portugal, 17-40.

Pariseau, W.G. (1993). Applications of Finite Element Analysis to Mining Engineering. Comprehensive Rock Engineering: Principles, Practice and Projects, Vol 1: Fundamentals, J.A. Hudson (ed.), Pergamon Press Ltd, First Edition, Oxford, UK, 491-522.

Plaxis (2016). Material Models Manual. 2216 p.

Rosenblueth, E. (1975). Point Estimates for Probability Moments. Proc. Nacional Academy of Sciences, 72(10): 3812-3814.

Serafim, J.L. and Pereira, J.P. (1983). Consideration of the Geomechanics Classification of Bieniawski. Proc. Intnl. Symp. Engng. Geol. And Underground Construction. Lisbon, Portugal, Vol. 1, Part 11:33-44.

Soriano, H.L. (2009). Elementos Finitos, Formulação e Aplicação na Estática e Dinâmica das 
Estruturas. Editora Ciência Moderna, Rio de Janeiro, 411 p.

Terzaghi, K. \& Richart Jr., F.E. (1952). Stresses in Rock about Cavities. Géotechnique, 3: 5790.

Walpole, R. E., Myers, R. H. and Myers, S. L. 1998. Probability and Statistics for Engineers and Scientists, Upper Saddle River, New Jersey, Prentice-Hall. 


\section{APÊNDICES}

\section{A. DADOS DE ENTRADA}

O Apêndice A reúne os dados de entrada necessários para inserção no software PLAXIS, bem como a conversão dos parâmetros do critério de ruptura de Hoek \& Brown para o critério de ruptura de Mohr Coulomb.

Assim, os parâmetros foram calculados inicialmente por meio das Equações 3.5, 3.6, 3.7 e 3.8 do critério de ruptura generalizado de Hoek-Brown e convertidos para os parâmetros c e $\phi$ do critério de Mohr Coulomb através das Equações 3.12 e 3.13. De forma similar, o módulo de deformabilidade do maciço rochoso foi determinado a partir da equação simplificada de Hoek \& Diederichs apresentada na Tabela 4.1.

Portanto, esses dados podem ser apreciados nas tabelas a seguir, cuja organização é apresentada separando-se em duas seções:

\section{A.1 Rocha Metamórfica (Gnaisse)}

- Tabela A.1 - Dados de entrada - Rocha metamórfica, $\mathrm{k}_{\mathrm{o}}=0,5$.

- Tabela A.2 - Dados de entrada - Rocha metamórfica, $\mathrm{k}_{0}=1,0$.

- Tabela A.3 - Dados de entrada - Rocha metamórfica, $\mathrm{k}_{\mathrm{o}}=2,0$.

- Tabela A.4 - Dados de entrada - Rocha metamórfica, $\mathrm{k}_{\mathrm{o}}=4,0$.

\section{A.2 Rocha Sedimentar (Siltito)}

- Tabela A.5 - Dados de entrada - Rocha sedimentar, $\mathrm{k}_{\mathrm{o}}=0,5$.

- Tabela A.5 - Dados de entrada - Rocha sedimentar, $\mathrm{k}_{\mathrm{o}}=1,0$.

- Tabela A.5 - Dados de entrada - Rocha sedimentar, $\mathrm{k}_{\mathrm{o}}=2,0$.

- Tabela A.5 - Dados de entrada - Rocha sedimentar, $\mathrm{k}_{\mathrm{o}}=4,0$.

\section{A.1. ROCHA METAMÓRFICA (GNAISSE)}


Tabela A.1 - Dados de entrada - Rocha metamórfica, $\mathrm{k}_{\mathrm{o}}=0,5$.

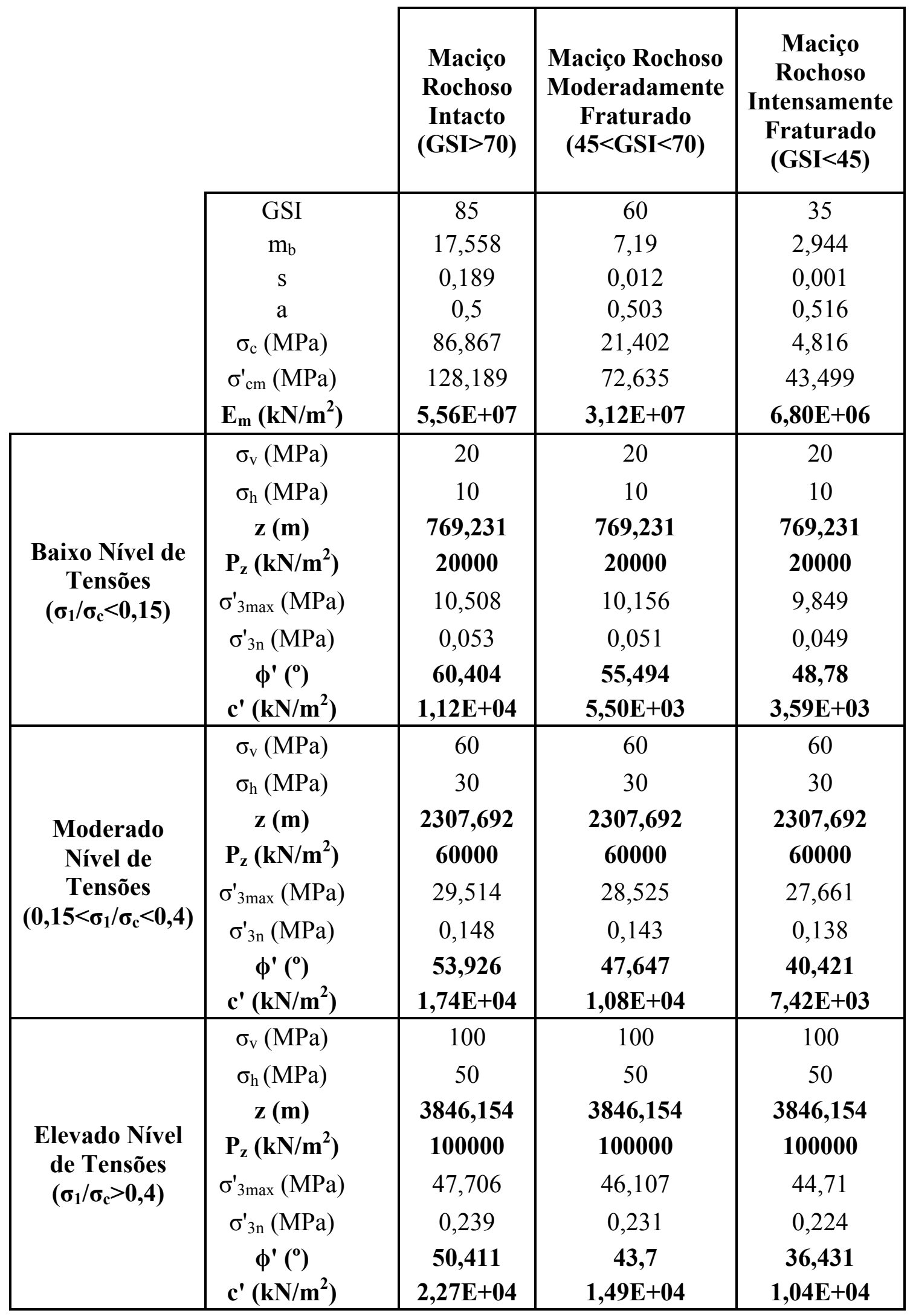


Tabela A.2 - Dados de entrada - Rocha metamórfica, $\mathrm{k}_{\mathrm{o}}=1,0$.

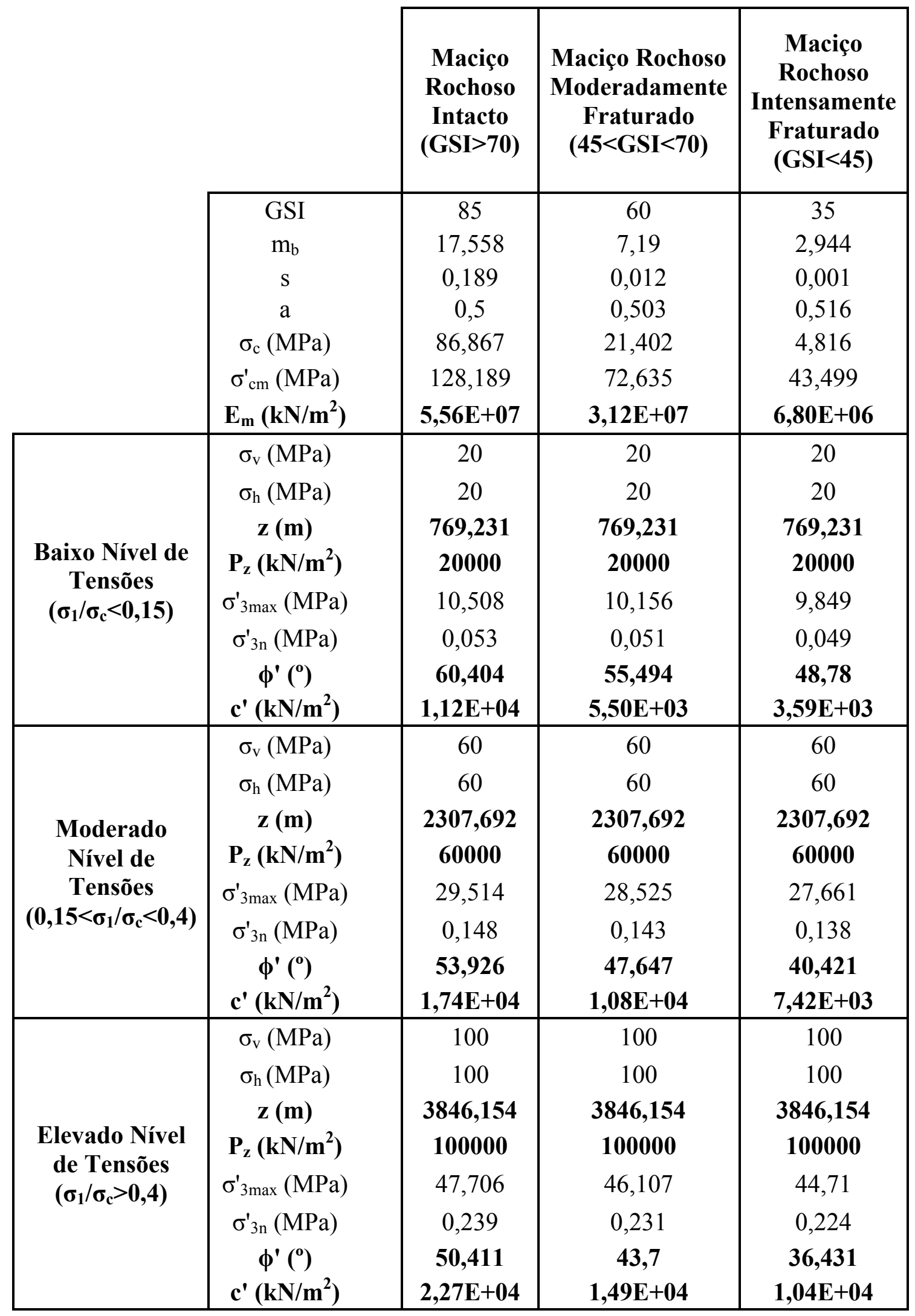


Tabela A.3 - Dados de entrada - Rocha metamórfica, $\mathrm{k}_{\mathrm{o}}=2,0$.

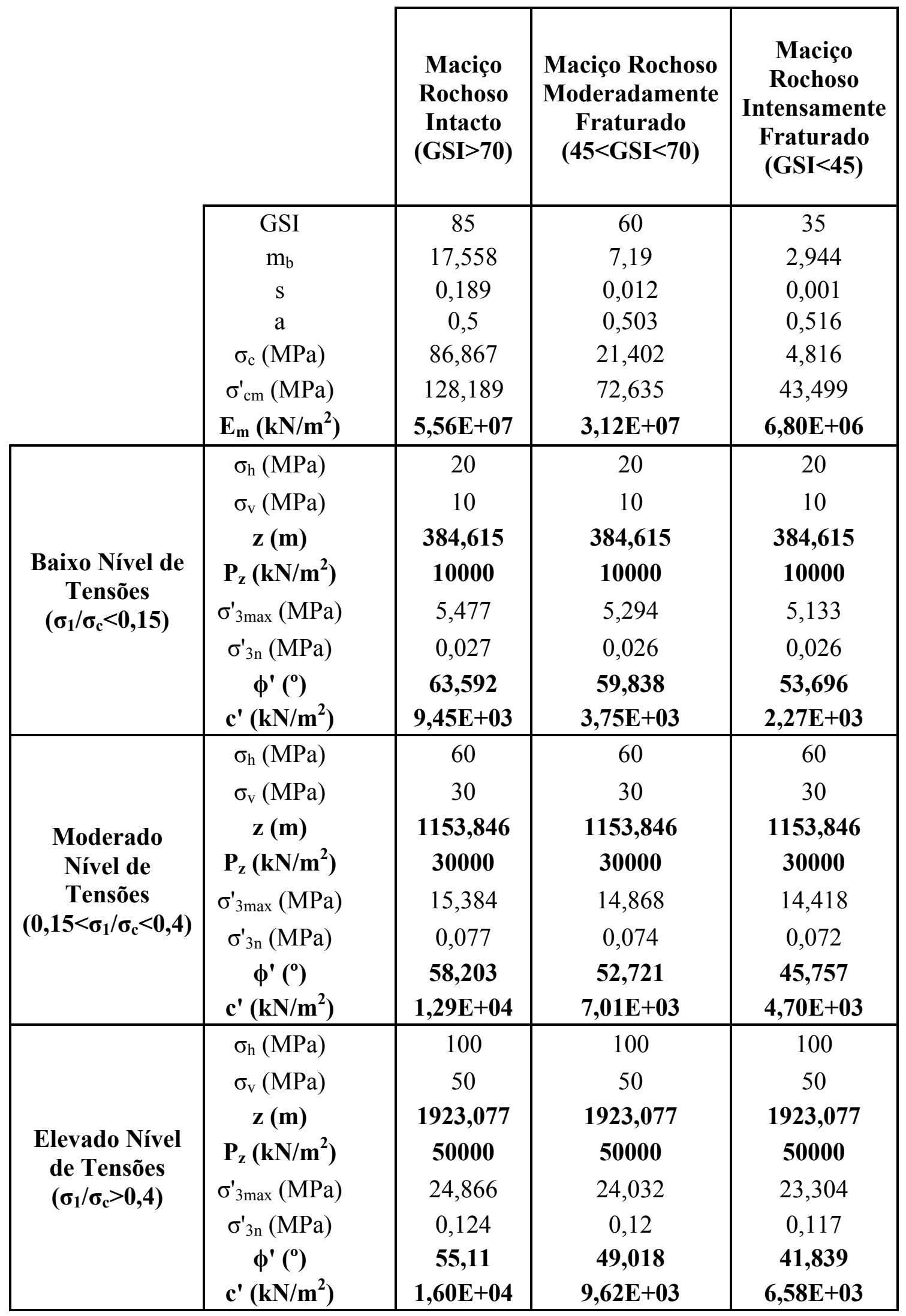


Tabela A.4 - Dados de entrada - Rocha metamórfica, $\mathrm{k}_{0}=4,0$.

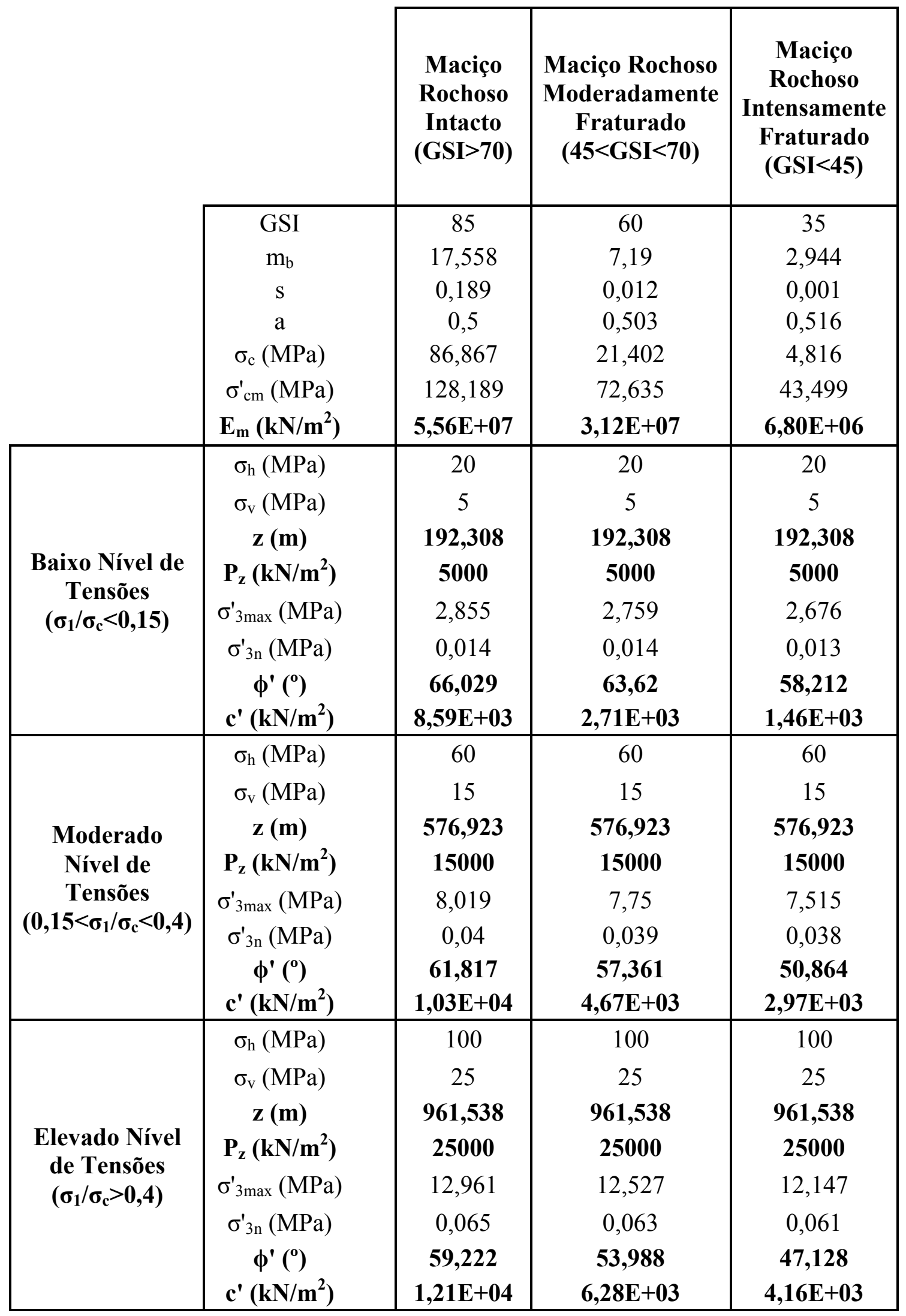




\section{A.2. ROCHA SEDIMENTAR (SILTITO)}

Tabela A.5 - Dados de entrada - Rocha sedimentar, $\mathrm{k}_{\mathrm{o}}=0,5$.

\begin{tabular}{|c|c|c|c|c|}
\hline & & $\begin{array}{c}\text { Maciço } \\
\text { Rochoso } \\
\text { Intacto } \\
\text { (GSI }>70)\end{array}$ & $\begin{array}{c}\text { Maciço Rochoso } \\
\text { Moderadamente } \\
\text { Fraturado } \\
(\mathbf{4 5}<\text { GSI }<70)\end{array}$ & $\begin{array}{c}\text { Maciço } \\
\text { Rochoso } \\
\text { Intensamente } \\
\text { Fraturado } \\
(\text { GSI }<45) \\
\end{array}$ \\
\hline & $\begin{array}{c}\text { GSI } \\
\mathrm{m}_{\mathrm{b}} \\
\mathrm{s} \\
\mathrm{a} \\
\sigma_{\mathrm{c}}(\mathrm{MPa}) \\
\sigma_{\mathrm{cm}}^{\prime}(\mathrm{MPa}) \\
\mathbf{E}_{\mathbf{m}}\left(\mathbf{k N} / \mathbf{m}^{2}\right)\end{array}$ & $\begin{array}{c}85 \\
5,853 \\
0,189 \\
0,5 \\
32,575 \\
34,504 \\
\mathbf{9 , 2 7 E + 0 6}\end{array}$ & $\begin{array}{c}60 \\
2,397 \\
0,012 \\
0,503 \\
8,026 \\
16,377 \\
\mathbf{5 , 2 0 E}+\mathbf{0 6}\end{array}$ & $\begin{array}{c}35 \\
0,981 \\
0,001 \\
0,516 \\
1,806 \\
9,322 \\
\mathbf{1 , 1 3 E + 0 6}\end{array}$ \\
\hline $\begin{array}{c}\text { Baixo Nível de } \\
\text { Tensões } \\
\left(\sigma_{1} / \sigma_{c}<0,15\right)\end{array}$ & $\begin{array}{c}\sigma_{\mathrm{v}}(\mathrm{MPa}) \\
\sigma_{\mathrm{h}}(\mathrm{MPa}) \\
\mathbf{z}(\mathbf{m}) \\
\mathbf{P}_{\mathbf{z}}\left(\mathbf{k N} / \mathbf{m}^{2}\right) \\
\sigma_{3 \max }(\mathrm{MPa}) \\
\sigma_{3 \mathrm{n}}^{\prime}(\mathrm{MPa}) \\
\boldsymbol{\phi}^{\prime}\left(\mathbf{(}^{\mathbf{0}}\right) \\
\mathbf{c}^{\prime}\left(\mathbf{k N} / \mathbf{m}^{2}\right) \\
\end{array}$ & $\begin{array}{c}7,5 \\
3,75 \\
\mathbf{2 8 8 , 4 6 2} \\
\mathbf{7 5 0 0} \\
3,863 \\
0,052 \\
\mathbf{5 0 , 3 3 3} \\
\mathbf{5 , 4 4 E}+\mathbf{0 3} \\
\end{array}$ & $\begin{array}{c}7,5 \\
3,75 \\
\mathbf{2 8 8 , 4 6 2} \\
\mathbf{7 5 0 0} \\
3,694 \\
0,049 \\
\mathbf{4 6 , 5 7} \\
\mathbf{1 , 8 0 E}+\mathbf{0 3}\end{array}$ & $\begin{array}{c}7,5 \\
3,75 \\
\mathbf{2 8 8 , 4 6 2} \\
\mathbf{7 5 0 0} \\
3,571 \\
0,048 \\
\mathbf{3 9 , 4 3 6} \\
\mathbf{9 , 7 9 E + 0 2}\end{array}$ \\
\hline $\begin{array}{c}\text { Moderado } \\
\text { Nível de } \\
\text { Tensões } \\
\left(\mathbf{0 , 1 5}<\boldsymbol{\sigma}_{\mathbf{1}} / \boldsymbol{\sigma}_{\mathbf{c}}<\mathbf{0 , 4 )}\right.\end{array}$ & $\begin{array}{c}\sigma_{\mathrm{v}}(\mathrm{MPa}) \\
\sigma_{\mathrm{h}}(\mathrm{MPa}) \\
\mathbf{z}(\mathbf{m}) \\
\mathbf{P}_{\mathbf{z}}\left(\mathbf{k N} / \mathbf{m}^{\mathbf{2}}\right) \\
\sigma_{3 \max }^{\prime}(\mathrm{MPa}) \\
\sigma_{3 \mathrm{n}}^{\prime}(\mathrm{MPa}) \\
\boldsymbol{\phi}^{\prime}\left(\mathbf{(}^{\mathbf{o}}\right) \\
\mathbf{c}^{\prime}\left(\mathbf{k N} / \mathbf{m}^{\mathbf{2}}\right) \\
\end{array}$ & $\begin{array}{c}22,5 \\
11,25 \\
\mathbf{8 6 5 , 3 8 5} \\
\mathbf{2 2 5 0 0} \\
10,85 \\
0,145 \\
\mathbf{4 4 , 1 9 4} \\
\mathbf{6 , 6 5 E}+\mathbf{0 3} \\
\end{array}$ & $\begin{array}{c}22,5 \\
11,25 \\
\mathbf{8 6 5 , 3 8 5} \\
\mathbf{2 2 5 0 0} \\
10,375 \\
0,138 \\
\mathbf{3 8 , 3 5 7} \\
\mathbf{3 , 0 9 E}+\mathbf{0 3} \\
\end{array}$ & $\begin{array}{c}22,5 \\
11,25 \\
\mathbf{8 6 5 , 3 8 5} \\
\mathbf{2 2 5 0 0} \\
10,03 \\
0,134 \\
\mathbf{3 0 , 9 9 1} \\
\mathbf{1 , 9 3 E + 0 3} \\
\end{array}$ \\
\hline $\begin{array}{c}\text { Elevado Nível } \\
\text { de Tensões } \\
\left(\sigma_{1} / \sigma_{c}>0,4\right)\end{array}$ & $\begin{array}{c}\sigma_{\mathrm{v}}(\mathrm{MPa}) \\
\sigma_{\mathrm{h}}(\mathrm{MPa}) \\
\mathbf{z}(\mathbf{m}) \\
\mathbf{P}_{\mathbf{z}}\left(\mathbf{k} \mathbf{N} / \mathbf{m}^{2}\right) \\
\sigma_{3 \max }^{\prime}(\mathrm{MPa}) \\
\sigma_{3 \mathrm{n}}^{\prime}(\mathrm{MPa}) \\
\boldsymbol{\phi}^{\prime}\left(\mathbf{(}^{\mathbf{o}}\right) \\
\mathbf{c}^{\prime}\left(\mathbf{k} \mathbf{N} / \mathbf{m}^{\mathbf{2}}\right)\end{array}$ & $\begin{array}{c}37,5 \\
18,75 \\
\mathbf{1 4 4 2 , 3 0 8} \\
\mathbf{3 7 5 0 0} \\
17,537 \\
0,234 \\
\mathbf{4 0 , 7 2 2} \\
\mathbf{7 , 8 0 E}+\mathbf{0 3}\end{array}$ & $\begin{array}{c}37,5 \\
18,75 \\
\mathbf{1 4 4 2 , 3 0 8} \\
\mathbf{3 7 5 0 0} \\
16,77 \\
0,224 \\
\mathbf{3 4 , 3 7 3} \\
\mathbf{4 , 1 1 E + 0 3}\end{array}$ & $\begin{array}{c}37,5 \\
18,75 \\
\mathbf{1 4 4 2 , 3 0 8} \\
\mathbf{3 7 5 0 0} \\
16,213 \\
0,216 \\
\mathbf{2 7 , 2 0 4} \\
\mathbf{2 , 6 4 E + 0 3}\end{array}$ \\
\hline
\end{tabular}


Tabela A.6 - Dados de entrada - Rocha sedimentar, $\mathrm{k}_{\mathrm{o}}=1,0$.

\begin{tabular}{|c|c|c|c|c|}
\hline & & $\begin{array}{c}\text { Maciço } \\
\text { Rochoso } \\
\text { Intacto } \\
\text { (GSI }>70)\end{array}$ & $\begin{array}{c}\text { Maciço Rochoso } \\
\text { Moderadamente } \\
\text { Fraturado } \\
(45<\text { GSI }<70)\end{array}$ & $\begin{array}{c}\text { Maciço } \\
\text { Rochoso } \\
\text { Intensamente } \\
\text { Fraturado } \\
(\mathbf{G S I}<\mathbf{4 5}) \\
\end{array}$ \\
\hline & $\begin{array}{c}\text { GSI } \\
\mathrm{m}_{\mathrm{b}} \\
\mathrm{s} \\
\mathrm{a} \\
\sigma_{\mathrm{c}}(\mathrm{MPa}) \\
\sigma_{\mathrm{cm}}^{\prime}(\mathrm{MPa}) \\
\mathbf{E}_{\mathbf{m}}\left(\mathbf{k} \mathbf{N} / \mathbf{m}^{2}\right)\end{array}$ & $\begin{array}{c}85 \\
5,853 \\
0,189 \\
0,5 \\
32,575 \\
34,504 \\
\mathbf{9 , 2 7 E + 0 6}\end{array}$ & $\begin{array}{c}60 \\
2,397 \\
0,012 \\
0,503 \\
8,026 \\
16,377 \\
\mathbf{5 , 2 0 E + 0 6}\end{array}$ & $\begin{array}{c}35 \\
0,981 \\
0,001 \\
0,516 \\
1,806 \\
9,322 \\
\mathbf{1 , 1 3 E + 0 6}\end{array}$ \\
\hline $\begin{array}{c}\text { Baixo Nível de } \\
\text { Tensões } \\
\left(\sigma_{1} / \sigma_{\mathrm{c}}<0,15\right)\end{array}$ & $\begin{array}{c}\sigma_{1}(\mathrm{MPa}) \\
\sigma_{3}(\mathrm{MPa}) \\
\mathbf{z}(\mathbf{m}) \\
\mathbf{P}_{\mathbf{z}}\left(\mathbf{k N} / \mathbf{m}^{\mathbf{2}}\right) \\
\sigma_{3 \max }^{\prime}(\mathrm{MPa}) \\
\sigma_{3 \mathrm{n}}^{\prime}(\mathrm{MPa}) \\
\boldsymbol{\phi}^{\prime}\left(\mathbf{(}^{\mathbf{0}}\right) \\
\mathbf{c}^{\prime}\left(\mathbf{k N} / \mathbf{m}^{\mathbf{2}}\right)\end{array}$ & $\begin{array}{c}7,5 \\
7,5 \\
\mathbf{2 8 8 , 4 6 2} \\
\mathbf{7 5 0 0} \\
3,863 \\
0,052 \\
\mathbf{5 0 , 3 3 3} \\
\mathbf{5 , 4 4 E}+\mathbf{0 3}\end{array}$ & $\begin{array}{c}7,5 \\
7,5 \\
\mathbf{2 8 8 , 4 6 2} \\
\mathbf{7 5 0 0} \\
3,694 \\
0,049 \\
\mathbf{4 6 , 5 7} \\
\mathbf{1 , 8 0 E}+\mathbf{0 3}\end{array}$ & $\begin{array}{c}7,5 \\
7,5 \\
\mathbf{2 8 8 , 4 6 2} \\
\mathbf{7 5 0 0} \\
3,571 \\
0,048 \\
\mathbf{3 9 , 4 3 6} \\
\mathbf{9 , 7 9 E + 0 2}\end{array}$ \\
\hline $\begin{array}{c}\text { Moderado } \\
\text { Nível de } \\
\text { Tensões } \\
\left(\mathbf{0 , 1 5}<\boldsymbol{\sigma}_{\mathbf{1}} / \boldsymbol{\sigma}_{\mathbf{c}}<\mathbf{0 , 4 )}\right.\end{array}$ & $\begin{array}{c}\sigma_{1}(\mathrm{MPa}) \\
\sigma_{3}(\mathrm{MPa}) \\
\mathbf{z}(\mathbf{m}) \\
\mathbf{P}_{\mathbf{z}}\left(\mathbf{k N} / \mathbf{m}^{\mathbf{2}}\right) \\
\sigma_{3 \max }^{\prime}(\mathrm{MPa}) \\
\sigma_{3 \mathrm{n}}^{\prime}(\mathrm{MPa}) \\
\boldsymbol{\phi}^{\prime}\left(\mathbf{(}^{\mathbf{o}}\right) \\
\mathbf{c}^{\prime}\left(\mathbf{k N} / \mathbf{m}^{\mathbf{2}}\right)\end{array}$ & $\begin{array}{c}22,5 \\
22,5 \\
\mathbf{8 6 5 , 3 8 5} \\
\mathbf{2 2 5 0 0} \\
10,85 \\
0,145 \\
\mathbf{4 4 , 1 9 4} \\
\mathbf{6 , 6 5 E}+\mathbf{0 3}\end{array}$ & $\begin{array}{c}22,5 \\
22,5 \\
\mathbf{8 6 5 , 3 8 5} \\
\mathbf{2 2 5 0 0} \\
10,375 \\
0,138 \\
\mathbf{3 8 , 3 5 7} \\
\mathbf{3 , 0 9 E}+\mathbf{0 3}\end{array}$ & $\begin{array}{c}22,5 \\
22,5 \\
\mathbf{8 6 5 , 3 8 5} \\
\mathbf{2 2 5 0 0} \\
10,03 \\
0,134 \\
\mathbf{3 0 , 9 9 1} \\
\mathbf{1 , 9 3 E + 0 3}\end{array}$ \\
\hline $\begin{array}{l}\text { Elevado Nível } \\
\text { de Tensões } \\
\left(\sigma_{1} / \sigma_{\mathrm{c}}>\mathbf{0 , 4}\right)\end{array}$ & $\begin{array}{c}\sigma_{1}(\mathrm{MPa}) \\
\sigma_{3}(\mathrm{MPa}) \\
\mathbf{z}(\mathbf{m}) \\
\mathbf{P}_{\mathbf{z}}\left(\mathbf{k N} / \mathbf{m}^{\mathbf{2}}\right) \\
\sigma_{3 \max }^{\prime}(\mathrm{MPa}) \\
\sigma_{3 \mathrm{n}}^{\prime}(\mathrm{MPa}) \\
\boldsymbol{\phi}^{\prime}\left(\mathbf{(}^{\mathbf{o}}\right) \\
\mathbf{c}^{\prime}\left(\mathbf{k N} / \mathbf{m}^{\mathbf{2}}\right) \\
\end{array}$ & $\begin{array}{c}37,5 \\
37,5 \\
\mathbf{1 4 4 2 , 3 0 8} \\
\mathbf{3 7 5 0 0} \\
17,537 \\
0,234 \\
\mathbf{4 0 , 7 2 2} \\
\mathbf{7 , 8 0 E}+\mathbf{0 3} \\
\end{array}$ & $\begin{array}{c}37,5 \\
37,5 \\
\mathbf{1 4 4 2 , 3 0 8} \\
\mathbf{3 7 5 0 0} \\
16,77 \\
0,224 \\
\mathbf{3 4 , 3 7 3} \\
\mathbf{4 , 1 1 E}+\mathbf{0 3} \\
\end{array}$ & $\begin{array}{c}37,5 \\
37,5 \\
\mathbf{1 4 4 2 , 3 0 8} \\
\mathbf{3 7 5 0 0} \\
16,213 \\
0,216 \\
\mathbf{2 7 , 2 0 4} \\
\mathbf{2 , 6 4 E}+\mathbf{0 3} \\
\end{array}$ \\
\hline
\end{tabular}


Tabela A.7 - Dados de entrada - Rocha sedimentar, $\mathrm{k}_{\mathrm{o}}=2,0$.

\begin{tabular}{|c|c|c|c|c|}
\hline & & $\begin{array}{c}\text { Maciço } \\
\text { Rochoso } \\
\text { Intacto } \\
\text { (GSI }>70)\end{array}$ & $\begin{array}{c}\text { Maciço Rochoso } \\
\text { Moderadamente } \\
\text { Fraturado } \\
(\mathbf{4 5}<\text { GSI }<70)\end{array}$ & $\begin{array}{c}\text { Maciço } \\
\text { Rochoso } \\
\text { Intensamente } \\
\text { Fraturado } \\
(\text { GSI }<\mathbf{4 5})\end{array}$ \\
\hline & GSI & 85 & 60 & 35 \\
\hline & $\mathrm{m}_{\mathrm{b}}$ & 5,853 & 2,397 & 0,981 \\
\hline & $\mathrm{S}$ & 0,189 & 0,012 & 0,001 \\
\hline & $\mathrm{a}$ & 0,5 & 0,503 & 0,516 \\
\hline & $\sigma_{\mathrm{c}}(\mathrm{MPa})$ & 32,575 & 8,026 & 1,806 \\
\hline & $\sigma_{\mathrm{cm}}^{\prime}(\mathrm{MPa})$ & 34,504 & 16,377 & 9,322 \\
\hline & $E_{m}\left(k N / m^{2}\right)$ & $9,27 E+06$ & $5,20 \mathrm{E}+06$ & $1,13 E+06$ \\
\hline \multirow{8}{*}{$\begin{array}{c}\text { Baixo Nível de } \\
\text { Tensões } \\
\left(\sigma_{1} / \sigma_{\mathrm{c}}<0,15\right)\end{array}$} & $\sigma_{\mathrm{h}}(\mathrm{MPa})$ & 7,5 & 7,5 & 7,5 \\
\hline & $\sigma_{\mathrm{v}}(\mathrm{MPa})$ & 3,8 & 3,8 & 3,8 \\
\hline & $\mathbf{z}(\mathbf{m})$ & 144,231 & 144,231 & 144,231 \\
\hline & $\mathbf{P}_{\mathrm{z}}\left(\mathbf{k N} / \mathbf{m}^{2}\right)$ & 3750 & 3750 & 3750 \\
\hline & $\sigma_{3 \max }^{\prime}(\mathrm{MPa})$ & 2,014 & 1,925 & 1,861 \\
\hline & $\sigma_{3 n}^{\prime}(\mathrm{MPa})$ & 0,027 & 0,026 & 0,025 \\
\hline & $\phi^{\prime}\left({ }^{0}\right)$ & 53,052 & 51,167 & 44,696 \\
\hline & $c^{\prime}\left(k N / m^{2}\right)$ & $5,18 \mathrm{E}+03$ & $1,40 E+03$ & $6,48 \mathrm{E}+02$ \\
\hline \multirow{8}{*}{$\begin{array}{c}\text { Moderado } \\
\text { Nível de } \\
\text { Tensões } \\
\left(\mathbf{0 , 1 5}<\boldsymbol{\sigma}_{\mathbf{1}} / \boldsymbol{\sigma}_{\mathbf{c}}<\mathbf{0 , 4}\right)\end{array}$} & $\sigma_{\mathrm{h}}(\mathrm{MPa})$ & 22,5 & 22,5 & 22,5 \\
\hline & $\sigma_{\mathrm{v}}(\mathrm{MPa})$ & 11,3 & 11,3 & 11,3 \\
\hline & $\mathbf{z}(\mathbf{m})$ & 432,692 & 432,692 & 432,692 \\
\hline & $\mathbf{P}_{\mathrm{z}}\left(\mathbf{k N} / \mathbf{m}^{2}\right)$ & 11250 & 11250 & 11250 \\
\hline & $\sigma_{3 \max }^{\prime}(\mathrm{MPa})$ & 5,655 & 5,408 & 5,228 \\
\hline & $\sigma_{3 n}^{\prime}(\mathrm{MPa})$ & 0,075 & 0,072 & 0,07 \\
\hline & $\phi^{\prime}\left({ }^{0}\right)$ & 48,314 & 43,636 & 36,304 \\
\hline & $c^{\prime}\left(k N / m^{2}\right)$ & $5,74 E+03$ & $2,17 E+03$ & $1,26 \mathrm{E}+03$ \\
\hline \multirow{8}{*}{$\begin{array}{c}\text { Elevado Nível } \\
\text { de Tensões } \\
\left(\sigma_{1} / \sigma_{\mathbf{c}}>0,4\right)\end{array}$} & $\sigma_{\mathrm{h}}(\mathrm{MPa})$ & 37,5 & 37,5 & 37,5 \\
\hline & $\sigma_{\mathrm{v}}(\mathrm{MPa})$ & 18,8 & 18,8 & 18,8 \\
\hline & z (m) & 721,154 & 721,154 & 721,154 \\
\hline & $\mathbf{P}_{\mathrm{z}}\left(\mathrm{kN} / \mathbf{m}^{2}\right)$ & 18750 & 18750 & 18750 \\
\hline & $\sigma_{3 \max }^{\prime}(\mathrm{MPa})$ & 9,141 & 8,741 & 8,451 \\
\hline & $\sigma_{3 n}^{\prime}(\mathrm{MPa})$ & 0,122 & 0,117 & 0,113 \\
\hline & $\phi^{\prime}\left({ }^{\circ}\right)$ & 45,352 & 39,768 & 32,375 \\
\hline & $c^{\prime}\left(k N / m^{2}\right)$ & $6,35 E+03$ & $2,80 E+03$ & $1,72 E+03$ \\
\hline
\end{tabular}


Tabela A.8 - Dados de entrada - Rocha sedimentar, $\mathrm{k}_{0}=4,0$.

\begin{tabular}{|c|c|c|c|c|}
\hline & & $\begin{array}{c}\text { Maciço } \\
\text { Rochoso } \\
\text { Intacto } \\
\text { (GSI }>70)\end{array}$ & $\begin{array}{c}\text { Maciço Rochoso } \\
\text { Moderadamente } \\
\text { Fraturado } \\
(\mathbf{4 5}<\text { GSI }<70)\end{array}$ & $\begin{array}{c}\text { Maciço } \\
\text { Rochoso } \\
\text { Intensamente } \\
\text { Fraturado } \\
(\text { GSI }<45)\end{array}$ \\
\hline & $\begin{array}{c}\text { GSI } \\
\mathrm{m}_{\mathrm{b}} \\
\mathrm{s} \\
\mathrm{a} \\
\sigma_{\mathrm{c}}(\mathrm{MPa}) \\
\sigma_{\mathrm{cm}}^{\prime}(\mathrm{MPa}) \\
\mathbf{E}_{\mathbf{m}}\left(\mathbf{k N} / \mathbf{m}^{2}\right)\end{array}$ & $\begin{array}{c}85 \\
5,853 \\
0,189 \\
0,5 \\
32,575 \\
34,504 \\
\mathbf{9 , 2 7 E + 0 6}\end{array}$ & $\begin{array}{c}60 \\
2,397 \\
0,012 \\
0,503 \\
8,026 \\
16,377 \\
\mathbf{5 , 2 0 E + 0 6}\end{array}$ & $\begin{array}{c}35 \\
0,981 \\
0,001 \\
0,516 \\
1,806 \\
9,322 \\
\mathbf{1 , 1 3 E + 0 6}\end{array}$ \\
\hline $\begin{array}{c}\text { Baixo Nível de } \\
\text { Tensões } \\
\left(\sigma_{1} / \sigma_{c}<0,15\right)\end{array}$ & $\begin{array}{c}\sigma_{\mathrm{h}}(\mathrm{MPa}) \\
\sigma_{\mathrm{v}}(\mathrm{MPa}) \\
\mathbf{z}(\mathbf{m}) \\
\mathbf{P}_{\mathbf{z}}\left(\mathbf{k N} / \mathbf{m}^{2}\right) \\
\sigma_{3 \max }^{\prime}(\mathrm{MPa}) \\
\sigma_{3 \mathrm{n}}^{\prime}(\mathrm{MPa}) \\
\boldsymbol{\phi}^{\prime}\left(\mathbf{(}^{\mathbf{0}}\right) \\
\mathbf{c}^{\prime}\left(\mathbf{k N} / \mathbf{m}^{2}\right)\end{array}$ & $\begin{array}{c}7,5 \\
1,9 \\
\mathbf{7 2 , 1 1 5} \\
\mathbf{1 8 7 5} \\
1,05 \\
0,014 \\
\mathbf{5 4 , 8 9 7} \\
\mathbf{5 , 0 9 E}+\mathbf{0 3}\end{array}$ & $\begin{array}{c}7,5 \\
1,9 \\
\mathbf{7 2 , 1 1 5} \\
\mathbf{1 8 7 5} \\
1,004 \\
0,013 \\
\mathbf{5 5 , 0 7 1} \\
\mathbf{1 , 1 7 E}+\mathbf{0 3}\end{array}$ & $\begin{array}{c}7,5 \\
1,9 \\
\mathbf{7 2 , 1 1 5} \\
\mathbf{1 8 7 5} \\
0,97 \\
0,013 \\
\mathbf{4 9 , 6 7 6} \\
\mathbf{4 , 4 4 E + 0 2}\end{array}$ \\
\hline $\begin{array}{c}\text { Moderado } \\
\text { Nível de } \\
\text { Tensões } \\
\left(\mathbf{0 , 1 5}<\boldsymbol{\sigma}_{\mathbf{1}} / \boldsymbol{\sigma}_{\mathbf{c}}<\mathbf{0 , 4}\right)\end{array}$ & $\begin{array}{c}\sigma_{\mathrm{h}}(\mathrm{MPa}) \\
\sigma_{\mathrm{v}}(\mathrm{MPa}) \\
\mathbf{z}(\mathbf{m}) \\
\mathbf{P}_{\mathbf{z}}\left(\mathbf{k N} / \mathbf{m}^{2}\right) \\
\sigma_{3 \max }^{\prime}(\mathrm{MPa}) \\
\sigma_{3 \mathrm{n}}^{\prime}(\mathrm{MPa}) \\
\boldsymbol{\phi}^{\prime}\left(\mathbf{(}^{\mathbf{0}}\right) \\
\mathbf{c}^{\prime}\left(\mathbf{k N} / \mathbf{m}^{\mathbf{2}}\right)\end{array}$ & $\begin{array}{c}22,5 \\
5,6 \\
\mathbf{2 1 6 , 3 4 6} \\
\mathbf{5 6 2 5} \\
2,948 \\
0,039 \\
\mathbf{5 1 , 5 7 4} \\
\mathbf{5 , 3 0 E}+\mathbf{0 3}\end{array}$ & $\begin{array}{c}22,5 \\
5,6 \\
\mathbf{2 1 6 , 3 4 6} \\
\mathbf{5 6 2 5} \\
2,819 \\
0,038 \\
\mathbf{4 8 , 5 5 1} \\
\mathbf{1 , 6 1 E + 0 3}\end{array}$ & $\begin{array}{c}22,5 \\
5,6 \\
\mathbf{2 1 6 , 3 4 6} \\
\mathbf{5 6 2 5} \\
2,725 \\
0,036 \\
\mathbf{4 1 , 6 4 1} \\
\mathbf{8 , 2 3 E + 0 2}\end{array}$ \\
\hline $\begin{array}{c}\text { Elevado Nível } \\
\text { de Tensões } \\
\left(\sigma_{1} / \sigma_{\mathrm{c}}>\mathbf{0 , 4}\right)\end{array}$ & $\begin{array}{c}\sigma_{\mathrm{h}}(\mathrm{MPa}) \\
\sigma_{\mathrm{v}}(\mathrm{MPa}) \\
\mathbf{z}(\mathbf{m}) \\
\mathbf{P}_{\mathbf{z}}\left(\mathbf{k N} / \mathbf{m}^{2}\right) \\
\sigma_{3 \max }^{\prime}(\mathrm{MPa}) \\
\sigma_{3 \mathrm{n}}^{\prime}(\mathrm{MPa}) \\
\boldsymbol{\phi}^{\prime}\left(\mathbf{(}^{\mathbf{0}}\right) \\
\mathbf{c}^{\prime}\left(\mathbf{k N} / \mathbf{m}^{\mathbf{2}}\right)\end{array}$ & $\begin{array}{c}37,5 \\
9,4 \\
\mathbf{3 6 0 , 5 7 7} \\
\mathbf{9 3 7 5} \\
4,765 \\
0,064 \\
\mathbf{4 9 , 2 6} \\
\mathbf{5 , 5 9 E}+\mathbf{0 3}\end{array}$ & $\begin{array}{c}37,5 \\
9,4 \\
\mathbf{3 6 0 , 5 7 7} \\
\mathbf{9 3 7 5} \\
4,556 \\
0,061 \\
\mathbf{4 4 , 9 7 4} \\
\mathbf{1 , 9 9 E + 0 3}\end{array}$ & $\begin{array}{c}37,5 \\
9,4 \\
\mathbf{3 6 0 , 5 7 7} \\
\mathbf{9 3 7 5} \\
4,405 \\
0,059 \\
\mathbf{3 7 , 7 1 4} \\
\mathbf{1 , 1 2 E + 0 3}\end{array}$ \\
\hline
\end{tabular}




\section{B. ANÁLISE PROBABILÍSTICA}

O Apêndice B reúne os resultados obtidos na etapa de análise probabilística utilizado o método dos pontos de estimativa (Point Estimate Method) de Rosenblueth.

Na Tabelas B.1 a B.46 são apresentados os dados de entrada $\left(k_{0}\right.$, c e $\left.\phi\right)$ bem como os dados de saída (FS, Ap e U). Estes últimos foram plotados em gráficos (Figuras B.1 a B.46) que apresentam a distribuição probabilística e a probabilidade de falha para cada indicador.

A organização é apresentada separando-se em duas seções, contento figuras e tabelas. A seção 2.01 mostra os resultados obtidos para rocha metamórfica e a seção 2.02 os resultados para rocha sedimentar, com $\mathrm{k}_{\mathrm{o}}$ variando entre 0,5, 1,0, 2,0 e 4,0. O nível de tensões (baixo, moderado ou elevado) e o grau de faturamento (maciço rochoso intacto, moderadamente fraturado e intensamente fraturado) variam de acordo com a Figura 3.4.

\section{B.1. ROCHA METAMÓRFICA (GNAISSE)}

\section{B.1.1. $K_{O}=0,5$}

\section{B.1.1.1. Baixo Nível de Tensões}

Tabela B.1 - Resultados obtidos com o método dos pontos de estimativa (Rosenblueth) Rocha metamórfica, $\mathrm{k}_{\mathrm{o}}=0,5$, baixo nível de tensões, maciço rochoso intensamente fraturado.

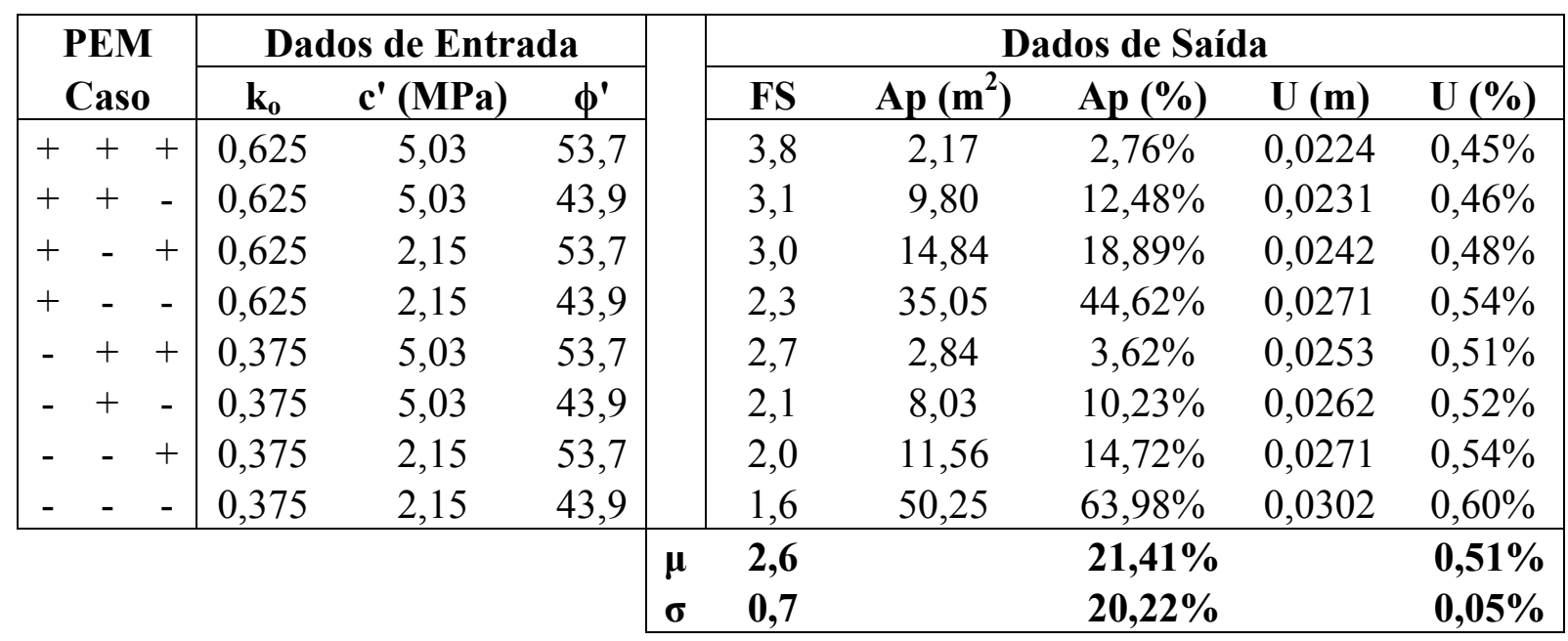




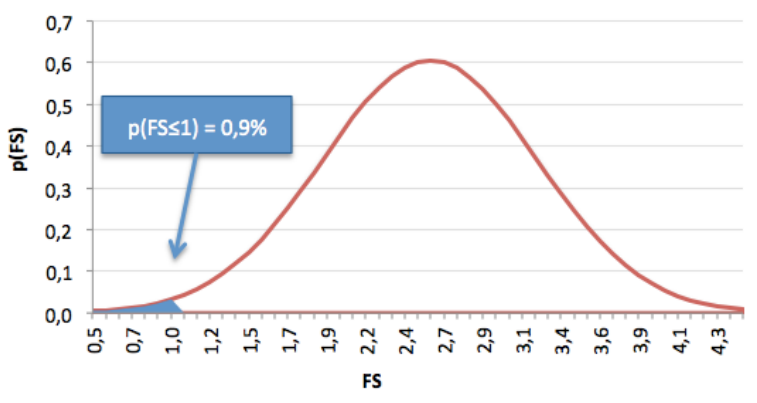

a)

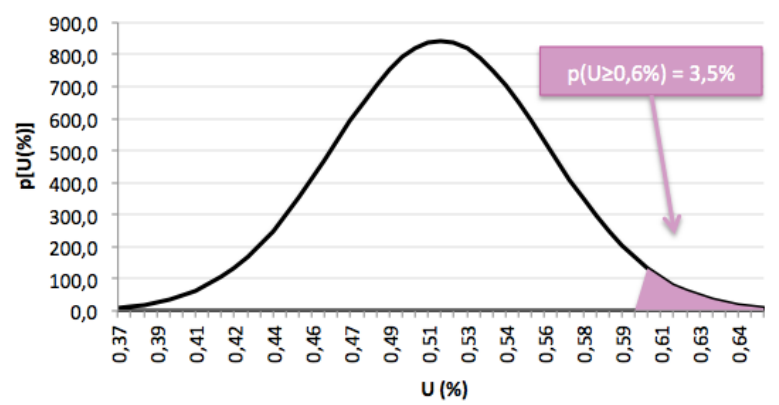

b)

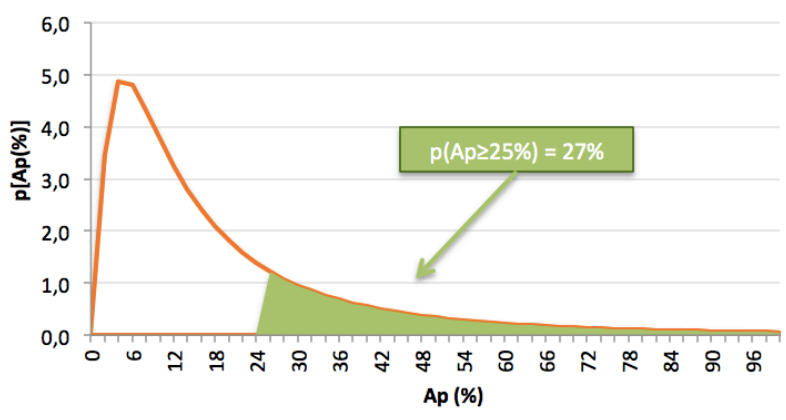

c)

Figura B.1- Frequência de ocorrência e probabilidade de falha: a) Fator de Segurança (FS);

b) Convergência $(\mathrm{U})$; c) Área Plástica (Ap) - Rocha metamórfica, $\mathrm{k}_{\mathrm{o}}=0,5$, baixo nível de tensões, maciço rochoso intensamente fraturado.

\section{B.1.1.2. Moderado Nível de Tensões}

Tabela B.2 - Resultados obtidos com o método dos pontos de estimativa (Rosenblueth) Rocha metamórfica, $\mathrm{k}_{\mathrm{o}}=0,5$, moderado nível de tensões, maciço rochoso moderadamente fraturado.

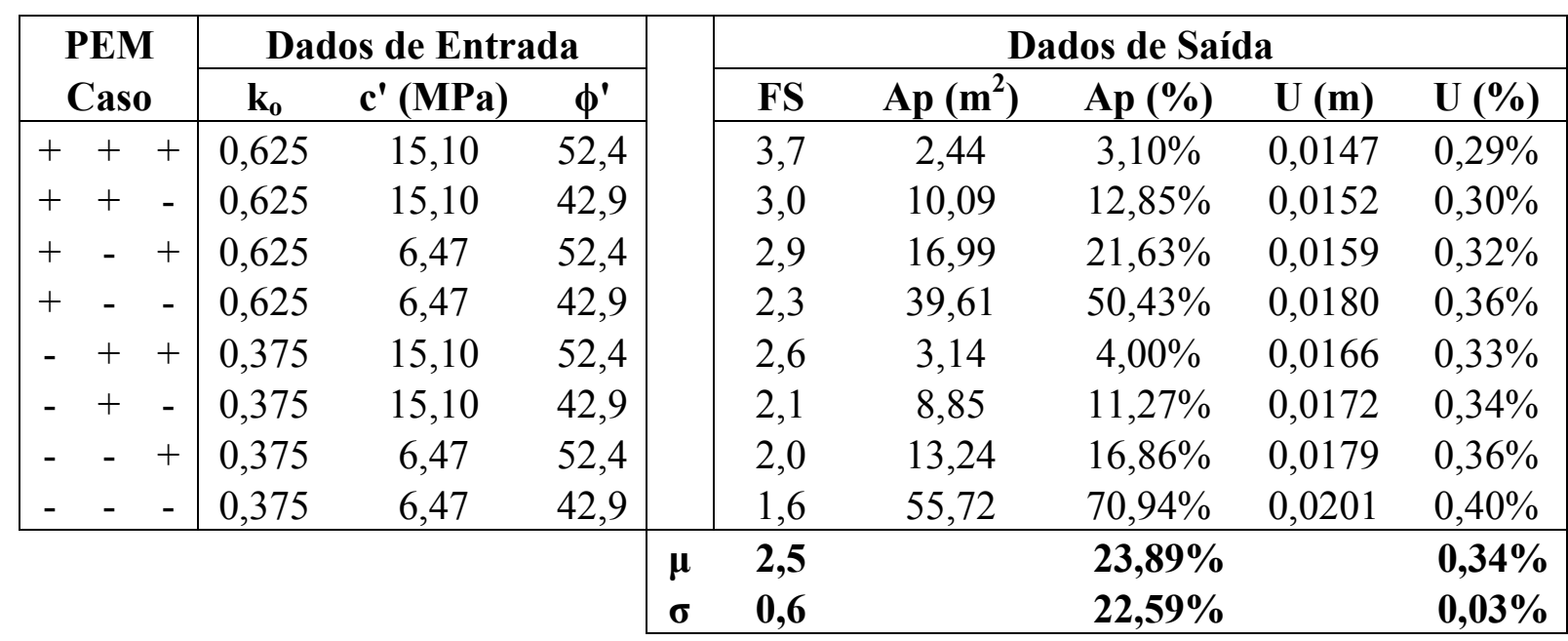




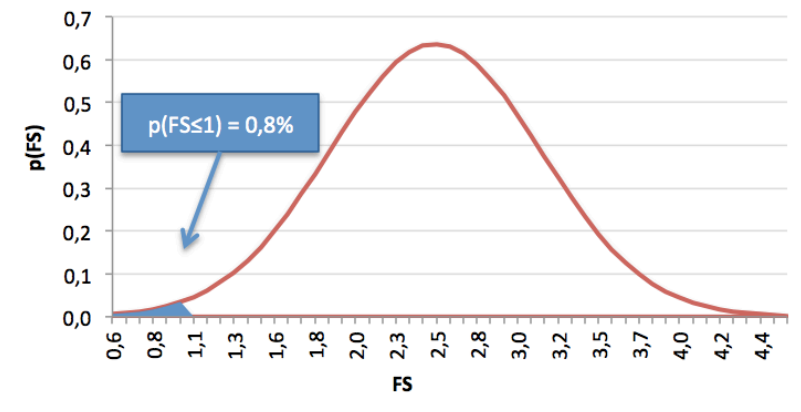

a)

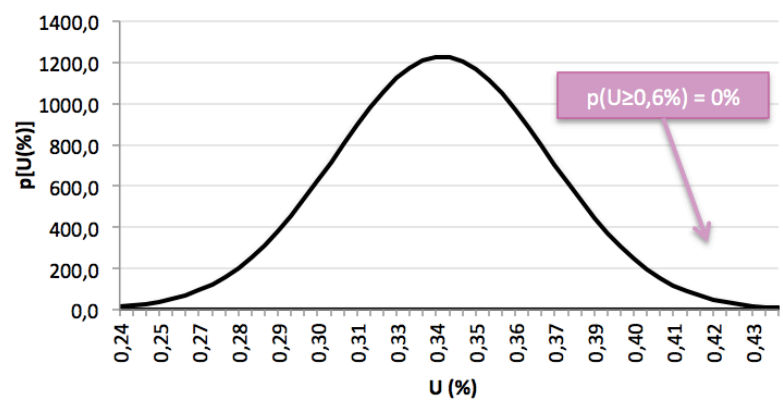

b)

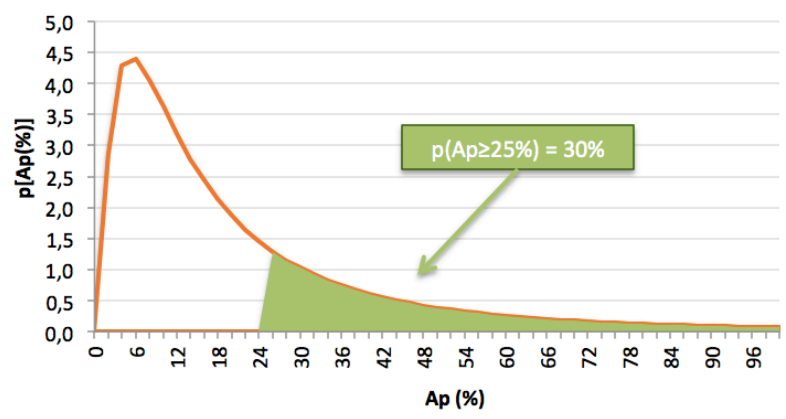

c)

Figura B.2- Frequência de ocorrência e probabilidade de falha: a) Fator de Segurança (FS);

b) Convergência (U); c) Área Plástica (Ap) - Rocha metamórfica, $\mathrm{k}_{\mathrm{o}}=0,5$, moderado nível de tensões, maciço rochoso moderadamente fraturado.

Tabela B.3 - Resultados obtidos com o método dos pontos de estimativa (Rosenblueth) Rocha metamórfica, $\mathrm{k}_{\mathrm{o}}=0,5$, moderado nível de tensões, maciço rochoso intensamente fraturado.

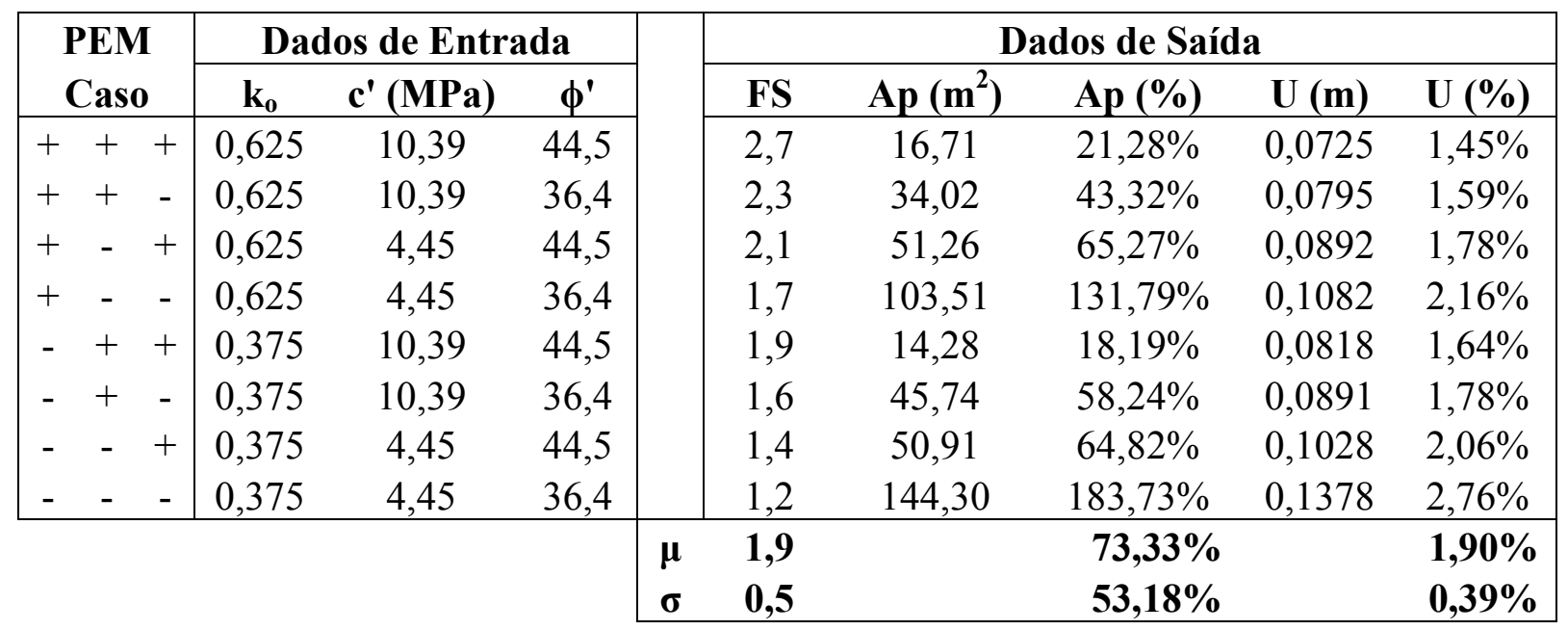




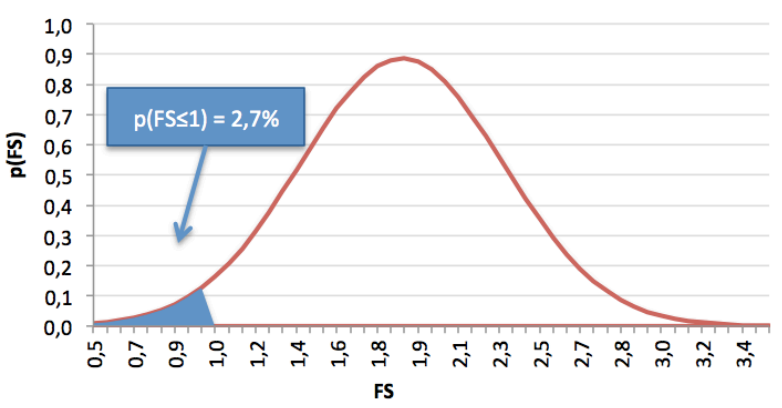

a)

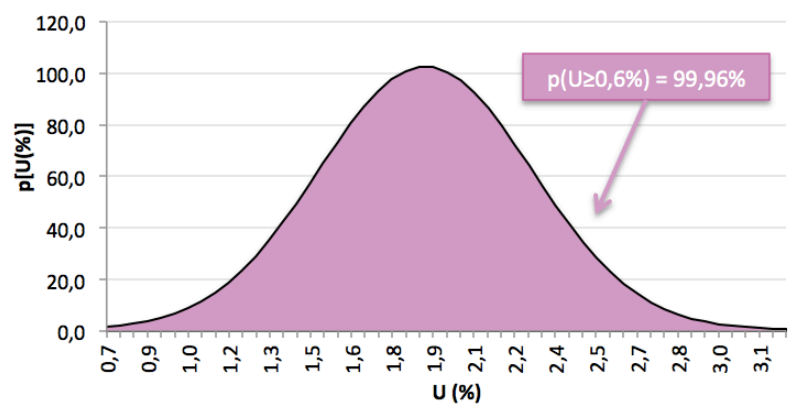

b)

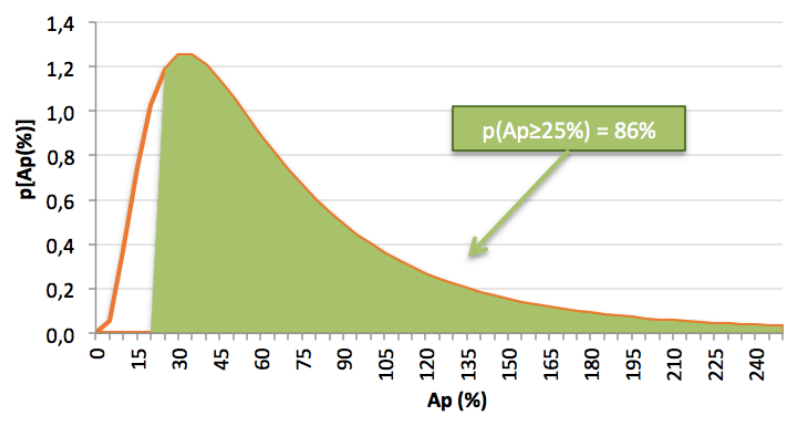

c)

Figura B.3 - Frequência de ocorrência e probabilidade de falha: a) Fator de Segurança (FS);

b) Convergência (U); c) Área Plástica (Ap) - Rocha metamórfica, $\mathrm{k}_{\mathrm{o}}=0,5$, moderado nível de tensões, maciço rochoso intensamente fraturado.

\section{B.1.1.3. Elevado Nível de Tensões}

Tabela B.4 - Resultados obtidos com o método dos pontos de estimativa (Rosenblueth) Rocha metamórfica, $\mathrm{k}_{\mathrm{o}}=0,5$, elevado nível de tensões, maciço rochoso intacto.

\begin{tabular}{|c|c|c|c|c|c|c|c|c|c|}
\hline \multirow{2}{*}{$\begin{array}{l}\text { PEM } \\
\text { Caso }\end{array}$} & \multicolumn{3}{|c|}{ Dados de Entrada } & & \multicolumn{5}{|c|}{ Dados de Saída } \\
\hline & $\mathbf{k}_{\mathbf{0}}$ & $\mathrm{c}^{\prime}$ (MPa) & $\phi^{\prime}$ & & FS & $\operatorname{Ap}\left(\mathrm{m}^{2}\right)$ & $\operatorname{Ap}(\%)$ & $\mathbf{U}(\mathbf{m})$ & $\mathrm{U}(\%)$ \\
\hline$+\quad+\quad+$ & 0,625 & 31,74 & 55,5 & & 4,3 & 0,20 & $0,26 \%$ & 0,0136 & $0,27 \%$ \\
\hline$+\quad+-$ & 0,625 & 31,74 & 45,4 & & 3,5 & 3,89 & $4,95 \%$ & 0,0137 & $0,27 \%$ \\
\hline$+\quad-\quad+$ & 0,625 & 13,60 & 55,5 & & 3,4 & 8,62 & $10,98 \%$ & 0,0141 & $0,28 \%$ \\
\hline$+\quad-\quad-$ & 0,625 & 13,60 & 45,4 & & 2,6 & 23,51 & $29,93 \%$ & 0,0154 & $0,31 \%$ \\
\hline$-\quad+\quad+$ & 0,375 & 31,74 & 55,5 & & 3,0 & 0,86 & $1,10 \%$ & 0,0154 & $0,31 \%$ \\
\hline$-\quad+\quad-$ & 0,375 & 31,74 & 45,4 & & 2,4 & 4,08 & $5,20 \%$ & 0,0156 & $0,31 \%$ \\
\hline$-\quad-\quad+$ & 0,375 & 13,60 & 55,5 & & 2,3 & 7,85 & $10,00 \%$ & 0,0160 & $0,32 \%$ \\
\hline$-\quad-\quad-$ & 0,375 & 13,60 & 45,4 & & 1,8 & 18,87 & $24,02 \%$ & 0,0172 & $0,34 \%$ \\
\hline & & & & $\begin{array}{l}\mu \\
\sigma \\
\end{array}$ & $\begin{array}{l}2,9 \\
0,7 \\
\end{array}$ & & $\begin{array}{l}10,80 \% \\
10,08 \% \\
\end{array}$ & & $\begin{array}{l}0,30 \% \\
0,02 \% \\
\end{array}$ \\
\hline
\end{tabular}




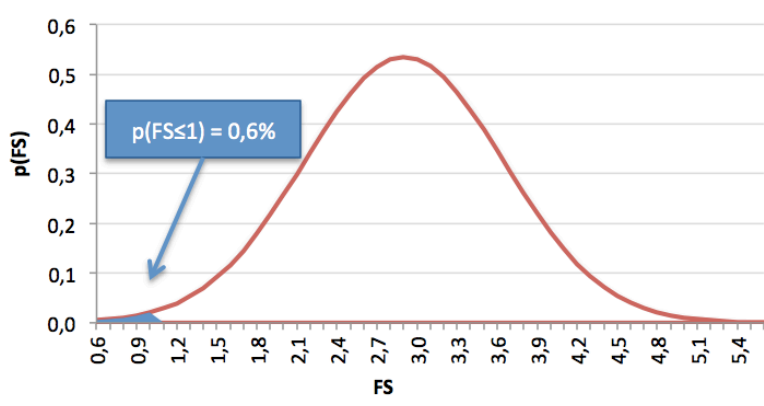

a)

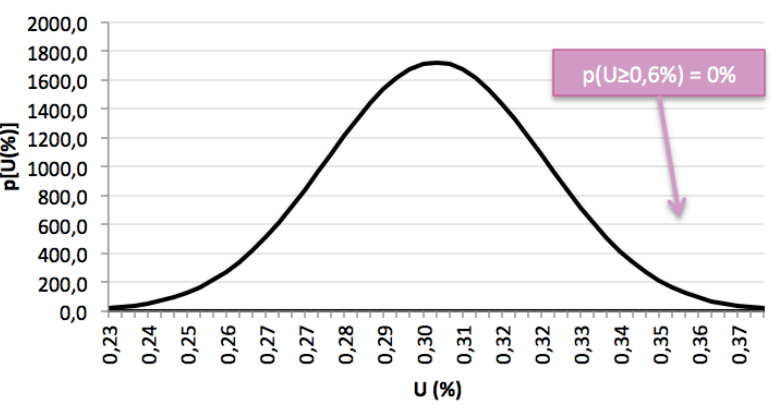

b)

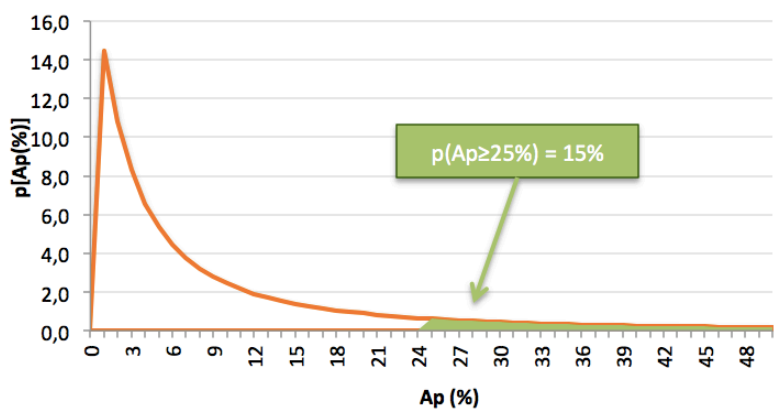

c)

Figura B.4- Frequência de ocorrência e probabilidade de falha: a) Fator de Segurança (FS); b) Convergência (U); c) Área Plástica (Ap) - Rocha metamórfica, $\mathrm{k}_{\mathrm{o}}=0,5$, elevado nível de tensões, maciço rochoso intacto.

Tabela B.5 - Resultados obtidos com o método dos pontos de estimativa (Rosenblueth) Rocha metamórfica, $\mathrm{k}_{\mathrm{o}}=0,5$, elevado nível de tensões, maciço rochoso moderadamente fraturado.

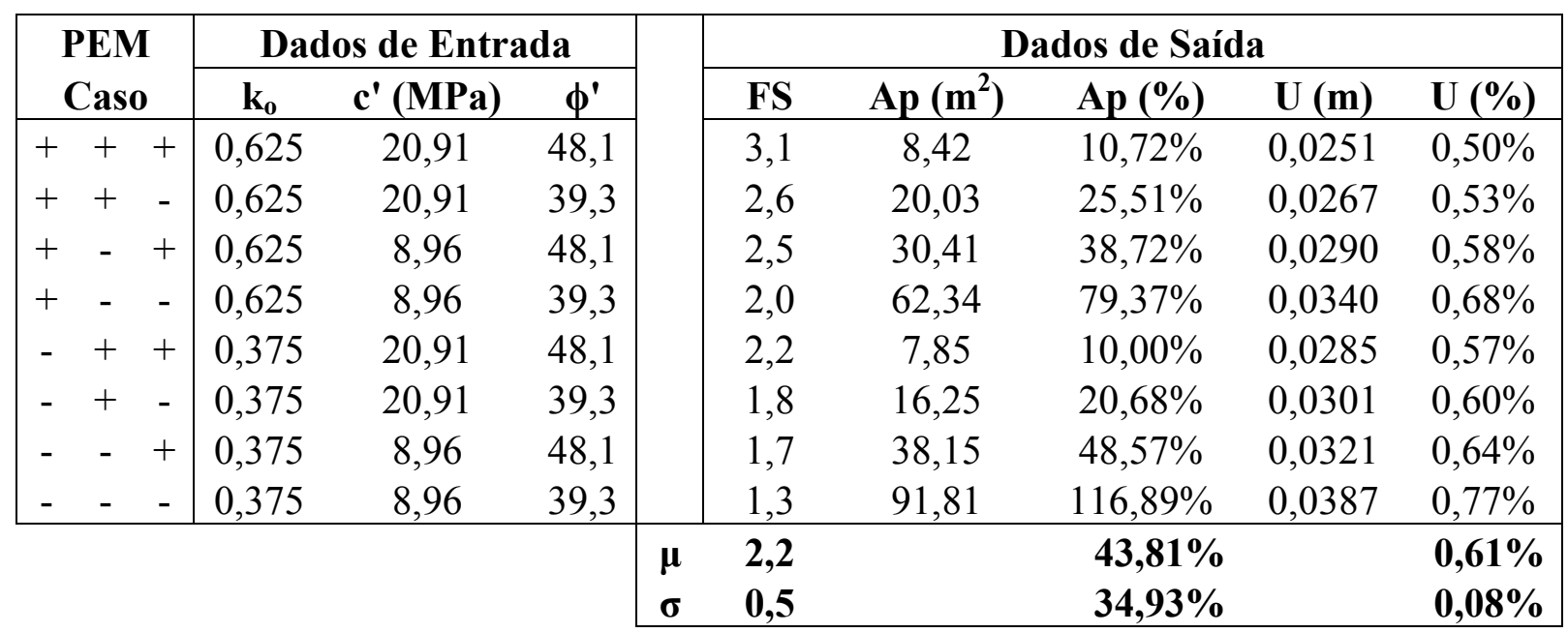




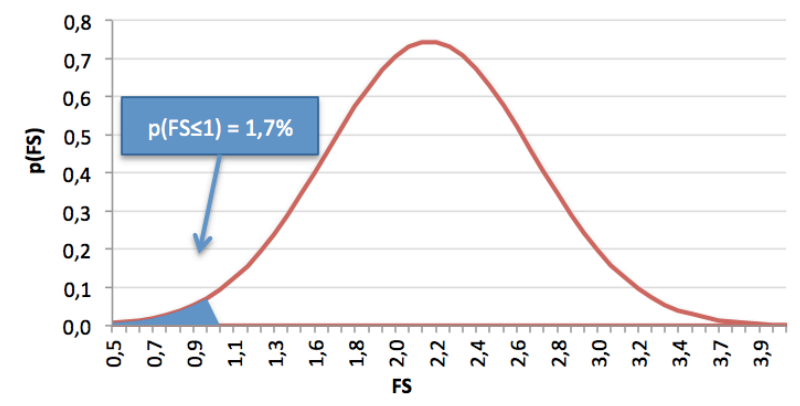

a)

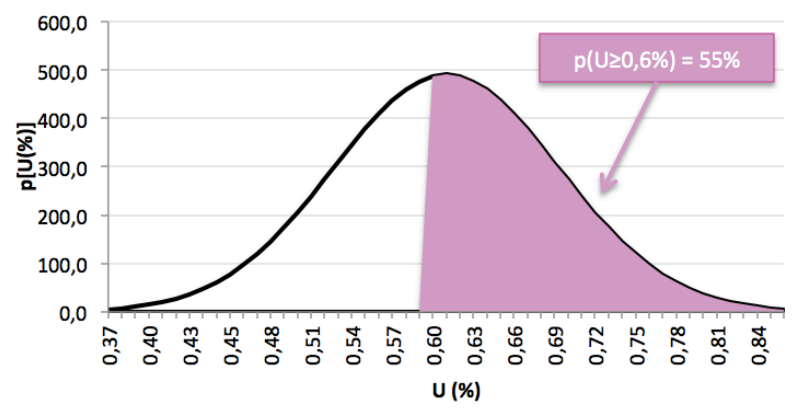

b)

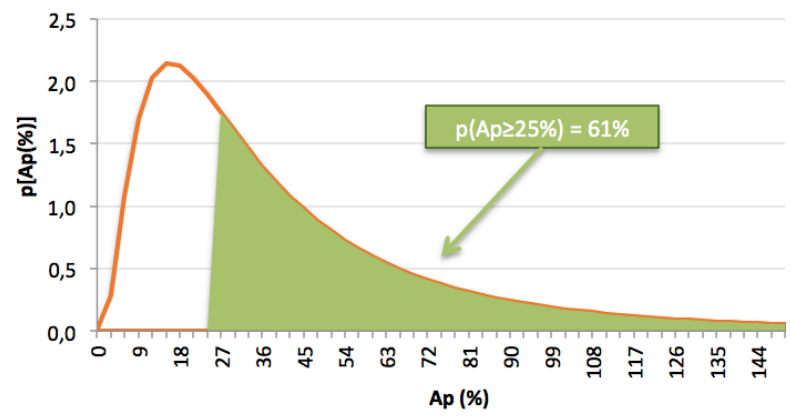

c)

Figura B.5- Frequência de ocorrência e probabilidade de falha: a) Fator de Segurança (FS);

b) Convergência (U); c) Área Plástica (Ap) - Rocha metamórfica, $\mathrm{k}_{\mathrm{o}}=0,5$, elevado nível de tensões, maciço rochoso moderadamente fraturado.

Tabela B.6 - Resultados obtidos com o método dos pontos de estimativa (Rosenblueth) Rocha metamórfica, $\mathrm{k}_{\mathrm{o}}=0,5$, elevado nível de tensões, maciço rochoso intensamente fraturado.

\begin{tabular}{|c|c|c|c|c|c|c|c|c|c|}
\hline \multirow{2}{*}{$\begin{array}{l}\text { PEM } \\
\text { Caso }\end{array}$} & \multicolumn{3}{|c|}{ Dados de Entrada } & & \multicolumn{5}{|c|}{ Dados de Saída } \\
\hline & $\mathbf{k}_{\mathbf{0}}$ & $\mathbf{c}^{\prime}$ (MPa) & $\phi^{\prime}$ & & FS & $\operatorname{Ap}\left(\mathrm{m}^{2}\right)$ & Ap (\%) & $\mathbf{U}(\mathbf{m})$ & $\mathrm{U}(\%)$ \\
\hline$+\quad+\quad+$ & 0,625 & 14,52 & 40,1 & & 2,3 & 30,86 & $39,29 \%$ & 0,1325 & $2,65 \%$ \\
\hline$+\quad+\quad-$ & 0,625 & 14,52 & 32,8 & & 1,9 & 53,49 & $68,11 \%$ & 0,1494 & $2,99 \%$ \\
\hline$+\quad-\quad+$ & 0,625 & 6,22 & 40,1 & & 1,8 & 88,98 & $113,30 \%$ & 0,1737 & $3,47 \%$ \\
\hline$+\quad-\quad-$ & 0,625 & 6,22 & 32,8 & & 1,5 & 164,41 & $209,33 \%$ & 0,2659 & $5,32 \%$ \\
\hline$-\quad+\quad+$ & 0,375 & 14,52 & 40,1 & & 1,6 & 40,28 & $51,29 \%$ & 0,1481 & $2,96 \%$ \\
\hline$-\quad+\quad-$ & 0,375 & 14,52 & 32,8 & & 1,4 & 109,89 & $139,92 \%$ & 0,1708 & $3,42 \%$ \\
\hline$-\quad-\quad+$ & 0,375 & 6,22 & 40,1 & & 1,2 & 118,14 & $150,42 \%$ & 0,2087 & $4,17 \%$ \\
\hline$-\quad-\quad-$ & 0,375 & 6,22 & 32,8 & & 1,1 & 503,81 & $641,47 \%$ & 0,2730 & $5,46 \%$ \\
\hline & & & & $\begin{array}{l}\mu \\
\sigma\end{array}$ & $\begin{array}{l}1,6 \\
0,4\end{array}$ & & $\begin{array}{l}176,64 \% \\
183,56 \%\end{array}$ & & $\begin{array}{l}3,81 \% \\
1,01 \%\end{array}$ \\
\hline
\end{tabular}




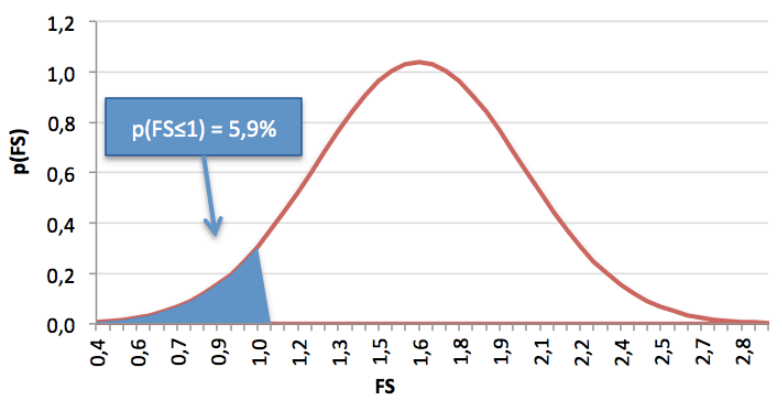

a)

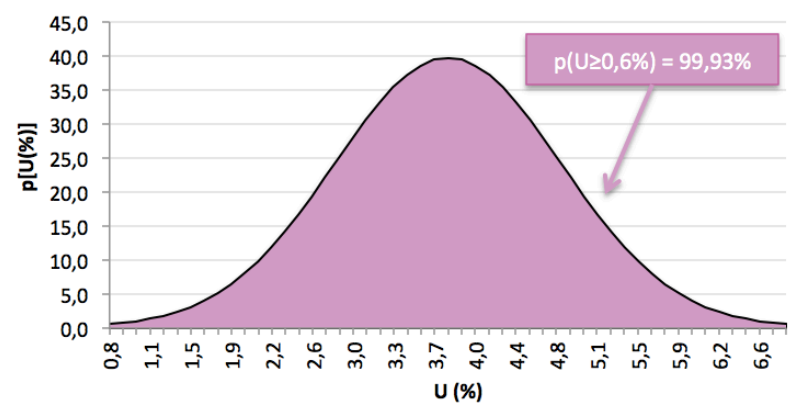

b)

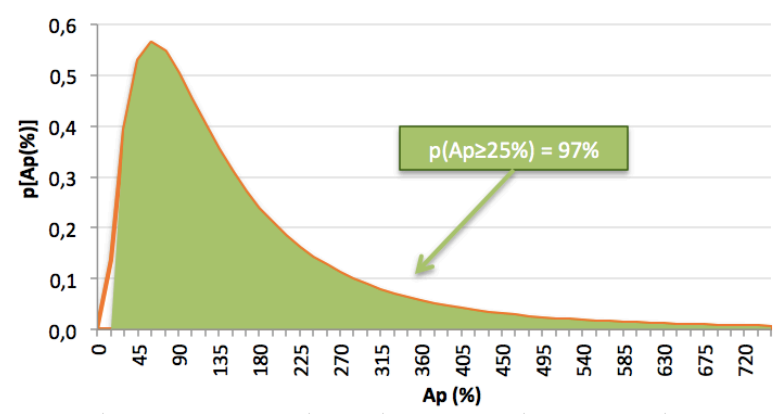

c)

Figura B.6- Frequência de ocorrência e probabilidade de falha: a) Fator de Segurança (FS);

b) Convergência (U); c) Área Plástica (Ap) - Rocha metamórfica, $\mathrm{k}_{\mathrm{o}}=0,5$, elevado nível de tensões, maciço rochoso intensamente fraturado.

\section{B.1.2. $K_{0}=1,0$}

\section{B.1.2.1. Baixo Nível de Tensões}

Tabela B.7 - Resultados obtidos com o método dos pontos de estimativa (Rosenblueth) Rocha metamórfica, $\mathrm{k}_{\mathrm{o}}=1,0$, baixo nível de tensões, maciço rochoso intensamente fraturado.

\begin{tabular}{|c|c|c|c|c|c|c|c|c|c|}
\hline \multirow{2}{*}{$\begin{array}{l}\text { PEM } \\
\text { Caso }\end{array}$} & \multicolumn{3}{|c|}{ Dados de Entrada } & & \multicolumn{5}{|c|}{ Dados de Saída } \\
\hline & $\mathbf{k}_{\mathbf{0}}$ & $\mathbf{c}^{\prime}$ (MPa) & $\phi^{\prime}$ & & FS & $\operatorname{Ap}\left(m^{2}\right)$ & Ap (\%) & $\mathbf{U}(\mathbf{m})$ & $\mathrm{U}(\%)$ \\
\hline$+\quad+\quad+$ & 1,25 & 5,03 & 53,7 & & 4,0 & 5,66 & $7,20 \%$ & 0,0257 & $0,51 \%$ \\
\hline$+\quad+\quad-$ & 1,25 & 5,03 & 43,9 & & 3,2 & 15,77 & $20,08 \%$ & 0,0275 & $0,55 \%$ \\
\hline$+\quad-\quad+$ & 1,25 & 2,15 & 53,7 & & 3,1 & 22,97 & $29,24 \%$ & 0,0294 & $0,59 \%$ \\
\hline$+\quad-\quad-$ & 1,25 & 2,15 & 43,9 & & 2,4 & 55,22 & $70,31 \%$ & 0,0351 & $0,70 \%$ \\
\hline$-\quad+\quad+$ & 0,75 & 5,03 & 53,7 & & 4,2 & 2,23 & $2,84 \%$ & 0,0209 & $0,42 \%$ \\
\hline$-\quad+\quad-$ & 0,75 & 5,03 & 43,9 & & 3,4 & 10,90 & $13,88 \%$ & 0,0217 & $0,43 \%$ \\
\hline$-\quad-\quad+$ & 0,75 & 2,15 & 53,7 & & 3,2 & 17,41 & $22,17 \%$ & 0,0230 & $0,46 \%$ \\
\hline$-\quad-\quad-$ & 0,75 & 2,15 & 43,9 & & 2,5 & 40,84 & $52,00 \%$ & 0,0262 & $0,52 \%$ \\
\hline & & & & $\begin{array}{l}\mu \\
\sigma\end{array}$ & $\begin{array}{l}3,3 \\
0,6\end{array}$ & & $\begin{array}{l}27,22 \% \\
21,57 \%\end{array}$ & & $\begin{array}{l}0,52 \% \\
0,09 \%\end{array}$ \\
\hline
\end{tabular}




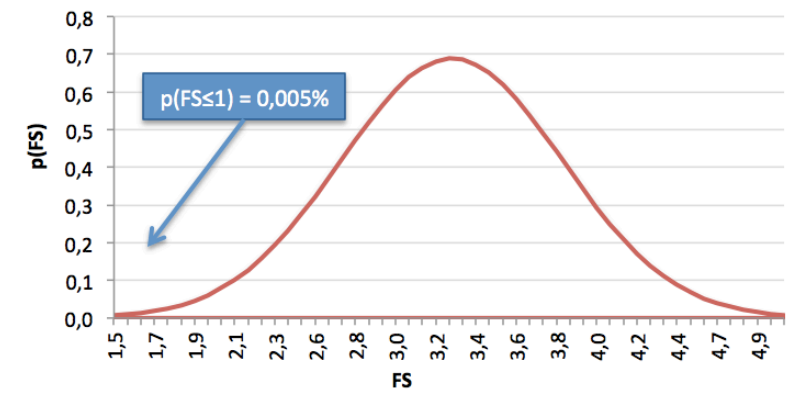

a)

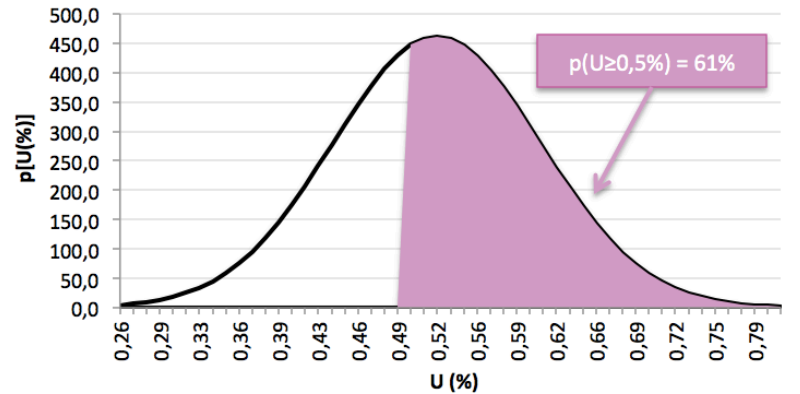

b)

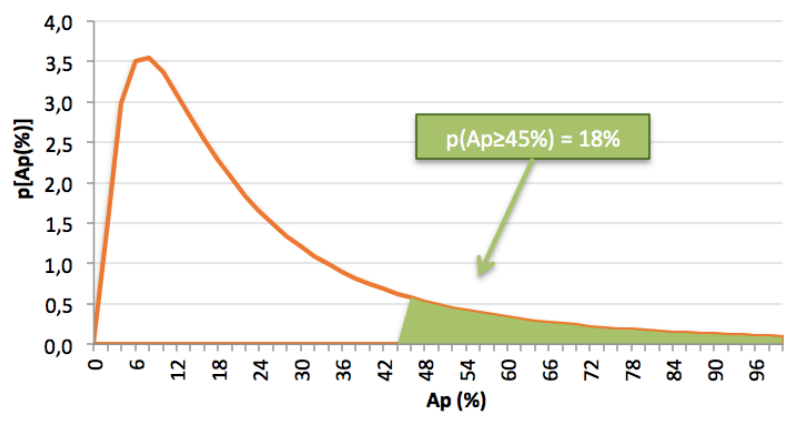

c)

Figura B.7- Frequência de ocorrência e probabilidade de falha: a) Fator de Segurança (FS);

b) Convergência (U); c) Área Plástica (Ap) - Rocha metamórfica, $\mathrm{k}_{\mathrm{o}}=1,0$, baixo nível de tensões, maciço rochoso intensamente fraturado.

\section{B.1.2.2. Moderado Nível de Tensões}

Tabela B.8 - Resultados obtidos com o método dos pontos de estimativa (Rosenblueth) Rocha metamórfica, $\mathrm{k}_{\mathrm{o}}=1,0$, moderado nível de tensões, maciço rochoso moderadamente fraturado.

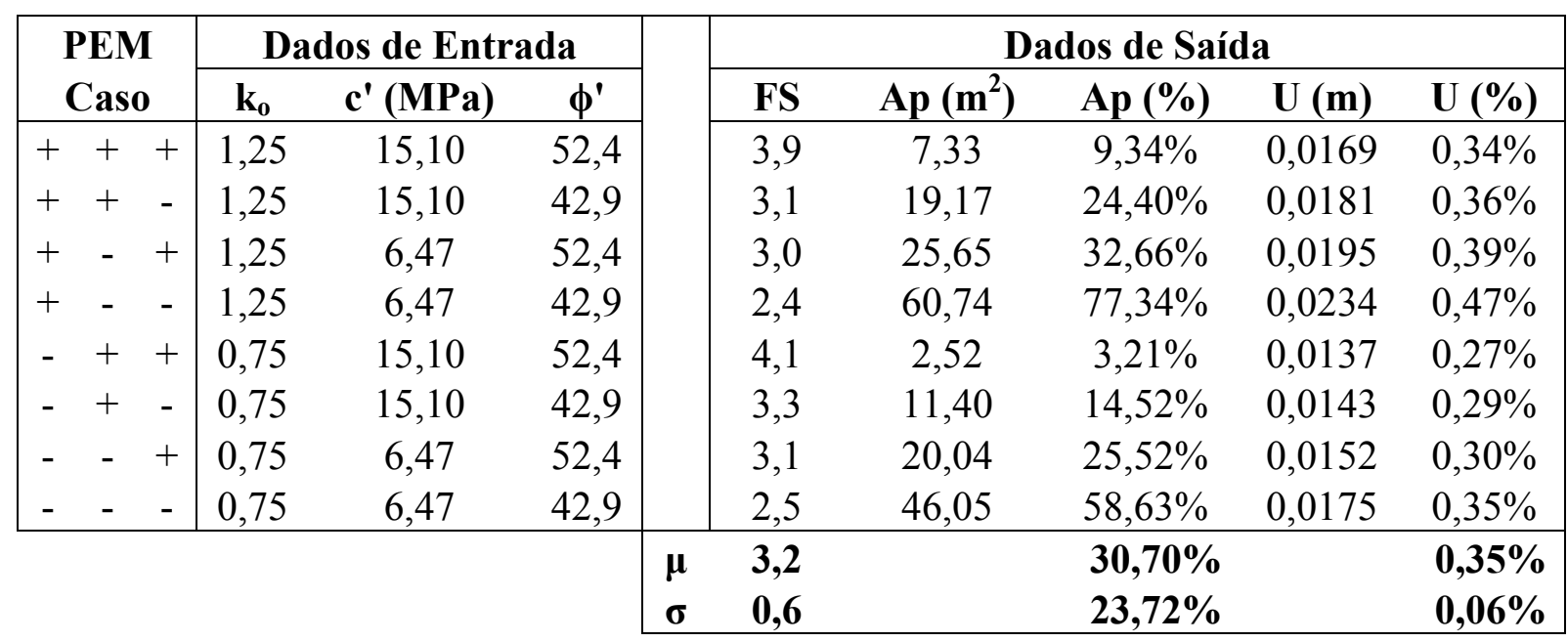




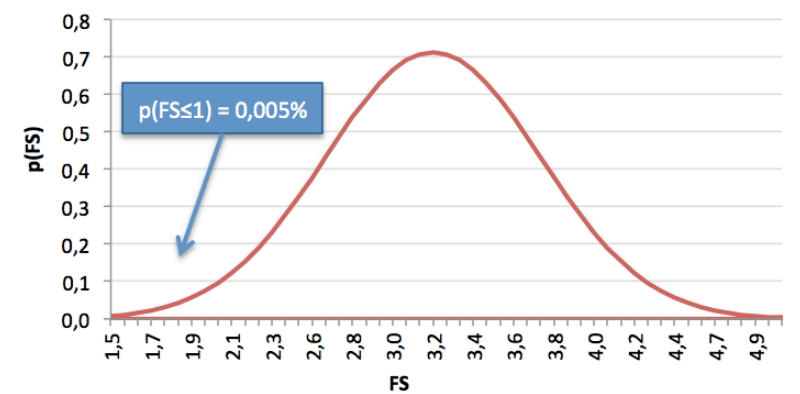

a)

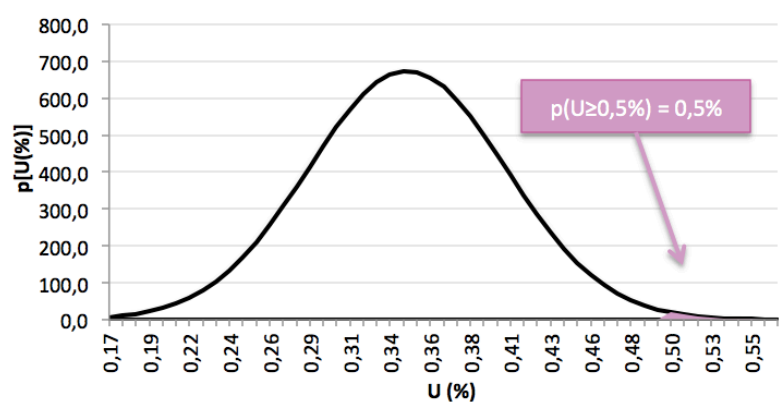

b)

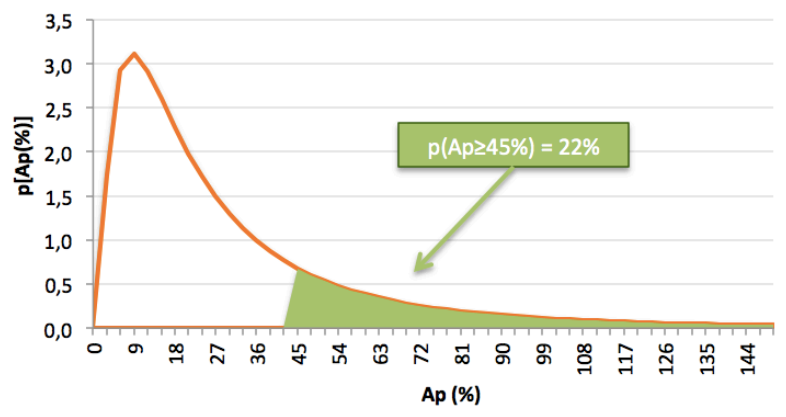

c)

Figura B.8- Frequência de ocorrência e probabilidade de falha: a) Fator de Segurança (FS);

b) Convergência (U); c) Área Plástica (Ap) - Rocha metamórfica, $\mathrm{k}_{\mathrm{o}}=1,0$, moderado nível de tensões, maciço rochoso moderadamente fraturado.

Tabela B.9 - Resultados obtidos com o método dos pontos de estimativa (Rosenblueth) Rocha metamórfica, $\mathrm{k}_{\mathrm{o}}=1,0$, moderado nível de tensões, maciço rochoso intensamente fraturado.

\begin{tabular}{|c|c|c|c|c|c|c|c|c|c|}
\hline \multirow{2}{*}{$\begin{array}{l}\text { PEM } \\
\text { Caso }\end{array}$} & \multicolumn{3}{|c|}{ Dados de Entrada } & & \multicolumn{5}{|c|}{ Dados de Saída } \\
\hline & $\mathbf{k}_{\mathbf{0}}$ & $\mathrm{c}^{\prime}(\mathrm{MPa})$ & $\phi^{\prime}$ & & FS & $\operatorname{Ap}\left(m^{2}\right)$ & Ap (\%) & $\mathbf{U}(\mathrm{m})$ & $\mathrm{U}(\%)$ \\
\hline$+\quad+\quad+$ & 1,25 & 10,39 & 44,5 & & 2,8 & 30,63 & $38,99 \%$ & 0,0895 & $1,79 \%$ \\
\hline$+\quad+\quad-$ & 1,25 & 10,39 & 36,4 & & 2,3 & 60,29 & $76,76 \%$ & 0,1031 & $2,06 \%$ \\
\hline$+\quad-\quad+$ & 1,25 & 4,45 & 44,5 & & 2,2 & 74,03 & $94,26 \%$ & 0,1179 & $2,36 \%$ \\
\hline$+\quad-\quad-$ & 1,25 & 4,45 & 36,4 & & 1,8 & 148,56 & $189,16 \%$ & 0,1659 & $3,32 \%$ \\
\hline$-\quad+\quad+$ & 0,75 & 10,39 & 44,5 & & 3,0 & 20,04 & $25,51 \%$ & 0,0687 & $1,37 \%$ \\
\hline$-\quad+\quad-$ & 0,75 & 10,39 & 36,4 & & 2,5 & 41,03 & $52,23 \%$ & 0,0761 & $1,52 \%$ \\
\hline$-\quad-\quad+$ & 0,75 & 4,45 & 44,5 & & 3,3 & 58,54 & $74,54 \%$ & 0,0874 & $1,75 \%$ \\
\hline$-\quad-$ & 0,75 & 4,45 & 36,4 & & 1,9 & 117,29 & $149,34 \%$ & 0,1097 & $2,19 \%$ \\
\hline & & & & $\begin{array}{l}\mu \\
\sigma\end{array}$ & $\begin{array}{l}2,5 \\
0,5\end{array}$ & & $\begin{array}{l}87,60 \% \\
52,35 \%\end{array}$ & & $\begin{array}{l}2,05 \% \\
0,57 \%\end{array}$ \\
\hline
\end{tabular}




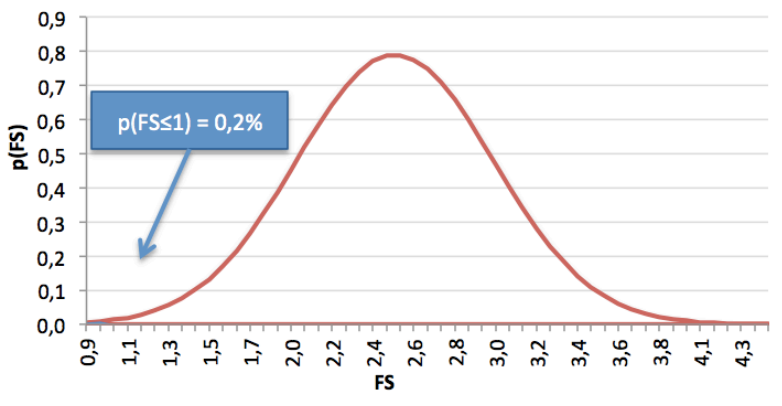

a)

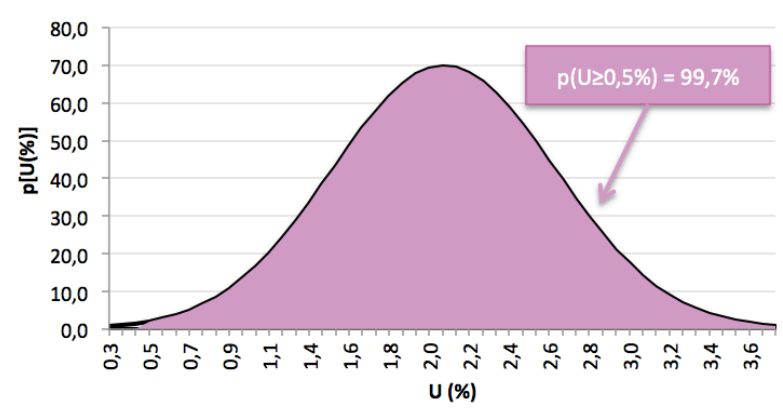

b)

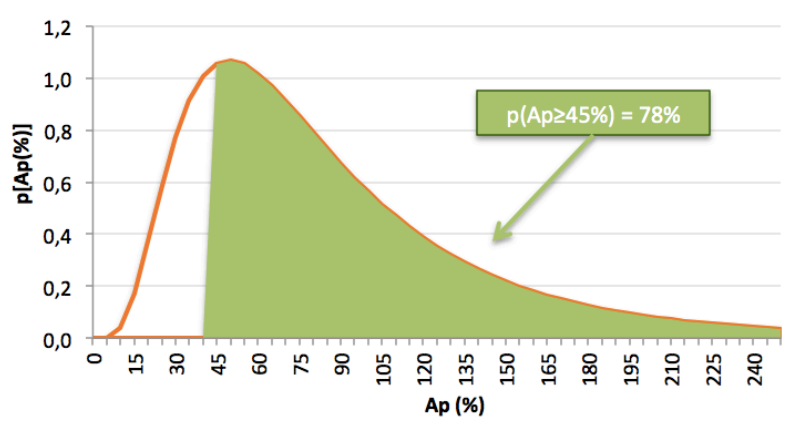

c)

Figura B.9- Frequência de ocorrência e probabilidade de falha: a) Fator de Segurança (FS);

b) Convergência (U); c) Área Plástica (Ap) - Rocha metamórfica, $\mathrm{k}_{\mathrm{o}}=1,0$, moderado nível de tensões, maciço rochoso intensamente fraturado.

\section{B.1.2.3. Elevado Nível de Tensões}

Tabela B.10 - Resultados obtidos com o método dos pontos de estimativa (Rosenblueth) Rocha metamórfica, $\mathrm{k}_{\mathrm{o}}=1,0$, elevado nível de tensões, maciço rochoso intacto.

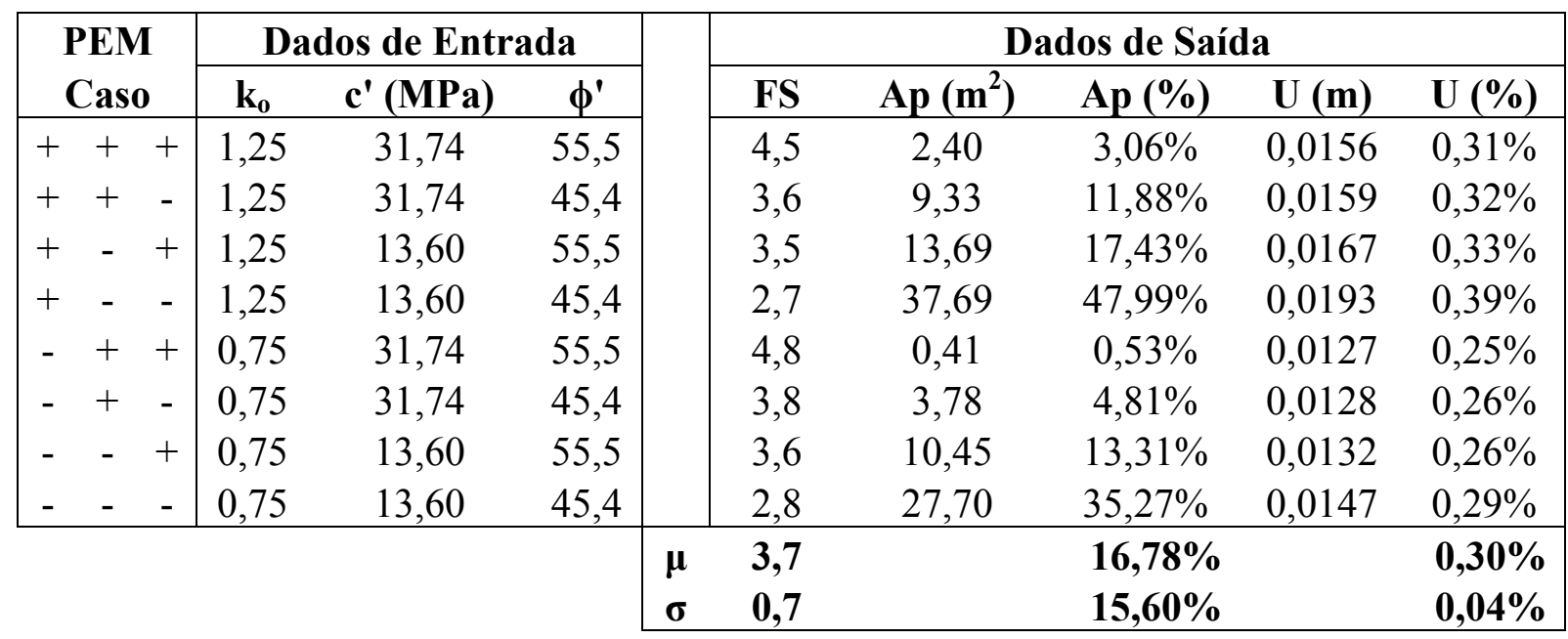




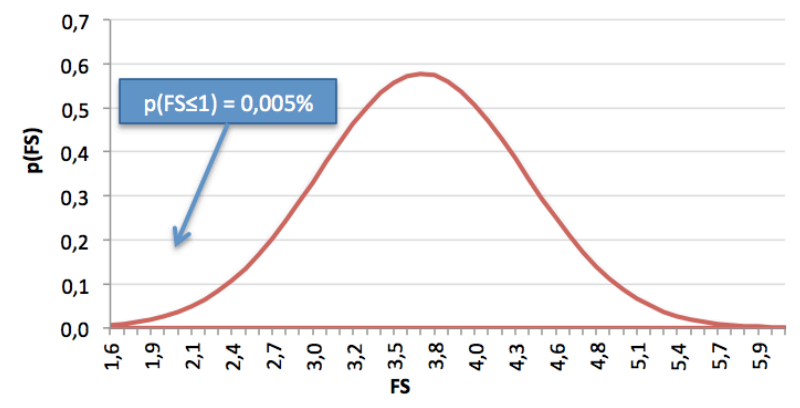

a)

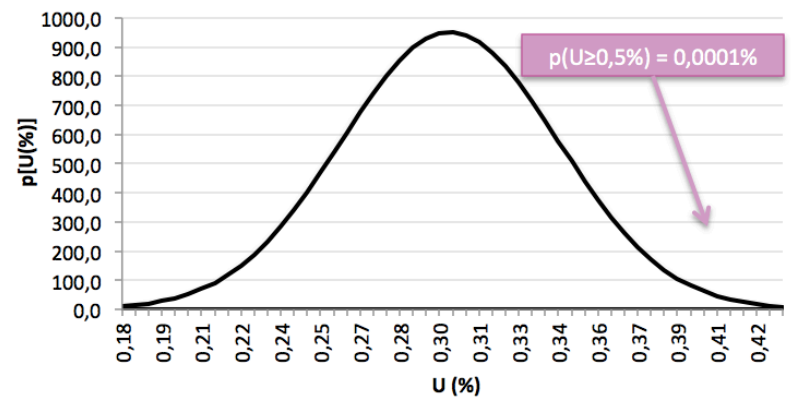

b)

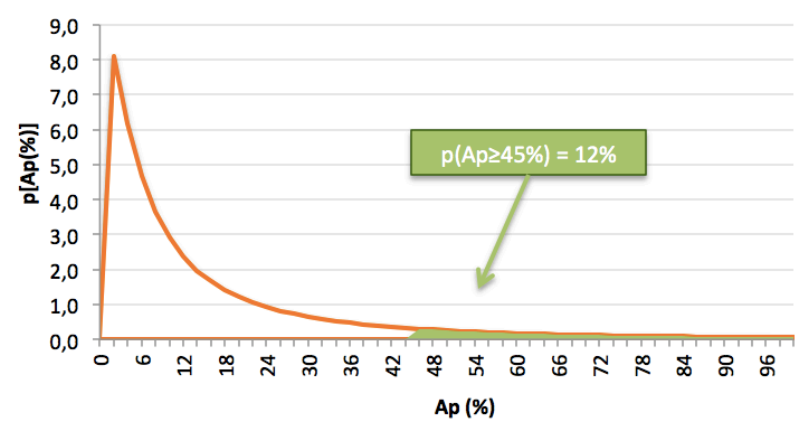

c)

Figura B.10 - Frequência de ocorrência e probabilidade de falha: a) Fator de Segurança (FS); b) Convergência (U); c) Área Plástica (Ap) - Rocha metamórfica, $\mathrm{k}_{\mathrm{o}}=1$, 0 , elevado nível de tensões, maciço rochoso intacto.

Tabela B.11 - Resultados obtidos com o método dos pontos de estimativa (Rosenblueth) Rocha metamórfica, $\mathrm{k}_{\mathrm{o}}=1,0$, elevado nível de tensões, maciço rochoso moderadamente fraturado.

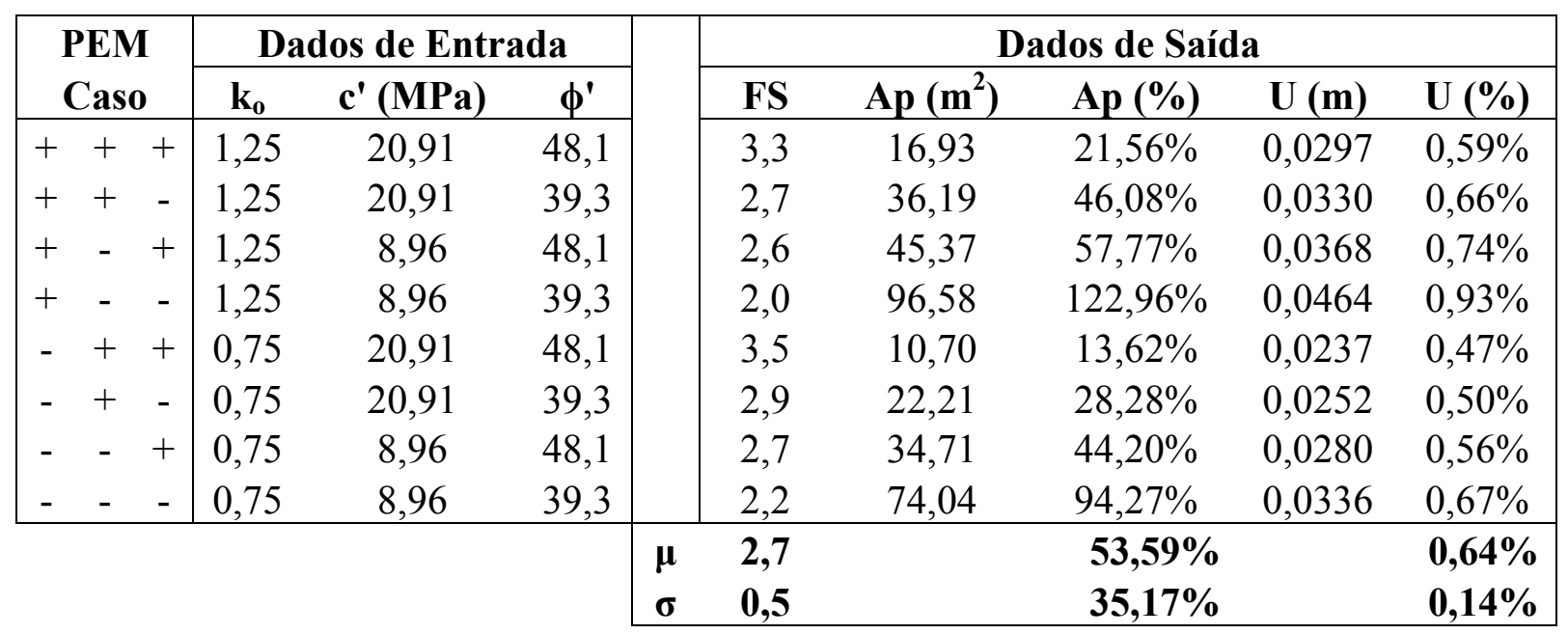




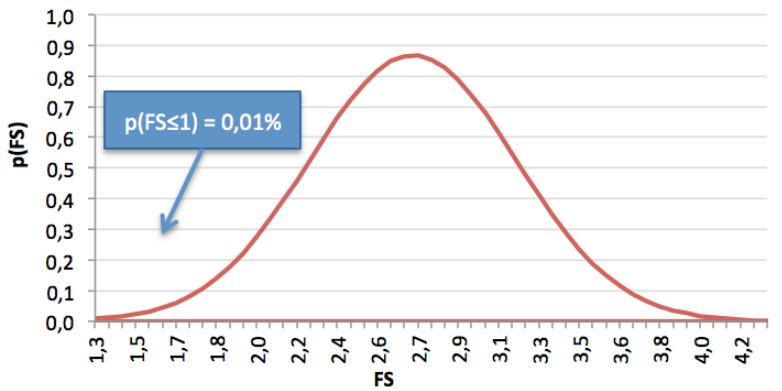

a)

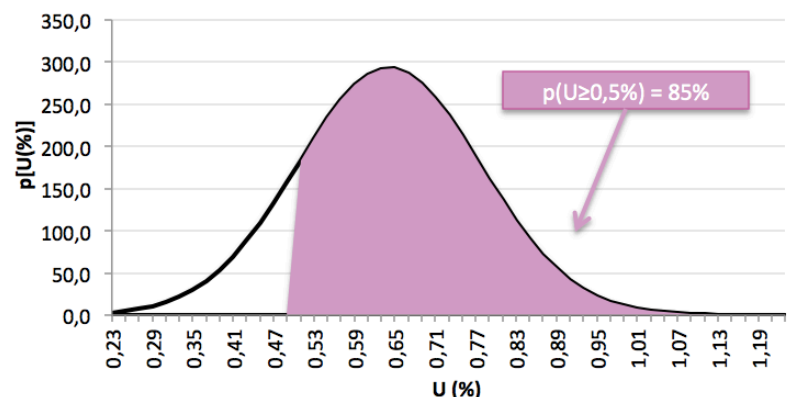

b)

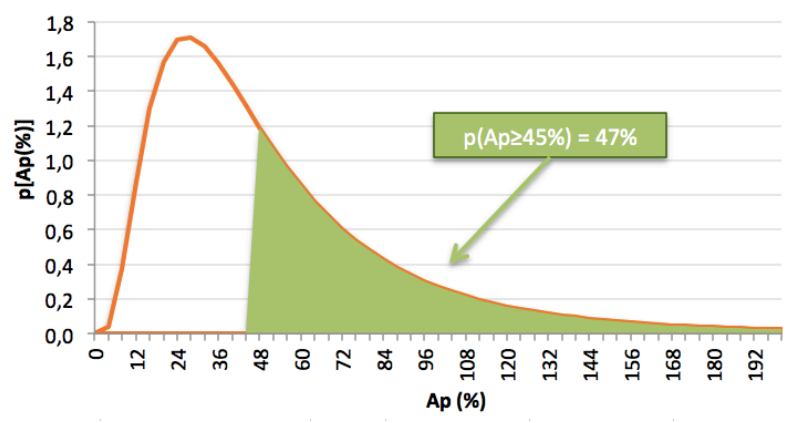

c)

Figura B.11- Frequência de ocorrência e probabilidade de falha: a) Fator de Segurança (FS); b) Convergência (U); c) Área Plástica (Ap) - Rocha metamórfica, $\mathrm{k}_{\mathrm{o}}=1$, 0 , elevado nível de tensões, maciço rochoso moderadamente fraturado.

Tabela B.12 - Resultados obtidos com o método dos pontos de estimativa (Rosenblueth) Rocha metamórfica, $\mathrm{k}_{\mathrm{o}}=1,0$, elevado nível de tensões, maciço rochoso intensamente fraturado.

\begin{tabular}{|c|c|c|c|c|c|c|c|c|c|}
\hline \multirow{2}{*}{$\begin{array}{l}\text { PEM } \\
\text { Caso }\end{array}$} & \multicolumn{3}{|c|}{ Dados de Entrada } & & \multicolumn{5}{|c|}{ Dados de Saída } \\
\hline & $\mathbf{k}_{\mathbf{0}}$ & $\mathrm{c}^{\prime}$ (MPa) & $\phi^{\prime}$ & & FS & $\operatorname{Ap}\left(m^{2}\right)$ & Ap (\%) & $\mathbf{U}(\mathbf{m})$ & $\mathrm{U}(\%)$ \\
\hline$+\quad+\quad+$ & 1,25 & 14,52 & 40,1 & & 2,4 & 56,32 & $71,71 \%$ & 0,1709 & $3,42 \%$ \\
\hline$+\quad+-$ & 1,25 & 14,52 & 32,8 & & 2,0 & 102,66 & $130,71 \%$ & 0,2052 & $4,10 \%$ \\
\hline$+\quad-\quad+$ & 1,25 & 6,22 & 40,1 & & 1,9 & 124,65 & $158,71 \%$ & 0,2455 & $4,91 \%$ \\
\hline$+\quad-\quad-$ & 1,25 & 6,22 & 32,8 & & 1,5 & 289,30 & $368,35 \%$ & 0,4293 & $8,59 \%$ \\
\hline$-\quad+\quad+$ & 0,75 & 14,52 & 40,1 & & 2,5 & 38,76 & $49,34 \%$ & 0,1272 & $2,54 \%$ \\
\hline$-\quad+\quad-$ & 0,75 & 14,52 & 32,8 & & 2,1 & 72,03 & $91,71 \%$ & 0,1459 & $2,92 \%$ \\
\hline$-\quad-\quad+$ & 0,75 & 6,22 & 40,1 & & 2,0 & 99,10 & $126,18 \%$ & 0,1742 & $3,48 \%$ \\
\hline$-\quad-$ & 0,75 & 6,22 & 32,8 & & 1,6 & 203,80 & $259,49 \%$ & 0,2745 & $5,49 \%$ \\
\hline & & & & $\mu$ & 2,0 & & $157,03 \%$ & & $4,43 \%$ \\
\hline & & & & $\sigma$ & $\mathbf{0 , 3}$ & & $99,97 \%$ & & $1,82 \%$ \\
\hline
\end{tabular}




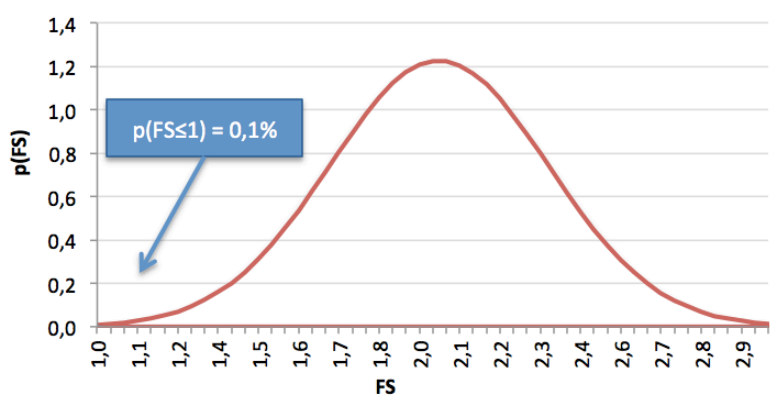

a)

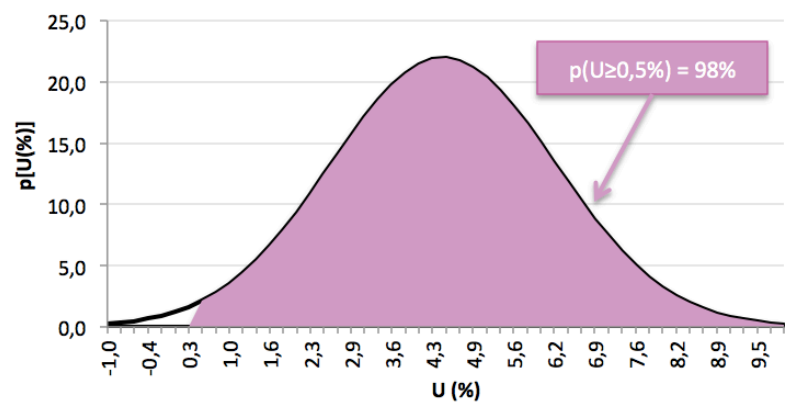

b)

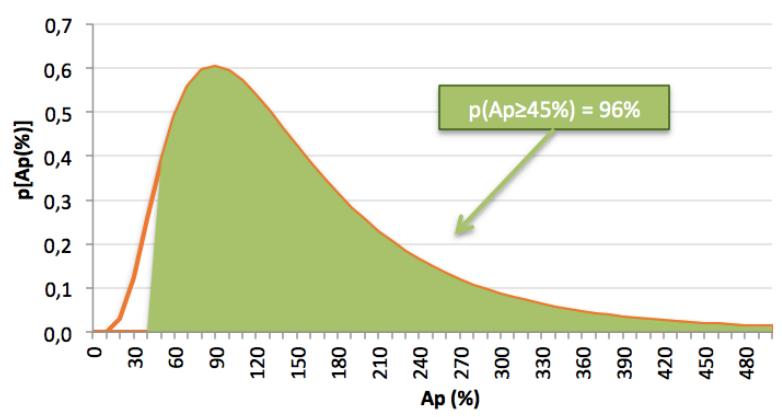

c)

Figura B.12 - Frequência de ocorrência e probabilidade de falha: a) Fator de Segurança (FS); b) Convergência (U); c) Área Plástica (Ap) - Rocha metamórfica, $\mathrm{k}_{\mathrm{o}}=1,0$, elevado nível de tensões, maciço rochoso intensamente fraturado.

\section{B.1.3. $K_{0}=2,0$}

\section{B.1.3.1. Baixo Nível de Tensões}

Tabela B.13 - Resultados obtidos com o método dos pontos de estimativa (Rosenblueth) Rocha metamórfica, $\mathrm{k}_{\mathrm{o}}=2,0$, baixo nível de tensões, maciço rochoso intensamente fraturado.

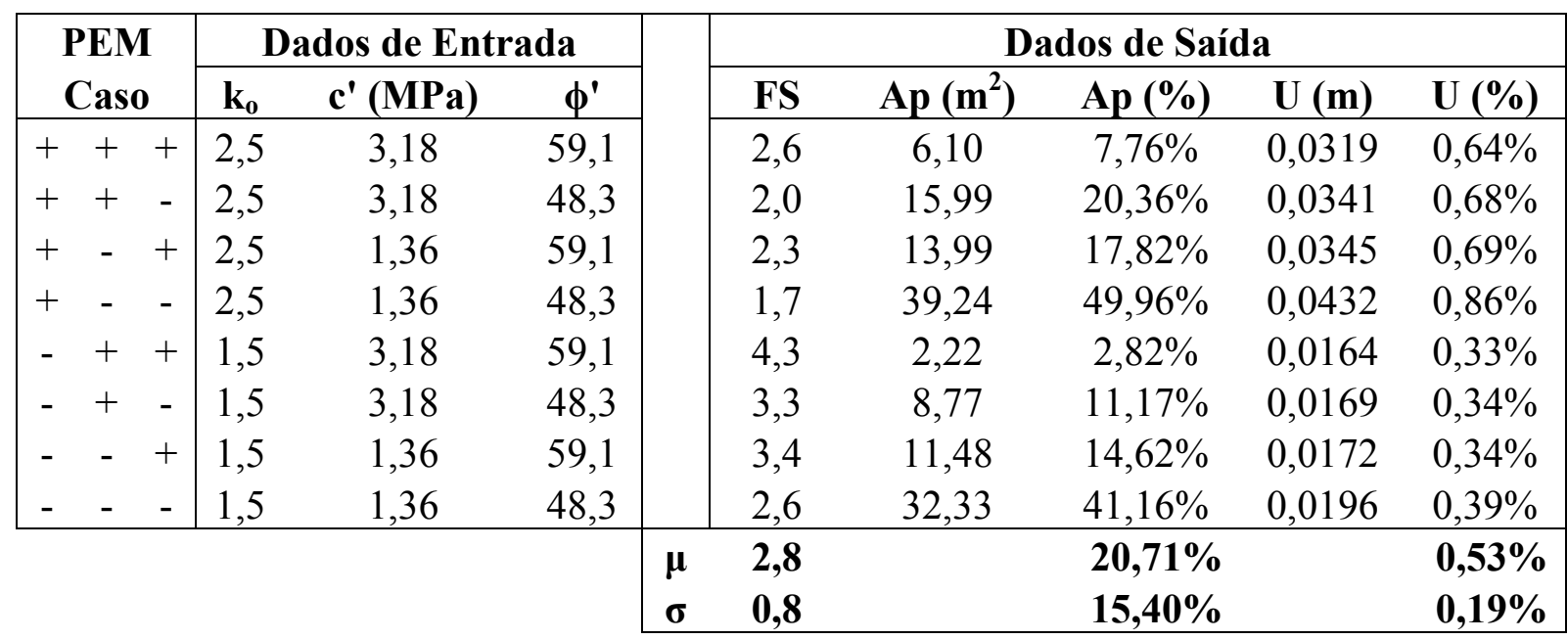




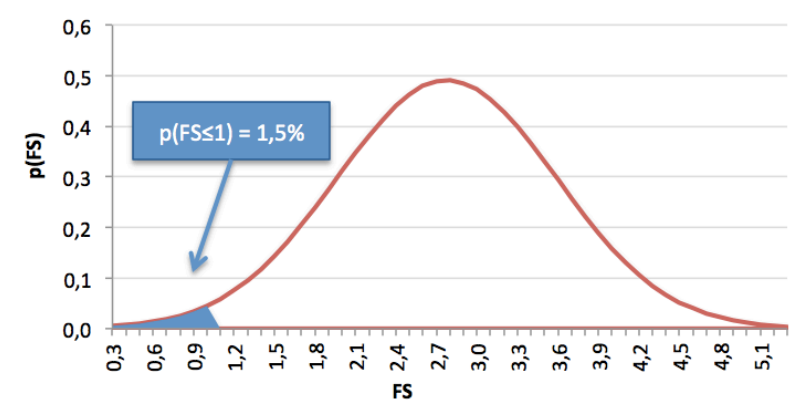

a)

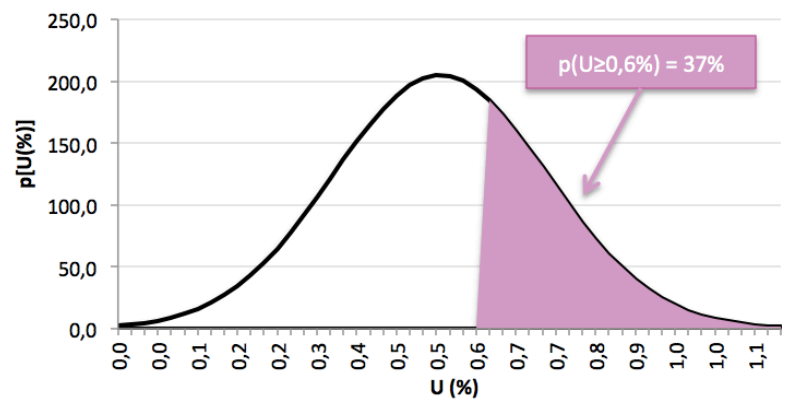

b)

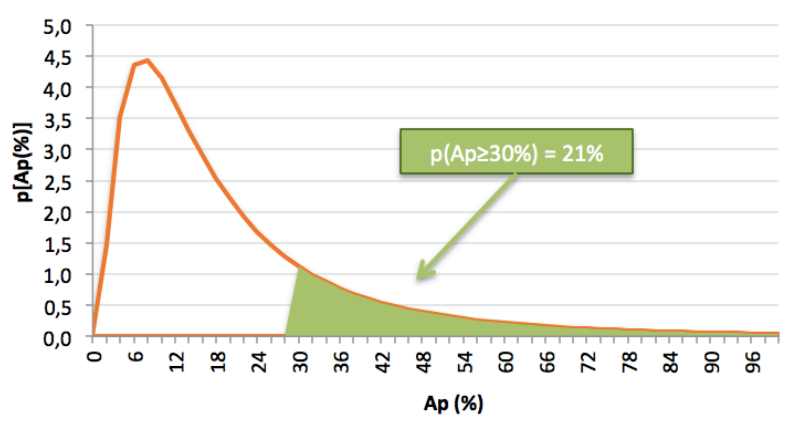

c)

Figura B.13 - Frequência de ocorrência e probabilidade de falha: a) Fator de Segurança (FS); b) Convergência $(U)$; c) Área Plástica (Ap) - Rocha metamórfica, $\mathrm{k}_{0}=2,0$, baixo nível de tensões, maciço rochoso intensamente fraturado.

\section{B.1.3.2. Moderado Nível de Tensões}

Tabela B.14 - Resultados obtidos com o método dos pontos de estimativa (Rosenblueth) Rocha metamórfica, $\mathrm{k}_{\mathrm{o}}=2,0$, moderado nível de tensões, maciço rochoso moderadamente fraturado.

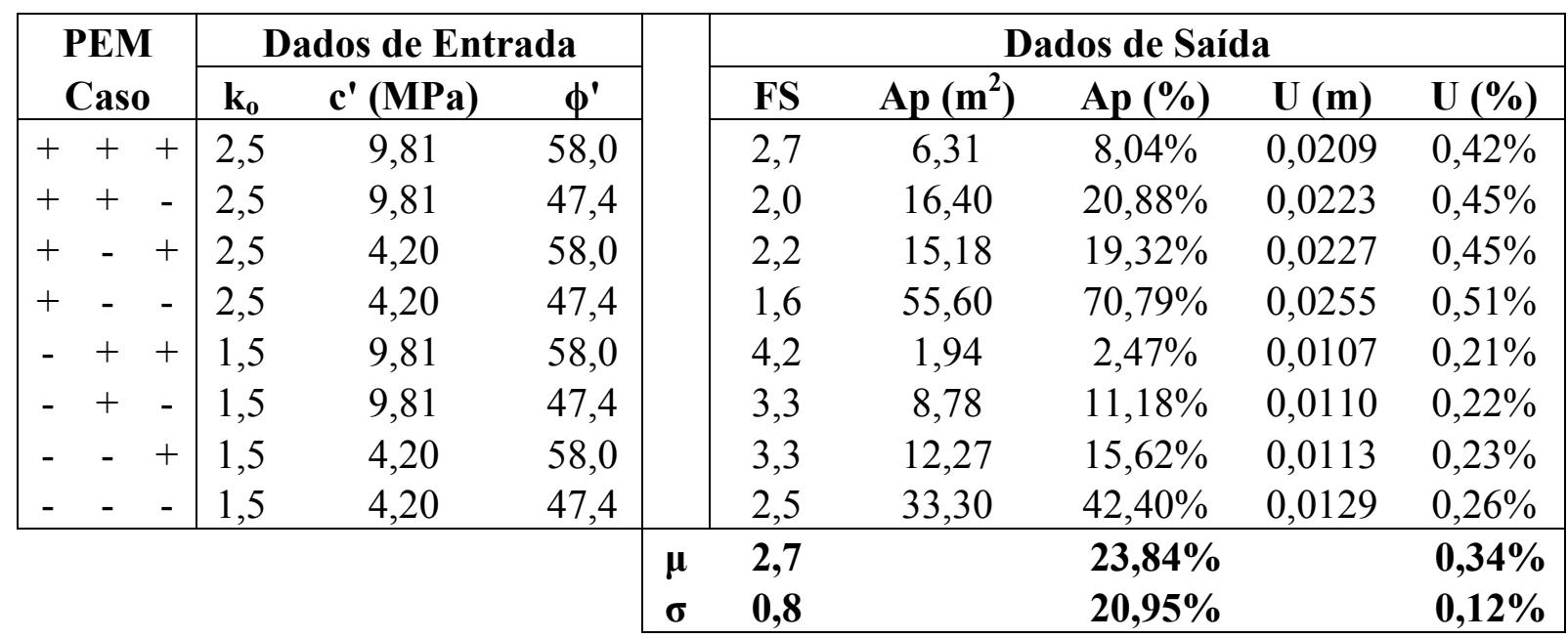




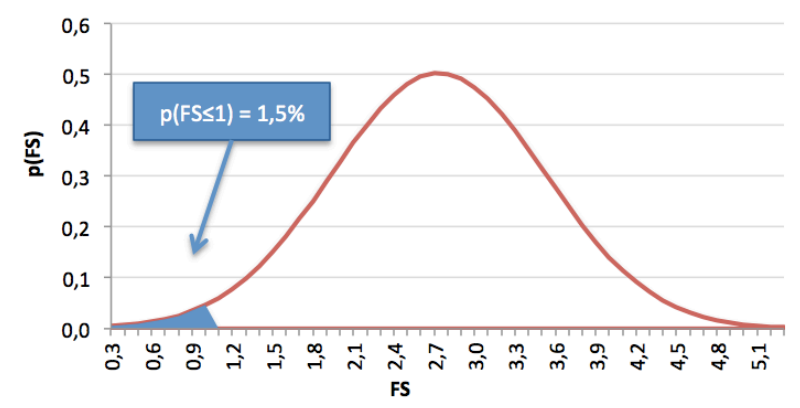

a)

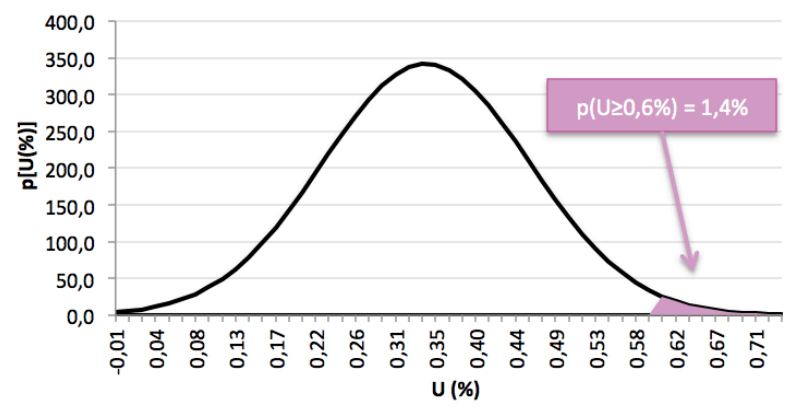

b)

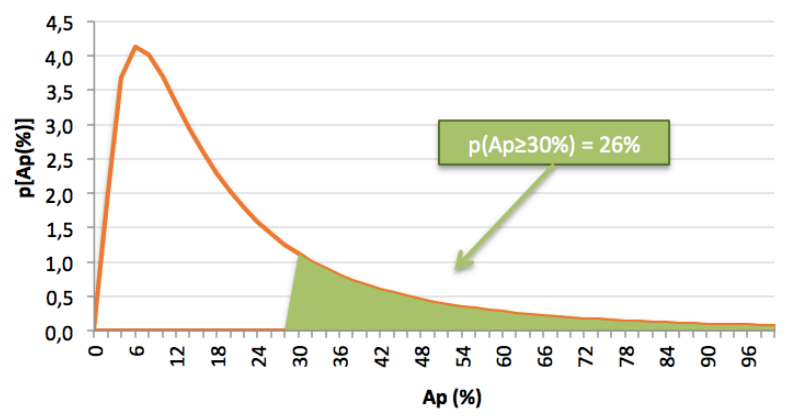

c)

Figura B.14- Frequência de ocorrência e probabilidade de falha: a) Fator de Segurança (FS);

b) Convergência (U); c) Área Plástica (Ap) - Rocha metamórfica, $\mathrm{k}_{\mathrm{o}}=2,0$, moderado nível de tensões, maciço rochoso moderadamente fraturado.

Tabela B.15 - Resultados obtidos com o método dos pontos de estimativa (Rosenblueth) -

Rocha metamórfica, $\mathrm{k}_{\mathrm{o}}=2,0$, moderado nível de tensões, maciço rochoso intensamente fraturado.

\begin{tabular}{|c|c|c|c|c|c|c|c|c|c|}
\hline \multirow{2}{*}{$\begin{array}{l}\text { PEM } \\
\text { Caso }\end{array}$} & \multicolumn{3}{|c|}{ Dados de Entrada } & & \multicolumn{5}{|c|}{ Dados de Saída } \\
\hline & $\mathbf{k}_{\mathbf{0}}$ & $\mathbf{c}^{\prime}$ (MPa) & $\phi^{\prime}$ & & FS & $\operatorname{Ap}\left(\mathrm{m}^{2}\right)$ & Ap (\%) & $\mathbf{U}(\mathbf{m})$ & U (\%) \\
\hline$+\quad+\quad+$ & 2,5 & 6,57 & 50,3 & & 1,9 & 21,26 & $27,07 \%$ & 0,1064 & $2,13 \%$ \\
\hline$+\quad+\quad-$ & 2,5 & 6,57 & 41,2 & & 1,5 & 80,85 & $102,94 \%$ & 0,1242 & $2,48 \%$ \\
\hline$+\quad-\quad+$ & 2,5 & 2,82 & 50,3 & & 1,6 & 39,72 & $50,58 \%$ & 0,1143 & $2,29 \%$ \\
\hline$+\quad-\quad-$ & 2,5 & 2,82 & 41,2 & & 1,3 & 134,47 & $171,22 \%$ & 0,1717 & $3,43 \%$ \\
\hline$-\quad+\quad+$ & 1,5 & 6,57 & 50,3 & & 3,1 & 13,92 & $17,72 \%$ & 0,0524 & $1,05 \%$ \\
\hline$-\quad+\quad-$ & 1,5 & 6,57 & 41,2 & & 2,5 & 31,79 & $40,47 \%$ & 0,0577 & $1,15 \%$ \\
\hline$-\quad-\quad+$ & 1,5 & 2,82 & 50,3 & & 2,5 & 37,01 & $47,12 \%$ & 0,0618 & $1,24 \%$ \\
\hline$-\quad-\quad-$ & 1,5 & 2,82 & 41,2 & & 1,9 & 80,38 & $102,34 \%$ & 0,0756 & $1,51 \%$ \\
\hline & & & & $\begin{array}{l}\mu \\
\sigma\end{array}$ & $\begin{array}{l}2,0 \\
0,6\end{array}$ & & $\begin{array}{l}69,93 \% \\
48,38 \%\end{array}$ & & $\begin{array}{l}1,91 \% \\
0,77 \%\end{array}$ \\
\hline
\end{tabular}




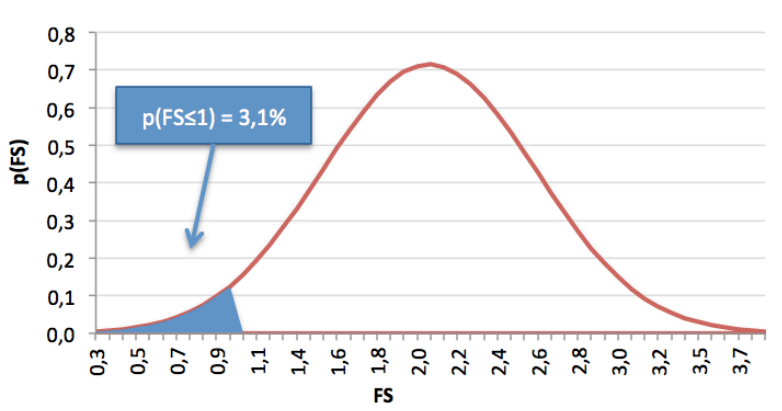

a)

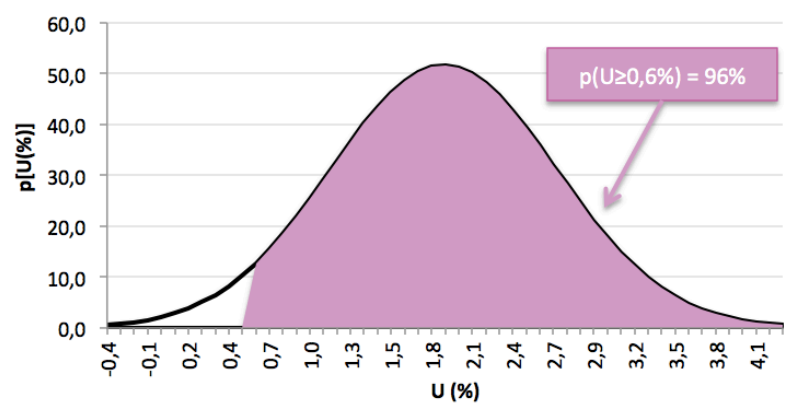

b)

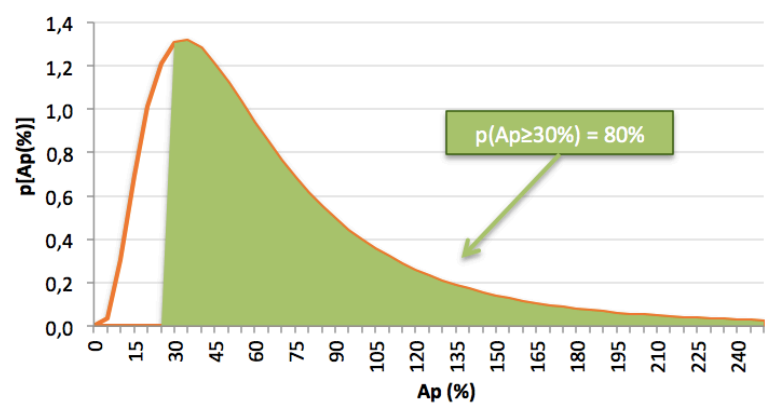

c)

Figura B.15- Frequência de ocorrência e probabilidade de falha: a) Fator de Segurança (FS); b) Convergência (U); c) Área Plástica (Ap) - Rocha metamórfica, $\mathrm{k}_{\mathrm{o}}=2,0$, moderado nível de tensões, maciço rochoso intensamente fraturado.

\section{B.1.3.3. Elevado Nível de Tensões}

Tabela B.16 - Resultados obtidos com o método dos pontos de estimativa (Rosenblueth) Rocha metamórfica, $\mathrm{k}_{\mathrm{o}}=2,0$, elevado nível de tensões, maciço rochoso intacto.

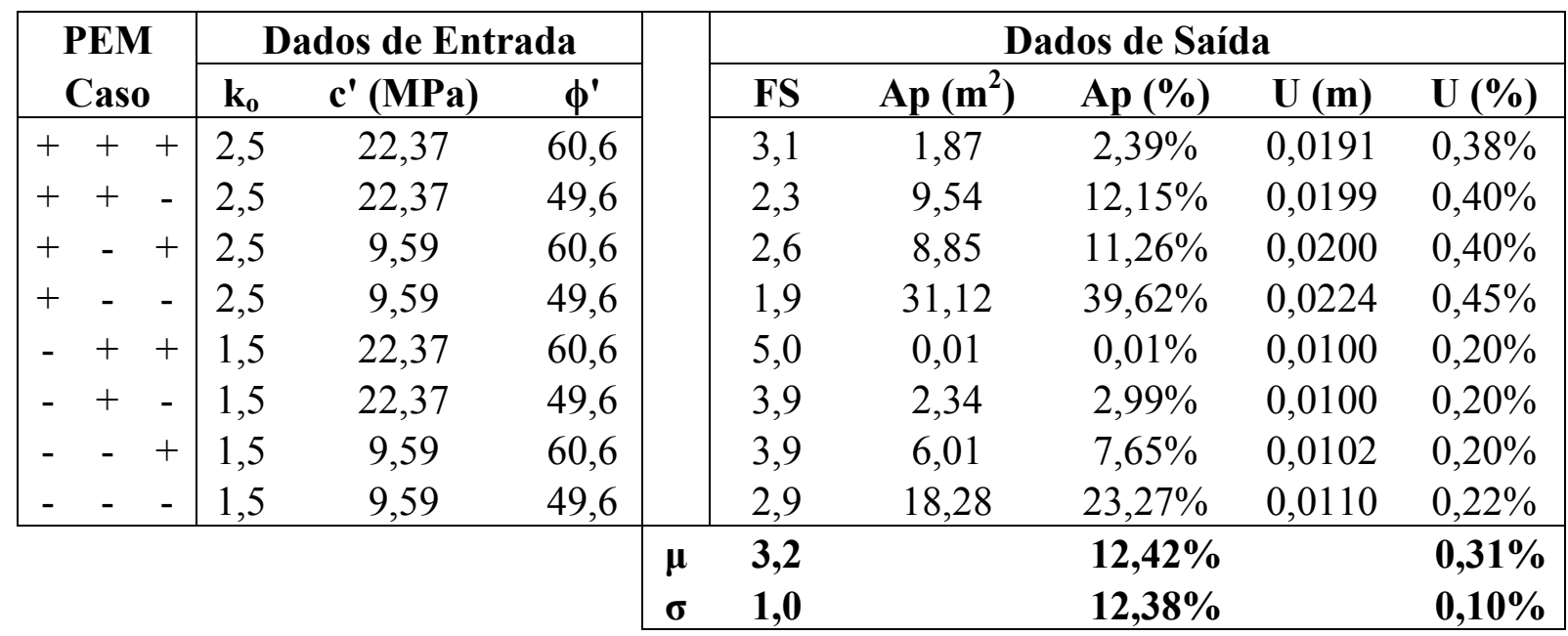




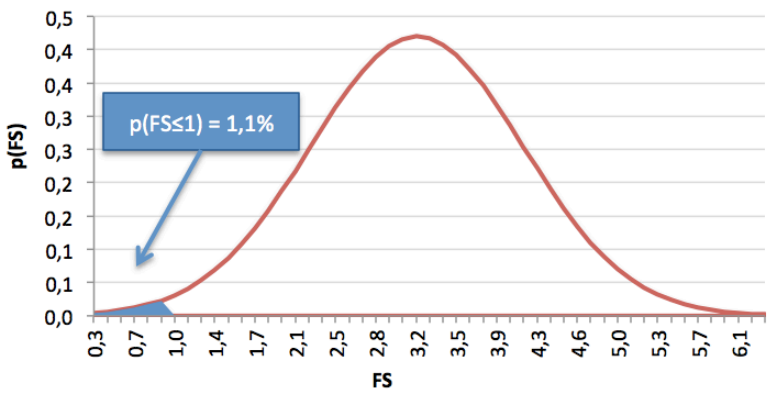

a)

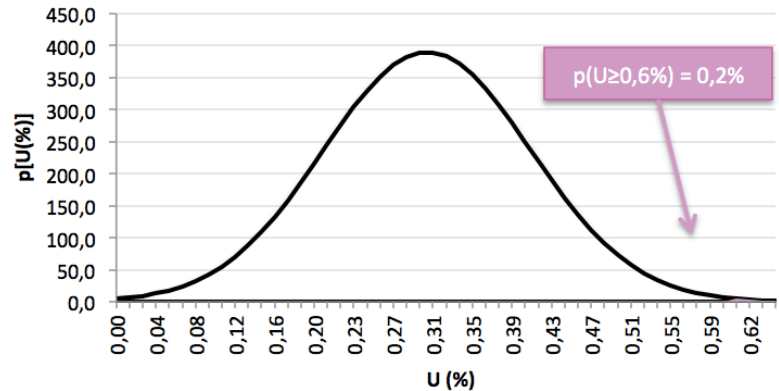

b)

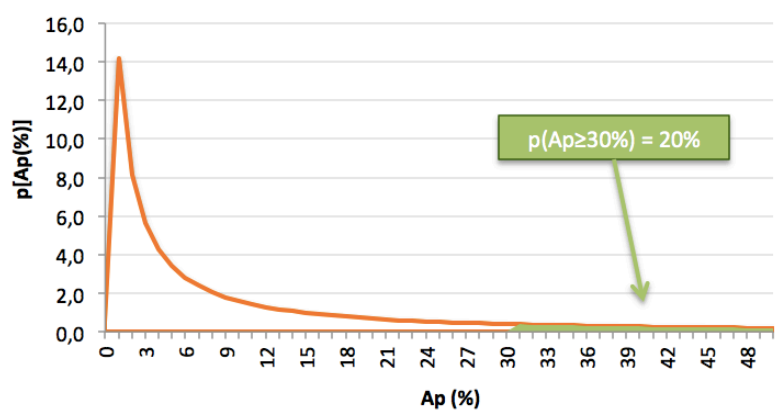

c)

Figura B.16- Frequência de ocorrência e probabilidade de falha: a) Fator de Segurança (FS); b) Convergência (U); c) Área Plástica (Ap) - Rocha metamórfica, $\mathrm{k}_{\mathrm{o}}=2,0$, elevado nível de tensões, maciço rochoso intacto.

Tabela B.17 - Resultados obtidos com o método dos pontos de estimativa (Rosenblueth) Rocha metamórfica, $\mathrm{k}_{\mathrm{o}}=2,0$, elevado nível de tensões, maciço rochoso moderadamente fraturado.

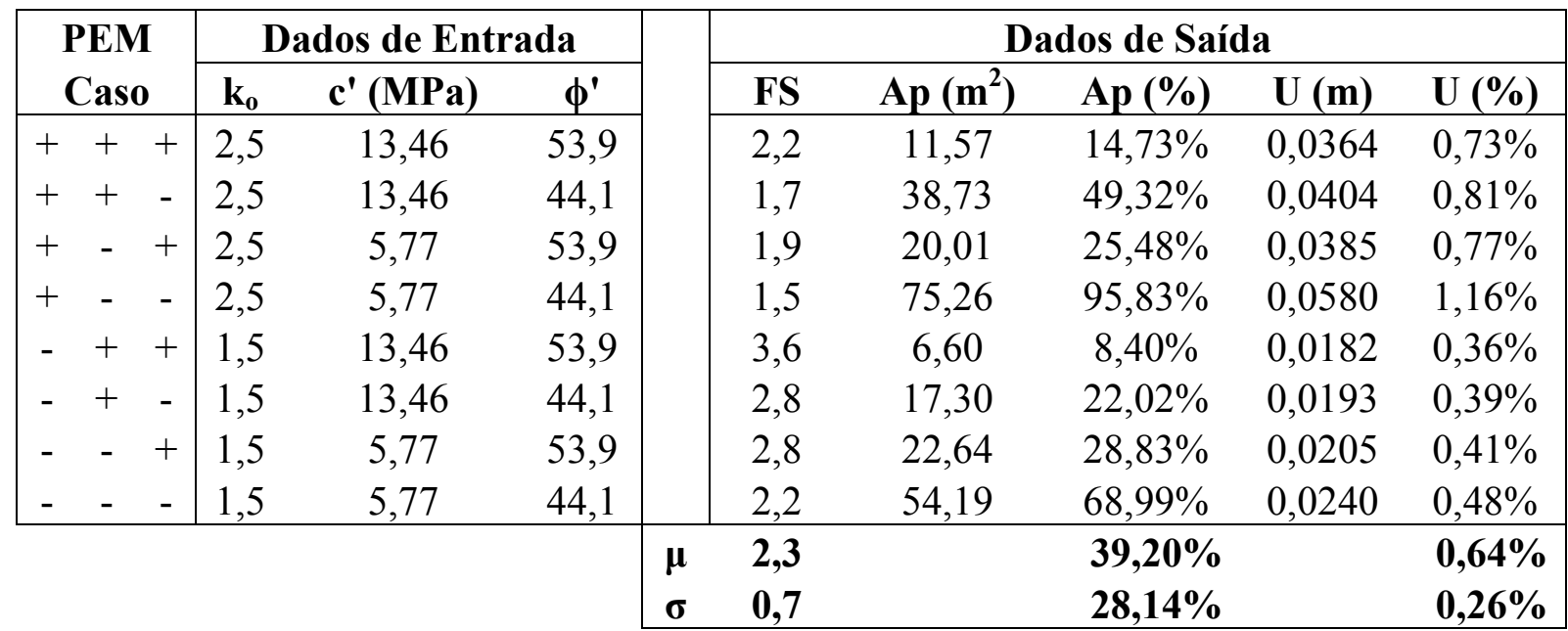




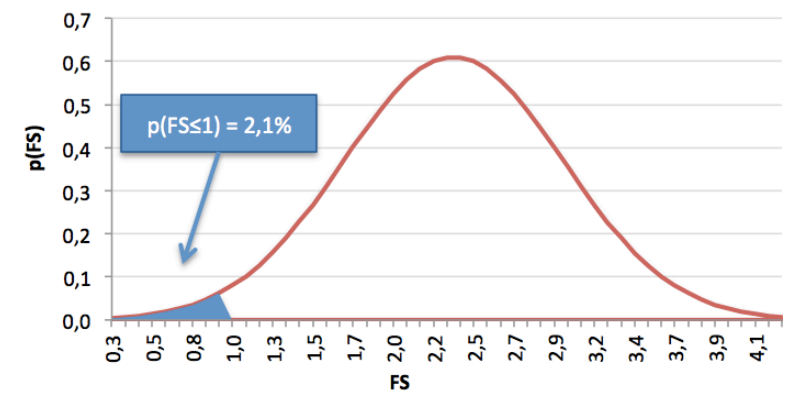

a)

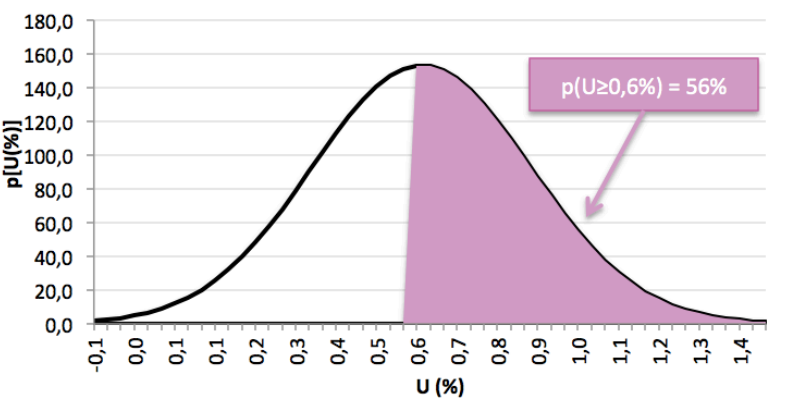

b)

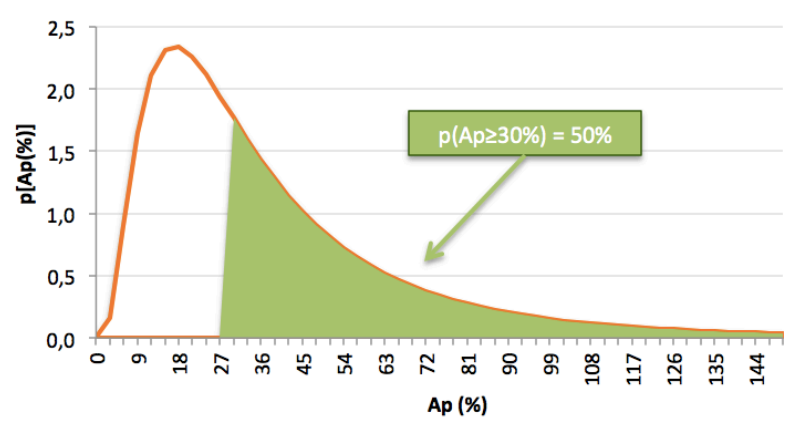

c)

Figura B.17- Frequência de ocorrência e probabilidade de falha: a) Fator de Segurança (FS); b) Convergência (U); c) Área Plástica (Ap) - Rocha metamórfica, $\mathrm{k}_{\mathrm{o}}=2$, 0 , elevado nível de tensões, maciço rochoso moderadamente fraturado.

Tabela B.18 - Resultados obtidos com o método dos pontos de estimativa (Rosenblueth) -

Rocha metamórfica, $\mathrm{k}_{\mathrm{o}}=2,0$, elevado nível de tensões, maciço rochoso intensamente fraturado.

\begin{tabular}{|c|c|c|c|c|c|c|c|c|c|}
\hline \multirow{2}{*}{$\begin{array}{l}\text { PEM } \\
\text { Caso }\end{array}$} & \multicolumn{3}{|c|}{ Dados de Entrada } & & \multicolumn{5}{|c|}{ Dados de Saída } \\
\hline & $\mathbf{k}_{\mathbf{0}}$ & $\mathbf{c}^{\prime}(\mathrm{MPa})$ & $\phi^{\prime}$ & & FS & $\operatorname{Ap}\left(\mathrm{m}^{2}\right)$ & $\operatorname{Ap}(\%)$ & $\mathbf{U}(\mathbf{m})$ & U (\%) \\
\hline$+\quad+\quad+$ & 2,5 & 9,22 & 46,0 & & 1,6 & 39,69 & $50,54 \%$ & 0,2032 & $4,06 \%$ \\
\hline$+\quad+\quad-$ & 2,5 & 9,22 & 37,7 & & 1,3 & 129,83 & $165,30 \%$ & 0,2615 & $5,23 \%$ \\
\hline$+\quad-\quad+$ & 2,5 & 3,95 & 46,0 & & 1,4 & 89,66 & $114,15 \%$ & 0,2766 & $5,53 \%$ \\
\hline$+\quad-\quad-$ & 2,5 & 3,95 & 37,7 & & 1,1 & 232,82 & $296,44 \%$ & 0,3329 & $6,66 \%$ \\
\hline$-\quad+\quad+$ & 1,5 & 9,22 & 46,0 & & 2,6 & 26,21 & $33,38 \%$ & 0,0943 & $1,89 \%$ \\
\hline$-\quad+\quad-$ & 1,5 & 9,22 & 37,7 & & 2,2 & 54,58 & $69,50 \%$ & 0,1076 & $2,15 \%$ \\
\hline$-\quad-\quad+$ & 1,5 & 3,95 & 46,0 & & 2,1 & 62,37 & $79,41 \%$ & 0,1170 & $2,34 \%$ \\
\hline$-\quad-\quad-$ & 1,5 & 3,95 & 37,7 & & 1,7 & 101,53 & $129,27 \%$ & 0,1517 & $3,03 \%$ \\
\hline & & & & $\sigma$ & $\begin{array}{l}1,8 \\
0,5\end{array}$ & & $\begin{array}{r}117,25 \% \\
78,87 \%\end{array}$ & & $\begin{array}{l}3,86 \% \\
1,67 \%\end{array}$ \\
\hline
\end{tabular}




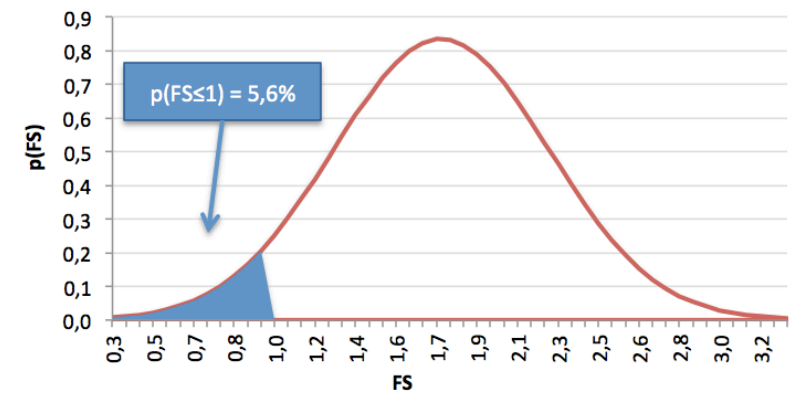

a)

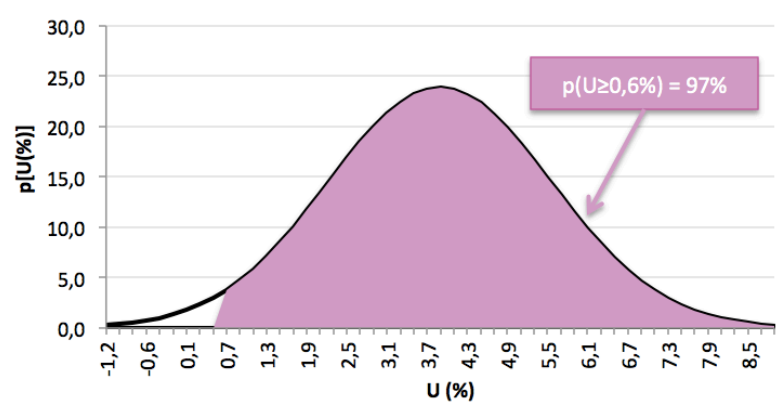

b)

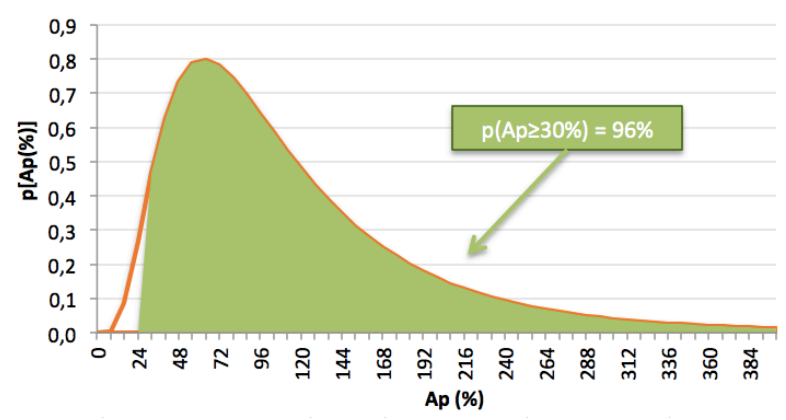

c)

Figura B.18- Frequência de ocorrência e probabilidade de falha: a) Fator de Segurança (FS); b) Convergência (U); c) Área Plástica (Ap) - Rocha metamórfica, $\mathrm{k}_{\mathrm{o}}=2$, 0 , elevado nível de tensões, maciço rochoso intensamente fraturado.

\section{B.1.4. $K_{0}=4,0$}

\section{B.1.4.1. Baixo Nível de Tensões}

Tabela B.19 - Resultados obtidos com o método dos pontos de estimativa (Rosenblueth) Rocha metamórfica, $\mathrm{k}_{\mathrm{o}}=4,0$, baixo nível de tensões, maciço rochoso intensamente fraturado.

\begin{tabular}{|c|c|c|c|c|c|c|c|c|c|}
\hline \multirow{2}{*}{$\begin{array}{l}\text { PEM } \\
\text { Caso }\end{array}$} & \multicolumn{3}{|c|}{ Dados de Entrada } & & \multicolumn{5}{|c|}{ Dados de Saída } \\
\hline & $\mathbf{k}_{\mathbf{0}}$ & $c^{\prime}$ (MPa) & $\phi^{\prime}$ & & FS & $\operatorname{Ap}\left(\mathbf{m}^{2}\right)$ & Ap (\%) & $\mathbf{U}(\mathbf{m})$ & $\mathbf{U}(\%)$ \\
\hline$+\quad+\quad+$ & 5 & 2,04 & 64,0 & & 1,6 & 12,32 & $15,68 \%$ & 0,0383 & $0,77 \%$ \\
\hline$+\quad+-$ & 5 & 2,04 & 52,4 & & 1,1 & 266,69 & $339,56 \%$ & 0,0390 & $0,78 \%$ \\
\hline$+\quad-\quad+$ & 5 & 0,87 & 64,0 & & 1,1 & 61,73 & $78,60 \%$ & 0,0374 & $0,75 \%$ \\
\hline$+\quad-\quad-$ & 5 & 0,87 & 52,4 & & 0,7 & 709,76 & $903,69 \%$ & 0,0390 & $0,78 \%$ \\
\hline$-\quad+\quad+$ & 3 & 2,04 & 64,0 & & 2,7 & 2,25 & $2,87 \%$ & 0,0193 & $0,39 \%$ \\
\hline$-\quad+\quad-$ & 3 & 2,04 & 52,4 & & 1,9 & 9,82 & $12,50 \%$ & 0,0204 & $0,41 \%$ \\
\hline$-\quad-\quad+$ & 3 & 0,87 & 64,0 & & 2,3 & 8,21 & $10,45 \%$ & 0,0201 & $0,40 \%$ \\
\hline$-\quad-\quad-$ & 3 & 0,87 & 52,4 & & 1,6 & 47,99 & $61,10 \%$ & 0,0230 & $0,46 \%$ \\
\hline & & & & $\begin{array}{l}\mu \\
\sigma\end{array}$ & $\begin{array}{l}1,6 \\
0,6\end{array}$ & & $\begin{array}{l}178,06 \% \\
293,42 \%\end{array}$ & & $\begin{array}{l}\mathbf{0 , 5 9 \%} \\
0,18 \%\end{array}$ \\
\hline
\end{tabular}




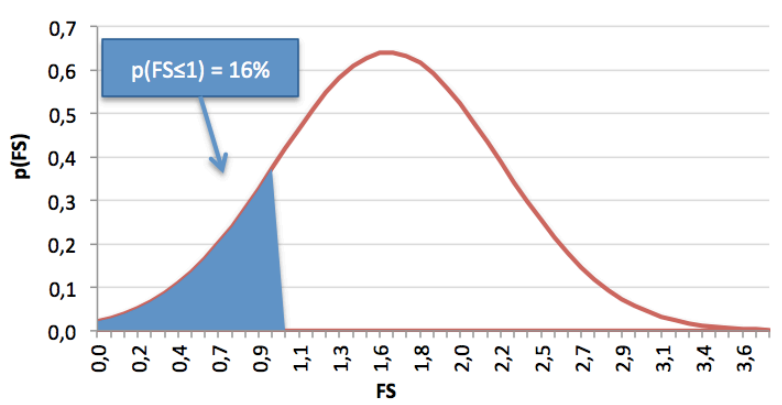

a)

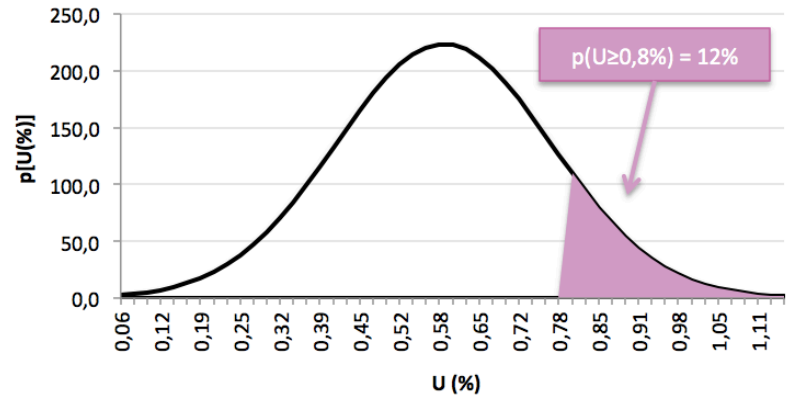

b)

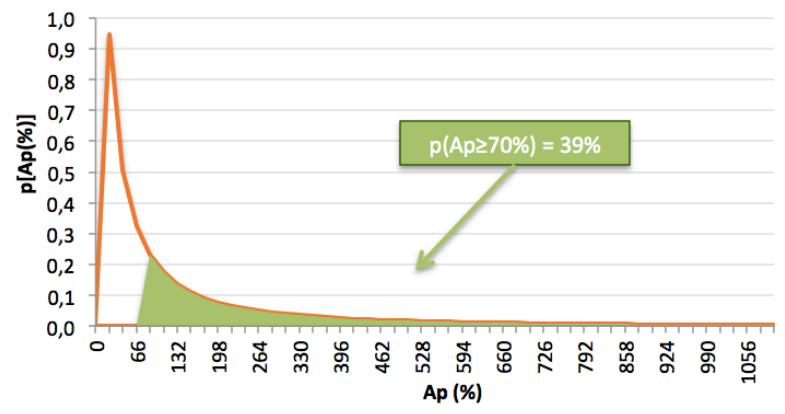

c)

Figura B.19- Frequência de ocorrência e probabilidade de falha: a) Fator de Segurança (FS);

b) Convergência (U); c) Área Plástica (Ap) - Rocha metamórfica, $\mathrm{k}_{\mathrm{o}}=4,0$, baixo nível de tensões, maciço rochoso intensamente fraturado.

\section{B.1.4.2. Moderado Nível de Tensões}

Tabela B.20 - Resultados obtidos com o método dos pontos de estimativa (Rosenblueth) Rocha metamórfica, $\mathrm{k}_{\mathrm{o}}=4,0$, moderado nível de tensões, maciço rochoso moderadamente fraturado.

\begin{tabular}{|c|c|c|c|c|c|c|c|c|c|}
\hline \multirow{2}{*}{$\begin{array}{l}\text { PEM } \\
\text { Caso }\end{array}$} & \multicolumn{3}{|c|}{ Dados de Entrada } & & \multicolumn{5}{|c|}{ Dados de Saída } \\
\hline & $\mathbf{k}_{\mathbf{0}}$ & $\overline{c^{\prime}(\mathbf{M P a})}$ & $\phi^{\prime}$ & & FS & $\operatorname{Ap}\left(\mathrm{m}^{2}\right)$ & Ap (\%) & $\mathrm{U}(\mathrm{m})$ & $\mathrm{U}(\%)$ \\
\hline$+\quad+\quad+$ & 5 & 6,53 & 63,1 & & 1,4 & 9,53 & $12,14 \%$ & 0,0250 & $0,50 \%$ \\
\hline$+\quad+\quad-$ & 5 & 6,53 & 51,6 & & 1,0 & 281,77 & $358,76 \%$ & 0,0256 & $0,51 \%$ \\
\hline$+\quad-\quad+$ & 5 & 2,80 & 63,1 & & 0,9 & 137,16 & $174,64 \%$ & 0,0242 & $0,48 \%$ \\
\hline$+\quad-\quad-$ & 5 & 2,80 & 51,6 & & 0,8 & 638,50 & $812,96 \%$ & 0,0252 & $0,50 \%$ \\
\hline$-\quad+\quad+$ & 3 & 6,53 & 63,1 & & 2,7 & 2,23 & $2,84 \%$ & 0,0126 & $0,25 \%$ \\
\hline$-\quad+\quad-$ & 3 & 6,53 & 51,6 & & 1,9 & 9,61 & $12,23 \%$ & 0,0133 & $0,27 \%$ \\
\hline$-\quad-\quad+$ & 3 & 2,80 & 63,1 & & 2,3 & 8,52 & $10,85 \%$ & 0,0132 & $0,26 \%$ \\
\hline$-\quad-\quad-$ & 3 & 2,80 & 51,6 & & 1,5 & 52,28 & $66,56 \%$ & 0,0151 & $0,30 \%$ \\
\hline & & & & $\begin{array}{l}\mu \\
\sigma\end{array}$ & $\begin{array}{l}1,6 \\
0,6\end{array}$ & & $\begin{array}{l}181,37 \% \\
265,00 \%\end{array}$ & & $\begin{array}{l}0,39 \% \\
0,12 \%\end{array}$ \\
\hline
\end{tabular}




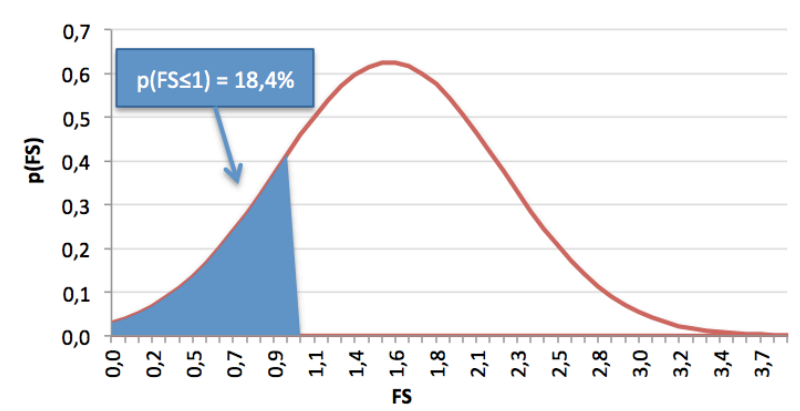

a)

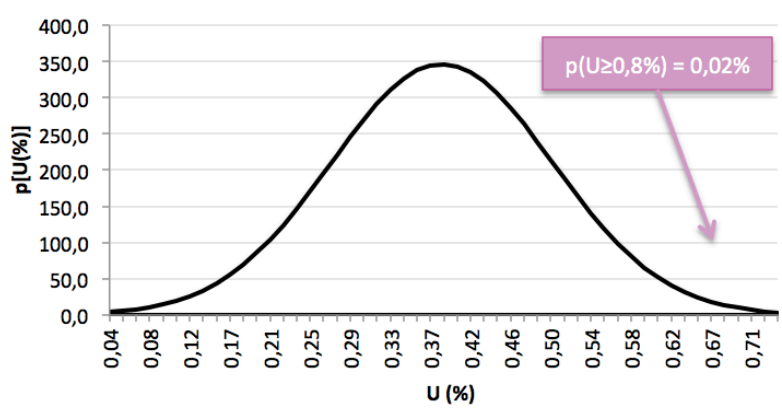

b)

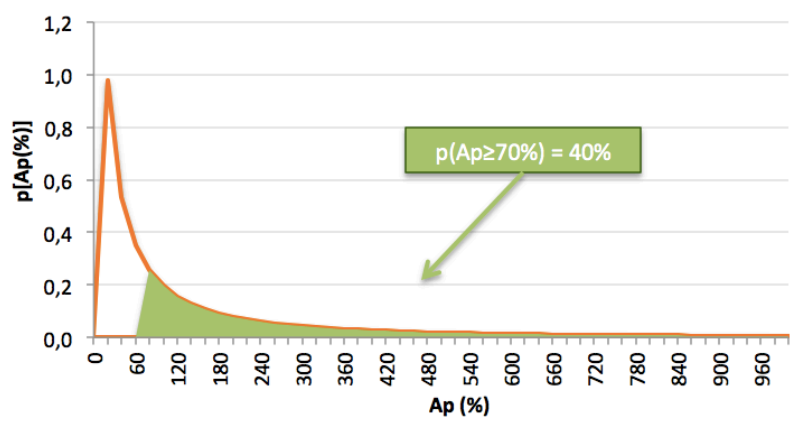

c)

Figura B.20 - Frequência de ocorrência e probabilidade de falha: a) Fator de Segurança (FS);

b) Convergência (U); c) Área Plástica (Ap) - Rocha metamórfica, $\mathrm{k}_{\mathrm{o}}=4,0$, moderado nível de tensões, maciço rochoso moderadamente fraturado.

Tabela B.21 - Resultados obtidos com o método dos pontos de estimativa (Rosenblueth) -

Rocha metamórfica, $\mathrm{k}_{\mathrm{o}}=4,0$, moderado nível de tensões, maciço rochoso intensamente fraturado.

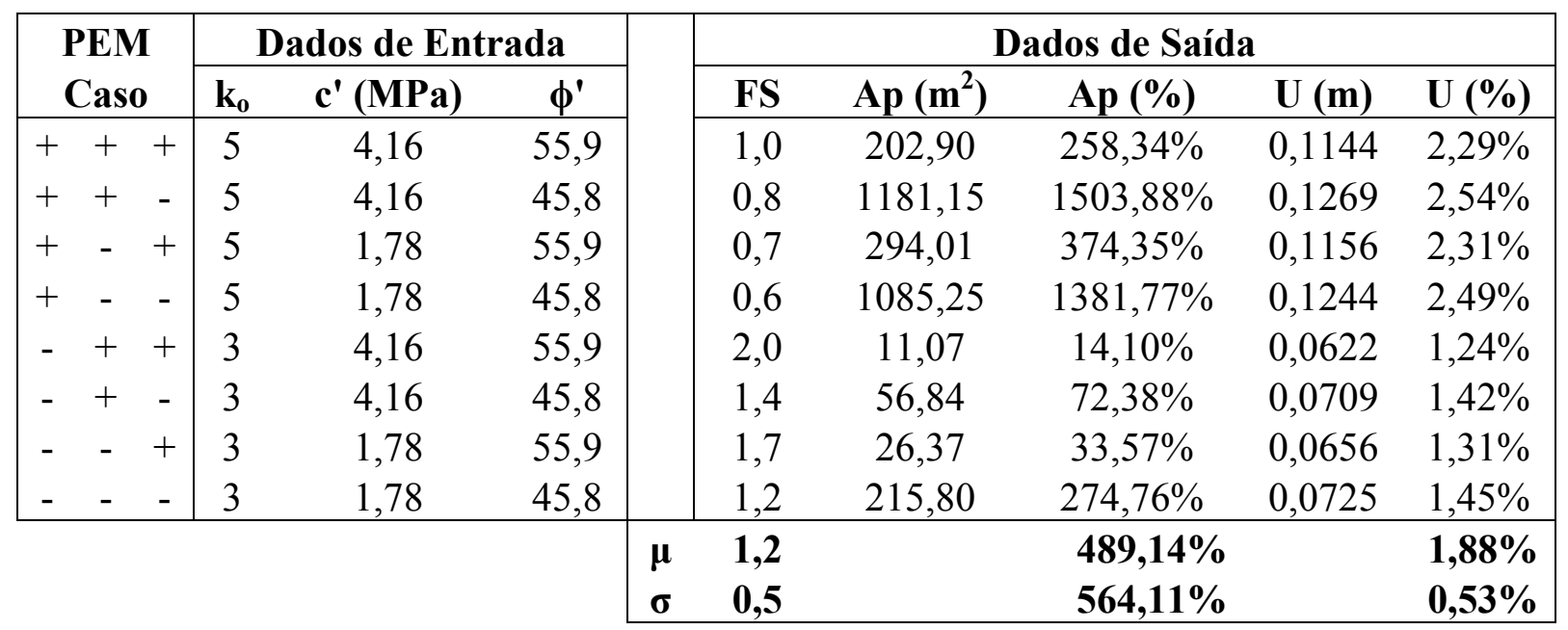




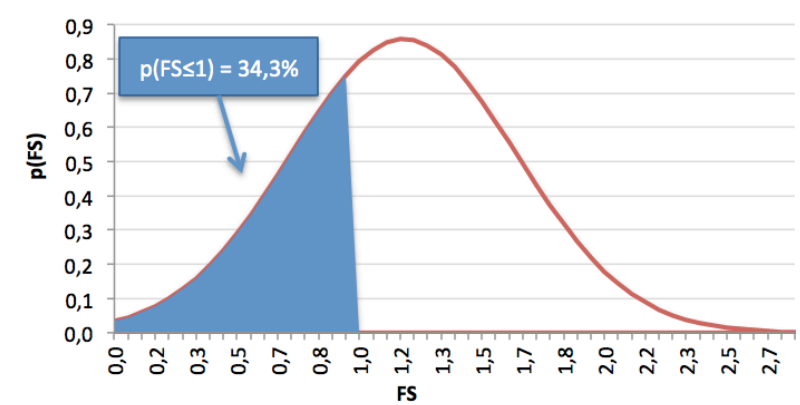

a)

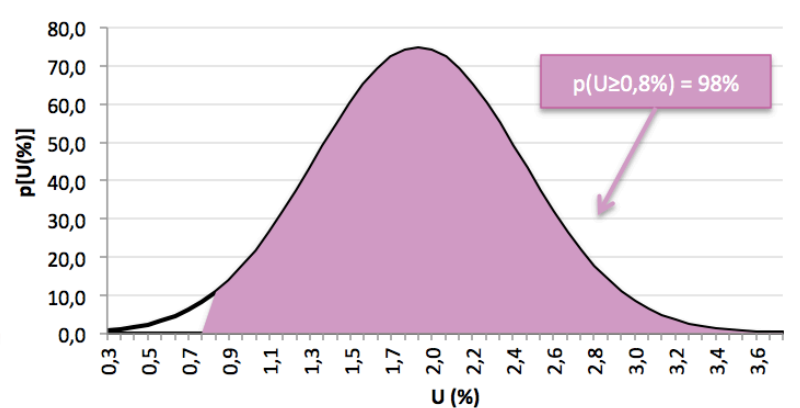

b)

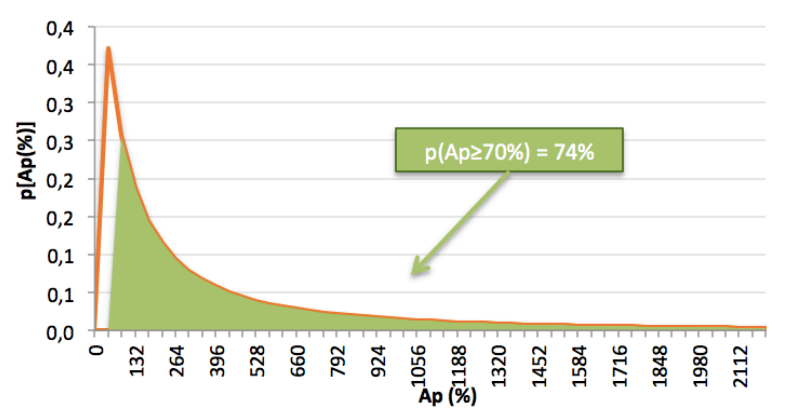

c)

Figura B.21- Frequência de ocorrência e probabilidade de falha: a) Fator de Segurança (FS);

b) Convergência (U); c) Área Plástica (Ap) - Rocha metamórfica, $\mathrm{k}_{\mathrm{o}}=4,0$, moderado nível de tensões, maciço rochoso intensamente fraturado.

\section{B.1.4.3. Elevado Nível de Tensões}

Tabela B.22 - Resultados obtidos com o método dos pontos de estimativa (Rosenblueth) Rocha metamórfica, $\mathrm{k}_{\mathrm{o}}=4,0$, elevado nível de tensões, maciço rochoso intacto.

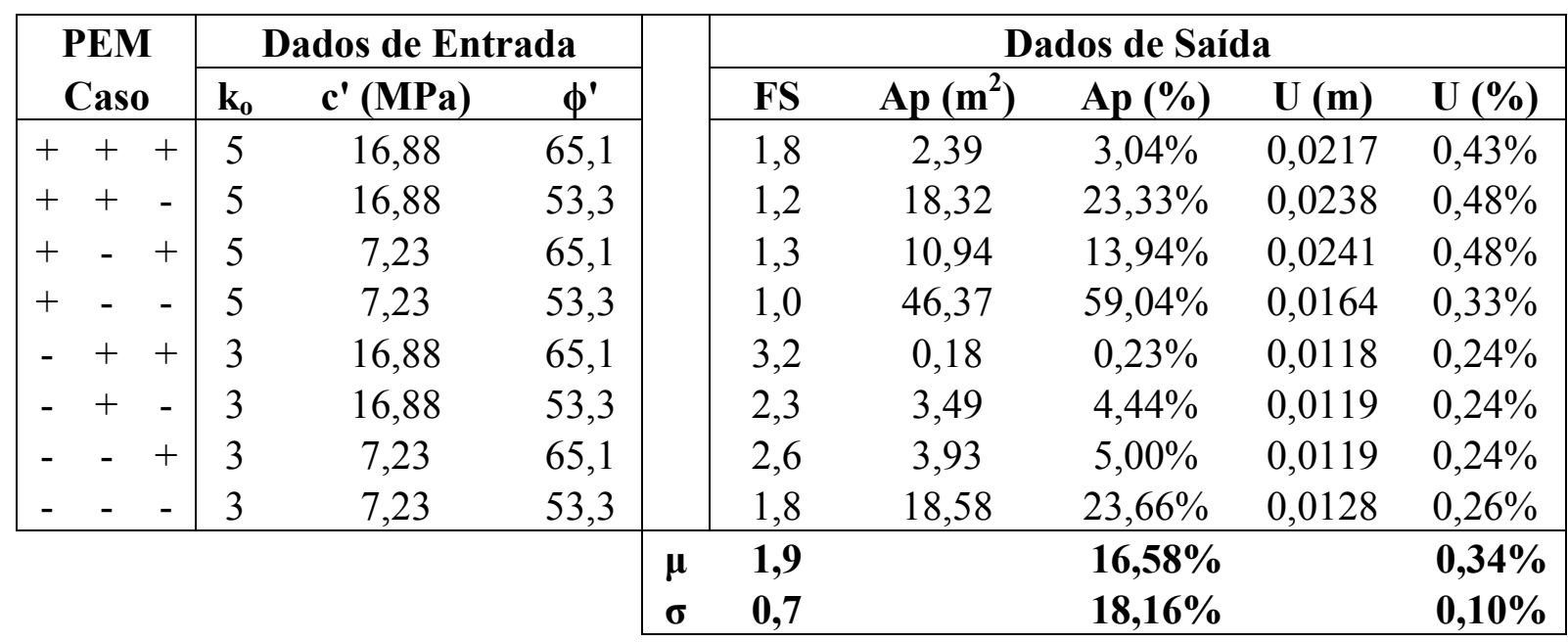




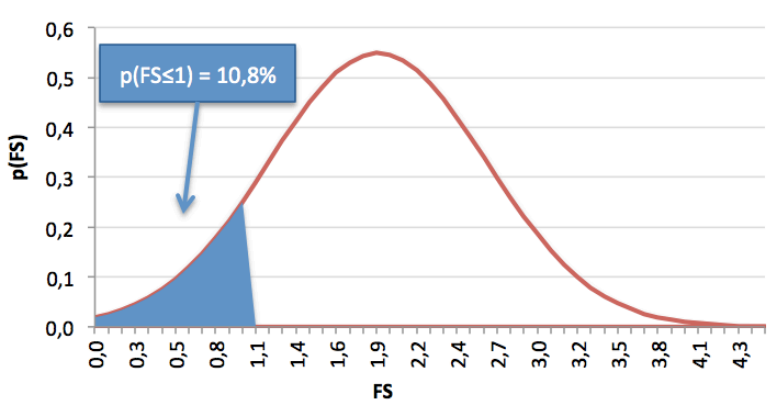

a)

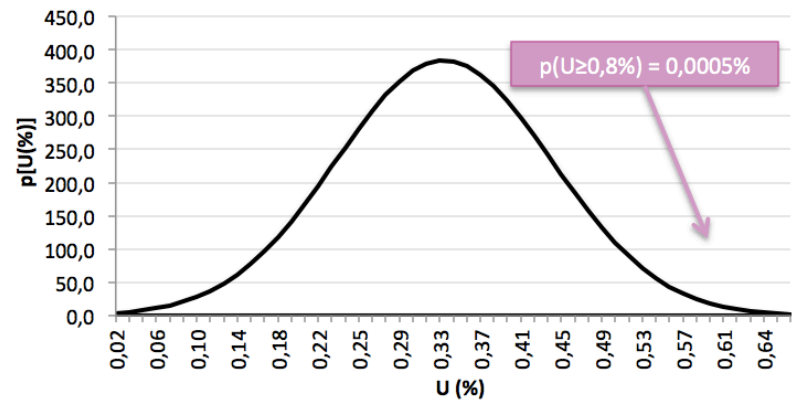

b)

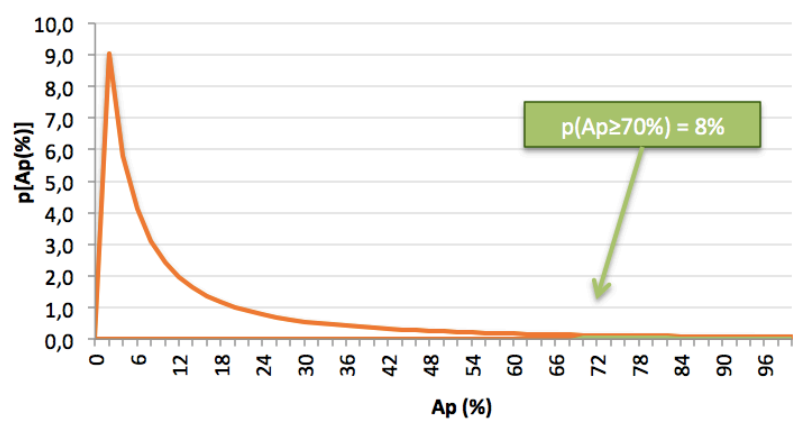

c)

Figura B.22 - Frequência de ocorrência e probabilidade de falha: a) Fator de Segurança (FS); b) Convergência (U); c) Área Plástica (Ap) - Rocha metamórfica, $\mathrm{k}_{\mathrm{o}}=4$,0, elevado nível de tensões, maciço rochoso intacto.

Tabela B.23 - Resultados obtidos com o método dos pontos de estimativa (Rosenblueth) Rocha metamórfica, $\mathrm{k}_{\mathrm{o}}=4,0$, elevado nível de tensões, maciço rochoso moderadamente fraturado.

\begin{tabular}{|c|c|c|c|c|c|c|c|c|c|}
\hline \multirow{2}{*}{$\begin{array}{l}\text { PEM } \\
\text { Caso }\end{array}$} & \multicolumn{3}{|c|}{ Dados de Entrada } & & \multicolumn{5}{|c|}{ Dados de Saída } \\
\hline & $\mathbf{k}_{\mathbf{0}}$ & $\mathrm{c}^{\prime}(\mathrm{MPa})$ & $\phi^{\prime}$ & & FS & $\operatorname{Ap}\left(m^{2}\right)$ & $\operatorname{Ap~(\% )}$ & $\mathbf{U}(\mathrm{m})$ & $\mathbf{U}(\%)$ \\
\hline$+\quad+\quad+$ & 5 & 8,79 & 59,4 & & 1,1 & 89,88 & $114,44 \%$ & 0,0417 & $0,83 \%$ \\
\hline$+\quad+\quad-$ & 5 & 8,79 & 48,6 & & 0,9 & 821,78 & $1046,31 \%$ & 0,0432 & $0,86 \%$ \\
\hline$+\quad-\quad+$ & 5 & 3,77 & 59,4 & & 0,9 & 199,79 & $254,38 \%$ & 0,0405 & $0,81 \%$ \\
\hline$+\quad-\quad-$ & 5 & 3,77 & 48,6 & & 0,7 & 871,89 & $1110,12 \%$ & 0,0461 & $0,92 \%$ \\
\hline$-\quad+\quad+$ & 3 & 8,79 & 59,4 & & 2,3 & 6,32 & $8,05 \%$ & 0,0216 & $0,43 \%$ \\
\hline$-\quad+\quad-$ & 3 & 8,79 & 48,6 & & 1,7 & 26,08 & $33,20 \%$ & 0,0234 & $0,47 \%$ \\
\hline$-\quad-\quad+$ & 3 & 3,77 & 59,4 & & 2,0 & 16,24 & $20,68 \%$ & 0,0239 & $0,48 \%$ \\
\hline$-\quad-\quad-$ & 3 & 3,77 & 48,6 & & 1,4 & 42,00 & $53,47 \%$ & 0,0232 & $0,46 \%$ \\
\hline & & & & $\begin{array}{l}\mu \\
\sigma\end{array}$ & $\begin{array}{l}1,4 \\
0,5\end{array}$ & & $\begin{array}{l}330,08 \% \\
438,43 \%\end{array}$ & & $\begin{array}{l}0,66 \% \\
0,20 \%\end{array}$ \\
\hline
\end{tabular}




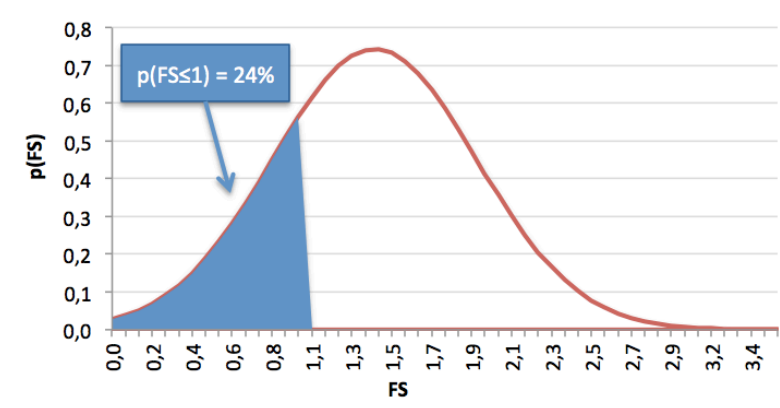

a)

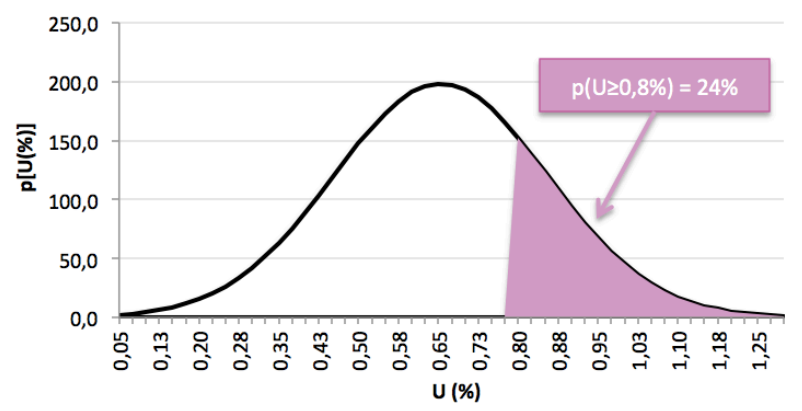

b)

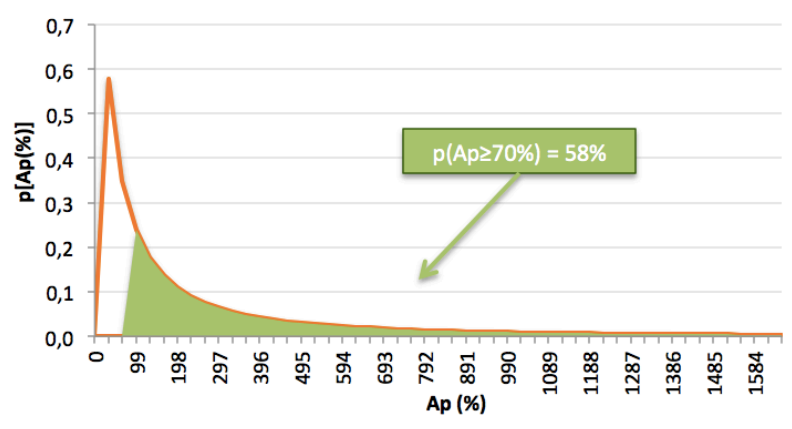

c)

Figura B.23 - Frequência de ocorrência e probabilidade de falha: a) Fator de Segurança (FS); b) Convergência (U); c) Área Plástica (Ap) - Rocha metamórfica, $\mathrm{k}_{\mathrm{o}}=4,0$, elevado nível de tensões, maciço rochoso moderadamente fraturado.

Tabela B.24 - Resultados obtidos com o método dos pontos de estimativa (Rosenblueth) Rocha metamórfica, $\mathrm{k}_{\mathrm{o}}=4,0$, elevado nível de tensões, maciço rochoso intensamente fraturado.

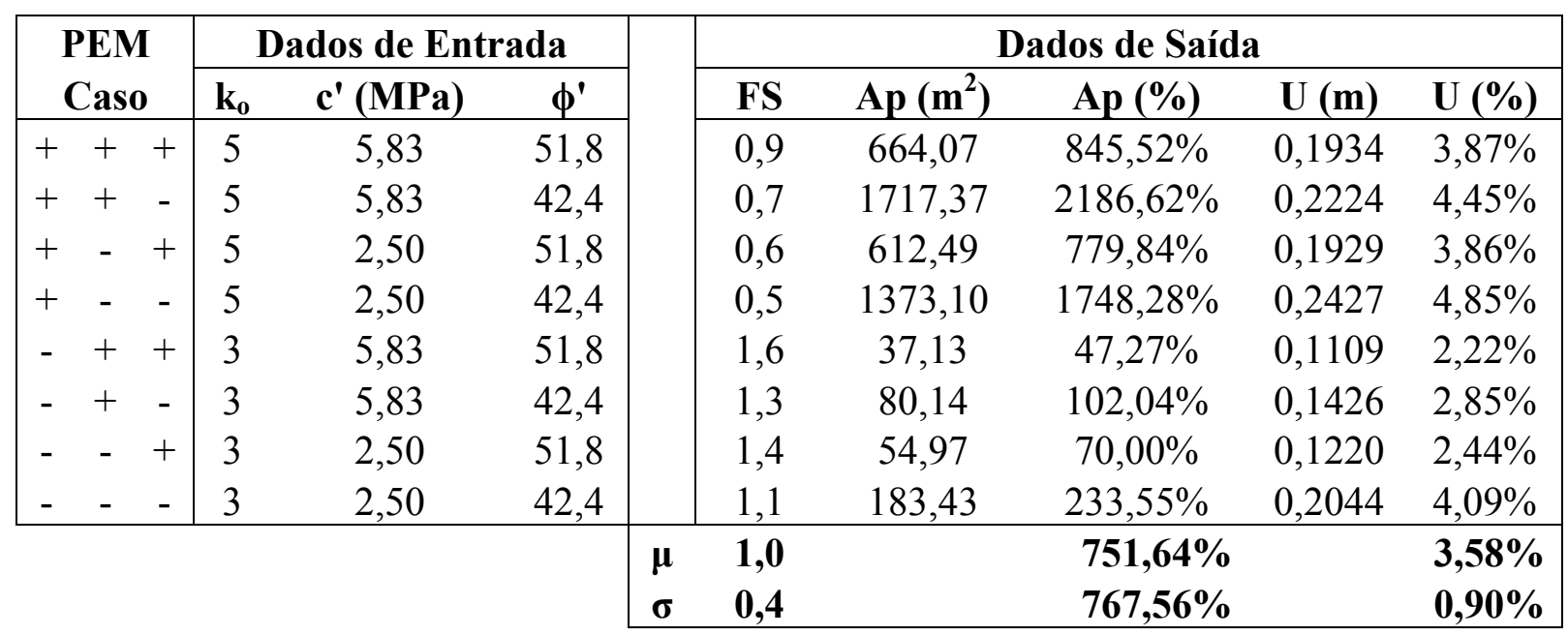




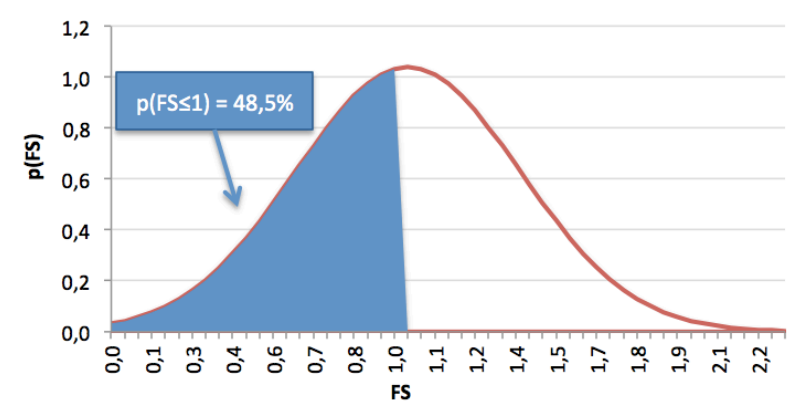

a)

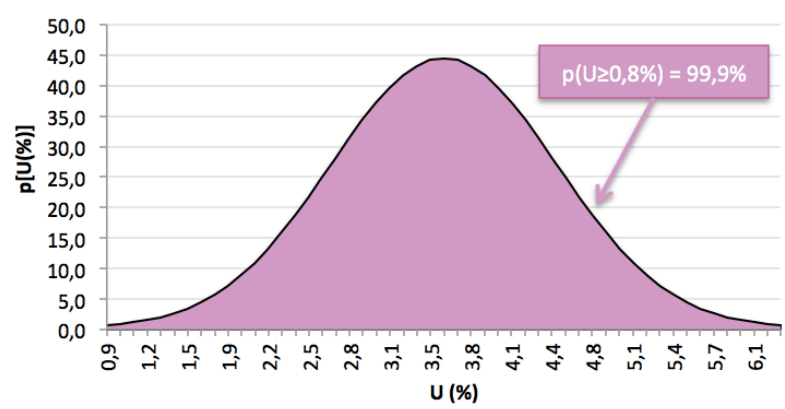

b)

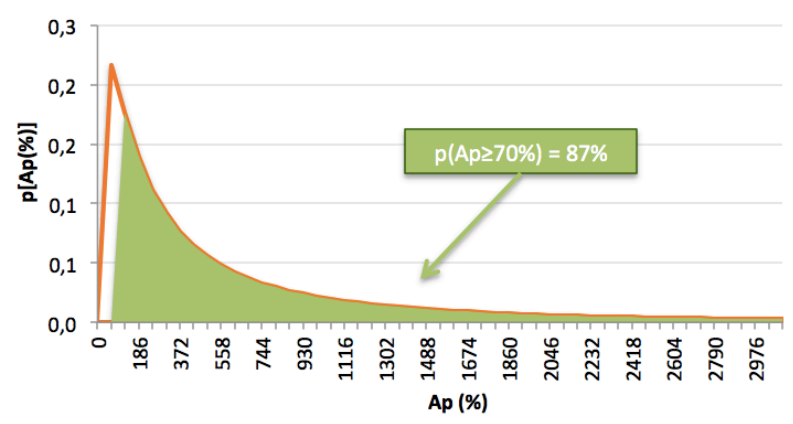

c)

Figura B.24- Frequência de ocorrência e probabilidade de falha: a) Fator de Segurança (FS); b) Convergência (U); c) Área Plástica (Ap) - Rocha metamórfica, $\mathrm{k}_{\mathrm{o}}=4,0$, elevado nível de tensões, maciço rochoso intensamente fraturado.

\section{B.2. ROCHA SEDIMENTAR (SILTITO)}

\section{B.2.1. $K_{0}=0,5$}

\section{B.2.1.1. Baixo Nível de Tensões}

Tabela B.25 - Resultados obtidos com o método dos pontos de estimativa (Rosenblueth) Rocha sedimentar, $\mathrm{k}_{\mathrm{o}}=0,5$, baixo nível de tensões, maciço rochoso intensamente fraturado.

\begin{tabular}{|c|c|c|c|c|c|c|c|c|c|}
\hline \multirow{2}{*}{$\begin{array}{l}\text { PEM } \\
\text { Caso }\end{array}$} & \multicolumn{3}{|c|}{ Dados de Entrada } & & \multicolumn{5}{|c|}{ Dados de Saída } \\
\hline & $\mathbf{k}_{\mathbf{0}}$ & $\mathbf{c}^{\prime}$ (MPa) & $\phi^{\prime}$ & & FS & $\operatorname{Ap}\left(\mathrm{m}^{2}\right)$ & Ap (\%) & $\mathbf{U}(\mathbf{m})$ & $\mathbf{U}(\%)$ \\
\hline$+\quad+\quad+$ & 0,625 & 1,37 & 43,4 & & 2,7 & 17,69 & $22,52 \%$ & 0,0550 & $1,10 \%$ \\
\hline$+\quad+\quad-$ & 0,625 & 1,37 & 35,5 & & 2,3 & 34,37 & $43,75 \%$ & 0,0598 & $1,20 \%$ \\
\hline$+\quad-\quad+$ & 0,625 & 0,59 & 43,4 & & 2,1 & 54,16 & $68,96 \%$ & 0,0676 & $1,35 \%$ \\
\hline$+\quad-\quad-$ & 0,625 & 0,59 & 35,5 & & 1,7 & 107,28 & $136,59 \%$ & 0,0813 & $1,63 \%$ \\
\hline$-\quad+\quad+$ & 0,375 & 1,37 & 43,4 & & 1,9 & 15,01 & $19,11 \%$ & 0,0611 & $1,22 \%$ \\
\hline$-\quad+\quad-$ & 0,375 & 1,37 & 35,5 & & 1,5 & 46,35 & $59,02 \%$ & 0,0662 & $1,32 \%$ \\
\hline$-\quad-\quad+$ & 0,375 & 0,59 & 43,4 & & 1,4 & 56,92 & $72,47 \%$ & 0,0769 & $1,54 \%$ \\
\hline$-\quad-\quad-$ & 0,375 & 0,59 & 35,5 & & 1,2 & 187,21 & $238,36 \%$ & 0,1024 & $2,05 \%$ \\
\hline & & & & $\begin{array}{l}\mu \\
\sigma\end{array}$ & $\begin{array}{l}1,9 \\
0,5\end{array}$ & & $\begin{array}{l}82,60 \% \\
68,16 \%\end{array}$ & & $\begin{array}{l}1,43 \% \\
0,29 \%\end{array}$ \\
\hline
\end{tabular}




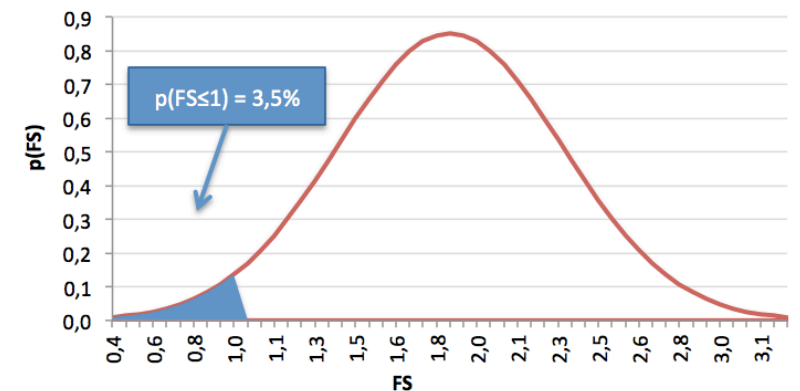

a)

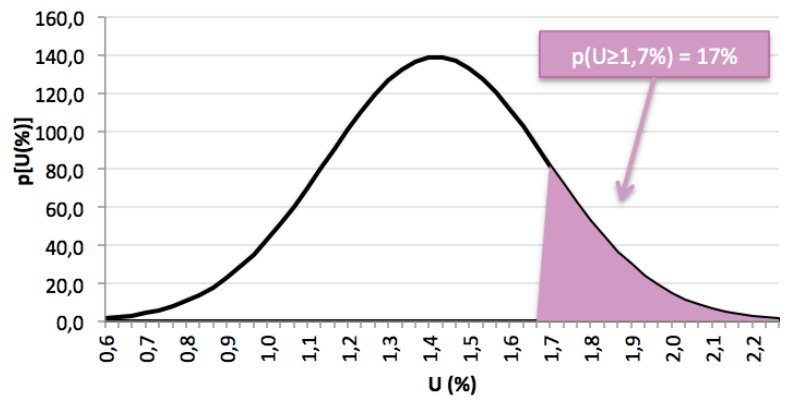

b)

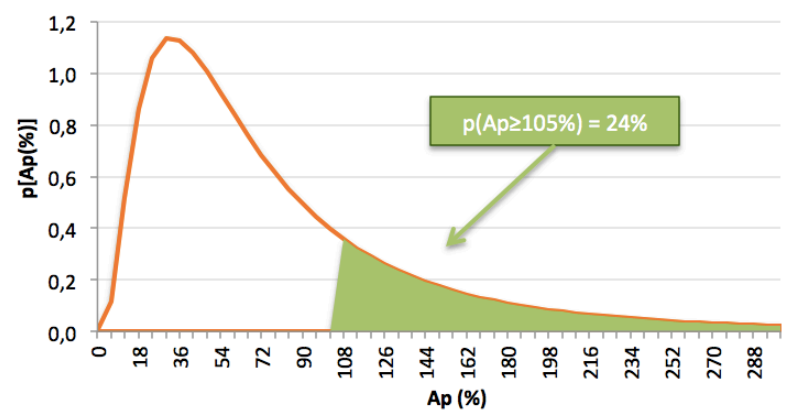

c)

Figura B.25- Frequência de ocorrência e probabilidade de falha: a) Fator de Segurança (FS);

b) Convergência (U); c) Área Plástica (Ap) - Rocha sedimentar, $\mathrm{k}_{\mathrm{o}}=0,5$, baixo nível de tensões, maciço rochoso intensamente fraturado.

\section{B.2.1.2. Moderado Nível de Tensões}

Tabela B.26 - Resultados obtidos com o método dos pontos de estimativa (Rosenblueth) -

Rocha sedimentar, $\mathrm{k}_{\mathrm{o}}=0,5$, moderado nível de tensões, maciço rochoso moderadamente fraturado.

\begin{tabular}{|c|c|c|c|c|c|c|c|c|c|}
\hline \multirow{2}{*}{$\begin{array}{l}\text { PEM } \\
\text { Caso }\end{array}$} & \multicolumn{3}{|c|}{ Dados de Entrada } & & \multicolumn{5}{|c|}{ Dados de Saída } \\
\hline & $\mathbf{k}_{\mathbf{0}}$ & $\mathrm{c}^{\prime}$ (MPa) & $\phi^{\prime}$ & & FS & $\operatorname{Ap}\left(m^{2}\right)$ & Ap (\%) & $\mathbf{U}(\mathbf{m})$ & $\mathrm{U}(\%)$ \\
\hline$+\quad+\quad+$ & 0,625 & 4,33 & 42,2 & & 2,7 & 18,29 & $23,29 \%$ & 0,0360 & $0,72 \%$ \\
\hline$+\quad+\quad-$ & 0,625 & 4,33 & 34,5 & & 2,3 & 34,30 & $43,67 \%$ & 0,0388 & $0,78 \%$ \\
\hline$+\quad-\quad+$ & 0,625 & 1,86 & 42,2 & & 2,1 & 57,23 & $72,87 \%$ & 0,0444 & $0,89 \%$ \\
\hline$+\quad-\quad-$ & 0,625 & 1,86 & 34,5 & & 1,7 & 109,16 & $138,98 \%$ & 0,0533 & $1,07 \%$ \\
\hline$-\quad+\quad+$ & 0,375 & 4,33 & 42,2 & & 1,8 & 14,94 & $19,02 \%$ & 0,0399 & $0,80 \%$ \\
\hline$-\quad+\quad-$ & 0,375 & 4,33 & 34,5 & & 1,6 & 45,22 & $57,58 \%$ & 0,0431 & $0,86 \%$ \\
\hline$-\quad-\quad+$ & 0,375 & 1,86 & 42,2 & & 1,5 & 71,73 & $91,32 \%$ & 0,0496 & $0,99 \%$ \\
\hline$-\quad-\quad-$ & 0,375 & 1,86 & 34,5 & & 1,2 & 200,66 & $255,49 \%$ & 0,0673 & $1,35 \%$ \\
\hline & & & & $\begin{array}{l}\mu \\
\boldsymbol{\sigma}\end{array}$ & $\begin{array}{l}1,9 \\
0,5\end{array}$ & & $\begin{array}{l}87,78 \% \\
73,08 \%\end{array}$ & & $\begin{array}{l}0,93 \% \\
0,19 \%\end{array}$ \\
\hline
\end{tabular}




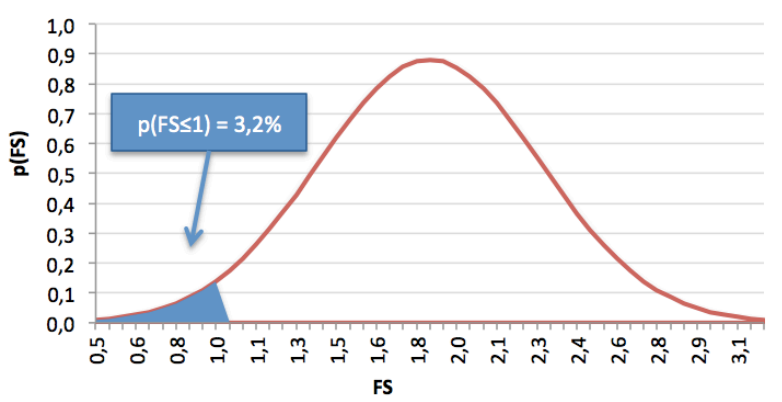

a)

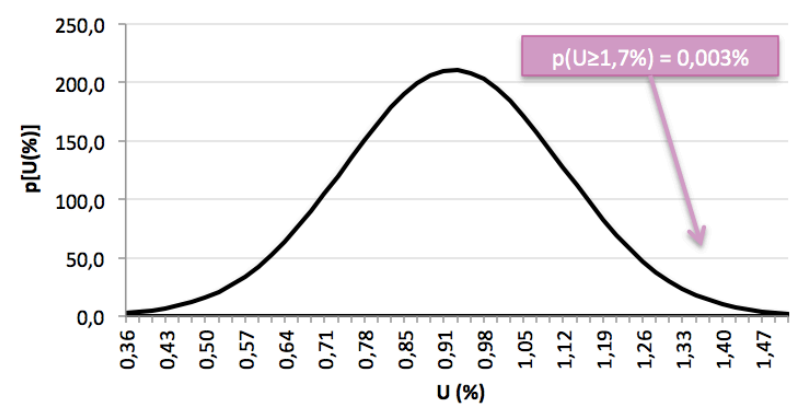

b)

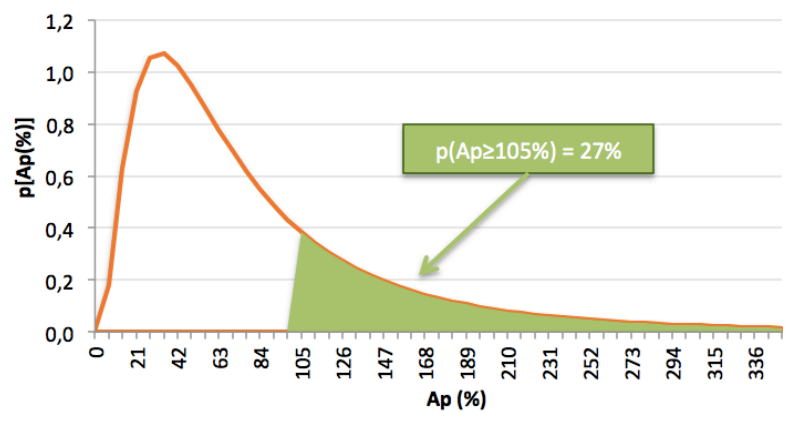

c)

Figura B.26- Frequência de ocorrência e probabilidade de falha: a) Fator de Segurança (FS); b) Convergência (U); c) Área Plástica (Ap) - Rocha sedimentar, $\mathrm{k}_{\mathrm{o}}=0,5$, moderado nível de tensões, maciço rochoso moderadamente.

Tabela B.27 - Resultados obtidos com o método dos pontos de estimativa (Rosenblueth) -

Rocha sedimentar, $\mathrm{k}_{\mathrm{o}}=0,5$, moderado nível de tensões, maciço rochoso intensamente fraturado.

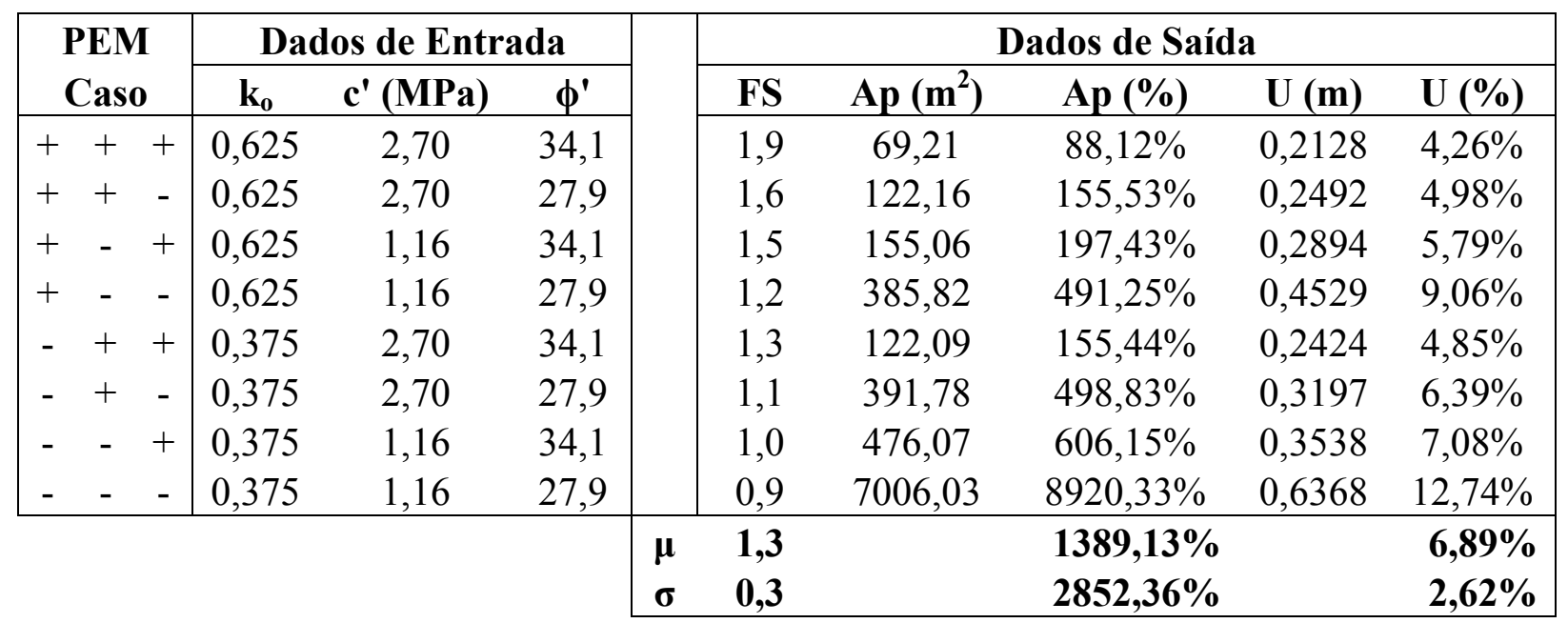




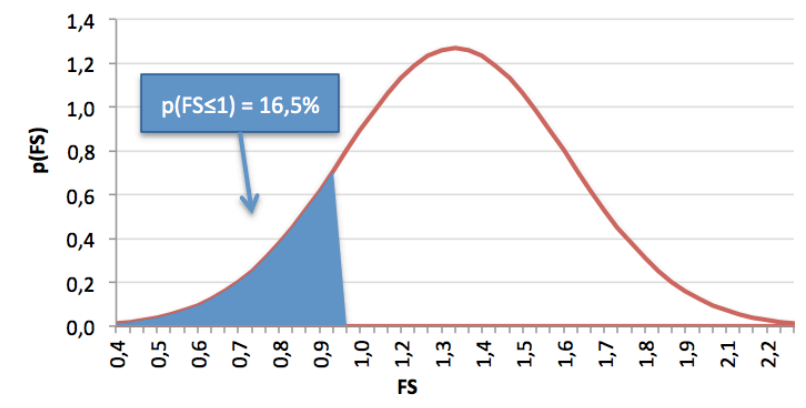

a)

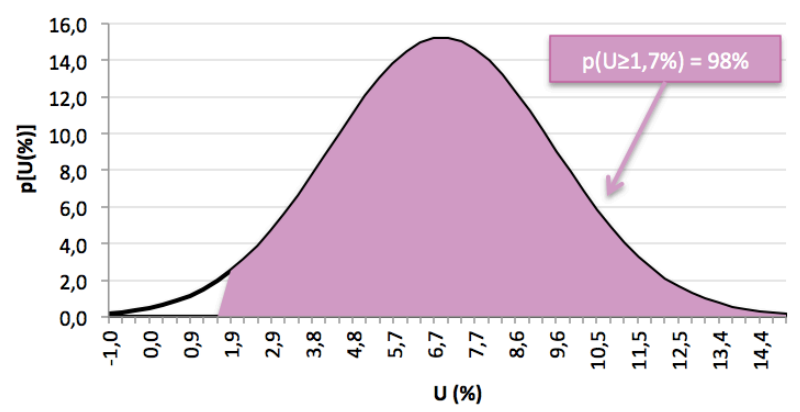

b)

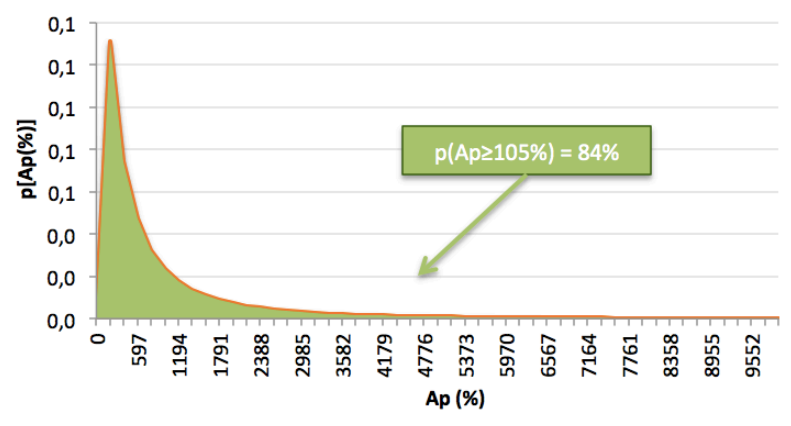

c)

Figura B.27- Frequência de ocorrência e probabilidade de falha: a) Fator de Segurança (FS); b) Convergência (U); c) Área Plástica (Ap) - Rocha sedimentar, $\mathrm{k}_{\mathrm{o}}=0,5$, moderado nível de tensões, maciço rochoso intensamente fraturado.

\section{B.2.1.3. Elevado Nível de Tensões}

Tabela B.28 - Resultados obtidos com o método dos pontos de estimativa (Rosenblueth) Rocha sedimentar, $\mathrm{k}_{\mathrm{o}}=0,5$, elevado nível de tensões, maciço rochoso intacto.

\begin{tabular}{|c|c|c|c|c|c|c|c|c|c|}
\hline \multirow{2}{*}{$\begin{array}{l}\text { PEM } \\
\text { Caso }\end{array}$} & \multicolumn{3}{|c|}{ Dados de Entrada } & & \multicolumn{5}{|c|}{ Dados de Saída } \\
\hline & $\mathbf{k}_{\mathbf{0}}$ & $\mathrm{c}^{\prime}$ (MPa) & $\phi^{\prime}$ & & FS & $\operatorname{Ap}\left(\mathrm{m}^{2}\right)$ & Ap (\%) & $\mathrm{U}(\mathrm{m})$ & $\mathrm{U}(\%)$ \\
\hline+++ & 0,625 & 10,92 & 44,8 & & 3,3 & 5,56 & $7,08 \%$ & 0,0314 & $0,63 \%$ \\
\hline$+\quad+$ & 0,625 & 10,92 & 36,7 & & 2,8 & 11,71 & $14,91 \%$ & 0,0326 & $0,65 \%$ \\
\hline$+\quad-\quad+$ & 0,625 & 4,68 & 44,8 & & 2,5 & 27,60 & $35,14 \%$ & 0,0357 & $0,71 \%$ \\
\hline$+\quad-\quad-$ & 0,625 & 4,68 & 36,7 & & 2,0 & 55,71 & $70,93 \%$ & 0,0405 & $0,81 \%$ \\
\hline$-\quad+\quad+$ & 0,375 & 10,92 & 44,8 & & 2,3 & 5,37 & $6,84 \%$ & 0,0352 & $0,70 \%$ \\
\hline$-\quad+\quad-$ & 0,375 & 10,92 & 36,7 & & 2,0 & 10,97 & $13,97 \%$ & 0,0364 & $0,73 \%$ \\
\hline$-\quad-\quad+$ & 0,375 & 4,68 & 44,8 & & 1,7 & 26,91 & $34,27 \%$ & 0,0393 & $0,79 \%$ \\
\hline$-\quad-$ & 0,375 & 4,68 & 36,7 & & 1,4 & 84,52 & $107,61 \%$ & 0,0451 & $0,90 \%$ \\
\hline & & & & $\mu$ & 2,2 & & $36,34 \%$ & & $0,74 \%$ \\
\hline & & & & $\boldsymbol{\sigma}$ & 0,6 & & $33,48 \%$ & & $0,08 \%$ \\
\hline
\end{tabular}




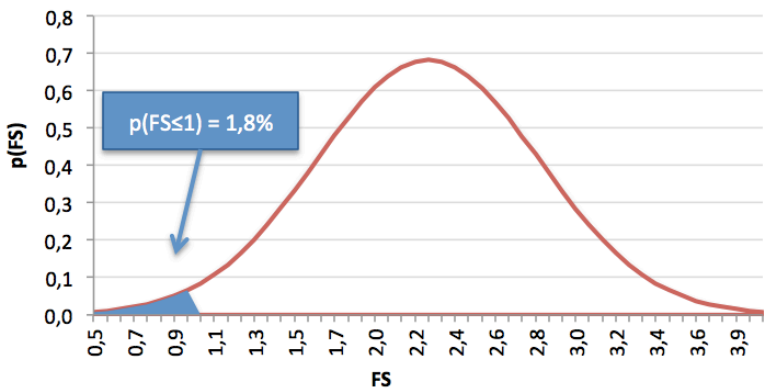

a)

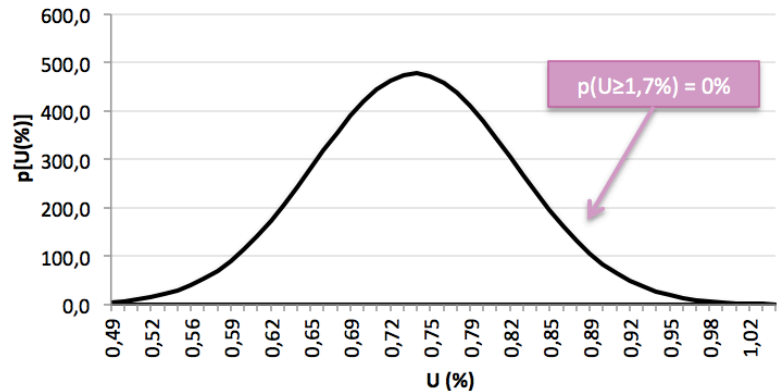

b)

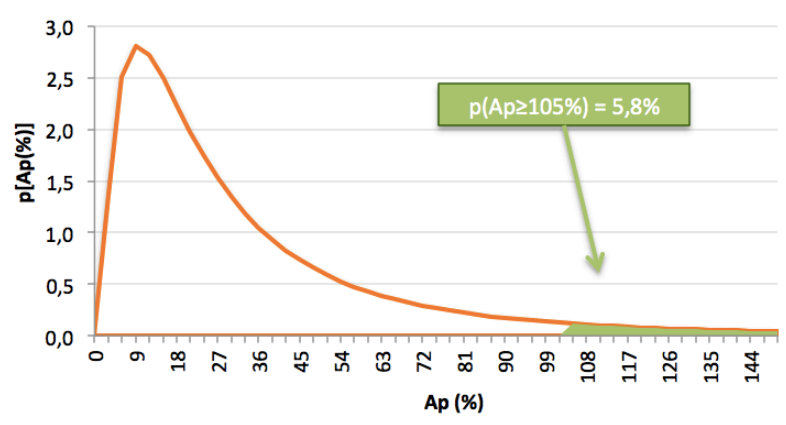

c)

Figura B.28 - Frequência de ocorrência e probabilidade de falha: a) Fator de Segurança (FS);

b) Convergência (U); c) Área Plástica (Ap) - Rocha sedimentar, $\mathrm{k}_{\mathrm{o}}=0$,5, elevado nível de tensões, maciço rochoso intacto.

Tabela B.29 - Resultados obtidos com o método dos pontos de estimativa (Rosenblueth) -

Rocha sedimentar, $\mathrm{k}_{\mathrm{o}}=0,5$, elevado nível de tensões, maciço rochoso moderadamente fraturado.

\begin{tabular}{|c|c|c|c|c|c|c|c|c|c|}
\hline \multirow{2}{*}{$\begin{array}{l}\text { PEM } \\
\text { Caso }\end{array}$} & \multicolumn{3}{|c|}{ Dados de Entrada } & & \multicolumn{5}{|c|}{ Dados de Saída } \\
\hline & $\mathbf{k}_{\mathbf{0}}$ & $\mathrm{c}^{\prime}$ (MPa) & $\phi^{\prime}$ & & FS & $\operatorname{Ap}\left(m^{2}\right)$ & Ap (\%) & $\mathrm{U}(\mathrm{m})$ & $\mathrm{U}(\%)$ \\
\hline$+\quad+\quad+$ & 0,625 & 5,76 & 37,8 & & 2,2 & 37,66 & $47,95 \%$ & 0,0662 & $1,32 \%$ \\
\hline$+\quad+\quad-$ & 0,625 & 5,76 & 30,9 & & 1,9 & 64,11 & $81,63 \%$ & 0,0744 & $1,49 \%$ \\
\hline$+\quad-\quad+$ & 0,625 & 2,47 & 37,8 & & 1,7 & 102,45 & $130,44 \%$ & 0,0886 & $1,77 \%$ \\
\hline$+\quad-\quad-$ & 0,625 & 2,47 & 30,9 & & 1,5 & 190,82 & $242,96 \%$ & 0,1127 & $2,25 \%$ \\
\hline$-\quad+\quad+$ & 0,375 & 5,76 & 37,8 & & 1,5 & 52,55 & $66,90 \%$ & 0,0733 & $1,47 \%$ \\
\hline$-\quad+\quad-$ & 0,375 & 5,76 & 30,9 & & 1,3 & 128,58 & $163,71 \%$ & 0,0845 & $1,69 \%$ \\
\hline$-\quad-\quad+$ & 0,375 & 2,47 & 37,8 & & 1,2 & 149,37 & $190,18 \%$ & 0,1116 & $2,23 \%$ \\
\hline$-\quad-$ & 0,375 & 2,47 & 30,9 & & 1,0 & 660,11 & $840,48 \%$ & 0,1514 & $3,03 \%$ \\
\hline & & & & $\begin{array}{l}\mu \\
\boldsymbol{\sigma}\end{array}$ & $\begin{array}{l}1,6 \\
0,4\end{array}$ & & $\begin{array}{l}220,53 \% \\
242,33 \%\end{array}$ & & $\begin{array}{l}1,91 \% \\
0,53 \%\end{array}$ \\
\hline
\end{tabular}




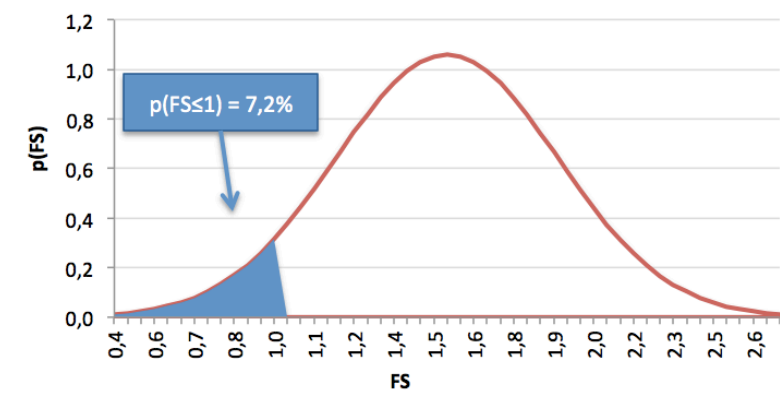

a)

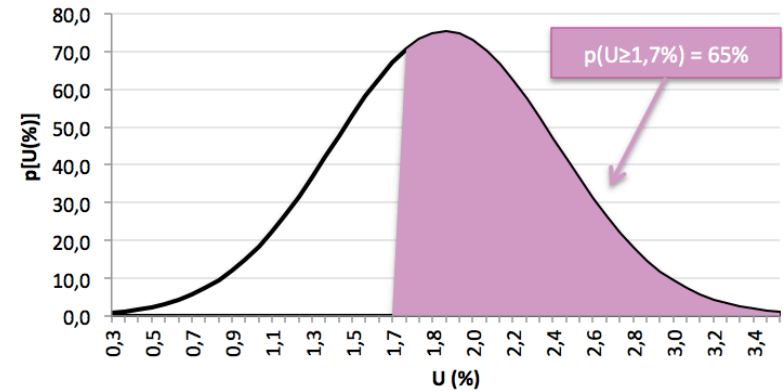

b)

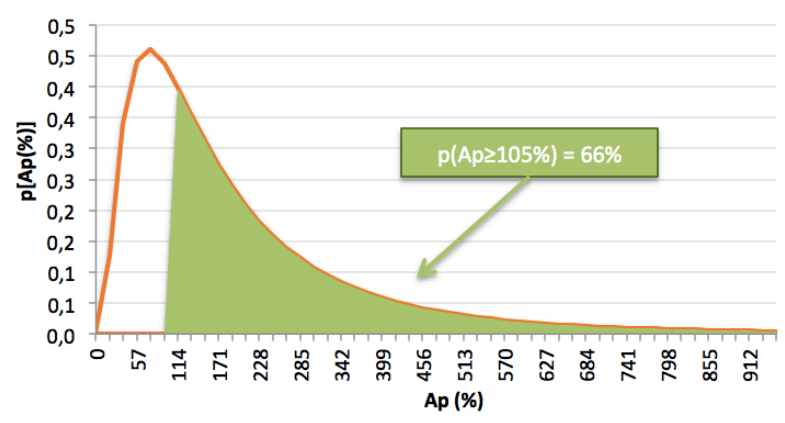

c)

Figura B.29- Frequência de ocorrência e probabilidade de falha: a) Fator de Segurança (FS);

b) Convergência (U); c) Área Plástica (Ap) - Rocha sedimentar, $\mathrm{k}_{\mathrm{o}}=0,5$, elevado nível de tensões, maciço rochoso moderadamente fraturado.

Tabela B.30 - Resultados obtidos com o método dos pontos de estimativa (Rosenblueth) Rocha sedimentar, $\mathrm{k}_{\mathrm{o}}=0,5$, elevado nível de tensões, maciço rochoso intensamente fraturado.

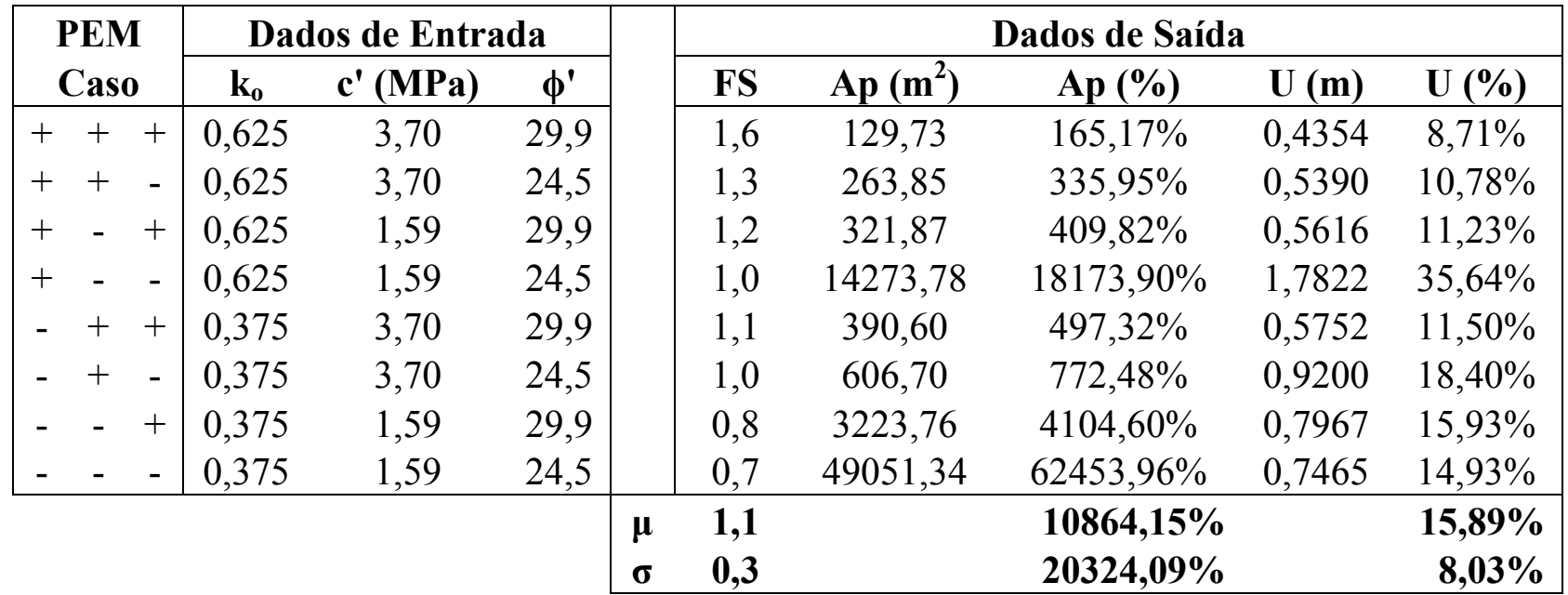




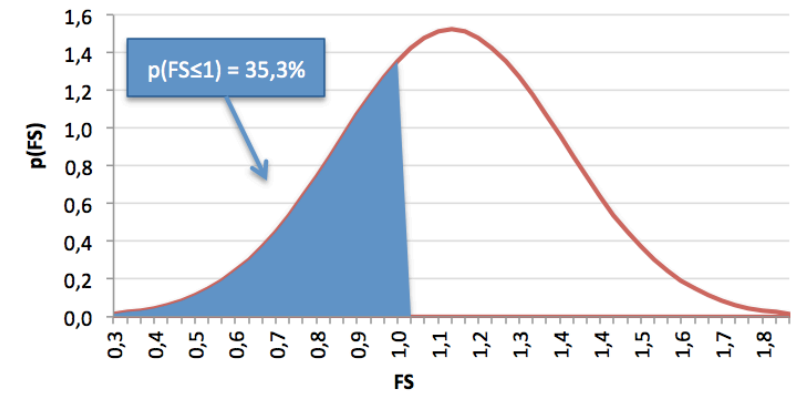

a)

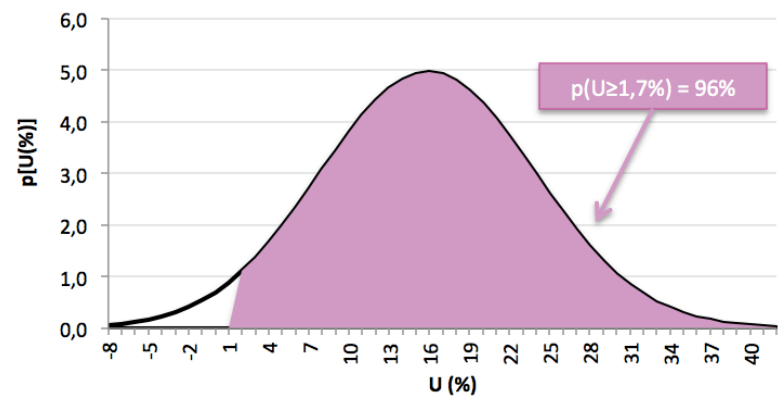

b)

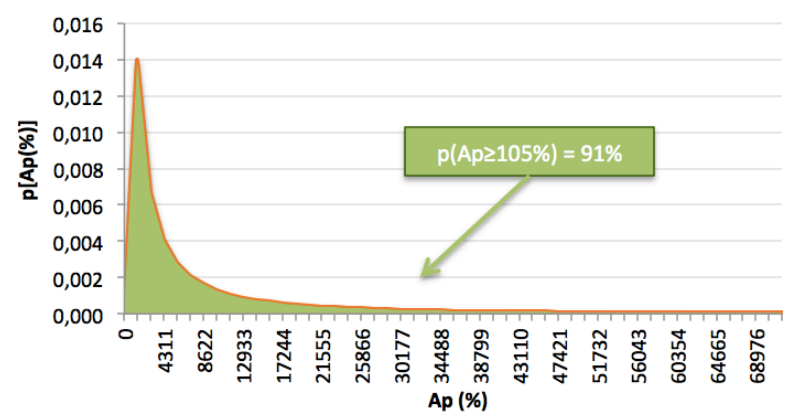

c)

Figura B.30 - Frequência de ocorrência e probabilidade de falha: a) Fator de Segurança (FS);

b) Convergência (U); c) Área Plástica (Ap) - Rocha sedimentar, $\mathrm{k}_{\mathrm{o}}=0,5$, elevado nível de tensões, maciço rochoso intensamente fraturado.

\section{B.2.2. $K_{0}=1,0$}

\section{B.2.2.1. Baixo Nível de Tensões}

Tabela B.31 - Resultados obtidos com o método dos pontos de estimativa (Rosenblueth) Rocha sedimentar, $\mathrm{k}_{\mathrm{o}}=1,0$, baixo nível de tensões, maciço rochoso intensamente fraturado.

\begin{tabular}{|c|c|c|c|c|c|c|c|c|c|}
\hline \multirow{2}{*}{$\begin{array}{l}\text { PEM } \\
\text { Caso }\end{array}$} & \multicolumn{3}{|c|}{ Dados de Entrada } & & \multicolumn{5}{|c|}{ Dados de Saída } \\
\hline & $\mathbf{k}_{\mathbf{0}}$ & $\mathbf{c}^{\prime}(\mathrm{MPa})$ & $\phi^{\prime}$ & & FS & $\operatorname{Ap}\left(\mathrm{m}^{2}\right)$ & Ap (\%) & $\mathbf{U}(\mathbf{m})$ & $\mathrm{U}(\%)$ \\
\hline$+\quad+\quad+$ & 1,25 & 1,37 & 43,4 & & 2,8 & 32,22 & $41,02 \%$ & 0,0684 & $1,37 \%$ \\
\hline$+\quad+\quad-$ & 1,25 & 1,37 & 35,5 & & 2,3 & 63,36 & $80,67 \%$ & 0,0780 & $1,56 \%$ \\
\hline$+\quad-\quad+$ & 1,25 & 0,59 & 43,4 & & 2,2 & 78,75 & $100,27 \%$ & 0,0903 & $1,81 \%$ \\
\hline$+\quad-\quad-$ & 1,25 & 0,59 & 35,5 & & 1,8 & 160,74 & $204,66 \%$ & 0,1274 & $2,55 \%$ \\
\hline$-\quad+\quad+$ & 0,75 & 1,37 & 43,4 & & 3,0 & 21,61 & $27,51 \%$ & 0,0526 & $1,05 \%$ \\
\hline$-\quad+\quad-$ & 0,75 & 1,37 & 35,5 & & 2,5 & 44,26 & $56,35 \%$ & 0,0576 & $1,15 \%$ \\
\hline$-\quad-\quad+$ & 0,75 & 0,59 & 43,4 & & 2,3 & 63,58 & $80,95 \%$ & 0,0666 & $1,33 \%$ \\
\hline$-\quad-\quad-$ & 0,75 & 0,59 & 35,5 & & 1,9 & 124,86 & $158,97 \%$ & 0,0824 & $1,65 \%$ \\
\hline & & & & $\begin{array}{l}\mu \\
\sigma\end{array}$ & $\begin{array}{l}2,4 \\
0,4\end{array}$ & & $\begin{array}{l}93,80 \% \\
56,46 \%\end{array}$ & & $\begin{array}{l}1,56 \% \\
0,44 \%\end{array}$ \\
\hline
\end{tabular}




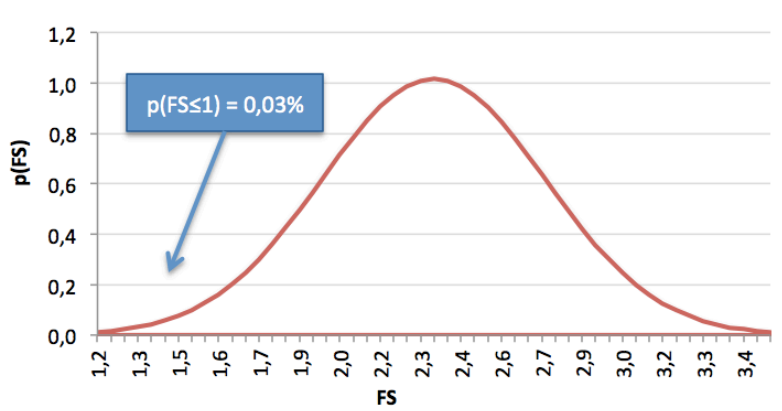

a)

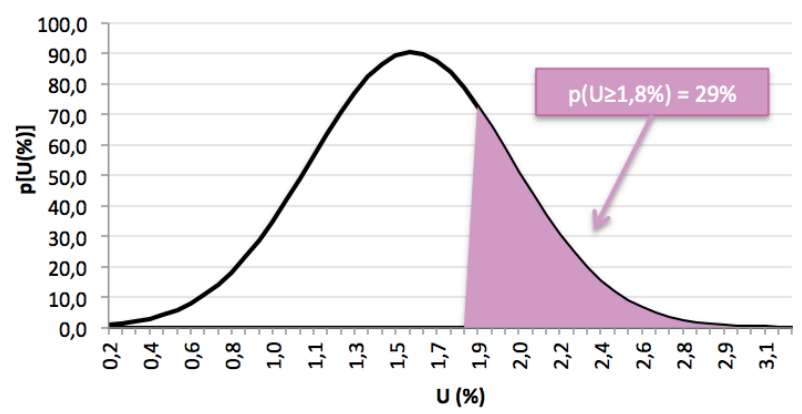

b)

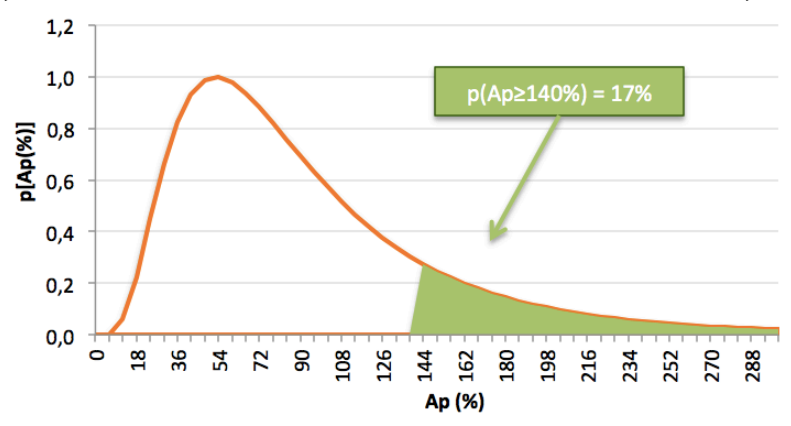

c)

Figura B.31 - Frequência de ocorrência e probabilidade de falha: a) Fator de Segurança (FS);

b) Convergência (U); c) Área Plástica (Ap) - Rocha sedimentar, $\mathrm{k}_{\mathrm{o}}=1,0$, baixo nível de tensões, maciço rochoso intensamente fraturado.

\section{B.2.2.2. Moderado Nível de Tensões}

Tabela B.32 - Resultados obtidos com o método dos pontos de estimativa (Rosenblueth) Rocha sedimentar, $\mathrm{k}_{\mathrm{o}}=1,0$, moderado nível de tensões, maciço rochoso moderadamente fraturado.

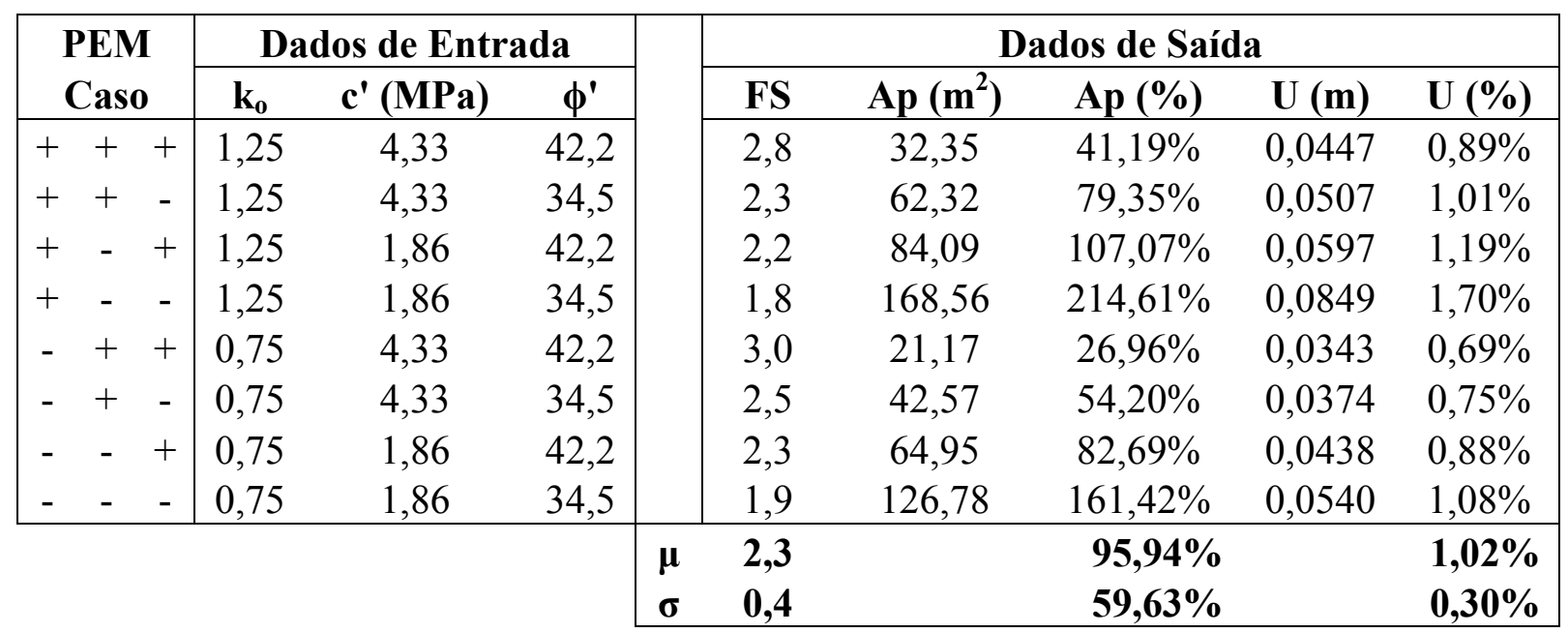




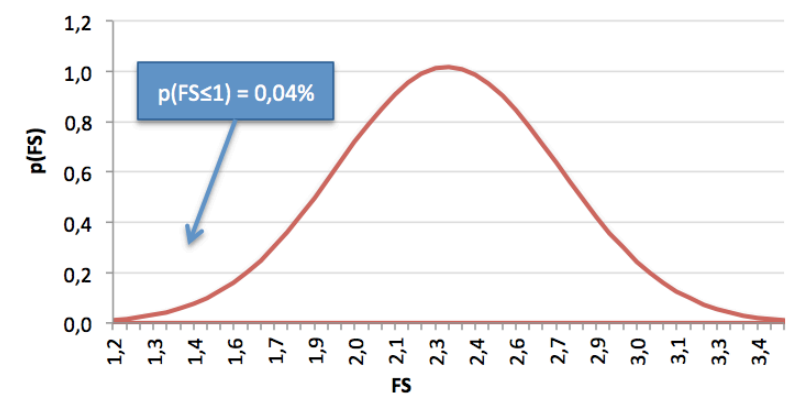

a)

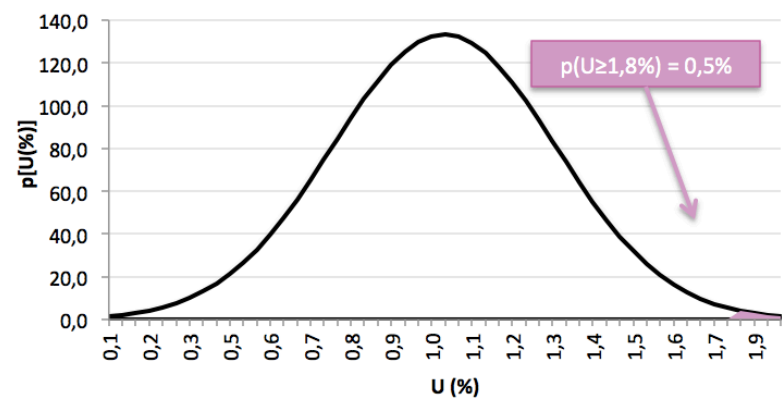

b)

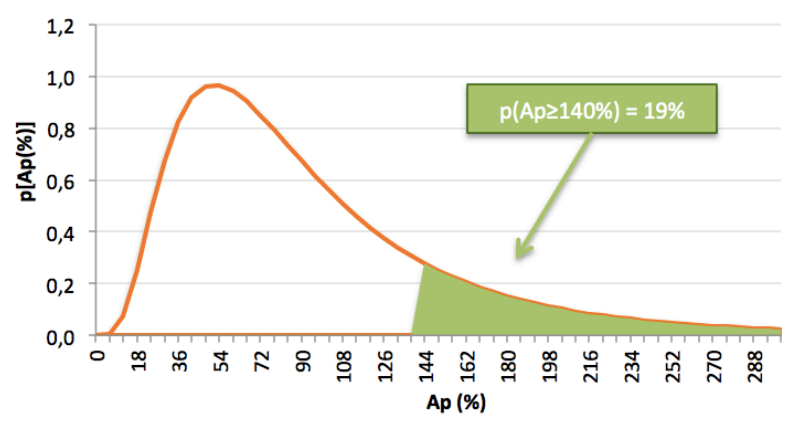

c)

Figura B.32- Frequência de ocorrência e probabilidade de falha: a) Fator de Segurança (FS); b) Convergência (U); c) Área Plástica (Ap) - Rocha sedimentar, $\mathrm{k}_{\mathrm{o}}=1,0$, moderado nível de tensões, maciço rochoso moderadamente fraturado.

Tabela B.33 - Resultados obtidos com o método dos pontos de estimativa (Rosenblueth) Rocha sedimentar, $\mathrm{k}_{\mathrm{o}}=1,0$, moderado nível de tensões, maciço rochoso intensamente fraturado.

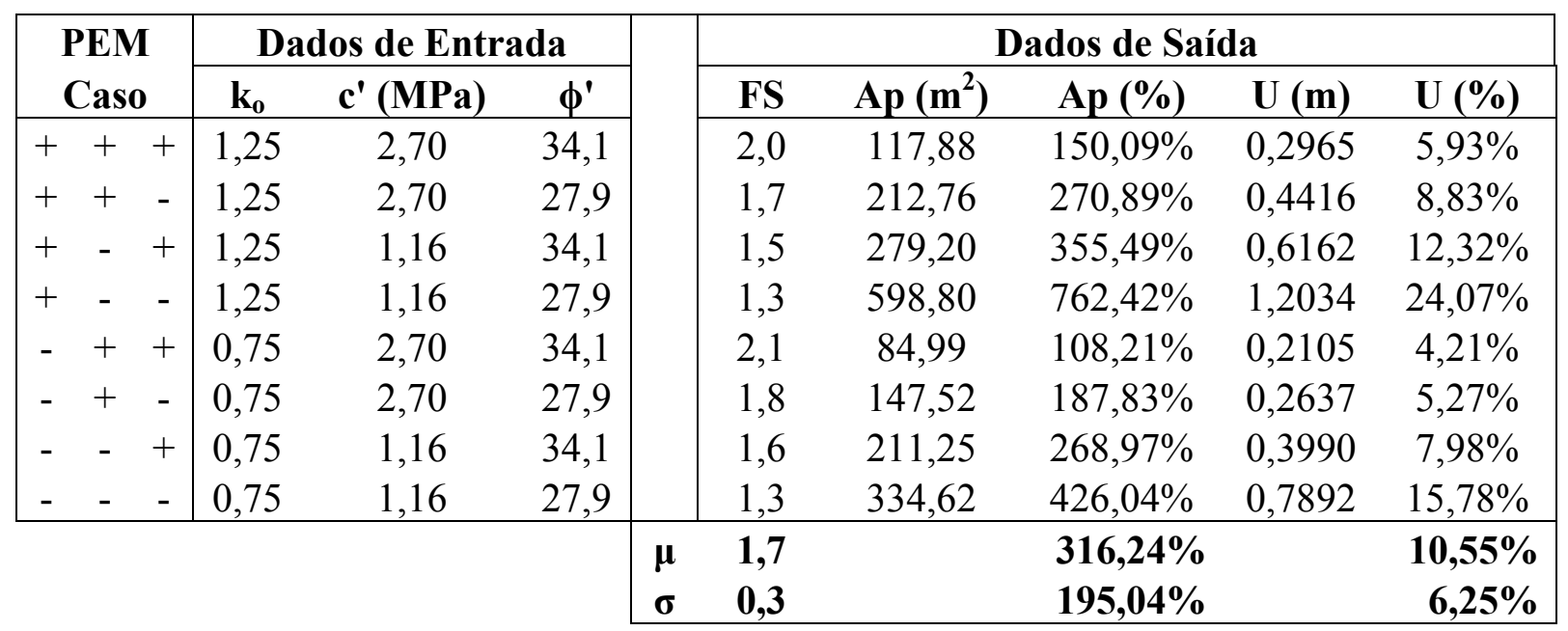




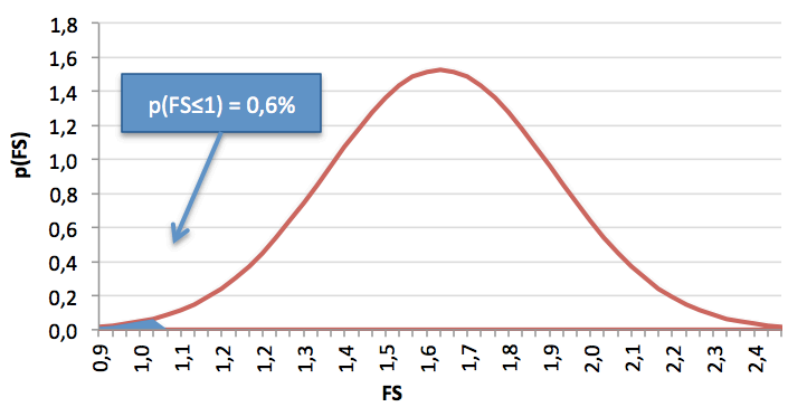

a)

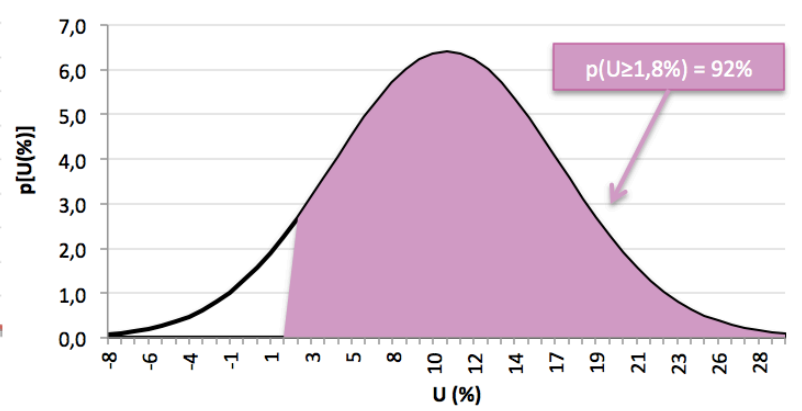

b)

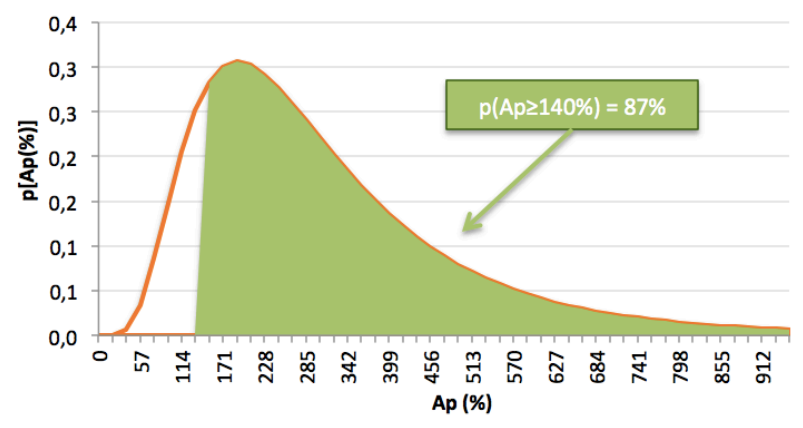

c)

Figura B.33- Frequência de ocorrência e probabilidade de falha: a) Fator de Segurança (FS); b) Convergência (U); c) Área Plástica (Ap) - Rocha sedimentar, $\mathrm{k}_{\mathrm{o}}=1,0$, moderado nível de tensões, maciço rochoso intensamente fraturado.

\section{B.2.2.3. Elevado Nível de Tensões}

Tabela B.34 - Resultados obtidos com o método dos pontos de estimativa (Rosenblueth) Rocha sedimentar, $\mathrm{k}_{\mathrm{o}}=1,0$, elevado nível de tensões, maciço rochoso intacto.

\begin{tabular}{|c|c|c|c|c|c|c|c|c|c|}
\hline \multirow{2}{*}{$\begin{array}{l}\text { PEM } \\
\text { Caso }\end{array}$} & \multicolumn{3}{|c|}{ Dados de Entrada } & & \multicolumn{5}{|c|}{ Dados de Saída } \\
\hline & $\mathbf{k}_{\mathbf{0}}$ & $\mathbf{c}^{\prime}$ (MPa) & $\phi^{\prime}$ & & FS & $\operatorname{Ap}\left(m^{2}\right)$ & Ap (\%) & $\mathbf{U}(\mathbf{m})$ & $\mathrm{U}(\%)$ \\
\hline$+\quad+\quad+$ & 1,25 & 10,92 & 44,8 & & 3,5 & 12,07 & $15,37 \%$ & 0,0373 & $0,75 \%$ \\
\hline$+\quad+\quad-$ & 1,25 & 10,92 & 36,7 & & 2,9 & 27,50 & $35,02 \%$ & 0,0397 & $0,79 \%$ \\
\hline$+\quad-\quad+$ & 1,25 & 4,68 & 44,8 & & 2,6 & 46,02 & $58,59 \%$ & 0,0455 & $0,91 \%$ \\
\hline$+\quad-\quad-$ & 1,25 & 4,68 & 36,7 & & 2,1 & 90,66 & $115,43 \%$ & 0,0548 & $1,10 \%$ \\
\hline$-\quad+\quad+$ & 0,75 & 10,92 & 44,8 & & 3,7 & 6,54 & $8,32 \%$ & 0,0296 & $0,59 \%$ \\
\hline$-\quad+\quad-$ & 0,75 & 10,92 & 36,7 & & 3,1 & 13,71 & $17,46 \%$ & 0,0308 & $0,62 \%$ \\
\hline$-\quad+$ & 0,75 & 4,68 & 44,8 & & 2,7 & 32,38 & $41,23 \%$ & 0,0345 & $0,69 \%$ \\
\hline$-\quad-$ & 0,75 & 4,68 & 36,7 & & 2,2 & 67,22 & $85,59 \%$ & 0,0397 & $0,79 \%$ \\
\hline & & & & $\begin{array}{l}\mu \\
\sigma\end{array}$ & $\begin{array}{l}2,9 \\
0,5\end{array}$ & & $\begin{array}{l}47,13 \% \\
35,09 \%\end{array}$ & & $\begin{array}{l}0,78 \% \\
0,15 \%\end{array}$ \\
\hline
\end{tabular}




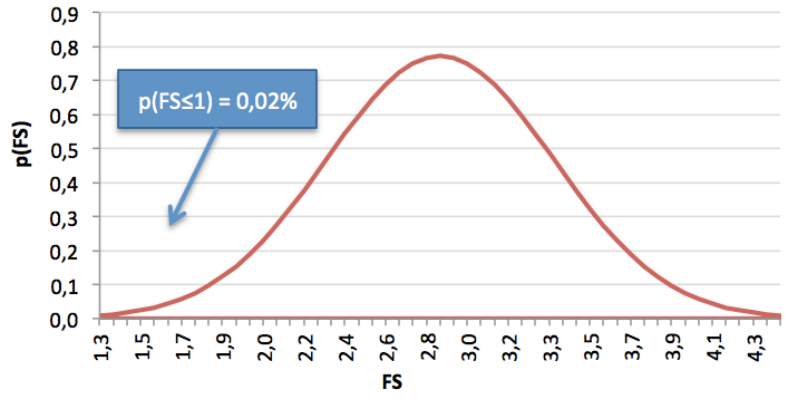

a)

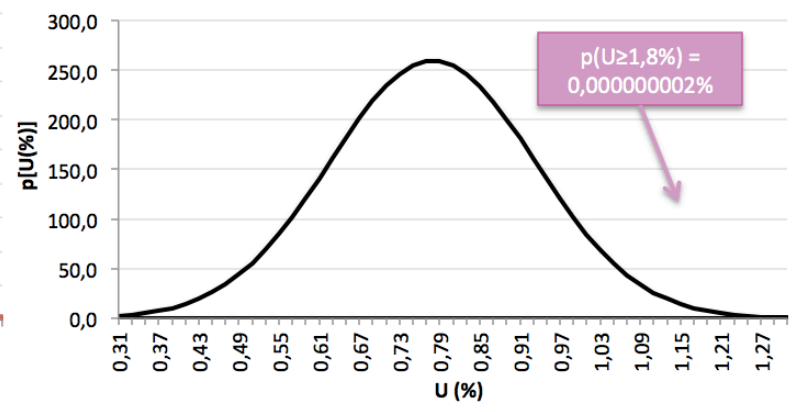

b)

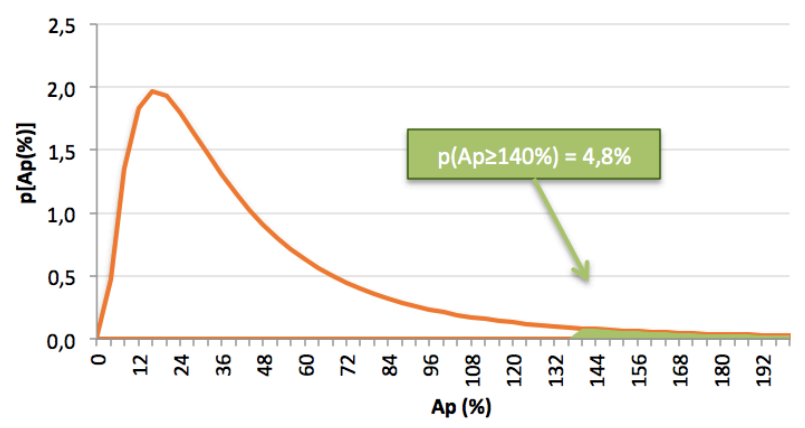

c)

Figura B.34- Frequência de ocorrência e probabilidade de falha: a) Fator de Segurança (FS); b) Convergência (U); c) Área Plástica (Ap) - Rocha sedimentar, $\mathrm{k}_{\mathrm{o}}=1,0$, elevado nível de tensões, maciço rochoso intacto.

Tabela B.35 - Resultados obtidos com o método dos pontos de estimativa (Rosenblueth) Rocha sedimentar, $\mathrm{k}_{\mathrm{o}}=1,0$, elevado nível de tensões, maciço rochoso moderadamente fraturado.

\begin{tabular}{|c|c|c|c|c|c|c|c|c|c|}
\hline \multirow{2}{*}{$\begin{array}{l}\text { PEM } \\
\text { Caso }\end{array}$} & \multicolumn{3}{|c|}{ Dados de Entrada } & & \multicolumn{5}{|c|}{ Dados de Saída } \\
\hline & $\mathbf{k}_{\mathbf{0}}$ & $\mathbf{c}^{\prime}$ (MPa) & $\phi^{\prime}$ & & FS & $\operatorname{Ap}\left(m^{2}\right)$ & $\operatorname{Ap}(\%)$ & $\mathbf{U}(\mathbf{m})$ & $\mathbf{U}(\%)$ \\
\hline$+\quad+\quad+$ & 1,25 & 5,76 & 37,8 & & 2,3 & 64,57 & $82,21 \%$ & 0,0868 & $1,74 \%$ \\
\hline$+\quad+\quad-$ & 1,25 & 5,76 & 30,9 & & 2,0 & 114,53 & $145,82 \%$ & 0,1034 & $2,07 \%$ \\
\hline$+\quad-\quad+$ & 1,25 & 2,47 & 37,8 & & 1,8 & 149,89 & $190,84 \%$ & 0,1350 & $2,70 \%$ \\
\hline$+\quad-\quad-$ & 1,25 & 2,47 & 30,9 & & 1,5 & 304,47 & $387,67 \%$ & 0,2373 & $4,75 \%$ \\
\hline$-\quad+\quad+$ & 0,75 & 5,76 & 37,8 & & 2,5 & 44,50 & $56,66 \%$ & 0,0641 & $1,28 \%$ \\
\hline$-\quad+\quad-$ & 0,75 & 5,76 & 30,9 & & 2,1 & 78,21 & $99,57 \%$ & 0,0730 & $1,46 \%$ \\
\hline$-\quad-\quad+$ & 0,75 & 2,47 & 37,8 & & 1,9 & 118,04 & $150,30 \%$ & 0,0900 & $1,80 \%$ \\
\hline$-\quad-\quad-$ & 0,75 & 2,47 & 30,9 & & 1,6 & 225,59 & $287,23 \%$ & 0,1484 & $2,97 \%$ \\
\hline & & & & $\begin{array}{l}\mu \\
\sigma\end{array}$ & $\begin{array}{l}2,0 \\
0,3\end{array}$ & & $\begin{array}{l}175,04 \% \\
104,79 \%\end{array}$ & & $\begin{array}{l}2,35 \% \\
1,06 \%\end{array}$ \\
\hline
\end{tabular}




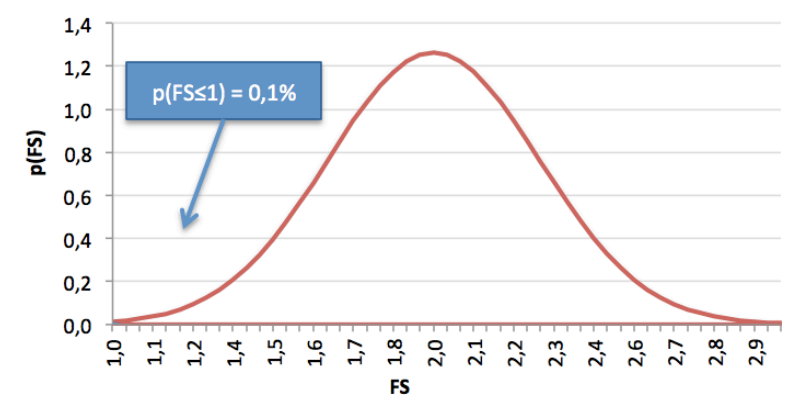

a)

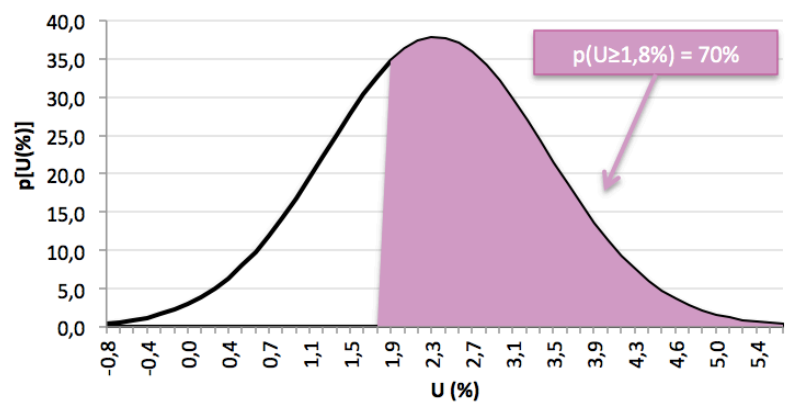

b)

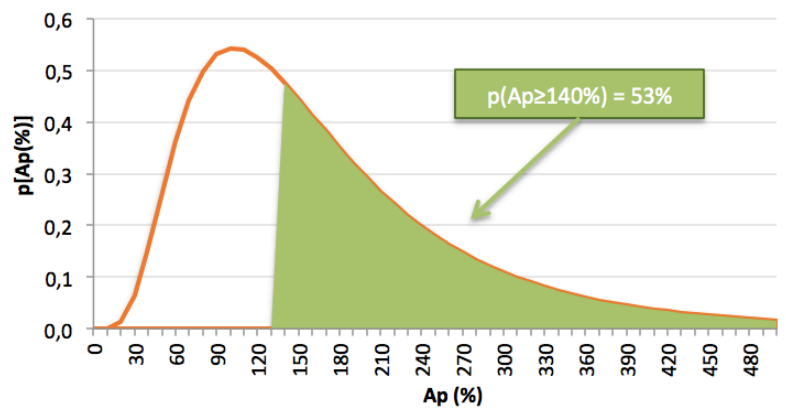

c)

Figura B.35- Frequência de ocorrência e probabilidade de falha: a) Fator de Segurança (FS); b) Convergência (U); c) Área Plástica (Ap) - Rocha sedimentar, $\mathrm{k}_{\mathrm{o}}=1,0$, elevado nível de tensões, maciço rochoso moderadamente fraturado.

Tabela B.36 - Resultados obtidos com o método dos pontos de estimativa (Rosenblueth) Rocha sedimentar, $\mathrm{k}_{\mathrm{o}}=1,0$, elevado nível de tensões, maciço rochoso intensamente fraturado.

\begin{tabular}{|c|c|c|c|c|c|c|c|c|c|}
\hline \multirow{2}{*}{$\begin{array}{l}\text { PEM } \\
\text { Caso }\end{array}$} & \multicolumn{3}{|c|}{ Dados de Entrada } & & \multicolumn{5}{|c|}{ Dados de Saída } \\
\hline & $\mathbf{k}_{\mathbf{0}}$ & $\mathrm{c}^{\prime}(\mathrm{MPa})$ & $\phi^{\prime}$ & & FS & $\operatorname{Ap}\left(\mathrm{m}^{2}\right)$ & Ap (\%) & $\mathrm{U}(\mathrm{m})$ & $\mathbf{U}(\%)$ \\
\hline$+\quad+\quad+$ & 1,25 & 3,70 & 29,9 & & 1,7 & 217,04 & $276,35 \%$ & 0,7778 & $15,56 \%$ \\
\hline$+\quad+-$ & 1,25 & 3,70 & 24,5 & & 1,4 & 423,36 & $539,03 \%$ & 1,2861 & $25,72 \%$ \\
\hline$+\quad-\quad+$ & 1,25 & 1,59 & 29,9 & & 1,3 & 477,29 & $607,71 \%$ & 1,4882 & $29,76 \%$ \\
\hline$+\quad-\quad-$ & 1,25 & 1,59 & 24,5 & & 1,1 & 2340,30 & $2979,75 \%$ & 5,2885 & $105,77 \%$ \\
\hline$-\quad+\quad+$ & 0,75 & 3,70 & 29,9 & & 1,7 & 155,94 & $198,55 \%$ & 0,4768 & $9,54 \%$ \\
\hline$-\quad+\quad-$ & 0,75 & 3,70 & 24,5 & & 1,5 & 269,94 & $343,70 \%$ & 0,7530 & $15,06 \%$ \\
\hline$-\quad-\quad+$ & 0,75 & 1,59 & 29,9 & & 1,3 & 248,05 & $315,83 \%$ & 1,0464 & $20,93 \%$ \\
\hline$-\quad-\quad-$ & 0,75 & 1,59 & 24,5 & & 1,1 & 1760,04 & $2240,95 \%$ & 2,7895 & $55,79 \%$ \\
\hline & & & & $\begin{array}{l}\mu \\
\sigma\end{array}$ & $\begin{array}{l}1,4 \\
0,2\end{array}$ & & $\begin{array}{l}937,73 \% \\
991,18 \%\end{array}$ & & $\begin{array}{l}34,77 \% \\
29,95 \%\end{array}$ \\
\hline
\end{tabular}




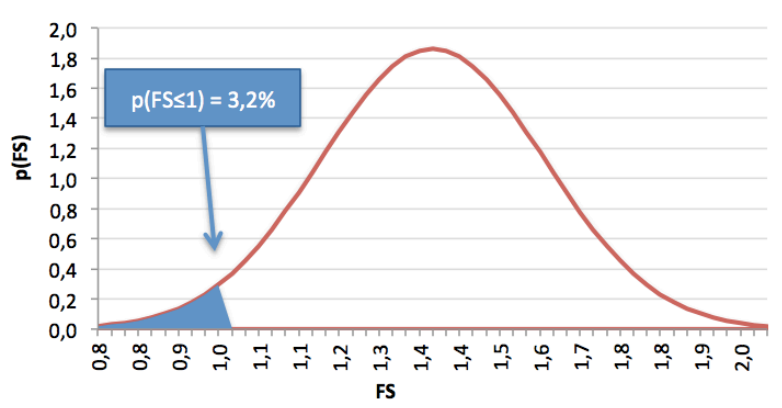

a)

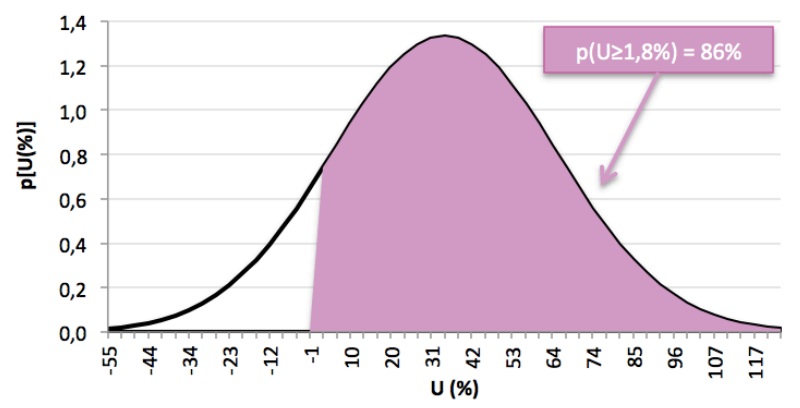

b)

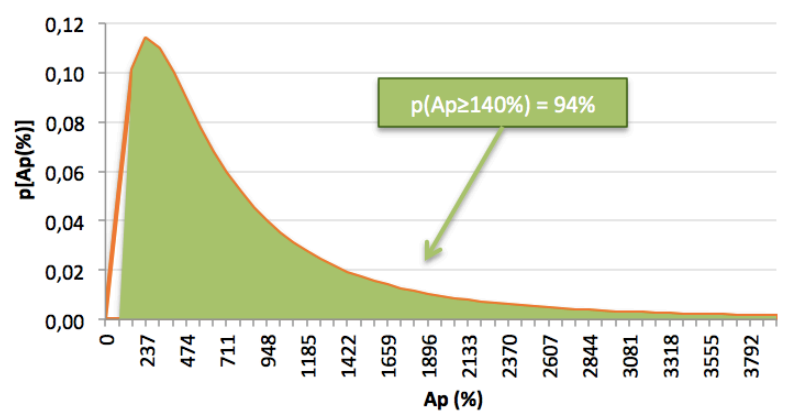

c)

Figura B.36 - Frequência de ocorrência e probabilidade de falha: a) Fator de Segurança (FS);

b) Convergência (U); c) Área Plástica (Ap) - Rocha sedimentar, $\mathrm{k}_{\mathrm{o}}=1,0$, elevado nível de tensões, maciço rochoso intensamente fraturado.

B.2.3. $K_{O}=2,0$

\section{B.2.3.1. Baixo Nível de Tensões}

Tabela B.37 - Resultados obtidos com o método dos pontos de estimativa (Rosenblueth) Rocha sedimentar, $\mathrm{k}_{\mathrm{o}}=2,0$, baixo nível de tensões, maciço rochoso intensamente fraturado.

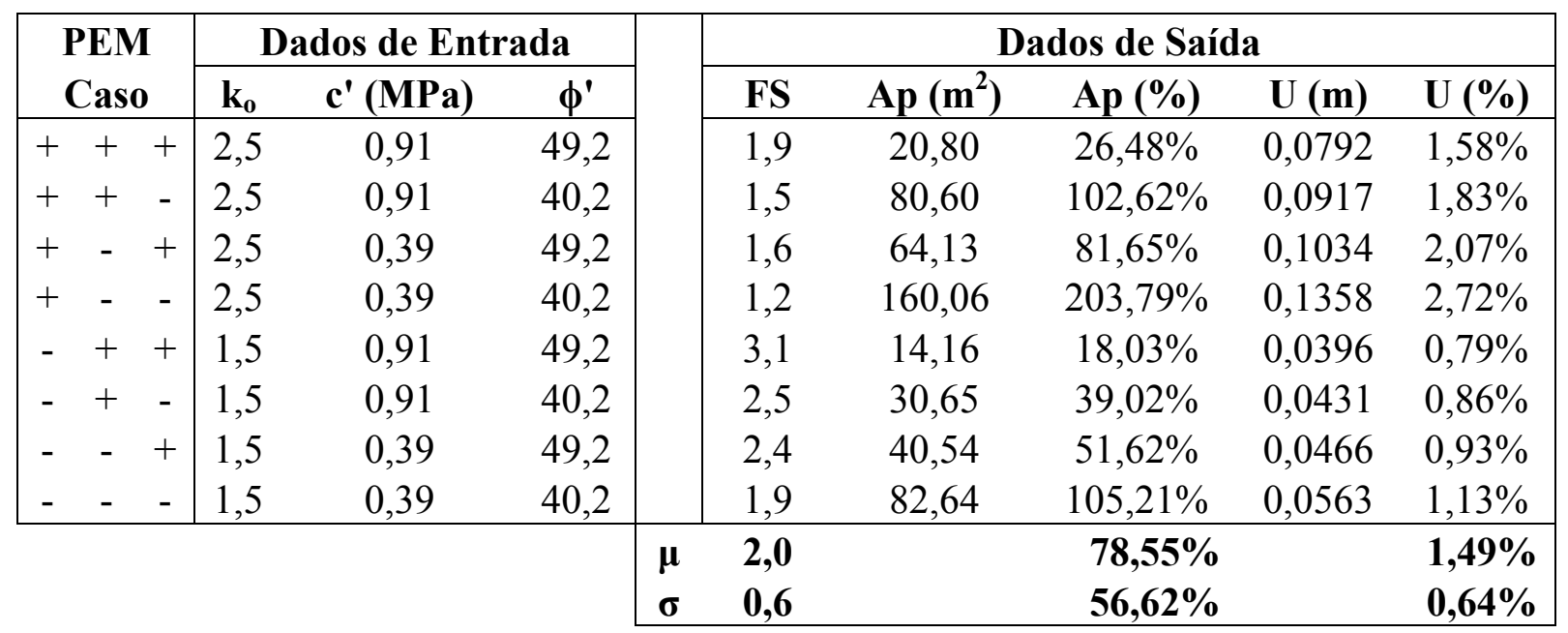




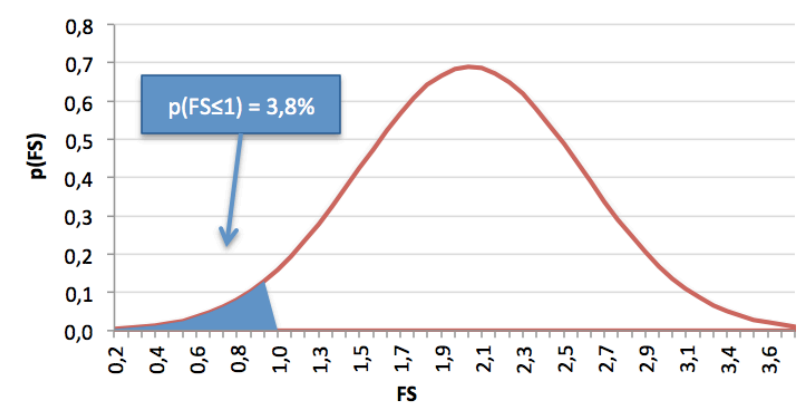

a)

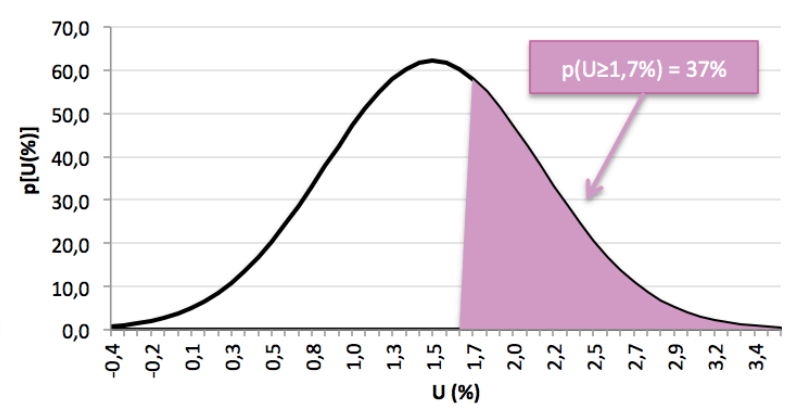

b)

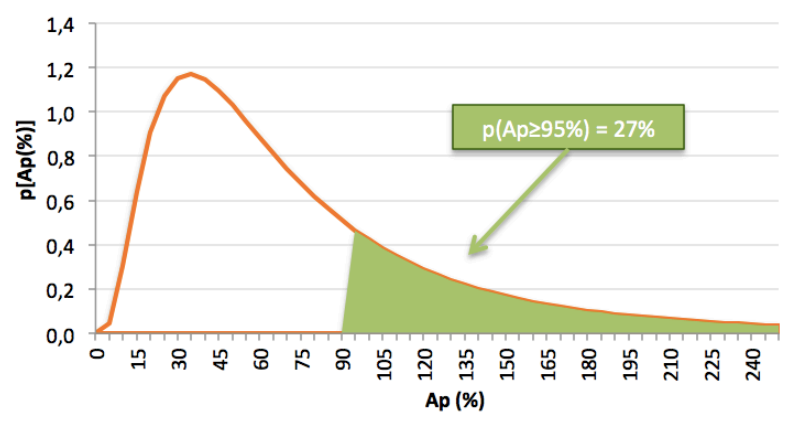

c)

Figura B.37- Frequência de ocorrência e probabilidade de falha: a) Fator de Segurança (FS);

b) Convergência (U); c) Área Plástica (Ap) - Rocha sedimentar, $\mathrm{k}_{\mathrm{o}}=2,0$, baixo nível de tensões, maciço rochoso intensamente fraturado.

\section{B.2.3.2. Moderado Nível de Tensões}

Tabela B.38 - Resultados obtidos com o método dos pontos de estimativa (Rosenblueth) Rocha sedimentar, $\mathrm{k}_{\mathrm{o}}=2,0$, moderado nível de tensões, maciço rochoso moderadamente fraturado.

\begin{tabular}{|c|c|c|c|c|c|c|c|c|c|}
\hline \multirow{2}{*}{$\begin{array}{l}\text { PEM } \\
\text { Caso }\end{array}$} & \multicolumn{3}{|c|}{ Dados de Entrada } & & \multicolumn{5}{|c|}{ Dados de Saída } \\
\hline & ko & $c^{\prime}$ (MPa) & $\phi^{\prime}$ & & FS & Ap (m2) & Ap (\%) & $\mathrm{U}(\mathrm{m})$ & $\mathrm{U}(\%)$ \\
\hline$+\quad+\quad+$ & 2,5 & 3,03 & 48,0 & & 1,9 & 19,91 & $25,36 \%$ & 0,0514 & $1,03 \%$ \\
\hline$+\quad+\quad-$ & 2,5 & 3,03 & 39,3 & & 1,5 & 78,70 & $100,20 \%$ & 0,0589 & $1,18 \%$ \\
\hline$+\quad-\quad+$ & 2,5 & 1,30 & 48,0 & & 1,6 & 58,99 & $75,11 \%$ & 0,0637 & $1,27 \%$ \\
\hline$+\quad-\quad-$ & 2,5 & 1,30 & 39,3 & & 1,3 & 167,89 & $213,77 \%$ & 0,0885 & $1,77 \%$ \\
\hline$-\quad+\quad+$ & 1,5 & 3,03 & 48,0 & & 3,1 & 12,92 & $16,45 \%$ & 0,0256 & $0,51 \%$ \\
\hline$-\quad+\quad-$ & 1,5 & 3,03 & 39,3 & & 2,5 & 28,81 & $36,68 \%$ & 0,0276 & $0,55 \%$ \\
\hline$-\quad-\quad+$ & 1,5 & 1,30 & 48,0 & & 2,4 & 40,37 & $51,41 \%$ & 0,0303 & $0,61 \%$ \\
\hline$-\quad-\quad-$ & 1,5 & 1,30 & 39,3 & & 1,9 & 81,70 & $104,02 \%$ & 0,0362 & $0,72 \%$ \\
\hline & & & & $\begin{array}{l}\mu \\
\sigma\end{array}$ & $\begin{array}{l}2,0 \\
0,6\end{array}$ & & $\begin{array}{l}\mathbf{7 7 , 8 7 \%} \\
\mathbf{5 9 , 7 8 \%}\end{array}$ & & $\begin{array}{l}0,96 \% \\
0,41 \%\end{array}$ \\
\hline
\end{tabular}




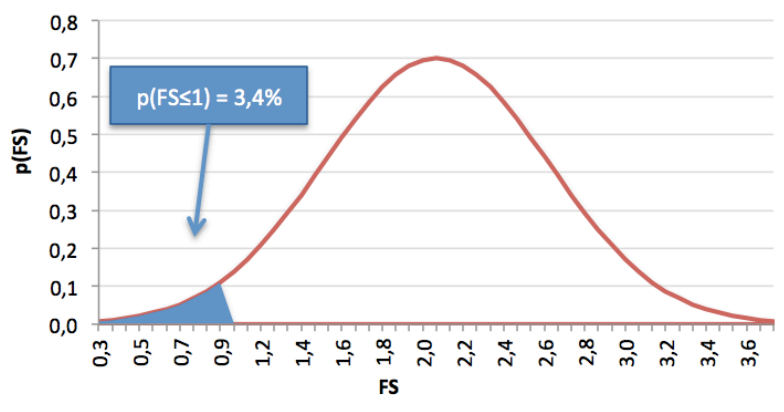

a)

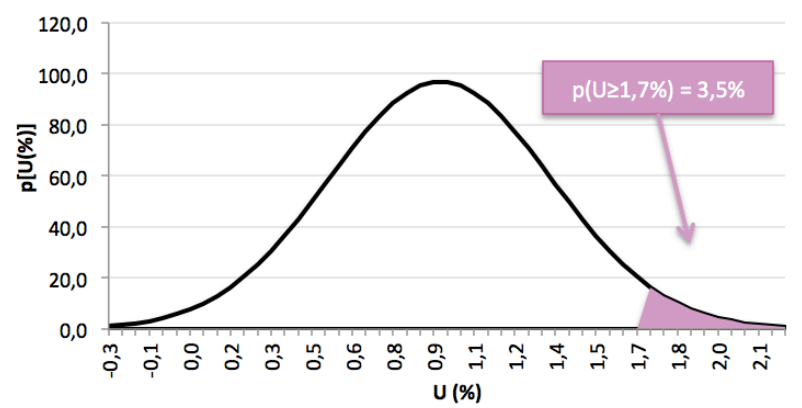

b)

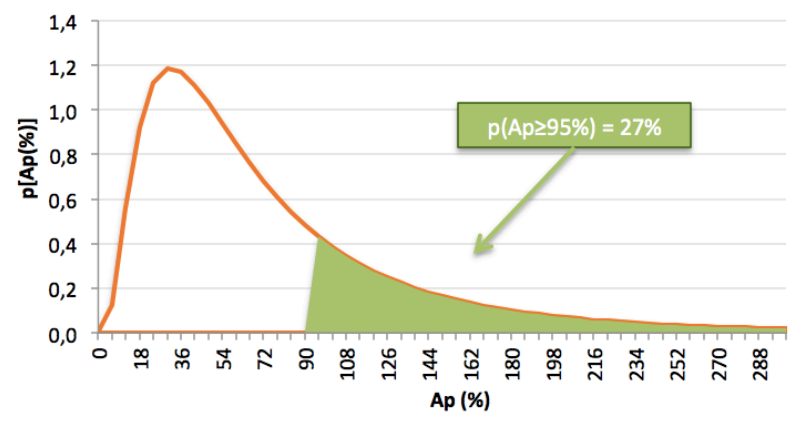

c)

Figura B.38- Frequência de ocorrência e probabilidade de falha: a) Fator de Segurança (FS); b) Convergência (U); c) Área Plástica (Ap) - Rocha sedimentar, $\mathrm{k}_{\mathrm{o}}=2,0$, moderado nível de tensões, maciço rochoso moderadamente fraturado.

Tabela B.39 - Resultados obtidos com o método dos pontos de estimativa (Rosenblueth) Rocha sedimentar, $\mathrm{k}_{\mathrm{o}}=2,0$, moderado nível de tensões, maciço rochoso intensamente fraturado.

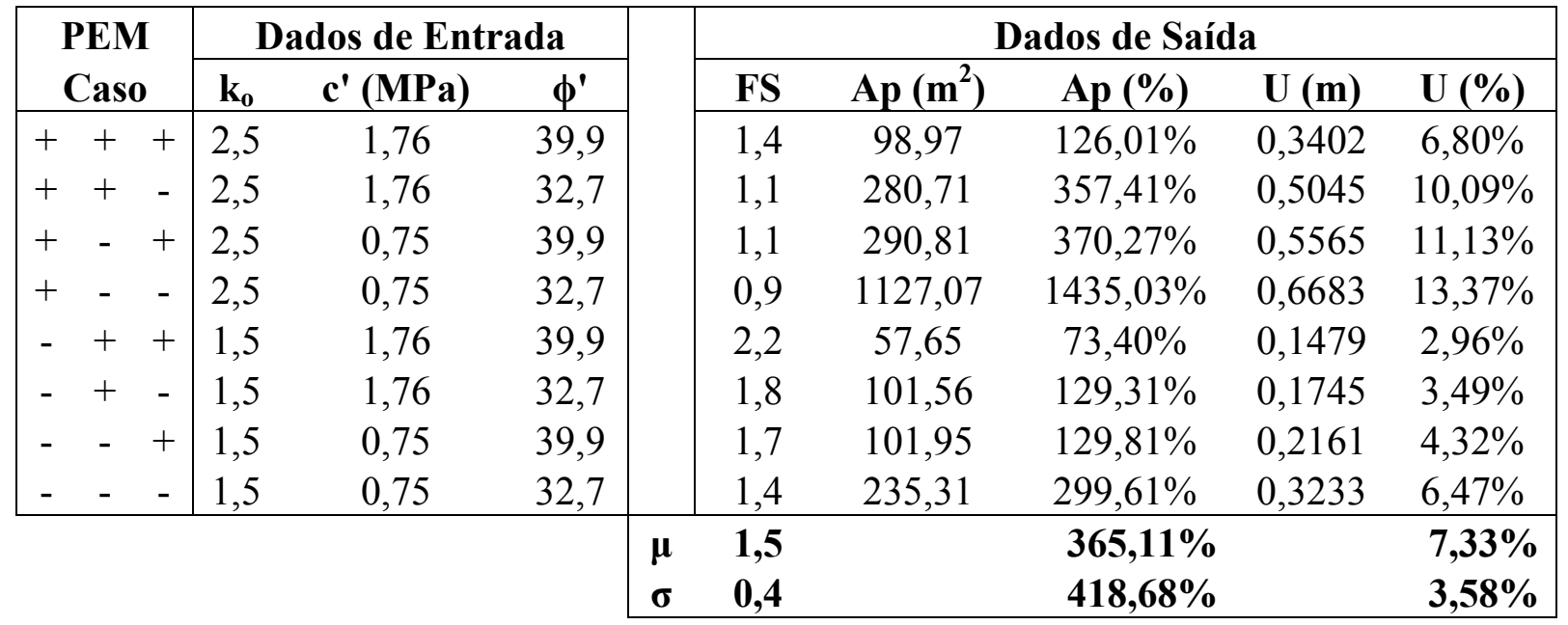




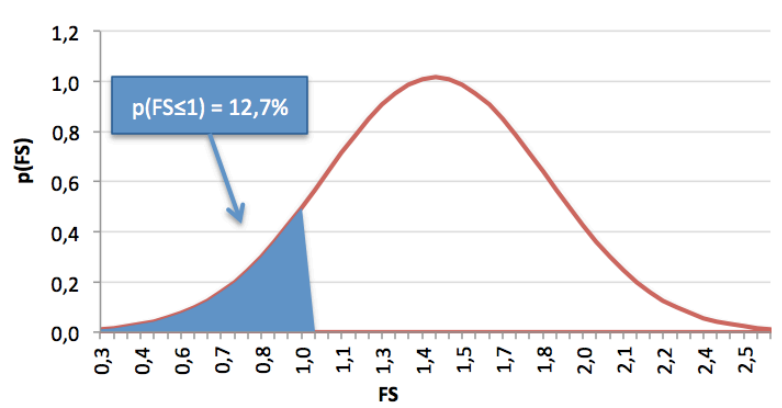

a)

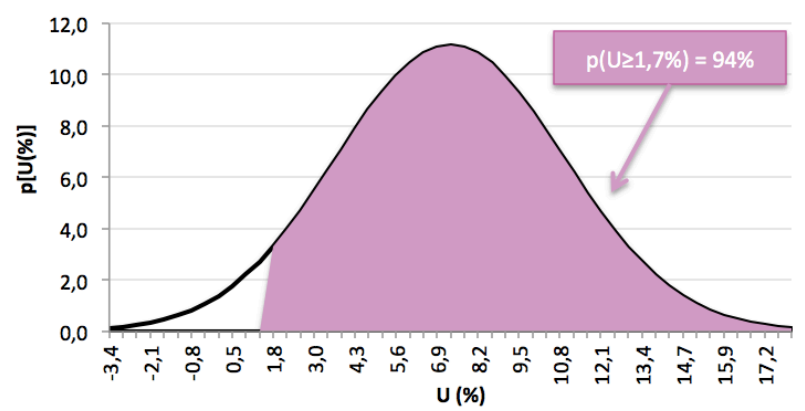

b)

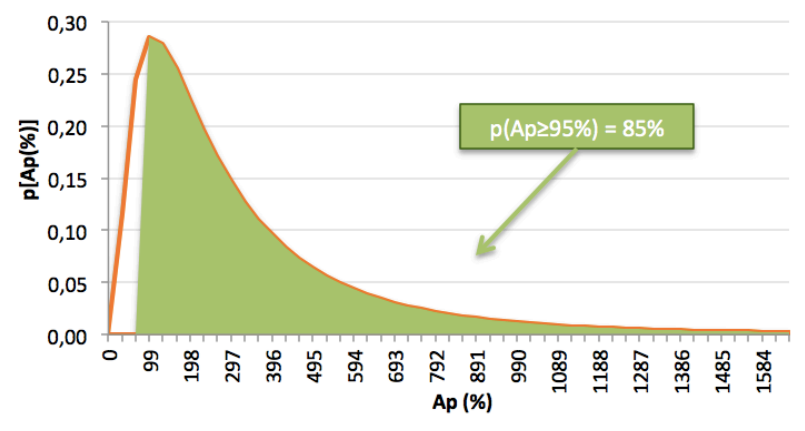

c)

Figura B.39- Frequência de ocorrência e probabilidade de falha: a) Fator de Segurança (FS);

b) Convergência (U); c) Área Plástica (Ap) - Rocha sedimentar, $\mathrm{k}_{\mathrm{o}}=2,0$, moderado nível de tensões, maciço rochoso intensamente fraturado.

\section{B.2.3.3. Elevado Nível de Tensões}

Tabela B.40 - Resultados obtidos com o método dos pontos de estimativa (Rosenblueth) Rocha sedimentar, $\mathrm{k}_{\mathrm{o}}=2,0$, elevado nível de tensões, maciço rochoso intacto.

\begin{tabular}{|c|c|c|c|c|c|c|c|c|c|}
\hline \multirow{2}{*}{$\begin{array}{l}\text { PEM } \\
\text { Caso }\end{array}$} & \multicolumn{3}{|c|}{ Dados de Entrada } & & \multicolumn{5}{|c|}{ Dados de Saída } \\
\hline & $\mathbf{k}_{\mathbf{0}}$ & $c^{\prime}$ (MPa) & $\phi^{\prime}$ & & FS & $\operatorname{Ap}\left(m^{2}\right)$ & Ap (\%) & $\mathbf{U}(\mathbf{m})$ & U (\%) \\
\hline+++ & 2,5 & 8,88 & 49,9 & & 2,3 & 8,82 & $11,23 \%$ & 0,0442 & $0,88 \%$ \\
\hline$+\quad+\quad-$ & 2,5 & 8,88 & 40,8 & & 1,9 & 17,87 & $22,75 \%$ & 0,0467 & $0,93 \%$ \\
\hline$+\quad-\quad+$ & 2,5 & 3,81 & 49,9 & & 1,9 & 28,77 & $36,63 \%$ & 0,0493 & $0,99 \%$ \\
\hline$+\quad-\quad-$ & 2,5 & 3,81 & 40,8 & & 1,5 & 87,54 & $111,46 \%$ & 0,0597 & $1,19 \%$ \\
\hline$-\quad+\quad+$ & 1,5 & 8,88 & 49,9 & & 4,0 & 2,11 & $2,68 \%$ & 0,0228 & $0,46 \%$ \\
\hline$-\quad+\quad-$ & 1,5 & 8,88 & 40,8 & & 3,3 & 6,90 & $8,78 \%$ & 0,0232 & $0,46 \%$ \\
\hline$-\quad-\quad+$ & 1,5 & 3,81 & 49,9 & & 3,0 & 16,70 & $21,26 \%$ & 0,0246 & $0,49 \%$ \\
\hline$-\quad-\quad-$ & 1,5 & 3,81 & 40,8 & & 2,4 & 38,97 & $49,61 \%$ & 0,0273 & $0,55 \%$ \\
\hline & & & & $\begin{array}{l}\mu \\
\sigma\end{array}$ & $\begin{array}{l}2,5 \\
0,8\end{array}$ & & $\begin{array}{l}33,05 \% \\
32,91 \%\end{array}$ & & $\begin{array}{l}0,74 \% \\
0,27 \%\end{array}$ \\
\hline
\end{tabular}




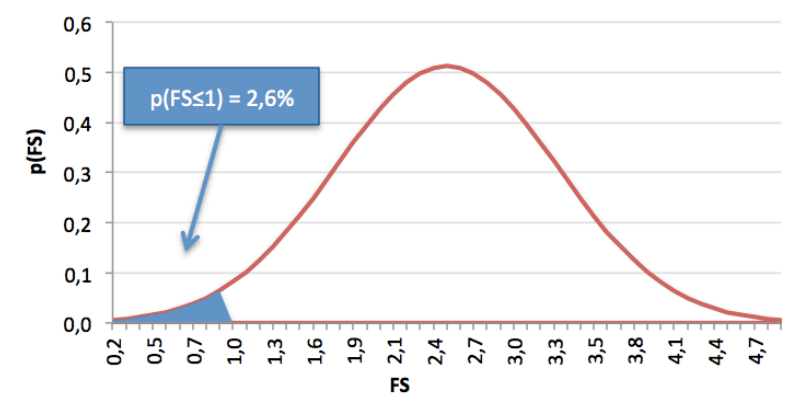

a)

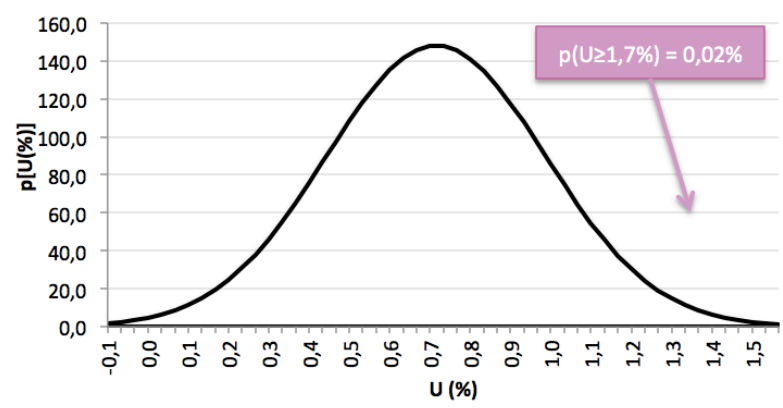

b)

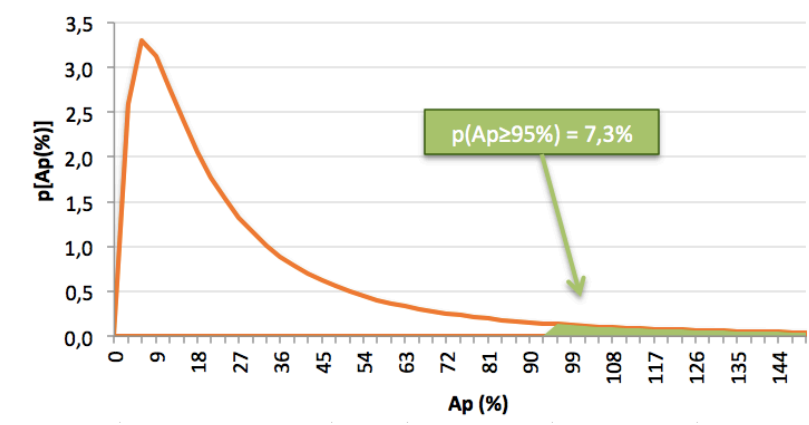

c)

Figura B.40 - Frequência de ocorrência e probabilidade de falha: a) Fator de Segurança (FS); b) Convergência (U); c) Área Plástica (Ap) - Rocha sedimentar, $\mathrm{k}_{\mathrm{o}}=2,0$, elevado nível de tensões, maciço rochoso intacto.

Tabela B.41 - Resultados obtidos com o método dos pontos de estimativa (Rosenblueth) Rocha sedimentar, $\mathrm{k}_{\mathrm{o}}=2,0$, elevado nível de tensões, maciço rochoso moderadamente fraturado.

\begin{tabular}{|c|c|c|c|c|c|c|c|c|c|}
\hline \multirow{2}{*}{$\begin{array}{c}\text { PEM } \\
\text { Caso }\end{array}$} & \multicolumn{3}{|c|}{ Dados de Entrada } & & \multicolumn{5}{|c|}{ Dados de Saída } \\
\hline & $\mathbf{k}_{\mathbf{0}}$ & $\mathrm{c}^{\prime}(\mathrm{MPa})$ & $\phi^{\prime}$ & & FS & $\operatorname{Ap}\left(m^{2}\right)$ & $\operatorname{Ap~(\% )}$ & $\mathbf{U}(\mathrm{m})$ & $\mathrm{U}(\%)$ \\
\hline$+\quad+\quad+$ & 2,5 & 3,93 & 43,7 & & 1,6 & 37,66 & $47,95 \%$ & 0,0966 & $1,93 \%$ \\
\hline$+\quad+\quad-$ & 2,5 & 3,93 & 35,8 & & 1,3 & 64,11 & $81,63 \%$ & 0,1270 & $2,54 \%$ \\
\hline$+\quad-\quad+$ & 2,5 & 1,68 & 43,7 & & 1,4 & 102,45 & $130,44 \%$ & 0,1404 & $2,81 \%$ \\
\hline$+\quad-\quad-$ & 2,5 & 1,68 & 35,8 & & 1,1 & 346,95 & $441,75 \%$ & 0,1523 & $3,05 \%$ \\
\hline$-\quad+\quad+$ & 1,5 & 3,93 & 43,7 & & 2,6 & 52,55 & $66,90 \%$ & 0,0465 & $0,93 \%$ \\
\hline$-\quad+\quad-$ & 1,5 & 3,93 & 35,8 & & 2,1 & 128,58 & $163,71 \%$ & 0,0522 & $1,04 \%$ \\
\hline$-\quad-\quad+$ & 1,5 & 1,68 & 43,7 & & 2,0 & 149,37 & $190,18 \%$ & 0,0589 & $1,18 \%$ \\
\hline$-\quad-\quad-$ & 1,5 & 1,68 & 35,8 & & 1,7 & 462,08 & $588,34 \%$ & 0,0793 & $1,59 \%$ \\
\hline & & & & $\begin{array}{l}\boldsymbol{\mu} \\
\boldsymbol{\sigma}\end{array}$ & $\begin{array}{l}1,7 \\
0,5\end{array}$ & & $\begin{array}{l}213,86 \% \\
183,31 \%\end{array}$ & & $\begin{array}{l}1,88 \% \\
0,78 \%\end{array}$ \\
\hline
\end{tabular}




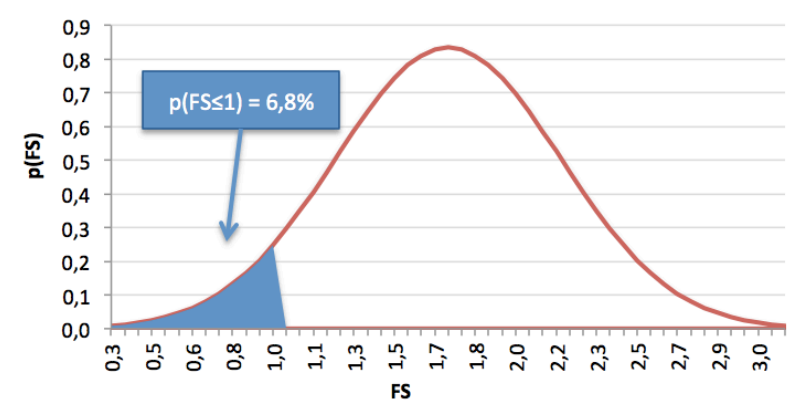

a)

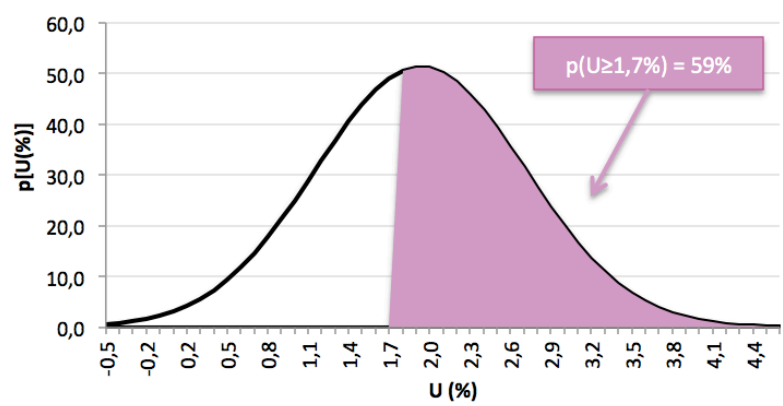

b)

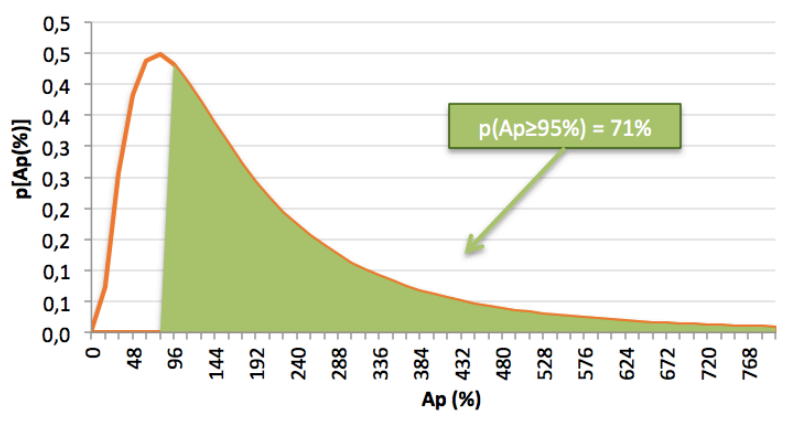

c)

Figura B.41- Frequência de ocorrência e probabilidade de falha: a) Fator de Segurança (FS);

b) Convergência (U); c) Área Plástica (Ap) - Rocha sedimentar, $\mathrm{k}_{\mathrm{o}}=2,0$, elevado nível de tensões, maciço rochoso moderadamente fraturado.

Tabela B.42 - Resultados obtidos com o método dos pontos de estimativa (Rosenblueth) Rocha sedimentar, $\mathrm{k}_{\mathrm{o}}=2,0$, elevado nível de tensões, maciço rochoso intensamente fraturado.

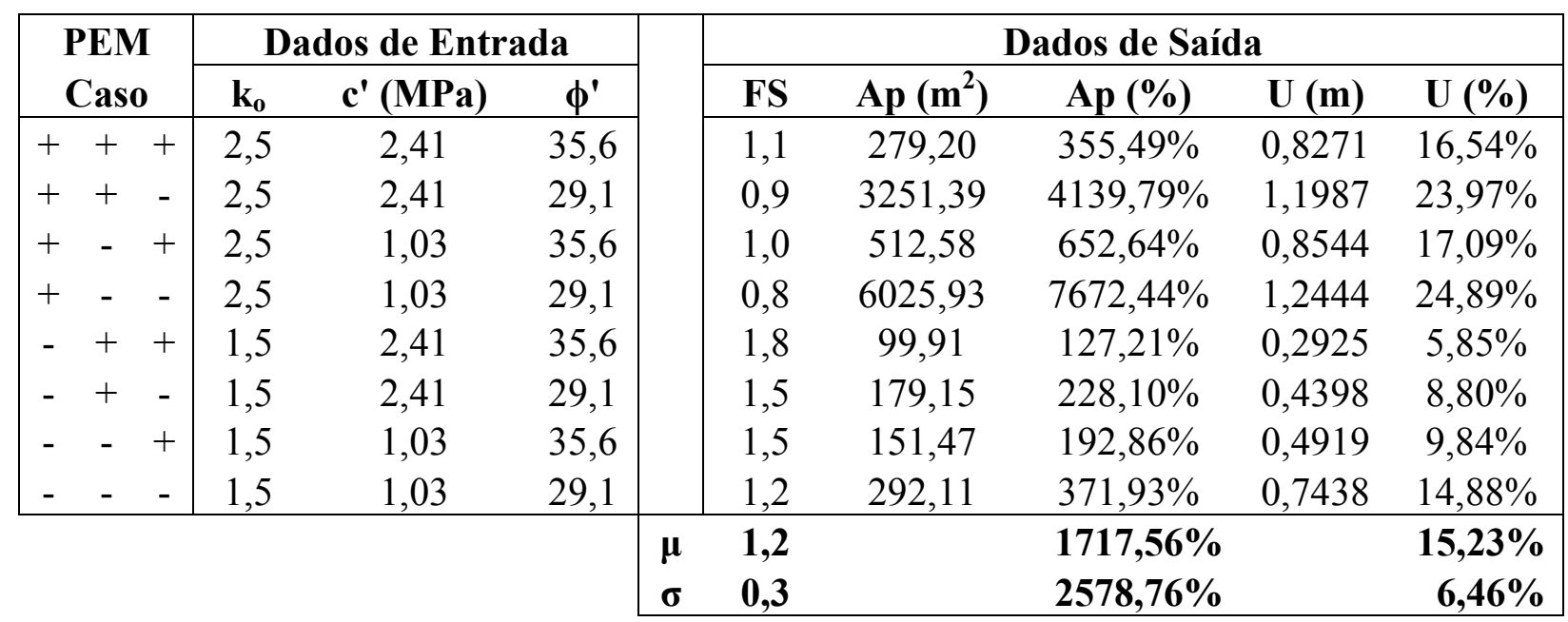




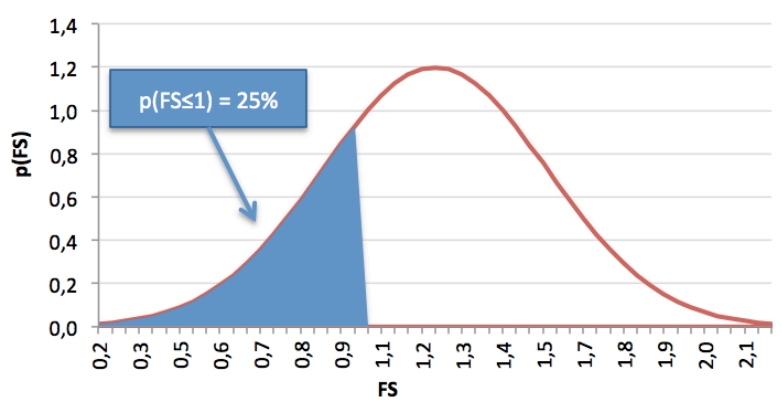

a)

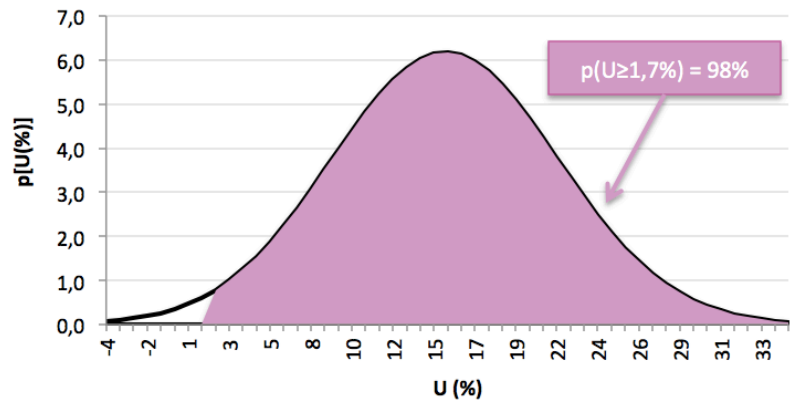

b)

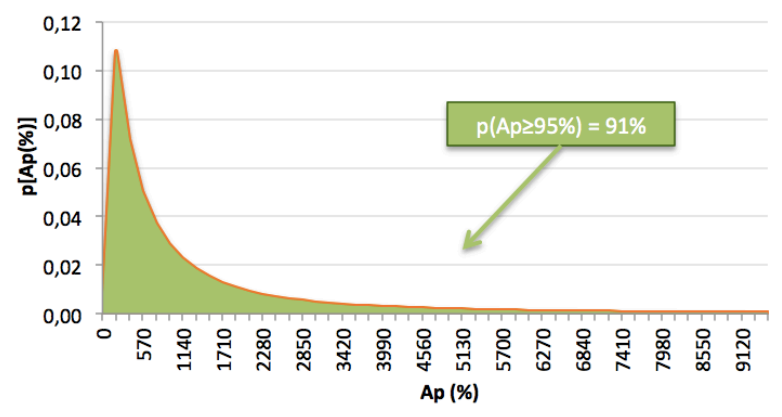

c)

Figura B.42 - Frequência de ocorrência e probabilidade de falha: a) Fator de Segurança (FS);

b) Convergência (U); c) Área Plástica (Ap) - Rocha sedimentar, $\mathrm{k}_{\mathrm{o}}=2,0$, elevado nível de tensões, maciço rochoso intensamente fraturado.

\section{B.2.4. $K_{0}=4,0$}

\section{B.2.4.1. Baixo Nível de Tensões}

Tabela B.43 - Resultados obtidos com o método dos pontos de estimativa (Rosenblueth) Rocha sedimentar, $\mathrm{k}_{\mathrm{o}}=4,0$, baixo nível de tensões, maciço rochoso intensamente fraturado.

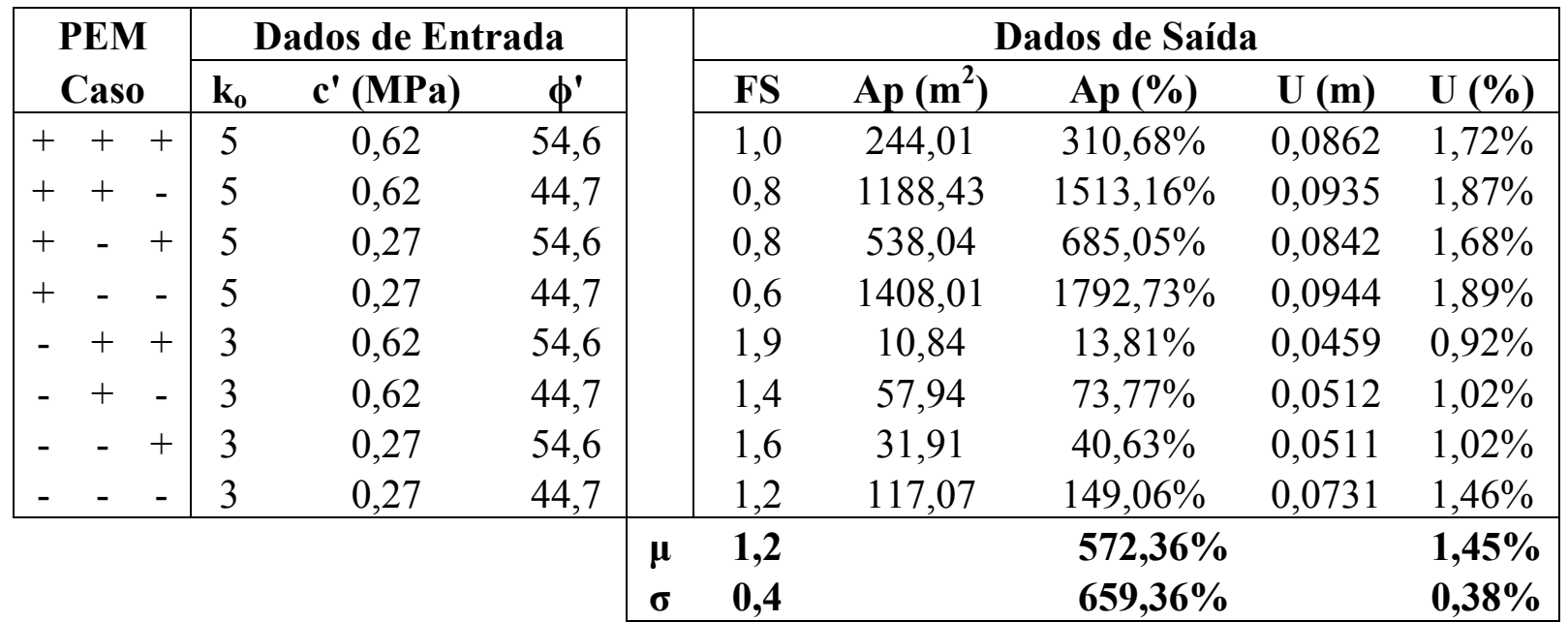




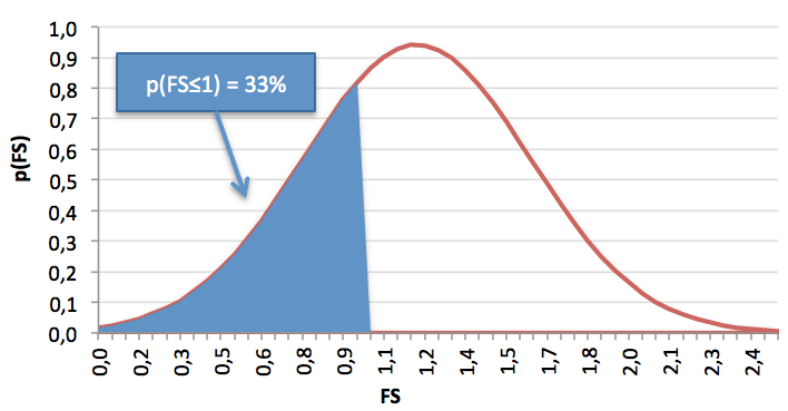

a)

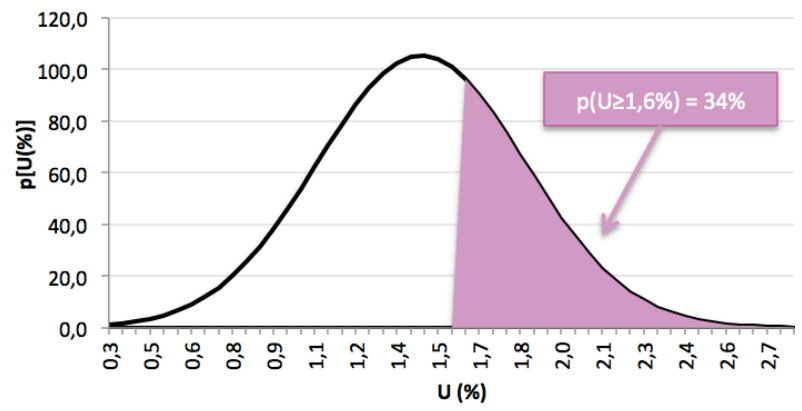

b)

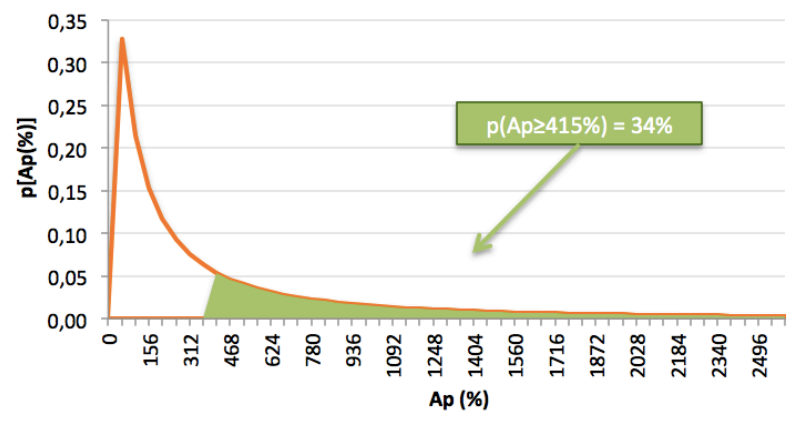

c)

Figura B.43 - Frequência de ocorrência e probabilidade de falha: a) Fator de Segurança (FS);

b) Convergência (U); c) Área Plástica (Ap) - Rocha sedimentar, $\mathrm{k}_{\mathrm{o}}=4,0$, baixo nível de tensões, maciço rochoso intensamente fraturado.

\section{B.2.4.2. Moderado Nível de Tensões}

Tabela B.44 - Resultados obtidos com o método dos pontos de estimativa (Rosenblueth) -

Rocha sedimentar, $\mathrm{k}_{\mathrm{o}}=4,0$, moderado nível de tensões, maciço rochoso moderadamente fraturado.

\begin{tabular}{|c|c|c|c|c|c|c|c|c|c|}
\hline \multirow{2}{*}{$\begin{array}{l}\text { PEM } \\
\text { Caso }\end{array}$} & \multicolumn{3}{|c|}{ Dados de Entrada } & & \multicolumn{5}{|c|}{ Dados de Saída } \\
\hline & $\mathbf{k}_{\mathbf{0}}$ & $\mathrm{c}^{\prime}$ (MPa) & $\phi^{\prime}$ & & FS & $\operatorname{Ap}\left(\mathrm{m}^{2}\right)$ & Ap (\%) & $\mathbf{U}(\mathbf{m})$ & U (\%) \\
\hline$+\quad+\quad+$ & 5 & 2,25 & 53,4 & & 1,1 & 48,58 & $61,86 \%$ & 0,0421 & $0,84 \%$ \\
\hline$+\quad+\quad-$ & 5 & 2,25 & 43,7 & & 0,9 & 1179,46 & $1501,73 \%$ & 0,0596 & $1,19 \%$ \\
\hline$+\quad-\quad+$ & 5 & 0,96 & 53,4 & & 0,9 & 632,45 & $805,26 \%$ & 0,0555 & $1,11 \%$ \\
\hline$+\quad-\quad-$ & 5 & 0,96 & 43,7 & & 0,6 & 1750,55 & $2228,87 \%$ & 0,0638 & $1,28 \%$ \\
\hline$-\quad+\quad+$ & 3 & 2,25 & 53,4 & & 2,0 & 9,71 & $12,36 \%$ & 0,0296 & $0,59 \%$ \\
\hline$-\quad+\quad-$ & 3 & 2,25 & 43,7 & & 1,6 & 45,16 & $57,50 \%$ & 0,0323 & $0,65 \%$ \\
\hline$-\quad-\quad+$ & 3 & 0,96 & 53,4 & & 1,7 & 36,66 & $46,68 \%$ & 0,0325 & $0,65 \%$ \\
\hline$-\quad-\quad-$ & 3 & 0,96 & 43,7 & & 1,2 & 77,96 & $99,26 \%$ & 0,0459 & $0,92 \%$ \\
\hline & & & & $\begin{array}{l}\mu \\
\sigma\end{array}$ & $\begin{array}{l}1,3 \\
0,4\end{array}$ & & $\begin{array}{l}601,69 \% \\
790,14 \%\end{array}$ & & $\begin{array}{l}0,90 \% \\
0,25 \%\end{array}$ \\
\hline
\end{tabular}




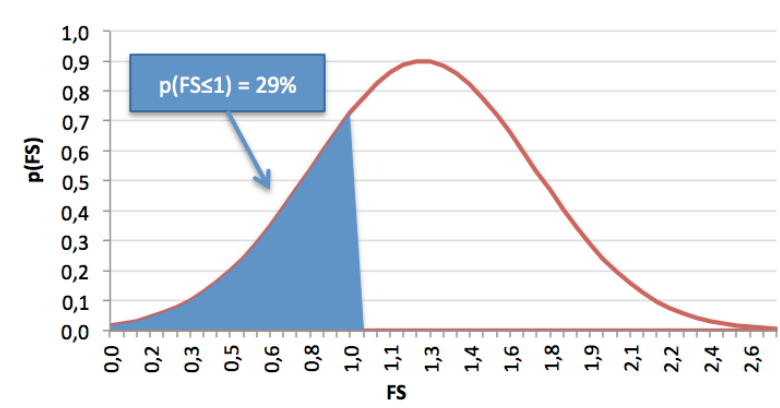

a)

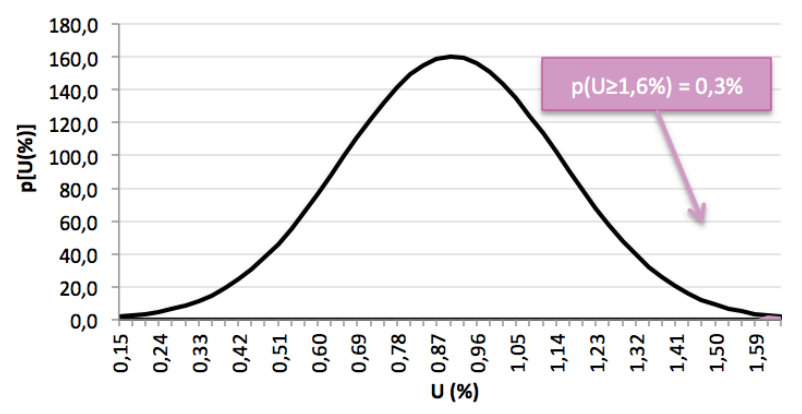

b)

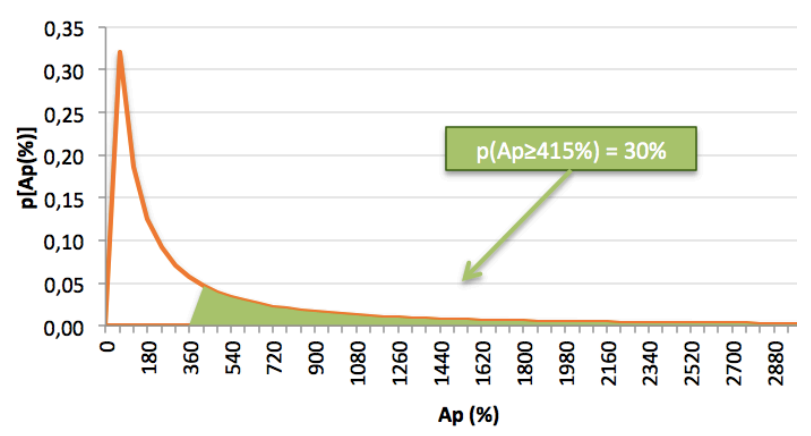

c)

Figura B.44- Frequência de ocorrência e probabilidade de falha: a) Fator de Segurança (FS); b) Convergência (U); c) Área Plástica (Ap) - Rocha sedimentar, $\mathrm{k}_{\mathrm{o}}=4,0$, moderado nível de tensões, maciço rochoso moderadamente fraturado.

\section{B.2.4.3. Elevado Nível de Tensões}

Tabela B.45 - Resultados obtidos com o método dos pontos de estimativa (Rosenblueth) Rocha sedimentar, $\mathrm{k}_{\mathrm{o}}=4,0$, elevado nível de tensões, maciço rochoso intacto.

\begin{tabular}{|c|c|c|c|c|c|c|c|c|c|}
\hline \multirow{2}{*}{$\begin{array}{l}\text { PEM } \\
\text { Caso }\end{array}$} & \multicolumn{3}{|c|}{ Dados de Entrada } & & \multicolumn{5}{|c|}{ Dados de Saída } \\
\hline & $\mathbf{k}_{\mathbf{0}}$ & $\mathbf{c}^{\prime}(\mathbf{M P a})$ & $\phi^{\prime}$ & & FS & $\operatorname{Ap}\left(m^{2}\right)$ & Ap (\%) & $\mathbf{U}(\mathbf{m})$ & U (\%) \\
\hline$+\quad+\quad+$ & 5 & 7,82 & 54,2 & & 1,4 & 11,70 & $14,90 \%$ & 0,0497 & $0,99 \%$ \\
\hline$+\quad+\quad-$ & 5 & 7,82 & 44,3 & & 1,2 & 36,84 & $46,91 \%$ & 0,0584 & $1,17 \%$ \\
\hline$+\quad-\quad+$ & 5 & 3,35 & 54,2 & & 1,0 & 240,84 & $306,65 \%$ & 0,0525 & $1,05 \%$ \\
\hline$+\quad-\quad-$ & 5 & 3,35 & 44,3 & & 0,9 & 1233,84 & $1570,96 \%$ & 0,0562 & $1,12 \%$ \\
\hline$-\quad+\quad+$ & 3 & 7,82 & 54,2 & & 2,5 & 2,33 & $2,96 \%$ & 0,0263 & $0,53 \%$ \\
\hline$-\quad+\quad-$ & 3 & 7,82 & 44,3 & & 2,0 & 6,93 & $8,83 \%$ & 0,0270 & $0,54 \%$ \\
\hline$-\quad-\quad+$ & 3 & 3,35 & 54,2 & & 1,9 & 10,23 & $13,03 \%$ & 0,0278 & $0,56 \%$ \\
\hline$-\quad-\quad-$ & 3 & 3,35 & 44,3 & & 1,4 & 56,62 & $72,10 \%$ & 0,0308 & $0,62 \%$ \\
\hline & & & & $\begin{array}{l}\mu \\
\sigma\end{array}$ & $\begin{array}{l}1,6 \\
0,5\end{array}$ & & $\begin{array}{l}254,54 \% \\
506,40 \%\end{array}$ & & $\begin{array}{l}0,82 \% \\
0,27 \%\end{array}$ \\
\hline
\end{tabular}




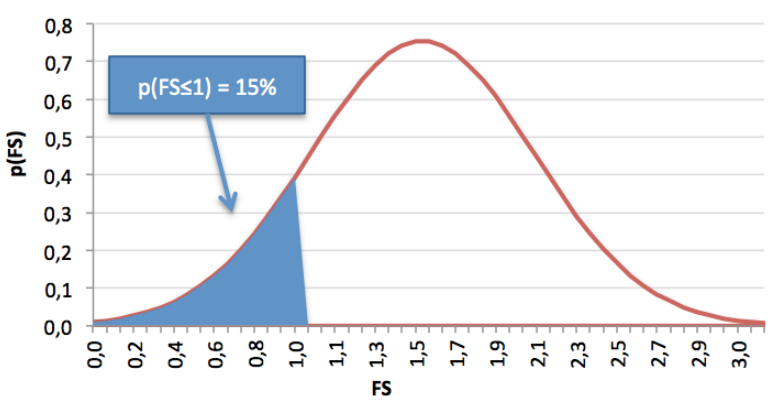

a)

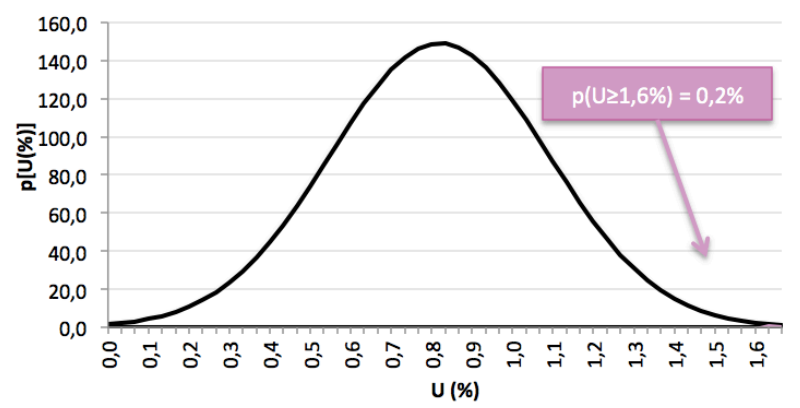

b)

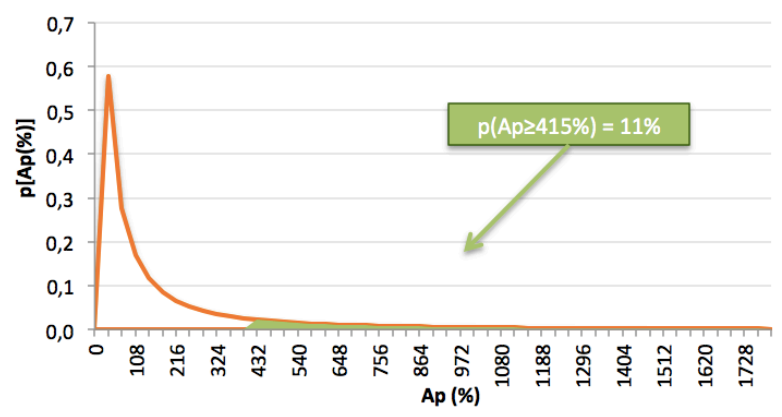

c)

Figura B.45- Frequência de ocorrência e probabilidade de falha: a) Fator de Segurança (FS);

b) Convergência (U); c) Área Plástica (Ap) - Rocha sedimentar, $\mathrm{k}_{\mathrm{o}}=4,0$, elevado nível de tensões, maciço rochoso intacto.

Tabela B.46 - Resultados obtidos com o método dos pontos de estimativa (Rosenblueth) -

Rocha sedimentar, $\mathrm{k}_{\mathrm{o}}=4,0$, elevado nível de tensões, maciço rochoso moderadamente fraturado.

\begin{tabular}{|c|c|c|c|c|c|c|c|c|c|}
\hline \multirow{2}{*}{$\begin{array}{l}\text { PEM } \\
\text { Caso }\end{array}$} & \multicolumn{3}{|c|}{ Dados de Entrada } & & \multicolumn{5}{|c|}{ Dados de Saída } \\
\hline & $\mathbf{k}_{\mathbf{0}}$ & $\mathrm{c}^{\prime}$ (MPa) & $\phi^{\prime}$ & & FS & $\operatorname{Ap}\left(m^{2}\right)$ & Ap (\%) & $\mathbf{U}(\mathbf{m})$ & U (\%) \\
\hline$+\quad+\quad+$ & 5 & 2,78 & 49,5 & & 0,8 & 883,71 & $1125,17 \%$ & 0,0956 & $1,91 \%$ \\
\hline$+\quad+\quad-$ & 5 & 2,78 & 40,5 & & 0,7 & 1800,75 & $2292,78 \%$ & 0,1066 & $2,13 \%$ \\
\hline$+\quad-\quad+$ & 5 & 1,19 & 49,5 & & 0,7 & 1005,37 & $1280,08 \%$ & 0,0983 & $1,97 \%$ \\
\hline$+\quad-\quad-$ & 5 & 1,19 & 40,5 & & 0,5 & 4882,17 & $6216,16 \%$ & 0,1425 & $2,85 \%$ \\
\hline$-\quad+\quad+$ & 3 & 2,78 & 49,5 & & 1,7 & 37,29 & $47,48 \%$ & 0,0531 & $1,06 \%$ \\
\hline$-\quad+\quad-$ & 3 & 2,78 & 40,5 & & 1,3 & 76,39 & $97,26 \%$ & 0,0645 & $1,29 \%$ \\
\hline$-\quad-\quad+$ & 3 & 1,19 & 49,5 & & 1,4 & 76,59 & $97,51 \%$ & 0,0756 & $1,51 \%$ \\
\hline$-\quad-\quad-$ & 3 & 1,19 & 40,5 & & 1,1 & 219,11 & $278,98 \%$ & 0,1015 & $2,03 \%$ \\
\hline & & & & $\begin{array}{l}\mu \\
\sigma\end{array}$ & $\begin{array}{l}1,0 \\
0,4\end{array}$ & & $\begin{array}{l}1429,43 \% \\
1954,32 \%\end{array}$ & & $\begin{array}{l}1,84 \% \\
0,52 \%\end{array}$ \\
\hline
\end{tabular}




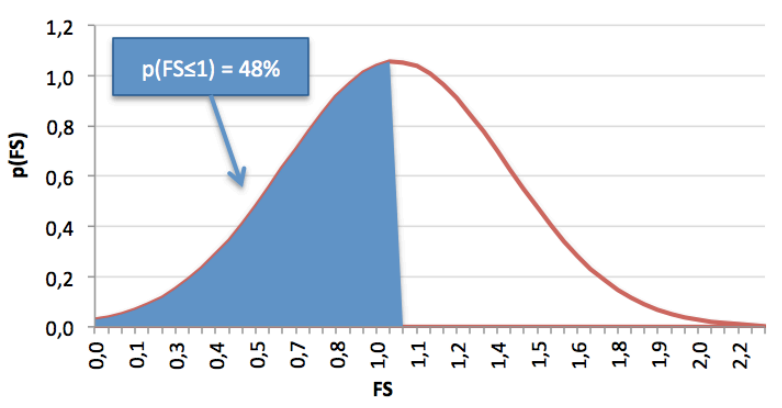

a)

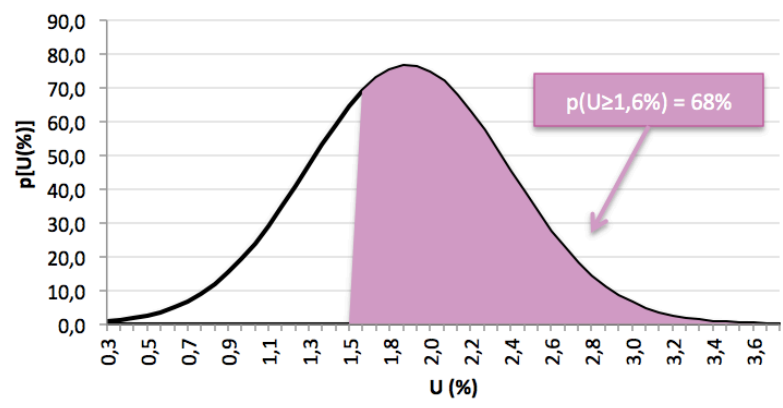

b)

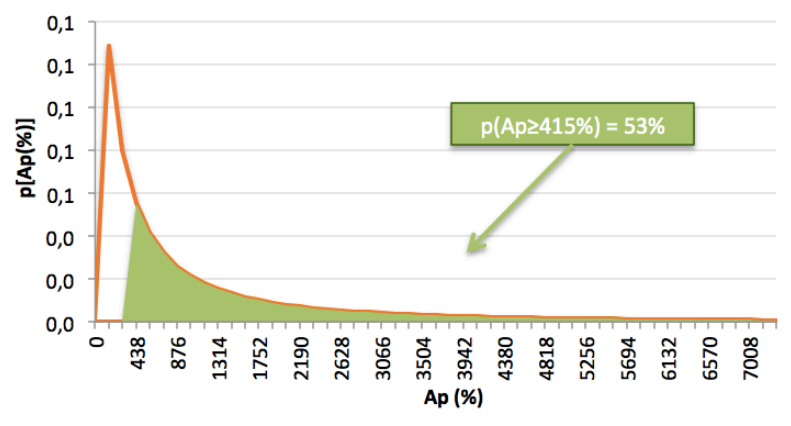

c)

Figura B.46- Frequência de ocorrência e probabilidade de falha: a) Fator de Segurança (FS);

b) Convergência (U); c) Área Plástica (Ap) - Rocha sedimentar, $\mathrm{k}_{\mathrm{o}}=4,0$, elevado nível de tensões, maciço rochoso moderadamente fraturado. 